Seri Pendidikan Aktuaris Indonesia

Siswadi Windiani Erliana

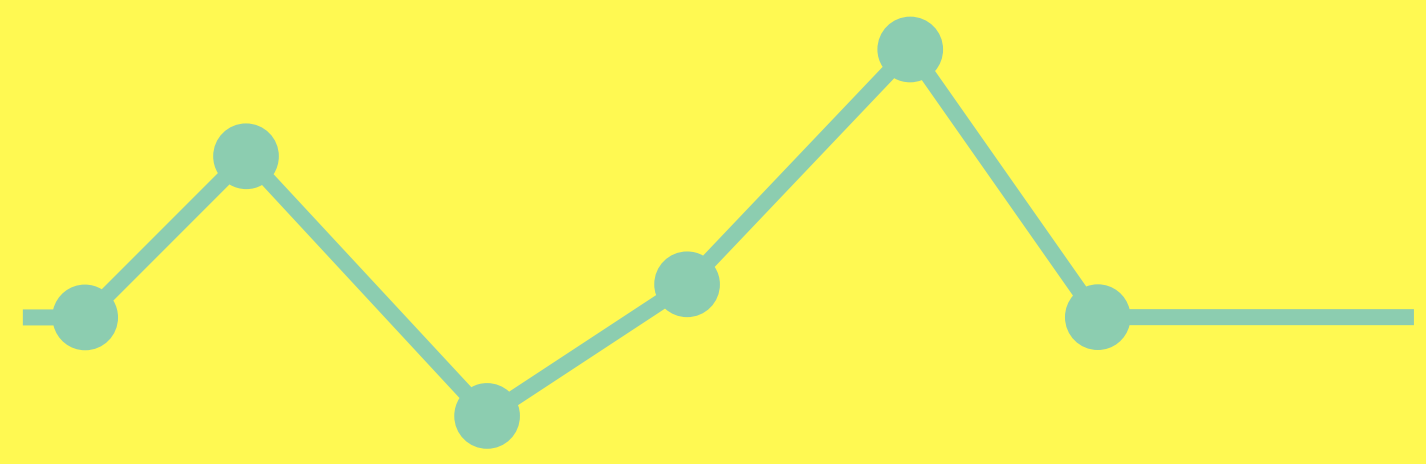

Statistika Matematik Untuk Aktuaris 


\section{STATISTIKA MATEMATIK UNTUK AKTUARIS}

Siswadi dan Windiani Erliana

e-book DOI: doi.org/10.31227/osf.io/nj3ag ISBN : 978-XXX-XXXX-XX-X

2019 


\section{Daftar Isi}

1 Sebaran Multivariat $\quad 1$

1.1 Vektor Peubah Acak . . . . . . . . . . . . . . . . . 1

1.2 Fungsi Sebaran Bersama . . . . . . . . . . . . . . . . . 1

1.2.1 Fungsi Massa Peluang Marginal . . . . . . . . . . . . 2

1.2.2 Fungsi Kepekatan Peluang Marginal . . . . . . . . . . 2

1.3 Nilai Harapan . . . . . . . . . . . . . . . . . . . . . . . 3

1.4 Kebebasan Vektor Peubah Acak . . . . . . . . . . . . . . . 4

1.5 Dekomposisi Spektrum . . . . . . . . . . . . . . . 5

1.6 Matriks Koragam . . . . . . . . . . . . . . . . . . . . . . . . . .

1.7 Sebaran Normal Multivariat . . . . . . . . . . . . . . . . . . 12

1.8 Latihan . . . . . . . . . . . . . . . . . . . . . . 19

2 Beberapa Sebaran Kontinu $\quad 21$

2.1 Sebaran Gamma . . . . . . . . . . . . . . . . . . . . . . . . . 21

2.2 Sebaran Khi-Kuadrat . . . . . . . . . . . . . . . . . . 24

2.3 Sebaran $t \ldots \ldots \ldots \ldots \ldots$. . . . . . . . . . . . . . 27

2.4 Sebaran $F \ldots \ldots \ldots \ldots \ldots$

2.5 Teorema Student . . . . . . . . . . . . . . . . . 33

2.6 Latihan . . . . . . . . . . . . . . . . . . 36

3 Pendugaan Parameter $\quad 37$

3.1 Penduga Titik . . . . . . . . . . . . . . . . . . . 37

3.2 Metode Pendugaan Titik . . . . . . . . . . . . . . . 38

3.2 .1 Metode Momen . . . . . . . . . . . . . . . . 38

3.2.2 Metode Kemungkinan Maksimum . . . . . . . . . . . . 42

3.3 Sifat-Sifat Penduga . . . . . . . . . . . . . . . . 51 
3.3.1 Ketakbiasan . . . . . . . . . . . . . 51

3.3.2 Efisiensi Relatif Penduga . . . . . . . . . . . . . . . . 54

3.3.3 Efisiensi dan Pertaksamaan Rao-Cramèr . . . . . . . . 55

3.3.4 Kekonsistenan . . . . . . . . . . . . . . . . 63

3.4 Penduga Selang . . . . . . . . . . . . . . . . . . . 66

3.4.1 Selang Kepercayaan Beda Dua Nilai Tengah . . . . . . 70

3.4.2 Selang Kepercayaan Nisbah Dua Ragam . . . . . . . . 71

3.5 Latihan . . . . . . . . . . . . . . . . . . . 73

$\begin{array}{lll}4 & \text { Kecukupan } & 76\end{array}$

4.1 Statistik Cukup . . . . . . . . . . . . . . . 76

4.2 Kelengkapan dan Kekhasan . . . . . . . . . . . . . . . . . 83

4.3 Kelas Eksponen . . . . . . . . . . . . . . . . . . . . . . 87

4.4 Latihan . . . . . . . . . . . . . . . . . . . 93

5 Pendugaan Bayes $\quad 94$

5.1 Prinsip Minimax . . . . . . . . . . . . . . . . . . . . . . 94

5.2 Sebaran Prior dan Posterior . . . . . . . . . . . . . . . 96

5.3 Metode Pendugaan Bayes . . . . . . . . . . . . . . . . . 98

5.4 Latihan . . . . . . . . . . . . . . . . . . . . . . . 103

6 Pengujian Hipotesis 105

6.1 Uji Paling Kuasa . . . . . . . . . . . . . . . . . . . . . . . 108

6.2 Uji Selalu Paling Kuasa . . . . . . . . . . . . . . . . . . . . . 111

6.3 Uji Rasio Kemungkinan . . . . . . . . . . . . . . . . . . . . 113

6.4 Uji Rasio Peluang Bersekuens . . . . . . . . . . . . . . . . . 120

6.5 Latihan . . . . . . . . . . . . . . . . . . . 126 


\section{KATA SAMBUTAN PERSATUAN AKTUARIS INDONESIA}

Persatuan Aktuaris Indonesia mengucapkan selamat atas penerbitan "Seri Catatan Kuliah Sains Aktuaria" dalam kerangka penyediaan bahan belajar bagi mereka yang menempuh pendidikan di bidang sains aktuaria. Pengajaran isi kurikulum pendidikan Persatuan Aktuaris Indonesia serta isi kurikulum pendidikan sains aktuaria di berbagai universitas di Indonesia secara umum akan terbantu dengan adanya pengadaan Seri Catatan Kuliah ini.

Sebagai organisasi profesi, Persatuan Aktuaris Indonesia akan senantiasa mendorong upaya berbagai pihak untuk menghasilkan karya bagi pembangunan di bidang sains aktuaria di Indonesia. Seri Catatan Kuliah ini dengan Editor Penerbitan yang juga sebagai Editor Utama Saudara Agah D. Garnadi merupakan salah satu kontribusi berharga dalam upaya meningkatkan kapasitas nasional di bidang sains aktuaria.

Akhir kata, Persatuan Aktuaris Indonesia menyatakan apresiasi kepada Saudara Agah D. Garnadi sebagai Editor Penerbitan atas penerbitan Seri Catatan Kuliah ini. Semoga Seri ini bisa dijadikan panduan belajar di bidang sains aktuaria serta mendapatkan tanggapan yang baik dari semua pihak.

Jakarta, 2 Mei 2016

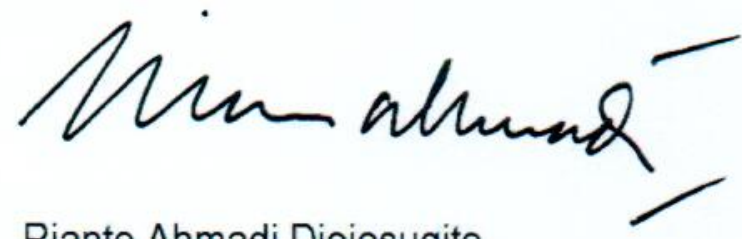

Rianto Ahmadi Djojosugito

Ketua Persatuan Aktuaris Indonesia 


\section{Kata Pengantar}

Buku ini disusun berdasarkan perkuliahan Statistika Matematik pada rentang waktu 2014/2015, 2015/2016, 2016/2017, 2017/2018, 2018/2019, yang diampu oleh penulis pertama.

Mata kuliah Statistika Matematik, merupakan salah satu bagian yang diakui untuk mata uji profesi Persatuan Aktuaris Indonesia (PAI). Sehingga dilengkapi dengan beberapa soal ujian A20 Probabilitas dan Statistika.

Pada Lampiran diberikan kumpulan soal ujian A20, terima kasih kepada Dr. Lia Yuliawati, MSi dari STKIP 11 April, Sumedang, yang telah memberikan kontribusi pada kumpulan soal tersebut. Serta saudari Grace Agustina, SMat., atas sejumlah catatannya.

Hibah PUPT-IPB, 'Pengembangan Perangkat Lunak Berbasis Finite Element Method (FEM) untuk Produk Jasa Keuangan dan Asuransi' dengan kontrak no: 079/SP2H/LT/DRPM/II/2016, secara tidak langsung memberi bantuan pendanaan kepada penulis yunior. Terima kasih kami ucapkan.

Terima kasih disampaikan kepada Dr. Ir. IG Putu Purnaba, yang memberikan koreksi atas jawaban soal ujian PAI. Dr. Ir. Sri Nurdiati, MSc., selaku peneliti utama Hibah PUPT-IPB tersebut di atas, yang memberikan kesempatan kepada penulis yunior mengembangkan ilmu aktuaria. Terakhir, kepada Drs. Agah D. Garnadi, Grad. Dip. Sci. yang berulangkali meminta agar naskah ini untuk diterbitkan dalam seri buku: 'Pendidikan Aktuaris Indonesia', sehingga bisa dimanfaatkan khususnya untuk pendidikan aktuaria di Indonesia.

Terima kasih kepada Rianto Ahmadi, PhD., ketua PAI periode 20142017, yang sudi memberikan kata sambutan seri buku 'Pendidikan Aktuaris Indonesia'.

Bogor, 09 Juni 2019

Siswadi

Windiani Erliana 


\section{${ }^{31}$ BAB 1}

\section{"Sebaran Multivariat}

\section{зз 1.1 Vektor Peubah Acak}

Definisi 1.1 Misalkan $\Omega$ adalah ruang contoh suatu percobaan acak. Peubah acak $X_{i}$ dari percobaan tersebut adalah suatu fungsi bernilai real $X_{i}: \Omega \rightarrow$ $\mathbb{R}, i=1,2, \ldots, n$ dengan $\left(X_{1}, X_{2}, \ldots, X_{n}\right)$ disebut vektor peubah acak dimensi$n$.

Dalam bab ini, digunakan notasi vektor untuk menyatakan peubah acak $X_{1}, X_{2}, \ldots, X_{n}$. Sebagai contoh, $\left(X_{1}, X_{2}, \ldots, X_{n}\right)^{\prime}$ merupakan vektor kolom $\mathbf{X}$ yang memiliki nilai $\left(x_{1}, x_{2}, \ldots, x_{n}\right)^{\prime}, \forall x_{i} \in \mathbb{R}$.

$$
\begin{aligned}
\mathbf{X} & =\mathbf{x} \\
\left(X_{1}, X_{2}, \ldots, X_{n}\right)^{\prime} & =\left(x_{1}, x_{2}, \ldots, x_{n}\right)^{\prime} \\
\left(\begin{array}{c}
X_{1} \\
X_{2} \\
\vdots \\
X_{n}
\end{array}\right) & =\left(\begin{array}{c}
x_{1} \\
x_{2} \\
\vdots \\
x_{n}
\end{array}\right)
\end{aligned}
$$

\section{}

39 Fungsi sebaran bersama bagi vektor peubah acak tersebut didefinisikan se-

40 bagai berikut

$$
F_{\mathbf{X}}(\mathbf{x})=P\left(X_{1} \leq x_{1}, \ldots, X_{n} \leq x_{n}\right) .
$$

${ }_{41}$ Jika $n$ peubah acak $X_{1}, X_{2}, \ldots, X_{n}$ adalah peubah acak diskret, maka 


$$
F_{\mathbf{X}}(\mathbf{x})=\sum_{w_{1} \leq x_{1}, \ldots, w_{n} \leq x_{n}} \sum p\left(w_{1}, \ldots, w_{n}\right),
$$

sedangkan jika $n$ peubah acak tersebut adalah peubah acak kontinu, maka

$$
\begin{gathered}
F_{\mathbf{X}}(\mathbf{x})=\int \begin{array}{c}
\ldots \\
w_{1} \leq x_{1}, \ldots, w_{n} \leq x_{n}
\end{array} \\
\frac{\partial^{n}}{\partial x_{1} \ldots \partial x_{n}} F_{\mathbf{X}}(\mathbf{x})=f\left(w_{1}, \ldots, w_{n}\right) d w_{1} \ldots d w_{n},
\end{gathered}
$$

Contoh 1.1 Misalkan fungsi kepekatan peluang dari peubah acak $X_{1}, X_{2}, X_{3}$ adalah sebagai berikut

$$
f\left(x_{1}, x_{2}, x_{3}\right)=e^{-\left(x_{1}+x_{2}+x_{3}\right)} \mathbf{I}\left(0<x_{1}, x_{2}, x_{3}<\infty\right),
$$

maka fungsi sebaran bersama bagi $X_{1}, X_{2}, X_{3}$ ialah

$$
\begin{aligned}
F_{X_{1}, X_{2}, X_{3}}\left(x_{1}, x_{2}, x_{3}\right) & =P\left(X_{1} \leq x_{1}, X_{2} \leq x_{2}, X_{3} \leq x_{3}\right) \\
& =\int_{0}^{x_{1}} \int_{0}^{x_{2}} \int_{0}^{x_{3}} e^{-\left(x_{1}+x_{2}+x_{3}\right)} d x_{1} d x_{2} d x_{3} \\
& =\left(1-e^{-x_{1}}\right)\left(1-e^{-x_{2}}\right)\left(1-e^{-x_{3}}\right) \mathbf{I}\left(0<x_{1}, x_{2}, x_{3}<\infty\right) .
\end{aligned}
$$

\section{${ }_{44} \quad$ 1.2.1 Fungsi Massa Peluang Marginal}

Definisi 1.2 Misalkan $X_{1}, \ldots, X_{n}$ adalah peubah acak diskret yang menyebar bersama dengan fungsi massa peluang bersama $p_{X_{1}, \ldots, X_{n}}\left(x_{1}, \ldots, x_{n}\right)$. Fungsi massa peluang marginal dari peubah acak $X_{1}$ ialah

$$
p_{X_{1}}\left(x_{1}\right)=\sum_{x_{2}} \ldots \sum_{x_{n}} p_{X_{1}, \ldots, X_{n}}\left(x_{1}, \ldots, x_{n}\right) .
$$

\subsubsection{Fungsi Kepekatan Peluang Marginal}

Definisi 1.3 Misalkan $X_{1}, \ldots, X_{n}$ adalah peubah acak kontinu yang menyebar bersama dengan fungsi kepekatan peluang bersama $f_{X_{1}, \ldots, X_{n}}\left(x_{1}, \ldots, x_{n}\right)$. Fungsi kepekatan peluang marginal dari peubah acak $X_{1}$ ialah

$$
f_{X_{1}}\left(x_{1}\right)=\int_{-\infty}^{\infty} \ldots \int_{-\infty}^{\infty} f_{X_{1}, \ldots, X_{n}}\left(x_{1}, \ldots, x_{n}\right) d x_{2} \ldots d x_{n} .
$$




\subsection{Nilai Harapan}

Definisi 1.4 Misalkan $Y=u\left(X_{1}, X_{2}, \ldots, X_{n}\right)$ adalah fungsi terhadap vektor peubah acak $\left(X_{1}, X_{2}, \ldots, X_{n}\right)^{\prime}$. Jika $X_{1}, X_{2}, \ldots, X_{n}$ adalah peubah acak diskret yang menyebar bersama dengan fungsi massa peluang bersama $p\left(x_{1}, x_{2}, \ldots, x_{n}\right)$, maka nilai harapan dari $Y$ didefinisikan sebagai

$$
E(Y)=\sum_{x_{n}} \ldots \sum_{x_{1}} u\left(x_{1}, x_{2}, \ldots, x_{n}\right) p\left(x_{1}, x_{2}, \ldots, x_{n}\right),
$$

asalkan jumlah di atas konvergen mutlak. Jika $X_{1}, X_{2}, \ldots, X_{n}$ adalah peubah acak kontinu yang menyebar bersama dengan fungsi kepekatan peluang bersama $f\left(x_{1}, x_{2}, \ldots, x_{n}\right)$, maka nilai harapan dari $Y$ didefinisikan sebagai

$$
E(Y)=\int_{-\infty}^{\infty} \ldots \int_{-\infty}^{\infty} u\left(x_{1}, x_{2}, \ldots, x_{n}\right) f\left(x_{1}, x_{2}, \ldots, x_{n}\right) d x_{1} d x_{2} \ldots d x_{n}
$$

47

asalkan integral di atas konvergen mutlak.

Teorema 1.1 Misalkan $X_{1}, X_{2}, \ldots, X_{n}$ adalah peubah acak yang terdefinisi dalam ruang peluang yang sama dan $k_{1}, k_{2}, \ldots, k_{m}$ adalah $m$ konstanta bilangan real. Jika $Y_{i}=u\left(X_{1}, X_{2}, \ldots, X_{n}\right), i=1,2, \ldots, m$, adalah fungsi terhadap vektor peubah acak $\left(X_{1}, X_{2}, \ldots, X_{n}\right)^{\prime}$, maka

$$
E\left(\sum_{i=1}^{m} k_{i} Y_{i}\right)=\sum_{i=1}^{m} k_{i} E\left(Y_{i}\right) .
$$

${ }_{48} \quad$ Misalkan $_{n} \mathbf{W}_{m}=\left(W_{i j}\right)$ merupakan matriks peubah acak berukuran $n \times m$ 49 yang berunsur peubah acak $W_{i j}$, maka

$$
\begin{aligned}
E(\mathbf{W}) & =\left(E\left(W_{i j}\right)\right) \\
& =\left[\begin{array}{cccc}
E\left(W_{11}\right) & E\left(W_{12}\right) & \ldots & E\left(W_{1 m}\right) \\
E\left(W_{21}\right) & E\left(W_{22}\right) & \ldots & E\left(W_{2 m}\right) \\
\vdots & \vdots & \ddots & \vdots \\
E\left(W_{n 1}\right) & E\left(W_{n 2}\right) & \ldots & E\left(W_{n m}\right)
\end{array}\right] .
\end{aligned}
$$

Berikut merupakan teorema yang menunjukkan sifat linearitas dari nilai harapan.

Teorema 1.2 Misalkan ${ }_{n} \mathbf{V}_{m}$ dan ${ }_{n} \mathbf{W}_{m}$ masing-masing merupakan matriks peubah acak; ${ }_{k} \mathbf{A}_{n},{ }_{k} \mathbf{B}_{n}$, dan ${ }_{m} \mathbf{C}_{p}$ masing-masing merupakan matriks berunsur konstanta, maka

$$
\begin{aligned}
E[\mathbf{A V}+\mathbf{B W}] & =\mathbf{A} E[\mathbf{V}]+\mathbf{B} E[\mathbf{W}] \\
E[\mathbf{A W C}] & =\mathbf{A} E[\mathbf{W}] \mathbf{C} .
\end{aligned}
$$


${ }_{55} \quad$ Bukti. Misal $\mathbf{A V}=\left(\sum_{k=1}^{n} a_{i k} V_{k j}\right)$ dan $\mathbf{B W}=\left(\sum_{k=1}^{n} b_{i k} W_{k j}\right)$, maka

$$
\begin{aligned}
E[\mathbf{A V}+\mathbf{B W}] & =\left(E\left[\sum_{k=1}^{n} a_{i k} V_{k j}+\sum_{k=1}^{n} b_{i k} W_{k j}\right]\right) \\
& =\left(\sum_{k=1}^{n} a_{i k} E\left[V_{k j}\right]\right)+\left(\sum_{k=1}^{n} b_{i k} E\left[W_{k j}\right]\right) \\
& =\mathbf{A} E[\mathbf{V}]+\mathbf{B} E[\mathbf{W}] .
\end{aligned}
$$

56 Pembuktian $E[\mathbf{A W C}]=\mathbf{A} E[\mathbf{W}] \mathbf{C}$ digunakan sebagai latihan.

\section{${ }_{57} 1.4$ Kebebasan Vektor Peubah Acak}

Misalkan peubah acak $X_{1}, X_{2}, \ldots, X_{n}$ memiliki fungsi kepekatan peluang bersama $f\left(x_{1}, x_{2}, \ldots, x_{n}\right)$ dan fungsi kepekatan peluang marginal $f_{1}\left(x_{1}\right), f_{2}\left(x_{2}\right), \ldots, f_{n}\left(x_{n}\right)$ secara berturut-turut bagi $x_{1}, \ldots, x_{n}$. Peubah acak $X_{1}, X_{2}, \ldots, X_{n}$ saling bebas jika

$$
f\left(x_{1}, x_{2}, \ldots, x_{n}\right)=f_{1}\left(x_{1}\right) f_{2}\left(x_{2}\right) \ldots f_{n}\left(x_{n}\right),
$$

untuk kasus kontinu. Pada kasus diskret, $X_{1}, X_{2}, \ldots, X_{n}$ dikatakan saling bebas jika

$$
p\left(x_{1}, x_{2}, \ldots, x_{n}\right)=p_{1}\left(x_{1}\right) p_{2}\left(x_{2}\right) \ldots p_{n}\left(x_{n}\right) .
$$

Misalkan $X_{1}, X_{2}, \ldots, X_{n}$ saling bebas, maka

1. $P\left(a_{1}<X_{1}<b_{1}, a_{2}<X_{2}<b_{2}, \ldots, a_{n}<X_{n}<b_{n}\right)$

$=P\left(a_{1}<X_{1}<b_{1}\right) P\left(a_{2}<X_{2}<b_{2}\right) \ldots P\left(a_{n}<X_{n}<b_{n}\right)$

$=\prod_{i=1}^{n} P\left(a_{i}<X_{i}<b_{i}\right)$

62

2. $E\left[\prod_{i=1}^{n} u\left(X_{i}\right)\right]=\prod_{i=1}^{n} E\left[u\left(X_{i}\right)\right]$.

3. Fungsi pembangkit momen bagi peubah acak $X_{1}, X_{2}, \ldots, X_{n}$ dinotasikan dengan $M_{\mathbf{X}}\left(t_{1}, t_{2}, \ldots, t_{n}\right)$ dan didefinisikan sebagai berikut

$$
\begin{aligned}
M_{\mathbf{X}}\left(t_{1}, t_{2}, \ldots, t_{n}\right) & =E\left[\exp \left(t_{1} X_{1}+t_{2} X_{2}+\ldots+t_{n} X_{n}\right)\right] \\
M_{\mathbf{X}}(\mathbf{t}) & =E\left[\exp \left(\mathbf{t}^{\prime} \mathbf{X}\right)\right], \forall \mathbf{t} \in B \subset \mathbb{R}^{n},
\end{aligned}
$$
marginal dari peubah acak $X_{i}$, fungsi pembangkit momen peubah acak $X_{i}$ didefinisikan sebagai $M_{\mathbf{X}}\left(0,0, \ldots, 0, t_{i}, 0, \ldots, 0\right), i=1,2, \ldots, n$. 
Teorema 1.3 Misalkan $X_{1}, X_{2}, \ldots, X_{n}$ adalah peubah acak yang saling bebas dan fungsi pembangkit momen bagi $X_{i}$ ialah $M_{X_{i}}(t), \forall i=1, \ldots, n$. Misalkan pula $T=\sum_{i=1}^{n} k_{i} X_{i}$, dengan $k_{1}, \ldots, k_{n}$ suatu konstanta, maka fungsi pembangkit momen bagi Tialah

$$
M_{T}(t)=\prod_{i=1}^{n} M_{X_{i}}\left(k_{i} t\right),-\min _{i}\left\{h_{i}\right\}<t<\min _{i}\left\{h_{i}\right\} .
$$

Contoh 1.2 Misalkan $X_{1}, X_{2}, X_{3}$ adalah peubah acak saling bebas yang masingmasing memiliki fungsi kepekatan peluang sebagai berikut

$$
f(x)=2 x \mathbf{I}(0<x<1) .
$$

66

Fungsi kepekatan peluang bersama bagi peubah acak tersebut ialah

$$
\begin{aligned}
f\left(x_{1}, x_{2}, x_{3}\right) & =f\left(x_{1}\right) f\left(x_{2}\right) f\left(x_{3}\right) \\
& =8 x_{1} x_{2} x_{3} \mathbf{I}\left(0<x_{1}, x_{2}, x_{3}<1\right) .
\end{aligned}
$$

Nilai harapan bagi $5 X_{1}\left(X_{2}\right)^{3}+3 X_{2}\left(X_{3}\right)^{4}$ ialah

$$
\int_{0}^{1} \int_{0}^{1} \int_{0}^{1}\left(5 x_{1}\left(x_{2}\right)^{3}+3 x_{2}\left(x_{3}\right)^{4}\right) 8 x_{1} x_{2} x_{3} \quad d x_{1} d x_{2} d x_{3}=2 .
$$

67 Jika peubah acak saling bebas memiliki sebaran yang sama, maka peubah acak tersebut disebut peubah acak bebas stokastik identik (bsi). Berikut ini merupakan akibat dari Teorema 1.3 untuk peubah acak bsi.

Akibat 1.1 Misalkan $X_{1}, X_{2}, \ldots, X_{n}$ adalah peubah acak bsi dengan fungsi pembangkit peluang $M_{X}(t),-h<t<h$ dengan $h>0$. Misalkan pula $T=$ $\sum_{i=1}^{n} X_{i}$, maka fungsi pembangkit momen bagi $T$ ialah

$$
M_{T}(t)=\left[M_{X}(t)\right]^{n},-h<t<h
$$

\subsection{Dekomposisi Spektrum}

Dari aljabar linear diperoleh bahwa suatu matriks dapat didekomposisikan atau diuraikan menjadi perkalian beberapa matriks. Khususnya bagi matriks 
$\boldsymbol{\Sigma}$ yang merupakan matriks $n \times n$, simetrik, dan semi-definit positif, maka dekomposisi spektrum dari $\Sigma$ ialah sebagai berikut

$$
\Sigma=\Gamma^{\prime} \Lambda \Gamma
$$

di mana $\boldsymbol{\Lambda}$ merupakan matriks diagonal,

$$
\boldsymbol{\Lambda}=\operatorname{diag}\left(\lambda_{1}, \lambda_{2}, \ldots, \lambda_{n}\right),
$$
satuan) tidak bersifat khas.

Penulisan dekomposisi tersebut dapat dituliskan dalam bentuk lain, yaitu

$$
\Sigma=\Gamma^{\prime} \Lambda \boldsymbol{\Gamma}=\sum_{i=1}^{n} \lambda_{i} \mathbf{v}_{i} \mathbf{v}_{i}^{\prime}
$$

Secara intuisi, pendekatan matriks dengan matriks lain (misalnya yang berperingkat lebih rendah) dapat diperoleh dengan membuang beberapa matriks terakhir yang terkait dengan nilai eigen yang kecil. Karena nilai eigen dari matriks semi-definit positif selalu $\geq 0$, maka matriks $\boldsymbol{\Sigma}$ dapat ditulis dalam bentuk lain, yaitu

$$
\Sigma=\Sigma^{\frac{1}{2}} \Sigma^{\frac{1}{2}}=\left(\Sigma^{\frac{1}{2}}\right)^{2}
$$

di mana $\Sigma^{\frac{1}{2}}=\Gamma^{\prime} \Lambda^{\frac{1}{2}} \Gamma$ dengan $\Lambda^{\frac{1}{2}}=\operatorname{diag}\left(\sqrt{\lambda_{1}}, \sqrt{\lambda_{2}}, \ldots, \sqrt{\lambda_{n}}\right)$. Misalkan $\boldsymbol{\Sigma}$ merupakan matriks yang definit positif, yang berarti nilai eigennya selalu positif, maka

$$
\left(\Sigma^{\frac{1}{2}}\right)^{-1}=\Sigma^{-\frac{1}{2}}=\Gamma^{\prime} \Lambda^{-\frac{1}{2}} \Gamma
$$

dengan

$$
\boldsymbol{\Lambda}^{-\frac{1}{2}}=\operatorname{diag}\left(\frac{1}{\sqrt{\lambda_{1}}}, \frac{1}{\sqrt{\lambda_{2}}}, \ldots, \frac{1}{\sqrt{\lambda_{n}}}\right)
$$

Contoh 1.3 Tentukan dekomposisi spektrum dari matriks berikut

$$
\boldsymbol{\Sigma}=\left[\begin{array}{ccc}
3 & 0 & -1 \\
0 & 4 & 0 \\
-1 & 0 & 3
\end{array}\right]
$$

79 Tentukan pula $\boldsymbol{\Sigma}^{\frac{1}{2}}$ dan $\boldsymbol{\Sigma}^{-\frac{1}{2}}$. 
Jawab. Berikut merupakan polinom karakteristik dari matriks $\boldsymbol{\Sigma}$ :

$$
\begin{aligned}
|\Sigma-\lambda \mathbf{I}| & =\left|\begin{array}{ccc}
3-\lambda & 0 & -1 \\
0 & 4-\lambda & 0 \\
-1 & 0 & 3-\lambda
\end{array}\right| \\
& =(-1)^{2+2}(4-\lambda)\left|\begin{array}{cc}
3-\lambda & -1 \\
-1 & 3-\lambda
\end{array}\right| \\
& =(4-\lambda)\left[(3-\lambda)^{2}-1\right] \\
& =(4-\lambda)(3-\lambda+1)(3-\lambda-1) \\
& =(4-\lambda)^{2}(2-\lambda),
\end{aligned}
$$

sehingga nilai eigen dari matriks tersebut ialah

$$
\lambda_{1}=\lambda_{2}=4, \lambda_{3}=2,
$$

dan vektor-vektor eigen yang berpadanan dengan nilai eigen tersebut ialah

$$
\mathbf{v}_{1}=\left[\begin{array}{l}
0 \\
1 \\
0
\end{array}\right], \mathbf{v}_{2}=\left[\begin{array}{c}
-1 \\
0 \\
1
\end{array}\right], \text { dan } \mathbf{v}_{3}=\left[\begin{array}{l}
1 \\
0 \\
1
\end{array}\right]
$$

Vektor-vektor ortonormal dari $\mathbf{v}_{1}, \mathbf{v}_{2}$, dan $\mathbf{v}_{3}$ tersebut secara berturut-turut ialah

$$
\mathbf{w}_{1}=\left[\begin{array}{l}
0 \\
1 \\
0
\end{array}\right], \mathbf{w}_{2}=\frac{1}{\sqrt{2}}\left[\begin{array}{c}
-1 \\
0 \\
1
\end{array}\right], \text { dan } \mathbf{w}_{3}=\frac{1}{\sqrt{2}}\left[\begin{array}{l}
1 \\
0 \\
1
\end{array}\right],
$$

sehingga matriks $\boldsymbol{\Lambda}$ dan $\Gamma^{\prime}$ ialah sebagai berikut

$$
\Lambda=\left[\begin{array}{lll}
4 & 0 & 0 \\
0 & 4 & 0 \\
0 & 0 & 2
\end{array}\right], \boldsymbol{\Gamma}^{\prime}=\left[\begin{array}{ccc}
0 & \frac{-1}{\sqrt{2}} & \frac{1}{\sqrt{2}} \\
1 & 0 & 0 \\
0 & \frac{1}{\sqrt{2}} & \frac{1}{\sqrt{2}}
\end{array}\right]
$$

81 Jadi, dekomposisi spektrum dari matriks $\boldsymbol{\Sigma}$ ialah

$$
\begin{aligned}
\boldsymbol{\Sigma} & =\Gamma^{\prime} \boldsymbol{\Lambda}^{1 / 2} \boldsymbol{\Gamma} \\
{\left[\begin{array}{ccc}
3 & 0 & -1 \\
0 & 4 & 0 \\
-1 & 0 & 3
\end{array}\right] } & =\left[\begin{array}{ccc}
0 & \frac{-1}{\sqrt{2}} & \frac{1}{\sqrt{2}} \\
1 & 0 & 0 \\
0 & \frac{1}{\sqrt{2}} & \frac{1}{\sqrt{2}}
\end{array}\right]\left[\begin{array}{lll}
4 & 0 & 0 \\
0 & 4 & 0 \\
0 & 0 & 2
\end{array}\right]\left[\begin{array}{ccc}
0 & 1 & 0 \\
\frac{-1}{\sqrt{2}} & 0 & \frac{1}{\sqrt{2}} \\
\frac{1}{\sqrt{2}} & 0 & \frac{1}{\sqrt{2}}
\end{array}\right]
\end{aligned}
$$


${ }_{82}$ Selanjutnya, berikut merupakan matriks $\boldsymbol{\Sigma}^{1 / 2}$ dan $\boldsymbol{\Sigma}^{-1 / 2}$.

$$
\begin{aligned}
\boldsymbol{\Sigma}^{1 / 2}= & \boldsymbol{\Gamma}^{\prime} \boldsymbol{\Lambda}^{1 / 2} \boldsymbol{\Gamma} \\
= & {\left[\begin{array}{ccc}
0 & \frac{-1}{\sqrt{2}} & \frac{1}{\sqrt{2}} \\
1 & 0 & 0 \\
0 & \frac{1}{\sqrt{2}} & \frac{1}{\sqrt{2}}
\end{array}\right]\left[\begin{array}{ccc}
2 & 0 & 0 \\
0 & 2 & 0 \\
0 & 0 & \sqrt{2}
\end{array}\right]\left[\begin{array}{ccc}
0 & 1 & 0 \\
\frac{-1}{\sqrt{2}} & 0 & \frac{1}{\sqrt{2}} \\
\frac{1}{\sqrt{2}} & 0 & \frac{1}{\sqrt{2}}
\end{array}\right] } \\
= & {\left[\begin{array}{ccc}
\left(\frac{1}{2} \sqrt{2}+1\right) & 0 & \left(\frac{1}{2} \sqrt{2}-1\right) \\
0 & 2 & 0 \\
\left(\frac{1}{2} \sqrt{2}-1\right) & 0 & \left(\frac{1}{2} \sqrt{2}+1\right)
\end{array}\right] . } \\
\boldsymbol{\Sigma}^{-1 / 2}= & \Gamma^{\prime} \boldsymbol{\Lambda}^{-1 / 2} \boldsymbol{\Gamma} \\
= & {\left[\begin{array}{ccc}
0 & \frac{-1}{\sqrt{2}} & \frac{1}{\sqrt{2}} \\
1 & 0 & 0 \\
0 & \frac{1}{\sqrt{2}} & \frac{1}{\sqrt{2}}
\end{array}\right]\left[\begin{array}{ccc}
\frac{1}{2} & 0 & 0 \\
0 & \frac{1}{2} & 0 \\
0 & 0 & \frac{1}{\sqrt{2}}
\end{array}\right]\left[\begin{array}{ccc}
0 & 1 & 0 \\
\frac{-1}{\sqrt{2}} & 0 & \frac{1}{\sqrt{2}} \\
\frac{1}{\sqrt{2}} & 0 & \frac{1}{\sqrt{2}}
\end{array}\right] } \\
= & {\left[\begin{array}{ccc}
\left(\frac{1}{4} \sqrt{2}+\frac{1}{4}\right) & 0 & \left(\frac{1}{4} \sqrt{2}-\frac{1}{4}\right) \\
0 & \frac{1}{2} & 0 \\
\left(\frac{1}{4} \sqrt{2}-\frac{1}{4}\right) & 0 & \left(\frac{1}{4} \sqrt{2}+\frac{1}{4}\right)
\end{array}\right] . }
\end{aligned}
$$

\section{${ }_{84} \quad \mathbf{1 . 6}$ Matriks Koragam}

Misalkan $X_{i}$ dan $X_{j}$ masing-masing merupakan peubah acak ke- $i$ dan ke- $j$ dengan nilai harapan $E\left[X_{i}\right]=\mu_{i}$ dan $E\left[X_{j}\right]=\mu_{j}$, serta koragam $\sigma_{i j}=$ $E\left(\left[X_{i}-\mu_{i}\right]\left[X_{j}-\mu_{j}\right]\right)$. Bila $\mathbf{X}=\left(X_{1}, X_{2}, \ldots, X_{n}\right)^{\prime}$ adalah suatu vektor dari $n$ peubah acak, maka

$$
E(\mathbf{X})=\left[\begin{array}{c}
\mu_{1} \\
\mu_{2} \\
\vdots \\
\mu_{n}
\end{array}\right],
$$


85

dan matriks koragam (covariance matrix) vektor peubah acak $\mathbf{X}$ ialah

$$
\begin{aligned}
\operatorname{Cov}(\mathbf{X})= & E\left([\mathbf{X}-\boldsymbol{\mu}][\mathbf{X}-\boldsymbol{\mu}]^{\prime}\right) \\
= & {\left[\begin{array}{ccc}
E\left(\left[X_{1}-\boldsymbol{\mu}_{1}\right]\left[X_{1}-\boldsymbol{\mu}_{1}\right]\right) & \ldots & E\left(\left[X_{1}-\boldsymbol{\mu}_{1}\right]\left[X_{m}-\boldsymbol{\mu}_{m}\right]\right) \\
E\left(\left[X_{2}-\boldsymbol{\mu}_{2}\right]\left[X_{1}-\boldsymbol{\mu}_{1}\right]\right) & \ldots & E\left(\left[X_{2}-\boldsymbol{\mu}_{2}\right]\left[X_{m}-\boldsymbol{\mu}_{m}\right]\right) \\
\vdots & \ddots & \vdots \\
E\left(\left[X_{n}-\boldsymbol{\mu}_{n}\right]\left[X_{1}-\boldsymbol{\mu}_{1}\right]\right) & \ldots & E\left(\left[X_{n}-\boldsymbol{\mu}_{n}\right]\left[X_{m}-\boldsymbol{\mu}_{m}\right]\right)
\end{array}\right] } \\
= & {\left[\begin{array}{cccc}
\sigma_{11} & \sigma_{12} & \ldots & \sigma_{1 m} \\
\sigma_{21} & \sigma_{22} & \ldots & \sigma_{2 m} \\
\vdots & \vdots & \ddots & \vdots \\
\sigma_{n 1} & \sigma_{n 2} & \ldots & \sigma_{n m}
\end{array}\right] . }
\end{aligned}
$$

Misalkan a adalah vektor berunsur konstanta yang berukuran $n \times 1$. Misalkan pula $Y=\mathbf{a}^{\prime} \mathbf{X}$ adalah peubah acak, maka $Y$ memiliki ragam bernilai nonnegatif, yaitu $0 \leq \operatorname{Var}(Y)=\operatorname{Var}\left(\mathbf{a}^{\prime} \mathbf{X}\right)=\mathbf{a}^{\prime} \operatorname{Cov}(\mathbf{X}) \mathbf{a}$. Dengan demikian, matriks koragam pada 1.1 merupakan matriks semi-definit positif.

Secara umum, kita dapat mendefinisikan matriks koragam antara vektor $p$-peubah acak $\mathbf{X}=\left(X_{1}, X_{2}, \ldots, X_{p}\right)^{\prime}$ dengan vektor $q$-peubah acak $\mathbf{Y}=$ $\left(Y_{1}, Y_{2}, \ldots, Y_{q}\right)^{\prime}$ sebagai

$$
\begin{aligned}
\operatorname{Cov}(\mathbf{X}, \mathbf{Y}) & =E\left([\mathbf{X}-E(\mathbf{X})][\mathbf{Y}-E(\mathbf{Y})]^{\prime}\right) \\
& =\left[\begin{array}{ccc}
E\left(\left[X_{1}-E\left(X_{1}\right)\right]\left[Y_{1}-E\left(Y_{1}\right)\right]\right) & \ldots & E\left(\left[X_{1}-E\left(X_{1}\right)\right]\left[Y_{q}-E\left(Y_{q}\right)\right]\right) \\
E\left(\left[X_{2}-E\left(X_{2}\right)\right]\left[Y_{1}-E\left(Y_{1}\right)\right]\right) & \ldots & E\left(\left[X_{2}-E\left(X_{2}\right)\right]\left[Y_{q}-E\left(Y_{q}\right)\right]\right) \\
\vdots & \ddots & \vdots \\
E\left(\left[X_{p}-E\left(X_{p}\right)\right]\left[Y_{1}-E\left(Y_{1}\right)\right]\right) & \ldots & E\left(\left[X_{p}-E\left(X_{p}\right)\right]\left[Y_{q}-E\left(Y_{q}\right)\right]\right)
\end{array}\right],
\end{aligned}
$$

3 sehingga $\operatorname{Cov}(\mathbf{X})$ merupakan $\operatorname{Cov}(\mathbf{X}, \mathbf{X})$. Selanjutnya, misalkan $\mathbf{X}$ dan $\mathbf{Y}$ merupakan vektor peubah acak dengan vektor nilai harapan $\boldsymbol{\mu}_{\mathbf{X}}$ dan $\boldsymbol{\mu}_{\mathbf{Y}}$, maka

$$
\begin{aligned}
\boldsymbol{\Sigma}_{\mathbf{X}, \mathbf{Y}} & =\operatorname{Cov}(\mathbf{X}, \mathbf{Y}) \\
& =E\left([\mathbf{X}-E(\mathbf{X})][\mathbf{Y}-E(\mathbf{Y})]^{\prime}\right) \\
& =E\left(\mathbf{X} \mathbf{Y}^{\prime}\right)-E(\mathbf{X})[E(\mathbf{Y})]^{\prime} \\
& =E\left(\mathbf{X Y}^{\prime}\right)-\boldsymbol{\mu}_{\mathbf{X}} \boldsymbol{\mu}_{\mathbf{Y}}^{\prime},
\end{aligned}
$$

sehingga

$$
\begin{aligned}
\boldsymbol{\Sigma}_{\mathbf{X}} & =\boldsymbol{\Sigma}_{\mathbf{X}, \mathbf{X}} \\
& =E\left(\mathbf{X X}^{\prime}\right)-\boldsymbol{\mu}_{\mathbf{X}} \boldsymbol{\mu}_{\mathbf{X}}^{\prime}
\end{aligned}
$$


97

98

Bila $\mathbf{A}$ dan $\mathbf{B}$ merupakan matriks konstanta, maka $E(\mathbf{A X})=\mathbf{A} \boldsymbol{\mu}_{\mathbf{X}}$ dan $E(\mathbf{B Y})=\mathbf{B} \boldsymbol{\mu}_{\mathbf{Y}}$, serta

$$
\begin{aligned}
\operatorname{Cov}(\mathbf{A X}, \mathbf{B Y}) & =\boldsymbol{\Sigma}_{\mathbf{A X}, \mathbf{B Y}} \\
& =E\left([\mathbf{A X}-E(\mathbf{A X})][\mathbf{B Y}-E(\mathbf{B Y})]^{\prime}\right) \\
& =E\left([\mathbf{A X}-\mathbf{A} E(\mathbf{X})][\mathbf{B Y}-\mathbf{B} E(\mathbf{Y})]^{\prime}\right) \\
& =E\left(\left[\mathbf{A X}-\mathbf{A} \boldsymbol{\mu}_{\mathbf{X}}\right]\left[\mathbf{B Y}-\mathbf{B} \boldsymbol{\mu}_{\mathbf{Y}}\right]^{\prime}\right) \\
& =E\left(\left[\mathbf{A}\left(\mathbf{X}-\boldsymbol{\mu}_{\mathbf{X}}\right)\right]\left[\mathbf{B}\left(\mathbf{Y}-\boldsymbol{\mu}_{\mathbf{Y}}\right)\right]^{\prime}\right) \\
& =E\left(\mathbf{A}\left(\mathbf{X}-\boldsymbol{\mu}_{\mathbf{X}}\right)\left(\mathbf{Y}-\boldsymbol{\mu}_{\mathbf{Y}}\right)^{\prime} \mathbf{B}^{\prime}\right) \\
& =\mathbf{A} E\left(\left(\mathbf{X}-\boldsymbol{\mu}_{\mathbf{X}}\right)\left(\mathbf{Y}-\boldsymbol{\mu}_{\mathbf{Y}}\right)^{\prime}\right) \mathbf{B}^{\prime} \\
& =\mathbf{A} \boldsymbol{\Sigma}_{\mathbf{X}, \mathbf{Y}} \mathbf{B}^{\prime}
\end{aligned}
$$

sehingga

$$
\operatorname{Cov}(\mathbf{A X})=\boldsymbol{\Sigma}_{\mathbf{A X}}=\mathbf{A} \boldsymbol{\Sigma}_{\mathbf{X}} \mathbf{A}^{\prime}
$$

99 Misalkan pula

$$
\begin{aligned}
\mathbf{V} & =\mathbf{A X}+\boldsymbol{\delta} \\
\mathbf{W} & =\mathbf{B Y}+\boldsymbol{\eta}
\end{aligned}
$$

100

dengan $\boldsymbol{\delta}$ dan $\boldsymbol{\eta}$ merupakan vektor berunsur konstanta, maka

$$
\begin{aligned}
E(\mathbf{V}) & =\mathbf{A} \boldsymbol{\mu}_{\mathbf{X}}+\boldsymbol{\delta}, \\
E(\mathbf{W}) & =\mathbf{B} \boldsymbol{\mu}_{\mathbf{Y}}+\boldsymbol{\eta}, \\
\operatorname{Cov}(\mathbf{V}, \mathbf{W}) & =\mathbf{A} \boldsymbol{\Sigma}_{\mathbf{X}, \mathbf{Y}} \mathbf{B}^{\prime},
\end{aligned}
$$

sehingga

$$
\operatorname{Cov}(\mathbf{V})=\mathbf{A} \Sigma_{\mathbf{X}} \mathbf{A}^{\prime}
$$

Contoh 1.4 Misalkan $\mathbf{X}=[X, Y, Z]^{\prime}$ merupakan vektor peubah acak dengan $E(\mathbf{X})=[1,4,-6]^{\prime}$ dan matriks koragam

$$
\Sigma=\left[\begin{array}{lll}
3 & 2 & 1 \\
2 & 2 & 1 \\
1 & 1 & 3
\end{array}\right]
$$

${ }_{101}$ Tentukan nilai harapan serta matriks koragam dari peubah acak $T$ dan $\mathbf{W}$ 102 jika

$$
T=2 X-Y+3 Z+1, \mathbf{W}=\left[\begin{array}{c}
X-Y+2 Z+2 \\
2 X+4 Y-Z+3
\end{array}\right]
$$


Jawab. Peubah acak $T$ dan $\mathbf{W}$ dapat dinyatakan sebagai suatu vektor, 104 yaitu

$$
\begin{aligned}
T & =2 X-Y+3 Z+1=[2,-1,3] \mathbf{X}+1 \\
\mathbf{W} & =\left[\begin{array}{c}
X-Y+2 Z \\
2 X+4 Y-Z
\end{array}\right]=\left[\begin{array}{ccc}
1 & -1 & 2 \\
2 & 4 & -1
\end{array}\right] \mathbf{X}+\left[\begin{array}{l}
2 \\
3
\end{array}\right] .
\end{aligned}
$$

105

Selanjutnya, menentukan nilai harapan dan matriks koragam bagi masing106 masing peubah acak.

$$
\begin{aligned}
& E(T)=[2,-1,3] E(\mathbf{X})+1 \\
& =[2,-1,3]\left[\begin{array}{c}
1 \\
4 \\
-6
\end{array}\right]+1 \\
& =-20+1 \\
& =-19 \\
& \boldsymbol{\Sigma}_{T}=[2,-1,3]\left[\begin{array}{lll}
3 & 2 & 1 \\
2 & 2 & 1 \\
1 & 1 & 3
\end{array}\right]\left[\begin{array}{c}
2 \\
-1 \\
3
\end{array}\right] \\
& =39 \\
& E(\mathbf{W})=\left[\begin{array}{ccc}
1 & -1 & 2 \\
2 & 4 & -1
\end{array}\right] E(\mathbf{X})+\left[\begin{array}{l}
2 \\
3
\end{array}\right] \\
& =\left[\begin{array}{ccc}
1 & -1 & 2 \\
2 & 4 & -1
\end{array}\right]\left[\begin{array}{c}
1 \\
4 \\
-6
\end{array}\right]+\left[\begin{array}{l}
2 \\
3
\end{array}\right] \\
& =\left[\begin{array}{l}
15 \\
24
\end{array}\right]+\left[\begin{array}{l}
2 \\
3
\end{array}\right] \\
& =\left[\begin{array}{l}
17 \\
27
\end{array}\right] \\
& \boldsymbol{\Sigma}_{\mathbf{W}}=\left[\begin{array}{ccc}
1 & -1 & 2 \\
2 & 4 & -1
\end{array}\right]\left[\begin{array}{lll}
3 & 2 & 1 \\
2 & 2 & 1 \\
1 & 1 & 3
\end{array}\right]\left[\begin{array}{cc}
1 & 2 \\
-1 & 4 \\
2 & -1
\end{array}\right] \\
& =\left[\begin{array}{cc}
13 & 8 \\
8 & 67
\end{array}\right] \text {. }
\end{aligned}
$$


Contoh 1.5 Misalkan $\mathbf{X}=\left(X_{1}, X_{2}, X_{3}\right)^{\prime}, \mathbf{Y}=\left(Y_{1}, Y_{2}, Y_{3}, Y_{4}\right)^{\prime}$, dan

$$
\operatorname{Cov}(\mathbf{X}, \mathbf{Y})=\left[\begin{array}{cccc}
1 & 3 & -2 & 5 \\
-1 & 2 & 4 & 6 \\
2 & 1 & 0 & 7
\end{array}\right]
$$

Tentukan :

1. $\operatorname{Cov}\left(X_{1}+2 X_{2}-3 X_{3}+1,2 Y_{1}+Y_{2}+4 Y_{3}-5 Y_{4}+2\right)$.

2. $\operatorname{Cov}(\mathbf{V}, \mathbf{W})$ jika

$$
\mathbf{V}=\left[\begin{array}{c}
X_{1}+2 X_{2}-3 X_{3}+3 \\
4 X_{1}-2 X_{2}+3 X_{3}+4
\end{array}\right] \text { dan } \mathbf{W}=\left[\begin{array}{c}
Y_{1}-2 Y_{2}+3 Y_{3}-5 Y_{4}+7 \\
2 Y_{1}+Y_{2}-4 Y_{3}-Y_{4} \\
Y_{1}+Y_{2}-6 Y_{3}+2 Y_{4}
\end{array}\right] .
$$

1. Misalkan $U=X_{1}+2 X_{2}-3 X_{3}+1$ dan $Z=2 Y_{1}+Y_{2}+4 Y_{3}-5 Y_{4}+2$, maka $U=[1,2,-3] \mathbf{X}+1$ dan $Z=[2,1,4,-5] \mathbf{Y}+2$.

$$
\operatorname{Cov}(U, Z)=(1,2,-3)\left[\begin{array}{cccc}
1 & 3 & -2 & 5 \\
-1 & 2 & 4 & 6 \\
2 & 1 & 0 & 7
\end{array}\right]\left[\begin{array}{c}
2 \\
1 \\
4 \\
-5
\end{array}\right]=34
$$

2. $\mathbf{V}=\left[\begin{array}{ccc}1 & 2 & -3 \\ 4 & -2 & 1\end{array}\right] \mathbf{X}+\left[\begin{array}{l}3 \\ 4\end{array}\right], \mathbf{W}=\left[\begin{array}{cccc}1 & -2 & 3 & -5 \\ 2 & 1 & -4 & -1 \\ 1 & 1 & -6 & 2\end{array}\right] \mathbf{Y}+\left[\begin{array}{l}7 \\ 0 \\ 0\end{array}\right]$

$$
\begin{aligned}
\operatorname{Cov}(\mathbf{V}, \mathbf{W}) & =\left[\begin{array}{ccc}
1 & 2 & -3 \\
4 & -2 & 1
\end{array}\right]\left[\begin{array}{cccc}
1 & 3 & -2 & 5 \\
-1 & 2 & 4 & 6 \\
2 & 1 & 0 & 7
\end{array}\right]\left[\begin{array}{ccc}
1 & 2 & 1 \\
-2 & 1 & 1 \\
3 & -4 & -6 \\
-5 & -1 & 2
\end{array}\right] \\
& =\left[\begin{array}{ccc}
23 & -30 & -47 \\
-133 & 74 & 143
\end{array}\right] .
\end{aligned}
$$

\subsection{Sebaran Normal Multivariat}

Pada subbab ini dibahas sebaran normal multivariat untuk vektor peubah acak dimensi- $n$. Misalkan vektor peubah acak $\mathbf{Z}=\left(Z_{1}, \ldots, Z_{n}\right)^{\prime}$ dengan $Z_{1}, \ldots, Z_{n}$ 
merupakan peubah acak bebas stokastik identik yang memiliki sebaran normal baku, $Z_{i} \sim N(0,1), i=1, \ldots, n$. Fungsi kepekatan peluang bagi $\mathbf{Z}$ ialah

$$
\begin{aligned}
f_{\mathbf{Z}}(\mathbf{z}) & =\prod_{i=1}^{n} \frac{1}{\sqrt{2 \pi}} \exp \left\{-\frac{1}{2} z_{i}^{2}\right\} \\
& =\left(\frac{1}{2 \pi}\right)^{\frac{n}{2}} \exp \left\{-\frac{1}{2} \sum_{i=1}^{n} z_{i}^{2}\right\} \\
& =\left(\frac{1}{2 \pi}\right)^{\frac{n}{2}} \exp \left\{-\frac{1}{2} \mathbf{z}^{\prime} \mathbf{z}\right\}, \mathbf{z} \in \mathbb{R}^{n} .
\end{aligned}
$$

Karena $E\left(Z_{i}\right)=0, \operatorname{Var}\left(Z_{i}\right)=1$, dan $\operatorname{Cov}\left(Z_{i}, Z_{j}\right)=0$ untuk $\forall i \neq j$, maka

1. $E(\mathbf{Z})=\mathbf{0}$,

2. $\operatorname{Cov}(\mathbf{Z})=\mathbf{\Sigma}_{\mathbf{Z}}=E\left([\mathbf{Z}-E(\mathbf{Z})][\mathbf{Z}-E(\mathbf{Z})]^{\prime}\right)$

$$
\begin{aligned}
& =\left[\begin{array}{cccc}
\operatorname{Var}\left(Z_{1}\right) & 0 & \cdots & 0 \\
0 & \operatorname{Var}\left(Z_{1}\right) & \cdots & 0 \\
\vdots & \vdots & \ddots & \vdots \\
0 & 0 & \cdots & \operatorname{Var}\left(Z_{n}\right)
\end{array}\right] \\
& =\left[\begin{array}{cccc}
1 & 0 & \cdots & 0 \\
0 & 1 & \cdots & 0 \\
\vdots & \vdots & \ddots & \vdots \\
0 & 0 & \cdots & 1
\end{array}\right]
\end{aligned}
$$

$$
=\mathbf{I}_{n} \text {, }
$$

dengan $\mathbf{I}_{n}$ adalah matriks identitas berukuran $n \times n$.

Selanjutnya, karena peubah acak $Z_{i}$ bebas stokastik identik, maka fungsi pembangkit momen bagi $\mathbf{Z}$ ialah 


$$
\begin{aligned}
M_{\mathbf{Z}}(\mathbf{t}) & =E\left[\exp \left\{\mathbf{t}^{\prime} \mathbf{Z}\right\}\right] \\
& =E\left[\prod_{i=1}^{n} \exp \left\{t_{i} Z_{i}\right\}\right] \\
& =\prod_{i=1}^{n} E\left[\exp \left\{t_{i} Z_{i}\right\}\right] \\
& =\prod_{i=1}^{n} M_{Z}\left(t_{i}\right) \\
& =\prod_{i=1}^{n} \exp \left\{\frac{1}{2} t_{i}^{2}\right\} \\
& =\exp \left\{\frac{1}{2} \sum_{i=1}^{n} t_{i}^{2}\right\} \\
& =\exp \left\{\frac{1}{2} \mathbf{t}^{\prime} \mathbf{t}\right\}, \forall \mathbf{t} \in \mathbb{R}^{n} .
\end{aligned}
$$

Dengan demikian, vektor peubah acak $\mathbf{Z}$ dikatakan memiliki sebaran normal multivariat dengan vektor nilai harapan $\mathbf{0}$ dan matriks koragam $\mathbf{I}_{n}$ yang dinotasikan dengan $\mathbf{Z} \sim N_{n}\left(\mathbf{0}, \mathbf{I}_{n}\right)$.

Misalkan $\mathbf{Z}$ memiliki sebaran $N_{n}\left(\mathbf{0}, \mathbf{I}_{n}\right)$. Misalkan pula $\boldsymbol{\Sigma}$ merupakan matriks simetrik dan semi-definit positif, serta $\boldsymbol{\mu}$ adalah vektor berunsur konstanta. Definisikan suatu vektor peubah acak $\mathbf{X}$ sebagai berikut

$$
\mathbf{X}=\boldsymbol{\Sigma}^{\frac{1}{2}} \mathbf{Z}+\boldsymbol{\mu},
$$

maka diperoleh

$$
E(\mathbf{X})=\boldsymbol{\mu} \text { dan } \operatorname{Cov}(\mathbf{X})=\boldsymbol{\Sigma}^{\frac{1}{2}} \boldsymbol{\Sigma}^{\frac{1}{2}}=\boldsymbol{\Sigma} .
$$


133

Kemudian, fungsi pembangkit momen bagi $\mathbf{X}$ ialah

$$
\begin{aligned}
M_{\mathbf{X}}(\mathbf{t}) & =E\left[\exp \left\{\mathbf{t}^{\prime} \mathbf{X}\right\}\right] \\
& =E\left[\exp \left\{\mathbf{t}^{\prime} \Sigma^{\frac{1}{2}} \mathbf{Z}+\mathbf{t}^{\prime} \boldsymbol{\mu}\right\}\right] \\
& =\exp \left\{\mathbf{t}^{\prime} \boldsymbol{\mu}\right\} E\left[\exp \left\{\mathbf{t}^{\prime} \boldsymbol{\Sigma}^{\frac{1}{2}} \mathbf{Z}\right\}\right] \\
& =\exp \left\{\mathbf{t}^{\prime} \boldsymbol{\mu}\right\} \exp \left\{\frac{1}{2}\left(\boldsymbol{\Sigma}^{\frac{1}{2}} \mathbf{t}\right)^{\prime} \boldsymbol{\Sigma}^{\frac{1}{2}} \mathbf{t}\right\} \\
& =\exp \left\{\mathbf{t}^{\prime} \boldsymbol{\mu}\right\} \exp \left\{\frac{1}{2} \mathbf{t}^{\prime} \boldsymbol{\Sigma} \mathbf{t}\right\} \\
& =\exp \left\{\mathbf{t}^{\prime} \boldsymbol{\mu}+\frac{1}{2} \mathbf{t}^{\prime} \boldsymbol{\Sigma} \mathbf{t}\right\} .
\end{aligned}
$$

Definisi 1.5 (Normal Multivariat) Vektor peubah acak $\mathbf{X}$ memiliki sebaran normal multivariat atau $\mathbf{X} \sim N_{n}(\boldsymbol{\mu}, \boldsymbol{\Sigma})$ jika $\mathbf{X}$ memiliki fungsi pembangkit momen sebagai berikut

$$
M_{\mathbf{X}}(\mathbf{t})=\exp \left\{\mathbf{t}^{\prime} \boldsymbol{\mu}+\frac{1}{2} \mathbf{t}^{\prime} \boldsymbol{\Sigma} \mathbf{t}\right\},
$$

untuk setiap $\mathbf{t} \in \mathbb{R}^{n}$ dan $\mathbf{\Sigma}$ merupakan matriks simetrik, semi-definit positif, serta $\boldsymbol{\mu} \in \mathbb{R}^{n}$.

Jika $\boldsymbol{\Sigma}$ merupakan matriks definit positif, maka matriks $\boldsymbol{\Sigma}^{\frac{1}{2}}$ memiliki invers, sehingga transformasi satu-satu antara peubah acak $\mathbf{X}$ dan $\mathbf{Z}$ pada persamaan 1.2

$$
\mathbf{Z}=\boldsymbol{\Sigma}^{-\frac{1}{2}}(\mathbf{X}-\boldsymbol{\mu})
$$

dengan Jacobi $\left|\boldsymbol{\Sigma}^{-1 / 2}\right|=|\boldsymbol{\Sigma}|^{-1 / 2}$ menghasilkan fungsi kepekatan peluang bagi $\mathbf{X}$, yaitu

$$
f_{\mathbf{X}}(\mathbf{x})=\frac{1}{(2 \pi)^{n / 2}|\boldsymbol{\Sigma}|^{1 / 2}} \exp \left\{-\frac{1}{2}(\mathbf{x}-\boldsymbol{\mu})^{\prime} \boldsymbol{\Sigma}^{-1}(\mathbf{x}-\boldsymbol{\mu})\right\}, \mathbf{x} \in R^{n} .
$$


Bukti. $\forall \mathbf{t} \in \mathbb{R}^{m}$, fungsi pembangkit momen bagi $\mathbf{Y}$ ialah

$$
\begin{aligned}
M_{\mathbf{Y}}(\mathbf{t}) & =E\left[\exp \left\{\mathbf{t}^{\prime} \mathbf{Y}\right\}\right] \\
& =E\left[\exp \left\{\mathbf{t}^{\prime}(\mathbf{A X}+\mathbf{b})\right\}\right] \\
& =\exp \left\{\mathbf{t}^{\prime} \mathbf{b}\right\} E\left[\exp \left\{\left(\mathbf{A}^{\prime} \mathbf{t}\right)^{\prime} \mathbf{X}\right\}\right] \\
& =\exp \left\{\mathbf{t}^{\prime} \mathbf{b}\right\} \exp \left\{\left(\mathbf{A}^{\prime} \mathbf{t}\right)^{\prime} \boldsymbol{\mu}+\frac{1}{2}\left(\mathbf{A}^{\prime} \mathbf{t}\right)^{\prime} \boldsymbol{\Sigma}\left(\mathbf{A}^{\prime} \mathbf{t}\right)\right\} \\
& =\exp \left\{\mathbf{t}^{\prime}(\mathbf{A} \boldsymbol{\mu}+\mathbf{b})+\frac{1}{2} \mathbf{t}^{\prime} \mathbf{A} \boldsymbol{\Sigma} \mathbf{A}^{\prime} \mathbf{t}\right\}
\end{aligned}
$$

di mana fungsi pembangkit momen tersebut adalah fungsi pembangkit momen bagi sebaran $N_{m}\left(\mathbf{A} \boldsymbol{\mu}+\mathbf{b}, \mathbf{A} \boldsymbol{\Sigma} \mathbf{A}^{\prime}\right)$.

Misalkan $\mathbf{X}_{1}$ merupakan subvektor berdimensi $m<n$ dari vektor peubah acak $\mathbf{X}$, maka $\mathbf{X}$ dapat dituliskan menjadi

$$
\mathbf{X}=\left[\begin{array}{l}
\mathbf{X}_{1} \\
\mathbf{X}_{2}
\end{array}\right]
$$

dengan $\mathbf{X}_{2}$ merupakan vektor berdimensi $p=n-m$. Karena $\mathbf{X}$ dipartisi seperti pada persamaan 1.3, maka nilai harapan dan matriks koragam dari $\mathbf{X}$ juga dapat dipartisi sebagai berikut

$$
\boldsymbol{\mu}=\left[\begin{array}{l}
\boldsymbol{\mu}_{1} \\
\boldsymbol{\mu}_{2}
\end{array}\right] \text { dan } \boldsymbol{\Sigma}=\left[\begin{array}{ll}
\boldsymbol{\Sigma}_{11} & \boldsymbol{\Sigma}_{12} \\
\boldsymbol{\Sigma}_{21} & \boldsymbol{\Sigma}_{22}
\end{array}\right],
$$

dengan $\boldsymbol{\Sigma}_{11}$ merupakan matriks koragam bagi $\mathbf{X}_{1}$ dan $\boldsymbol{\Sigma}_{12}$ merupakan matriks koragam antara $\mathbf{X}_{1}$ dan $\mathbf{X}_{2}$. Kemudian, definisikan matriks $\mathbf{A}$ sebagai berikut

$$
\mathbf{A}=\left[\begin{array}{lll}
\mathbf{I}_{m} & \vdots & \mathbf{O}_{m p}
\end{array}\right]
$$

di mana $\mathbf{O}_{m p}$ merupakan matriks nol $m \times p$, maka $\mathbf{X}_{1}=\mathbf{A X}$. Dengan menggunakan Teorema 1.4 pada transformasi tersebut, diperoleh akibat sebagai berikut:

Akibat 1.2 Misalkan $\mathbf{X} \sim N_{n}(\boldsymbol{\mu}, \boldsymbol{\Sigma})$. Jika $\mathbf{X}_{1}$ merupakan subvektor berdimensi $m<n$ dari vektor peubah acak $\mathbf{X}$ (persamaan 1.3), maka $\mathbf{X}_{1} \sim$ $N_{n}\left(\boldsymbol{\mu}_{1}, \boldsymbol{\Sigma}_{11}\right)$.

Akibat 1.2 dapat digunakan untuk mencari sebaran marginal dari peubah acak normal multivariat. 
Teorema 1.5 Misalkan $\mathbf{X} \sim N_{n}(\boldsymbol{\mu}, \boldsymbol{\Sigma})$ dan $\mathbf{X}$ dipartisi seperti pada persamaan 1.3 dan 1.4. $\mathbf{X}_{1}$ dan $\mathbf{X}_{2}$ saling bebas jika dan hanya jika $\boldsymbol{\Sigma}_{12}=\mathbf{O}$.

Bukti. Disediakan untuk latihan.

Teorema 1.6 Misalkan $\mathbf{X} \sim N_{n}(\boldsymbol{\mu}, \boldsymbol{\Sigma})$ dan $\mathbf{X}$ dipartisi seperti pada persamaan 1.3 dan 1.4. Asumsikan bahwa $\mathbf{\Sigma}$ adalah matriks definit positif, maka sebaran bersyarat dari $\mathbf{X}_{1} \mid \mathbf{X}_{2}$ ialah

$$
N_{m}\left(\boldsymbol{\mu}_{1}+\boldsymbol{\Sigma}_{12} \boldsymbol{\Sigma}_{22}^{-1}\left(\mathbf{X}_{2}-\boldsymbol{\mu}_{2}\right), \boldsymbol{\Sigma}_{11}-\boldsymbol{\Sigma}_{12} \boldsymbol{\Sigma}_{22}^{-1} \boldsymbol{\Sigma}_{21}\right) .
$$

Bukti. Perhatikan vektor peubah acak $\mathbf{W}=\mathbf{X}_{1}-\boldsymbol{\Sigma}_{12} \boldsymbol{\Sigma}_{22}^{-1} \mathbf{X}_{2}$ dan $\mathbf{X}_{2}$, maka

$$
\left[\begin{array}{l}
\mathbf{W} \\
\mathbf{X}_{2}
\end{array}\right]=\left[\begin{array}{cc}
\mathbf{I}_{m} & -\boldsymbol{\Sigma}_{12} \boldsymbol{\Sigma}_{22}^{-1} \\
\mathbf{O} & \mathbf{I}_{p}
\end{array}\right]\left[\begin{array}{l}
\mathbf{X}_{1} \\
\mathbf{X}_{2}
\end{array}\right]
$$

Berdasarkan Teorema 1.4, $E(\mathbf{W})=\boldsymbol{\mu}_{1}-\boldsymbol{\Sigma}_{12} \boldsymbol{\Sigma}_{22}^{-1} \boldsymbol{\mu}_{2}, E\left(\mathbf{X}_{2}\right)=\boldsymbol{\mu}_{2}$, dan matriks koragam

$$
\begin{aligned}
& {\left[\begin{array}{cc}
\mathbf{I}_{m} & -\Sigma_{12} \Sigma_{22}^{-1} \\
\mathbf{O} & \mathbf{I}_{p}
\end{array}\right]\left[\begin{array}{cc}
\Sigma_{11} & \Sigma_{12} \\
\Sigma_{21} & \Sigma_{22}
\end{array}\right]\left[\begin{array}{cc}
\mathbf{I}_{m} & \mathbf{O} \\
-\Sigma_{12} \Sigma_{22}^{-1} & \mathbf{I}_{p}
\end{array}\right] } \\
= & {\left[\begin{array}{cc}
\Sigma_{11}-\Sigma_{12} \Sigma_{22}^{-1} \Sigma_{21} & \mathbf{O} \\
\mathbf{O} & \Sigma_{22}
\end{array}\right] . }
\end{aligned}
$$

Dengan demikian, berdasarkan Teorema 1.5, vektor peubah acak $\mathbf{W}$ dan $\mathbf{X}_{2}$ saling bebas. Karena saling bebas, sebaran bersyarat $\mathbf{W} \mid \mathbf{X}_{2}$ sama dengan sebaran marginal dari $\mathbf{W} \sim N_{m}\left(\boldsymbol{\mu}_{1}-\boldsymbol{\Sigma}_{12} \boldsymbol{\Sigma}_{22}^{-1} \boldsymbol{\mu}_{2}, \boldsymbol{\Sigma}_{11}-\boldsymbol{\Sigma}_{12} \boldsymbol{\Sigma}_{22}^{-1} \boldsymbol{\Sigma}_{21}\right)$. Akibatnya,

$$
\mathbf{X}_{1} \mid \mathbf{X}_{2} \sim N_{m}\left(\boldsymbol{\mu}_{1}-\boldsymbol{\Sigma}_{12} \boldsymbol{\Sigma}_{22}^{-1} \boldsymbol{\mu}_{2}+\boldsymbol{\Sigma}_{12} \boldsymbol{\Sigma}_{22}^{-1} \mathbf{X}_{2}, \boldsymbol{\Sigma}_{11}-\boldsymbol{\Sigma}_{12} \boldsymbol{\Sigma}_{22}^{-1} \boldsymbol{\Sigma}_{21}\right),
$$

atau

$$
\left(\mathbf{W}+\boldsymbol{\Sigma}_{12} \boldsymbol{\Sigma}_{22}^{-1} \mathbf{X}_{2}\right) \mid \mathbf{X}_{2} \sim N_{m}\left(\boldsymbol{\mu}_{1}-\boldsymbol{\Sigma}_{12} \boldsymbol{\Sigma}_{22}^{-1} \boldsymbol{\mu}_{2}+\boldsymbol{\Sigma}_{12} \boldsymbol{\Sigma}_{22}^{-1} \mathbf{X}_{2}, \boldsymbol{\Sigma}_{11}-\boldsymbol{\Sigma}_{12} \boldsymbol{\Sigma}_{22}^{-1} \boldsymbol{\Sigma}_{21}\right) .
$$

Contoh 1.6 Misalkan dalam suatu populasi, bobot badan dan tinggi badan pria memiliki sebaran normal bivariat. Jika diketahui bahwa rata-rata dan ragam dari bobot badan pria secara berturut-turut sebesar $60 \mathrm{~kg}$ dan $25 \mathrm{~kg}^{2}$, kemudian rata-rata dan ragam dari tinggi badannya secara berturut-turut sebesar $165 \mathrm{~cm}$ dan $100 \mathrm{~cm}^{2}$, serta besar korelasi antara bobot badan dan tinggi badan sebesar 0.6, maka tentukan : 
a. $P(160<Y<175)$,

b. $P(160<Y<175 \mid X=65)$, dengan $X$ dan $Y$ secara berturut-turut menyatakan bobot badan dan tinggi badan pria.

\section{Jawab.}

a. $P(160<Y<175)$

$$
\begin{aligned}
P(160<Y<175) & =P\left(\frac{160-\mu_{y}}{\sigma_{y}}<\frac{Y-\mu_{y}}{\sigma_{y}}<\frac{175-\mu_{y}}{\sigma_{y}}\right) \\
& =P\left(\frac{160-165}{10}<Z<\frac{175-165}{10}\right) \\
& =P(-0.5<Z<1) \\
& =\Phi(1)-\Phi(-0.5) \\
& =\Phi(1)-[1-\Phi(0.5)] \\
& =0.8413-[1-0.6915] \\
& =0.5328 .
\end{aligned}
$$

b. $P(160<Y<175 \mid X=65)$

$$
\left[\begin{array}{l}
Y \\
X
\end{array}\right] \sim N_{2}\left[\left(\begin{array}{l}
\mu_{y} \\
\mu_{x}
\end{array}\right),\left(\begin{array}{ll}
\sigma_{11} & \sigma_{12} \\
\sigma_{21} & \sigma_{22}
\end{array}\right)\right]
$$

catatan: $\sigma_{y}^{2}=\sigma_{11}, \sigma_{x}^{2}=\sigma_{22}$, dan $\sigma_{12}=\sigma_{21}=\rho \sigma_{x} \sigma_{y}$.

Berdasarkan Teorema 1.6,

$$
\begin{aligned}
Y \mid X & \sim N_{2}\left(\mu_{y}+\frac{\sigma_{12}}{\sigma_{22}}\left(x-\mu_{x}\right), \sigma_{11}-\frac{\sigma_{12}}{\sigma_{22}} \sigma_{21}\right) \\
& \sim N_{2}\left(\mu_{y}+\frac{\rho \sigma_{x} \sigma_{y}}{\sigma_{x}^{2}}\left(x-\mu_{x}\right), \sigma_{y}^{2}-\frac{\rho \sigma_{x} \sigma_{y}}{\sigma_{x}^{2}}\left(\rho \sigma_{x} \sigma_{y}\right)\right) \\
& \sim N_{2}\left(\mu_{y}+\rho \frac{\sigma_{y}}{\sigma_{x}}\left(x-\mu_{x}\right), \sigma_{y}^{2}\left(1-\rho^{2}\right)\right) \\
E(Y \mid x=65) & =165+0.6\left(\frac{10}{5}\right)(65-60)=171 \\
\operatorname{Var}(Y \mid x=65) & =100(1-0.36)=64 .
\end{aligned}
$$


174

Jadi,

$$
\begin{aligned}
P(160<Y<175 \mid X=65) & =P\left(\frac{160-171}{8}<Z<\frac{175-171}{8}\right) \\
& =\Phi(0.5)-\Phi(-1.375) \\
& =\Phi(0.5)-[1-\Phi(1.375)] \\
& =0.6915-[1-0.9154] \\
& =0.6069 .
\end{aligned}
$$

\subsection{Latihan}

1. Misalkan $X, Y$, dan $Z$ adalah tiga peubah acak diskret yang menyebar bersama dengan fungsi massa peluang

$$
p_{X, Y, Z}(x, y, z)=c(x+y+z) \mathbf{I}(x=1,2 ; y=1,2 ; z=1,3)
$$

a. Tentukan nilai $c$.

b. Tentukan fungsi massa peluang marginal $p_{X, Y}(x, y)$ dan $p_{X}(x)$.

c. Tentukan $E(X+Y+Z)$.

2. Misalkan $X, Y$, dan $Z$ adalah tiga peubah acak kontinu yang menyebar bersama dengan fungsi kepekatan peluang

$$
f_{X, Y, Z}(x, y, z)=\operatorname{cxyz} \mathbf{I}(0 \leq x \leq y \leq z \leq 2)
$$

a. Tentukan nilai $c$.

b. Tentukan fungsi kepekatan peluang marginal $f_{X, Y}(x, y)$ dan $f_{X}(x)$.

c. Tentukan $E(X Y+Z)$.

3. Misalkan $X$ dan $Y$ memiliki sebaran normal bivariat dengan $\mu_{x}=3$, $\mu_{y}=1, \sigma_{x}^{2}=16, \sigma_{y}^{2}=25$, dan $\rho=\frac{3}{5}$. Tentukan:
a. $P(3<Y<8)$.
b. $P(3<Y<8 \mid X=7)$.
c. $P(-3<X<3)$.
d. $P(-3<X<3 \mid X=-4)$. 
4. Misalkan $\mathbf{X} \sim N_{2}(\boldsymbol{\mu}, \boldsymbol{\Sigma})$. Tentukan sebaran dari vektor peubah acak $\left(X_{1}+X_{2}, X_{1}-X_{2}\right)$ serta tunjukkan bahwa peubah acak $X_{1}+X_{2}$ dan $X_{1}-X_{2}$ saling bebas jika $\operatorname{Var}\left(X_{1}\right)=\operatorname{Var}\left(X_{2}\right)$.

5. Misalkan $\mathbf{X}=\left(X_{1}, X_{2}, X_{3}\right)^{\prime}$ memiliki sebaran $N_{3}(\boldsymbol{\mu}, \boldsymbol{\Sigma})$ di mana $\mu=$ $(3,2,1)^{\prime}$, dan

$$
\boldsymbol{\Sigma}=\left[\begin{array}{ccc}
5 & -1 & 2 \\
-1 & 2 & 1 \\
2 & 1 & 3
\end{array}\right]
$$

a. Tentukanlah sebaran dari vektor peubah acak

$$
\left(X_{1}-X_{2}+1,2 X_{2}+3 X_{3}-4\right)^{\prime},
$$

serta berikanlah korelasi dari kedua peubah acak tersebut.

b. Carilah $P\left(X_{1}>X_{2}-2 X_{3}+3\right)$.

c. Carilah $P\left(\left(X_{1}-X_{2}-X_{3}\right)^{2}>10\right)$.

6. Buktikan bahwa $\mathbf{X}_{1}$ dan $\mathbf{X}_{2}$ saling bebas jika dan hanya jika $\boldsymbol{\Sigma}_{12}=\mathbf{O}$, di mana $\mathbf{X} \sim N_{n}(\boldsymbol{\mu}, \boldsymbol{\Sigma})$ dan $\mathbf{X}$ dipartisi seperti pada persamaan 1.3 dan 1.4 . 


\section{${ }_{18}$ BAB 2}

\section{Beberapa Sebaran Kontinu}

\subsection{Sebaran Gamma}

Definisi 2.1 Fungsi Gamma yang dinotasikan $\Gamma(\alpha)$ didefinisikan sebagai

$$
\Gamma(\alpha)=\int_{0}^{\infty} y^{\alpha-1} e^{-y} d y
$$

201 dengan $\alpha>0$.

Jika $\alpha=1$, maka

$$
\Gamma(1)=\int_{0}^{\infty} e^{-y} d y=1 .
$$

202 Jika $\alpha>1$, maka dengan menggunakan teknik integral parsial diperoleh

$$
\begin{aligned}
\Gamma(\alpha) & =(\alpha-1) \int_{0}^{\infty} y^{\alpha-2} e^{-y} d y \\
& =(\alpha-1) \Gamma(\alpha-1) .
\end{aligned}
$$

203 204

Oleh karena itu, jika $\alpha$ adalah bilangan bulat positif yang lebih besar dari 1, maka

$$
\begin{aligned}
\Gamma(\alpha) & =(\alpha-1)(\alpha-2) \ldots(3)(2)(1) \Gamma(1) \\
& =(\alpha-1) !
\end{aligned}
$$

Misalkan suatu variabel baru $y=x / \beta$ di mana $\beta>0$, maka

$$
\Gamma(\alpha)=\int_{0}^{\infty}\left(\frac{x}{\beta}\right)^{\alpha-1} e^{-x / \beta}\left(\frac{1}{\beta}\right) d x
$$


atau ekuivalen dengan

$$
1=\int_{0}^{\infty} \frac{1}{\Gamma(\alpha) \beta^{\alpha}} x^{\alpha-1} e^{-x / \beta} d x
$$

Karena $\alpha>0, \beta>0$, dan $\Gamma(\alpha)>0$, maka

$$
f(x)=\frac{1}{\Gamma(\alpha) \beta^{\alpha}} x^{\alpha-1} e^{-x / \beta} \mathbf{I}(x>0)
$$

merupakan fungsi kepekatan peluang dari suatu peubah acak kontinu. Peubah acak $X$ yang memiliki fungsi kepekatan peluang tersebut disebut memiliki sebaran gamma dengan parameter $\alpha$ dan $\beta$, dinotasikan $\Gamma(\alpha, \beta)$.

Berikut merupakan ilustrasi dari sebaran gamma apabila salah satu parameternya dibuat tetap. Gambar 1 merupakan sebaran gamma dengan parameter $\beta$ tetap, yaitu $\beta=2$ dan parameter $\alpha$ yang berbeda, yaitu $\alpha=1,2,4$.

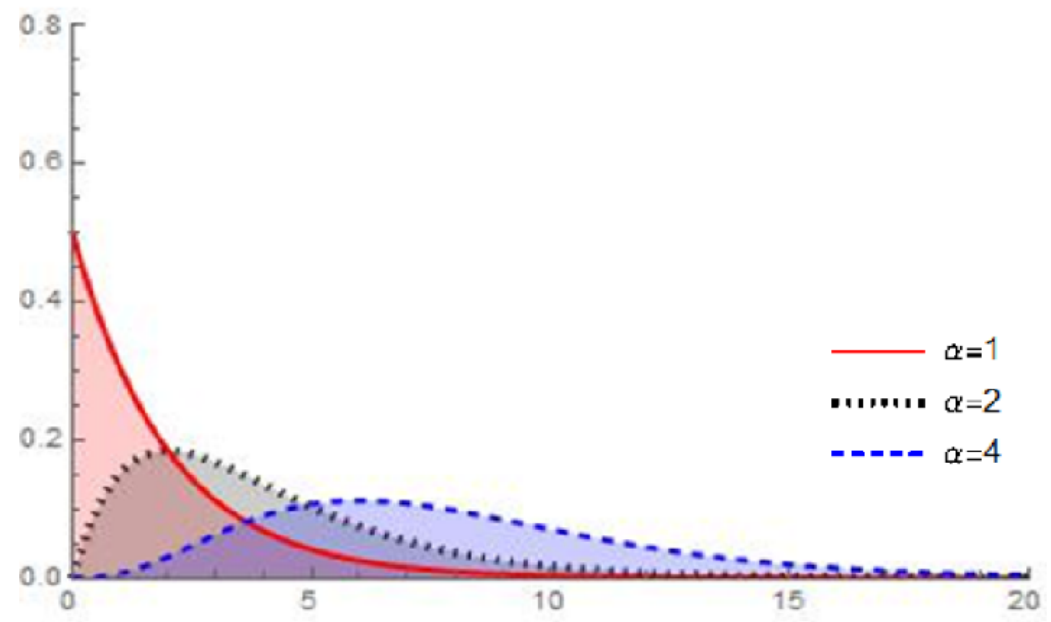

Gambar 1. Sebaran gamma dengan $\beta=2$ dan $\alpha=1,2,4$

Selanjutnya, Gambar 2 merupakan sebaran gamma dengan parameter $\alpha$ tetap, yaitu $\alpha=2$ dan parameter $\beta$ yang berbeda, yaitu $\beta=0.5,1,1.5$. 


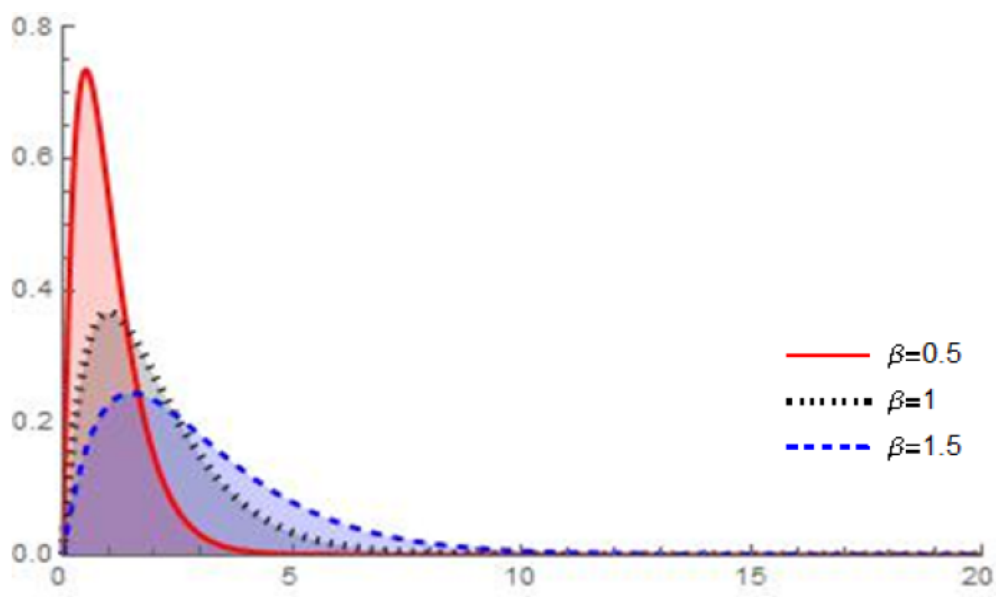

Gambar 2. Sebaran gamma dengan $\alpha=2$ dan $\beta=0.5,1,1.5$ ialah

Fungsi pembangkit momen bagi peubah acak $X$ yang menyebar gamma

$$
\begin{aligned}
M_{X}(t) & =\int_{0}^{\infty} e^{t x} \frac{1}{\Gamma(\alpha) \beta^{\alpha}} x^{\alpha-1} e^{-x / \beta} d x \\
& =\int_{0}^{\infty} \frac{1}{\Gamma(\alpha) \beta^{\alpha}} x^{\alpha-1} e^{-x(1-\beta t) / \beta} d x \\
& =\frac{1}{\Gamma(\alpha) \beta^{\alpha}} \times \Gamma(\alpha) \times\left(\frac{\beta}{1-\beta t}\right)^{\alpha} \\
& =\frac{1}{(1-\beta t)^{\alpha}}, t<\frac{1}{\beta} .
\end{aligned}
$$

Selanjutnya,

$$
M^{\prime}(t)=(-\alpha)(1-\beta t)^{-\alpha-1}(-\beta)
$$

dan

$$
M^{\prime \prime}(t)=(-\alpha)(-\alpha-1)(1-\beta t)^{-\alpha-2}(-\beta)^{2} .
$$

Dengan demikian, sebaran gamma memiliki nilai harapan dan ragam sebagai berikut

$$
E(X)=M^{\prime}(0)=\alpha \beta
$$

217 dan

$$
\begin{aligned}
\operatorname{Var}(X) & =M^{\prime \prime}(0)-[E(X)]^{2} \\
& =\alpha(\alpha+1) \beta^{2}-\alpha^{2} \beta^{2} \\
& =\alpha \beta^{2} .
\end{aligned}
$$


Teorema 2.1 Misalkan $X_{1}, X_{2}, \ldots, X_{n}$ adalah peubah acak yang saling bebas di mana $X_{i} \sim \Gamma\left(\alpha_{i}, \beta\right)$ untuk $i=1,2, \ldots, n$. Misalkan pula $Y=\sum_{i=1}^{n} X_{i}$, $\operatorname{maka} Y \sim \Gamma\left(\sum_{i=1}^{n} \alpha_{i}, \beta\right)$.

Bukti. Dengan menggunakan asumsi kebebasan dan fungsi pembangkit momen dari sebaran gamma, diperoleh

$$
\begin{aligned}
M_{Y}(t) & =E\left[\exp \left\{t \sum_{i=1}^{n} X_{i}\right\}\right] \\
& =\prod_{i=1}^{n} E\left[\exp \left\{t X_{i}\right\}\right] \\
& =\prod_{i=1}^{n}(1-\beta t)^{-\alpha_{i}} \\
& =(1-\beta t)^{-\sum_{i=1}^{n} \alpha_{i}}
\end{aligned}
$$

untuk $t<1 / \beta$. Persamaan 2.1 merupakan fungsi pembangkit momen dari sebaran $\Gamma\left(\sum_{i=1}^{n} \alpha_{i}, \beta\right)$.

\subsection{Sebaran Khi-Kuadrat}

Sebaran khi-kuadrat merupakan kasus khusus dari sebaran gamma, yaitu jika parameter $\alpha=\frac{r}{2}$ dan $\beta=2$ di mana $r$ adalah bilangan bulat positif. Nilai harapan dan ragam dari sebaran khi-kuadrat ialah

$$
E(X)=\alpha \beta=\left(\frac{r}{2}\right) \times 2=r
$$

dan

$$
\operatorname{Var}(X)=\alpha \beta^{2}=\left(\frac{r}{2}\right) \times 2^{2}=2 r .
$$

Jadi, fungsi kepekatan peluang bagi peubah acak kontinu $X$ yang memiliki sebaran khi kuadrat dengan parameter $r$, dinotasikan dengan $X \sim \chi^{2}(r)$, ialah

$$
f(x)=\frac{1}{\Gamma(r / 2) 2^{r / 2}} x^{r / 2-1} e^{-x / 2} \mathbf{I}(x>0),
$$

di mana parameter $r$ disebut sebagai derajat bebas dari sebaran $\chi^{2}(r)$. Gambar fungsi kepekatan peluang untuk $r=2, r=4$, dan $r=8$ diberikan pada Gambar 1. 
Teorema 2.2 Misalkan X memiliki sebaran $\chi^{2}(r)$. Jika $k>-r / 2$, maka nilai harapan dari $X^{k}$ ada dan

$$
E\left(X^{k}\right)=\frac{2^{k} \Gamma\left(\frac{r}{2}+k\right)}{\Gamma\left(\frac{r}{2}\right)} .
$$

229

Bukti.

$$
\begin{aligned}
E\left(X^{k}\right) & =\int_{0}^{\infty} \frac{1}{\Gamma(r / 2) 2^{r / 2}} x^{(r / 2)+k-1} e^{-x / 2} d x \\
& =\frac{1}{\Gamma(r / 2) 2^{r / 2}} \times \Gamma\left(\frac{r}{2}+k\right) \times 2^{r / 2+k} \\
& =2^{k} \frac{\Gamma\left(\frac{r}{2}+k\right)}{\Gamma(r / 2)} .
\end{aligned}
$$

Akibat 2.1 Misalkan $X_{1}, X_{2}, \ldots, X_{n}$ adalah peubah acak yang saling bebas di mana $X_{i} \sim \chi^{2}\left(r_{i}\right)$ untuk $i=1,2, \ldots, n$. Misalkan pula $Y=\sum_{i=1}^{n} X_{i}$, maka $Y \sim \chi^{2}\left(\sum_{i=1}^{n} r_{i}\right)$.

Bukti. Karena sebaran khi-kuadrat dengan derajat bebas $r$ merupakan kasus khusus dari sebaran gamma yang memiliki parameter $\alpha=\frac{r}{2}$ dan $\beta=2$, maka fungsi pembangkit momen bagi sebaran khi-kuadrat ialah

$$
M(t)=(1-\beta t)^{-\alpha}=(1-2 t)^{-r / 2} .
$$

Dengan menggunakan asumsi kebebasan dan fungsi pembangkit momen dari sebaran khi-kuadrat, diperoleh

$$
\begin{aligned}
M_{Y}(t) & =E\left[\exp \left\{t \sum_{i=1}^{n} X_{i}\right\}\right] \\
& =\prod_{i=1}^{n} E\left[\exp \left\{t X_{i}\right\}\right] \\
& =\prod_{i=1}^{n}(1-2 t)^{-r_{i} / 2} \\
& =(1-2 t)^{-\frac{1}{2} \sum_{i=1}^{n} r_{i}}
\end{aligned}
$$

untuk $t<1 / 2$. Persamaan 2.2 merupakan fungsi pembangkit momen dari sebaran $\chi^{2}\left(\sum_{i=1}^{n} r_{i}\right)$. 
238

Teorema 2.3 Jika $Z \sim N(0,1)$, maka $Z^{2} \sim \chi^{2}(1)$.

Bukti. Misalkan $Y=Z^{2}$, maka fungsi sebaran dari peubah acak $Y$ ialah

$$
\begin{aligned}
F(y) & =P(Y \leq y) \\
& =P\left(Z^{2} \leq y\right) \\
& =P(-\sqrt{y} \leq Z \leq \sqrt{y}) \\
& =2 P(0 \leq Z \leq \sqrt{y}) \\
& =2 \int_{0}^{\sqrt{y}} \frac{1}{\sqrt{2 \pi}} e^{-z^{2} / 2} d z .
\end{aligned}
$$

239

Dengan menggunakan butir (8) pada Appendix untuk $\beta(y)=\sqrt{y}, \alpha(y)=0$, dan $f(z, y)=\frac{1}{\sqrt{2 \pi}} e^{-z^{2} / 2}$, maka diperoleh fungsi kepekatan peluang peubah acak $Y$ yaitu

$$
\begin{aligned}
f(y) & =F^{\prime}(y) \\
& =0+2 \times \frac{1}{\sqrt{2 \pi}} e^{-\frac{1}{2}(\sqrt{y})^{2}}-\frac{1}{2} y^{-1 / 2}+0 \\
& =\frac{1}{\sqrt{\pi} \sqrt{2}} y^{-1 / 2} e^{-y / 2} \\
& =\frac{1}{\Gamma\left(\frac{1}{2}\right) 2^{1 / 2}} y^{1 / 2-1} e^{-y / 2} \mathbf{I}(y>0) .
\end{aligned}
$$

Dengan demikian, $Y=Z^{2} \sim \operatorname{Gamma}\left(\frac{1}{2}, 2\right)=\chi^{2}(1)$.

Akibat 2.2 Jika peubah acak $X$ menyebar $N\left(\mu, \sigma^{2}\right), \sigma^{2}>0$, maka peubah acak $V=(X-\mu)^{2} / \sigma^{2}$ menyebar $\chi^{2}(1)$.

Teorema 2.4 Jika $\mathbf{X} \sim N_{n}(\boldsymbol{\mu}, \boldsymbol{\Sigma})$ dengan $\boldsymbol{\Sigma}$ adalah matriks definit positif, maka peubah acak $W=(\mathbf{X}-\boldsymbol{\mu})^{\prime} \boldsymbol{\Sigma}^{-1}(\mathbf{X}-\boldsymbol{\mu})$ memiliki sebaran $\chi^{2}(n)$.

Bukti. $\boldsymbol{\Sigma}$ adalah matriks definit positif, maka $\boldsymbol{\Sigma}=\boldsymbol{\Sigma}^{\frac{1}{2}} \boldsymbol{\Sigma}^{\frac{1}{2}}$ dan $\boldsymbol{\Sigma}^{\frac{1}{2}}$ memiliki invers. Vektor peubah acak $\mathbf{Z}=\boldsymbol{\Sigma}^{-\frac{1}{2}}(\mathbf{X}-\boldsymbol{\mu}) \sim N_{n}\left(\mathbf{0}, \mathbf{I}_{n}\right)$. Misalkan peubah acak $W=\mathbf{Z}^{\prime} \mathbf{Z}=\sum_{i-1}^{n} Z_{i}^{2}$. Karena untuk $\forall i=1,2, \ldots, n, Z_{i}$ adalah peubah acak normal baku bebas, $Z_{i} \stackrel{b s i}{\sim} N(0,1)$, maka $\sum_{i-1}^{n} Z_{i}^{2}$ memiliki sebaran $\chi^{2}(n)$. 


\subsection{Sebaran $t$}

253 Misalkan peubah acak $Z$ menyebar $N(0,1)$ dan peubah acak $U$ menyebar ${ }_{254} \chi^{2}(r)$, kedua peubah acak tersebut saling bebas. Fungsi kepekatan peluang 255 bersama bagi $Z$ dan $U$ ialah

$$
\begin{aligned}
f(z, u) & =f(z) \cdot f(u) \\
& =\frac{1}{\sqrt{2 \pi}} \exp \left(-\frac{z^{2}}{2}\right) \cdot \frac{1}{\Gamma\left(\frac{r}{2}\right) 2^{r / 2}} u^{(r / 2)-1} \exp \left(-\frac{u}{2}\right) \mathbf{I}(-\infty<z<\infty, u>0)
\end{aligned}
$$

Definisikan suatu peubah acak

$$
T=\frac{Z}{\sqrt{U / r}}
$$

Dengan transformasi peubah $t=\frac{z}{\sqrt{u / r}}$ dan $w=u$, maka dapat diperoleh fungsi kepekatan peluang $g_{T}(t)$ dari peubah acak $T$. Dari transformasi satusatu,

$$
t=\frac{z}{\sqrt{u / r}} \operatorname{dan} w=u \Leftrightarrow z=t \sqrt{w / r}, u=w,
$$

256

diperoleh

$$
\begin{aligned}
J & =\left|\begin{array}{cc}
\frac{\partial z}{\partial t} & \frac{\partial z}{\partial w} \\
\frac{\partial u}{\partial t} & \frac{\partial u}{\partial w}
\end{array}\right| \\
& =\left|\begin{array}{cc}
\sqrt{w / r} & ? \\
0 & 1
\end{array}\right| \\
& =\frac{\sqrt{w}}{\sqrt{r}}
\end{aligned}
$$

Fungsi kepekatan peluang bersama bagi peubah acak $T$ dan $W=U$ ialah

$$
\begin{aligned}
g(t, w) & =f(t \sqrt{w / r}, w)|J| \\
& =\frac{1}{\sqrt{2 \pi r} \Gamma(r / 2) 2^{r / 2}} w^{\frac{r+1}{2}-1} \exp \left[-\frac{w}{2}\left(1+\frac{t^{2}}{r}\right)\right] \mathbf{I}(-\infty<t<\infty, w>0) .
\end{aligned}
$$


258

Dengan demikian, fungsi kepekatan peluang marginal bagi $T$ ialah

$$
\begin{aligned}
g_{T}(t) & =\int_{0}^{\infty} g(t, w) d w \\
& =\int_{0}^{\infty} \frac{1}{\sqrt{2 \pi r} \Gamma(r / 2) 2^{r / 2}} w^{\frac{r+1}{2}-1} \exp \left[-\frac{w}{2}\left(1+\frac{t^{2}}{r}\right)\right] d w \\
& =\frac{1}{\sqrt{2 \pi r} \Gamma(r / 2) 2^{r / 2}} \times \Gamma\left(\frac{r+1}{2}\right) \times\left(\frac{2}{1+\frac{t^{2}}{r}}\right)^{(r+1) / 2} \\
& =\frac{\Gamma\left(\frac{r+1}{2}\right)}{\sqrt{\pi r} \times \Gamma(r / 2)} \times\left(\frac{1}{1+\frac{t^{2}}{r}}\right)^{(r+1) / 2} \mathbf{I}(-\infty<t<\infty) .
\end{aligned}
$$

Definisi 2.2 Jika $Z \sim N(0,1), U \sim \chi^{2}(r)$, dan dua peubah acak tersebut saling bebas, maka sebaran dari $T=\frac{Z}{\sqrt{U / r}}$ disebut sebaran $t$ dengan derajat bebas $r$, dinotasikan $T \sim t(r)$, serta fungsi kepekatan peluang dari $T$ seperti pada persamaan 2.3.

Sebaran $t$ ini dikenal juga sebagai sebaran $t$-Student yang diperkenalkan pertama kali oleh W. S. Gosset dengan nama samaran Student. Berikut merupakan ilustrasi sebaran $t$ dengan parameter $r=0.5,1.5$, dan $\infty$.

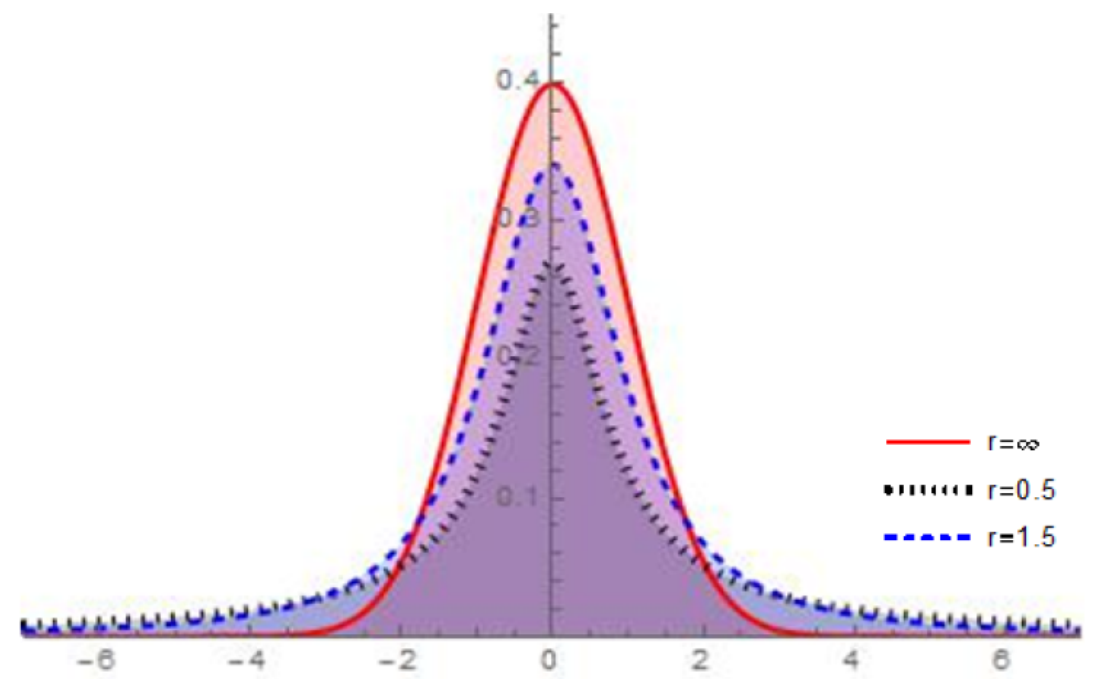

Gambar 3. Sebaran $t$ dengan parameter $r=0.5,1.5, \infty$ 
267

$$
\begin{aligned}
E(T) & =0, & \text { jika } r \geq 2 \\
\operatorname{Var}(T) & =\frac{r}{r-2}, & \text { jika } r \geq 3 .
\end{aligned}
$$

Bukti. Karena $T \sim t(r)$, maka

$$
T=\frac{Z}{\sqrt{U / r}}
$$

${ }_{269}$ dengan $Z \sim N(0,1), U \sim \chi^{2}(r)$, dan dua peubah acak tersebut saling 270 bebas.

$$
\begin{aligned}
E(T) & =E\left(\frac{Z}{\sqrt{U / r}}\right) \\
& =r^{1 / 2} E(Z) E\left(U^{-1 / 2}\right) \\
& =0 .
\end{aligned}
$$

Berdasarkan Teorema 2.2,

$$
E\left(U^{-1 / 2}\right)=2^{-1 / 2} \times \frac{\Gamma\left(\frac{r}{2}-\frac{1}{2}\right)}{\Gamma\left(\frac{r}{2}\right)},
$$

271 di mana $E\left(U^{-1 / 2}\right)$ terdefinisi bila $\frac{r}{2}-\frac{1}{2}>0 \Leftrightarrow r>1$, sehingga $E(T)=0$ 272 jika $r \geq 2$.

273 Selanjutnya, momen ke-2 dari peubah acak $T$ ialah

$$
\begin{aligned}
E\left(T^{2}\right) & =E\left(\frac{Z^{2}}{U / r}\right) \\
& =r E\left(Z^{2}\right) E\left(U^{-1}\right) .
\end{aligned}
$$

274 Berdasarkan Teorema 2.2,

$$
\begin{aligned}
E\left(U^{-1}\right) & =2^{-1} \times \frac{\Gamma\left(\frac{r}{2}-1\right)}{\Gamma\left(\frac{r}{2}\right)} \\
& =\frac{1}{2} \times \frac{\Gamma\left(\frac{r}{2}-1\right)}{\left(\frac{r}{2}-1\right) \Gamma\left(\frac{r}{2}-1\right)} \\
& =\frac{1}{r-2},
\end{aligned}
$$


275

sehingga ruas kanan pada persamaan 2.4 menjadi

$$
\begin{aligned}
E\left(T^{2}\right) & =r \times 1 \times \frac{1}{r-2} \\
& =\frac{r}{r-2}, r \geq 3 .
\end{aligned}
$$

276

Dengan demikian,

$$
\begin{aligned}
\operatorname{Var}(T) & =E\left(T^{2}\right)-(E(T))^{2} \\
& =\frac{r}{r-2}-0 \\
& =\frac{r}{r-2}, r \geq 3 .
\end{aligned}
$$

277

Contoh 2.1 Misalkan $X_{1}, X_{2}, X_{3}, X_{4}$ adalah peubah acak bebas dari sebaran normal baku. Tentukan nilai harapan dari peubah acak

$$
W=\frac{X_{1}-X_{2}+X_{3}}{\sqrt{X_{1}^{2}+X_{2}^{2}+X_{3}^{2}+X_{4}^{2}}} .
$$

Jawab. Karena $X_{i} \sim N(0,1)$, maka

$$
X_{1}-X_{2}+X_{3} \sim N(0,3)
$$

dan

$$
\frac{X_{1}-X_{2}+X_{3}}{\sqrt{3}} \sim N(0,1),
$$

serta $X_{i}^{2} \sim \chi^{2}(1)$, sehingga

$$
X_{1}^{2}+X_{2}^{2}+X_{3}^{2}+X_{4}^{2} \sim \chi^{2}(4) .
$$

Dengan demikian, peubah acak

$$
\frac{\frac{X_{1}-X_{2}+X_{3}}{\sqrt{3}}}{\sqrt{\frac{X_{1}^{2}+X_{2}^{2}+X_{3}^{2}+X_{4}^{2}}{4}}}=\left(\frac{2}{\sqrt{3}}\right) W \sim t(4) .
$$

278 Berdasarkan Teorema 2.5, nilai harapan dari $W$ ialah

$$
\begin{aligned}
E(W) & =\frac{\sqrt{3}}{2} E\left(\frac{2}{\sqrt{3}} W\right) \\
& =\frac{\sqrt{3}}{2} \times 0 \\
& =0 .
\end{aligned}
$$




\subsection{Sebaran $\boldsymbol{F}$}

Misalkan $U$ dan $Y$ adalah peubah acak bebas khi-kuadrat dengan derajat bebas $r_{1}$ dan $r_{2}$. Fungsi kepekatan peluang bersama bagi peubah acak $U$ dan $Y$ ialah

$$
h(u, y)=\frac{1}{\Gamma\left(r_{1} / 2\right) \Gamma\left(r_{2} / 2\right) 2^{\left(r_{1}+r_{2}\right) / 2}} u^{\left(r_{1} / 2\right)-1} y^{\left(r_{2} / 2\right)-1} e^{-(u+y) / 2} \mathbf{I}(u, y>0) .
$$

Definisikan suatu peubah acak

$$
W=\frac{U / r_{1}}{Y / r_{2}}
$$

Dengan transformasi satu-satu antara peubah $w=\frac{u / r_{1}}{y / r_{2}}$ dan $z=y$, maka dapat diperoleh fungsi kepekatan peluang $g_{W}(w)$ dari peubah acak $W$. Dari transformasi satu-satu,

$$
\begin{aligned}
w & =\frac{u / r_{1}}{y / r_{2}} \operatorname{dan} z=y \\
\Leftrightarrow \quad u & =\left(\frac{r_{1}}{r_{2}}\right) z w, y=z,
\end{aligned}
$$

281 diperoleh

$$
\begin{aligned}
J & =\left|\begin{array}{cc}
\frac{\partial u}{\partial w} & \frac{\partial u}{\partial z} \\
\frac{\partial y}{\partial w} & \frac{\partial y}{\partial z}
\end{array}\right| \\
& =\left|\begin{array}{cc}
\left(\frac{r_{1}}{r_{2}}\right) z & ? \\
0 & 1
\end{array}\right| \\
& =\left(\frac{r_{1}}{r_{2}}\right) z
\end{aligned}
$$

282 Fungsi kepekatan peluang $g(w, z)$ dari peubah acak $W$ dan $Z=Y$ ialah

$$
\begin{aligned}
g(w, z)= & \frac{1}{\Gamma\left(r_{1} / 2\right) \Gamma\left(r_{2} / 2\right) 2^{\left(r_{1}+r_{2}\right) / 2}}\left[\frac{r_{1} z w}{r_{2}}\right]^{\left(r_{1} / 2\right)-1} z^{\left(r_{2} / 2\right)-1} \\
& \exp \left[-\frac{z}{2}\left(1+\frac{r_{1}}{r_{2}} w\right)\right] \frac{r_{1} z}{r_{2}} \mathbf{I}(0<w, z<\infty) .
\end{aligned}
$$


283

Dengan demikian, fungsi kepekatan peluang marginal bagi $W$ ialah

$$
\begin{aligned}
g_{W}(w)= & \int_{0}^{\infty} g(w, z) d z \\
= & \int_{0}^{\infty} \frac{\left(r_{1} / r_{2}\right)^{r_{1} / 2} w^{\left(r_{1} / 2\right)-1}}{\Gamma\left(r_{1} / 2\right) \Gamma\left(r_{2} / 2\right) 2^{\left(r_{1}+r_{2}\right) / 2}} z^{\left(r_{1}+r_{2}\right) / 2-1} \\
& \times \exp \left[-\frac{z}{2}\left(1+\frac{r_{1}}{r_{2}} w\right)\right] \frac{r_{1} z}{r_{2}} d z . \\
= & \frac{\left(r_{1} / r_{2}\right)^{r_{1} / 2} w^{\left(r_{1} / 2\right)-1}}{\Gamma\left(r_{1} / 2\right) \Gamma\left(r_{2} / 2\right) 2^{\left(r_{1}+r_{2}\right) / 2}} \times \Gamma\left(\frac{r_{1}+r_{2}}{2}\right) \\
& \times \frac{2}{\left(1+\frac{r_{1}}{r_{2}} w\right)^{\left(r_{1}+r_{2}\right) / 2}} \mathbf{I}(w>0) . \\
= & \frac{\Gamma\left(\frac{r_{1}+r_{2}}{2}\right)\left(r_{1} / r_{2}\right)^{r_{1} / 2}}{\Gamma\left(r_{1} / 2\right) \Gamma\left(r_{2} / 2\right)} \times \frac{w^{\left(r_{1} / 2\right)-1}}{\left(1+\frac{r_{1}}{r_{2}} w\right)^{\left(r_{1}+r_{2}\right) / 2}} \mathbf{I}(w>0) .
\end{aligned}
$$

Definisi 2.3 Misalkan $U$ dan $Y$ peubah acak bebas khi-kuadrat dengan derajat bebas $r_{1}$ dan $r_{2}$. Sebaran dari

$$
W=\frac{U / r_{1}}{Y / r_{2}}
$$

disebut sebaran $F$ dengan derajat bebas $r_{1}$ dan $r_{2}$, dinotasikan $F\left(r_{1}, r_{2}\right)$, dengan fungsi kepekatan peluang seperti pada persamaan 2.5.

Berikut merupakan ilustrasi dari sebaran $F$, yaitu $F(5,10), F(10,5)$, dan $F(10,10)$.

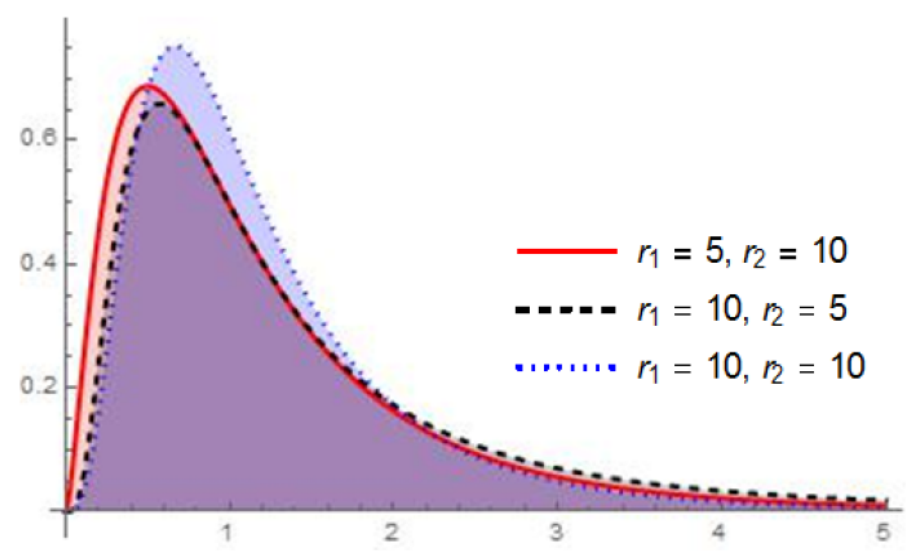

Gambar 4. Sebaran $F(5,10), F(10,5)$, dan $F(10,10)$ 


\subsection{Teorema Student}

Teorema 2.7 Misalkan $X_{1}, X_{2}, \ldots, X_{n}$ adalah peubah acak bebas stokastik identik yang menyebar $N\left(\mu, \sigma^{2}\right)$. Definisikan peubah acak

$$
\bar{X}=\frac{1}{n} \sum_{i=1}^{n} X_{i} \text { dan } S^{2}=\frac{1}{n-1} \sum_{i=1}^{n}\left(X_{i}-\bar{X}\right)^{2},
$$


maka
a. $\bar{X} \sim N\left(\mu, \frac{\sigma^{2}}{n}\right)$.
b. $\bar{X}$ dan $S^{2}$ saling bebas.
c. $(n-1) S^{2} / \sigma^{2} \sim \chi^{2}(n-1)$.
d. Peubah acak $T=\frac{\bar{X}-\mu}{S / \sqrt{n}}$ memiliki sebaran $t$ dengan derajat bebas $n-1$.

Bukti. Misalkan $\mathbf{X}=\left(X_{1}, X_{2}, \ldots, X_{n}\right)^{\prime}$. Karena $X_{1}, X_{2}, \ldots, X_{n}$ adalah peubah acak bebas stokastik identik dari sebaran $N\left(\mu, \sigma^{2}\right)$, maka $\mathbf{X}$ memiliki sebaran normal multivariat $N\left(\mu \mathbf{1}, \sigma^{2} \mathbf{I}\right)$ di mana $\mathbf{1}$ merupakan vektor yang berunsur 1. Misalkan $\mathbf{v}^{\prime}=(1 / n, \ldots, 1 / n)=(1 / n) \mathbf{1}^{\prime}$, maka $\bar{X}=\mathbf{v}^{\prime} \mathbf{X}$. Definisikan vektor peubah acak $\mathbf{Y}=\left(X_{1}-\bar{X}, \ldots, X_{n}-\bar{X}\right)^{\prime}$. Perhatikan transformasi peubah berikut.

$$
\mathbf{W}=\left[\begin{array}{c}
\bar{X} \\
\mathbf{Y}
\end{array}\right]=\left[\begin{array}{c}
\mathbf{v}^{\prime} \\
\mathbf{I}-\mathbf{1} \mathbf{v}^{\prime}
\end{array}\right] \mathbf{X}
$$

Karena W adalah transformasi linear dari vektor peubah acak normal multivariat, maka berdasarkan Teorema 1.4, W memiliki sebaran normal multivariat dengan nilai harapan

$$
E(\mathbf{W})=\left[\begin{array}{c}
\mathbf{v}^{\prime} \\
\mathbf{I}-\mathbf{1} \mathbf{v}^{\prime}
\end{array}\right] E(\mathbf{X})=\left[\begin{array}{c}
\mathbf{v}^{\prime} \\
\mathbf{I}-\mathbf{1} \mathbf{v}^{\prime}
\end{array}\right] \mu \mathbf{1}=\left[\begin{array}{c}
\mu \\
\mathbf{0}_{n}
\end{array}\right],
$$

di mana $\mathbf{0}_{n}$ adalah vektor yang berunsur 0 dan matriks koragam

$$
\begin{aligned}
\boldsymbol{\Sigma} & =\left[\begin{array}{c}
\mathbf{v}^{\prime} \\
\mathbf{I}-\mathbf{1} \mathbf{v}^{\prime}
\end{array}\right] \sigma^{2} \mathbf{I}\left[\begin{array}{c}
\mathbf{v}^{\prime} \\
\mathbf{I}-\mathbf{1} \mathbf{v}^{\prime}
\end{array}\right]^{\prime} \\
& =\sigma^{2}\left[\begin{array}{cc}
1 / n & \mathbf{0}_{n}^{\prime} \\
\mathbf{0}_{n} & \mathbf{I}-\mathbf{1} \mathbf{v}^{\prime}
\end{array}\right] .
\end{aligned}
$$

Karena koragamnya bernilai nol, maka $\bar{X}$ saling bebas dengan Y. Dengan demikian, $\bar{X}$ juga saling bebas dengan $S^{2}=(n-1)^{-1} \mathbf{Y}^{\prime} \mathbf{Y}$. Selanjutnya, berdasarkan persamaan 2.6 dan 2.7 diperoleh bahwa $\bar{X} \sim N\left(\mu, \frac{\sigma^{2}}{n}\right)$.

Misalkan suatu peubah acak

$$
V=\sum_{i=1}^{n}\left(\frac{X_{i}-\mu}{\sigma}\right)^{2},
$$


maka berdasarkan Teorema $2.2, \forall i=1, \ldots, n,\left(\frac{X_{i}-\mu}{\sigma}\right)^{2}$ menyebar $\chi^{2}(1)$, sehingga

$$
V=\sum_{i=1}^{n}\left(\frac{X_{i}-\mu}{\sigma}\right)^{2} \sim \chi^{2}(n)
$$

(lihat Akibat 2.1). Peubah acak $V$ juga dapat dituliskan menjadi

$$
\begin{aligned}
V & =\sum_{i=1}^{n}\left(\frac{\left(X_{i}-\bar{X}\right)+(\bar{X}-\mu)}{\sigma}\right)^{2} \\
& =\sum_{i=1}^{n}\left(\frac{X_{i}-\bar{X}}{\sigma}\right)^{2}+\left(\frac{\bar{X}-\mu}{\sigma / \sqrt{n}}\right)^{2} \\
& =\frac{(n-1) S^{2}}{\sigma^{2}}+\left(\frac{\bar{X}-\mu}{\sigma / \sqrt{n}}\right)^{2} .
\end{aligned}
$$

Karena $\bar{X}$ dan $S^{2}$ saling bebas, dua bagian pada ruas kanan persamaan 2.8, yaitu $\frac{(n-1) S^{2}}{\sigma^{2}} \operatorname{dan}\left(\frac{\bar{X}-\mu}{\sigma / \sqrt{n}}\right)^{2}$ juga saling bebas. Peubah acak $\left(\frac{\bar{X}-\mu}{\sigma / \sqrt{n}}\right)^{2}$ merupakan kuadrat dari peubah acak normal baku, sehingga memiliki sebaran $\chi^{2}(1)$. Selanjutnya, fungsi pembangkit momen dari kedua ruas pada persamaan 2.8, yaitu

$$
(1-2 t)^{-n / 2}=E\left[\exp \left\{t \frac{(n-1) S^{2}}{\sigma^{2}}\right\}\right](1-2 t)^{-1 / 2} .
$$

Dengan demikian,

$$
\begin{aligned}
E\left[\exp \left\{t \frac{(n-1) S^{2}}{\sigma^{2}}\right\}\right] & =\frac{(1-2 t)^{-n / 2}}{(1-2 t)^{-1 / 2}} \\
& =(1-2 t)^{-(n-1) / 2}
\end{aligned}
$$

sehingga $\frac{(n-1) S^{2}}{\sigma^{2}} \sim \chi^{2}(n-1)$

Selanjutnya, dapat disimpulkan bahwa peubah acak $T$, yaitu

$$
\begin{aligned}
T & =\frac{(\bar{X}-\mu) /(\sigma / \sqrt{n})}{\sqrt{(n-1) S^{2} /\left(\sigma^{2}(n-1)\right)}} \\
& =\frac{\bar{X}-\mu}{S / \sqrt{n}}
\end{aligned}
$$

memiliki sebaran $t$ dengan derajat bebas $(n-1)$. 
Contoh 2.3 Diketahui $X \sim N(10,25)$ dan $X_{1}, X_{2}, \ldots, X_{501}$ adalah contoh acak dari populasi $X$. Tentukan nilai harapan dari ragam contoh $S^{2}$.

Jawab. Berdasarkan Teorema 2.7, $\frac{(501-1) S^{2}}{25} \sim \chi^{2}(500)$, sehingga

$$
\begin{aligned}
E\left(\frac{(501-1) S^{2}}{25}\right) & =500 \\
\left(\frac{500}{25}\right) E\left(S^{2}\right) & =500 \\
E\left(S^{2}\right) & =\left(\frac{25}{500}\right)(500) \\
& =25
\end{aligned}
$$

\subsection{Latihan}

1. Misalkan $X_{1}$ dan $X_{2}$ merupakan contoh acak dari sebaran dengan fkp $f(x)=\exp (-x) \mathbf{I}(x>0)$, maka tunjukkanlah bahwa $Z=X_{1} / X_{2}$ merupakan peubah acak bersebaran $F$. Tentukan pula derajat bebasnya.

2. Tunjukkan bahwa fungsi kepekatan peluang bagi peubah acak $W=$ $\frac{U / r_{1}}{V / r_{2}}$ adalah seperti pada persamaan 2.5 , serta tentukan momen ke-k dari peubah acak $W$.

3. Misalkan peubah acak $T=\frac{W}{\sqrt{V / r}}$ di mana $W \sim N(0,1)$ dan $V \sim$ $\chi^{2}(r)$ saling bebas. Tunjukkan bahwa memiliki sebaran-F dengan parameter $r_{1}=1$ dan $r_{2}=r$.

4. Misalkan $X_{1}, X_{2}, X_{3}$ adalah tiga peubah acak bebas khi-kuadrat dengan derajat bebas masing-masing adalah $r_{1}, r_{2}$, dan $r_{3}$.

a. Tunjukkan bahwa $Y_{1}=\frac{X_{1}}{X_{2}}$ dan $Y_{2}=X_{1}+X_{2}$ saling bebas serta $Y_{2} \sim \chi^{2}\left(r_{1}+r_{2}\right)$.

b. Tunjukkan bahwa $\frac{X_{1} / r_{1}}{X_{2} / r_{2}}$ dan $\frac{X_{3} / r_{3}}{\left(X_{1}+X_{2}\right) /\left(r_{1}+r_{2}\right)}$ merupakan peubah acak bebas yang memiliki sebaran-F. 


\section{BAs 3}

\section{sendugaan Parameter}

\subsection{Penduga Titik}

Dalam statistika, populasi adalah sekumpulan data yang mempunyai karakteristik yang sama dan menjadi objek inferensi. Statistika inferensia mendasarkan diri pada dua konsep dasar, yaitu populasi sebagai keseluruhan data dan sampel sebagai bagian dari populasi yang digunakan untuk melakukan pendekatan terhadap populasi. Suatu populasi biasanya dijelaskan oleh suatu peubah acak $X$. Jika informasi mengenai sebaran $f(x ; \theta)$ dari peubah acak $X$ diketahui, maka informasi mengenai populasi tersebut juga akan diketahui. Misalkan $X_{1}, X_{2}, \ldots, X_{n}$ adalah peubah acak yang memiliki fungsi kepekatan peluang $f(x ; \theta)$ yang sama dengan populasi, maka

$$
X_{1}=x_{1}, X_{2}=x_{2}, \ldots, X_{n}=x_{n}
$$

merupakan data atau nilai amatan sampel yang digunakan untuk mewakili populasi.

Misalkan $X$ adalah peubah acak yang memiliki fungsi kepekatan peluang $f(x ; \theta)$ atau fungsi massa peluang $p(x ; \theta)$, di mana $\theta$ merupakan suatu bilangan real atau vektor bilangan real yang tidak diketahui. Asumsikan bahwa $\theta \in \Omega$ merupakan himpunan bagian dari $\mathbb{R}^{p}$ untuk $p \geq 1$. Dalam tulisan ini, kadangkala notasi $f(x ; \theta)$ digunakan baik sebagai fungsi kepekatan peluang atau fungsi massa peluang peubah acak $X$, yang hasilnya berlaku baik untuk kasus peubah acak kontinu maupun diskret. Sebagai contoh, $\theta$ merupakan vektor $\left(\mu, \sigma^{2}\right)$ jika $X \sim N\left(\mu, \sigma^{2}\right)$ atau $\theta$ merupakan peluang sukses $p$ jika $X$ memiliki sebaran binomial. Informasi mengenai parameter $\theta$ dapat diketahui berdasarkan sampel $X_{1}, X_{2}, \ldots, X_{n}$.

Definisi 3.1 Peubah acak $X_{1}, X_{2}, \ldots, X_{n}$ disebut sebagai sampel acak dari 
Misalkan $X_{1}, X_{2}, \ldots, X_{n}$ merupakan sampel acak dari populasi $X$ dengan fungsi kepekatan atau fungsi massa peluang $f\left(x ; \theta_{1}, \theta_{2}, \ldots, \theta_{m}\right)$ di mana $\theta_{1}, \theta_{2}$, $\ldots, \theta_{m}$ merupakan parameter-parameter yang tidak diketahui. Misalkan pula

$$
E\left(X^{k}\right)=g_{k}\left(\theta_{1}, \theta_{2}, \ldots, \theta_{m}\right)
$$


merupakan momen ke- $k$ dari populasi. Selanjutnya, misalkan

$$
M_{k}=\frac{1}{n} \sum_{i=1}^{n} X_{i}^{k}
$$

merupakan momen ke- $k$ dari sampel. Dengan menggunakan metode momen, penduga bagi $m$-parameter $\theta$ diperoleh dengan cara mencari solusi dari persamaan penduga $m$-momen pertama (jika ada) yang memberi solusi tunggal (khas) dari $X$, yaitu

$$
\begin{aligned}
g_{1}\left(\hat{\theta}_{1}, \hat{\theta}_{2}, \ldots, \hat{\theta}_{m}\right) & =M_{1} \\
g_{2}\left(\hat{\theta}_{1}, \hat{\theta}_{2}, \ldots, \hat{\theta}_{m}\right)= & M_{2} \\
g_{3}\left(\hat{\theta}_{1}, \hat{\theta}_{2}, \ldots, \hat{\theta}_{m}\right)= & M_{3} \\
& \vdots \\
g_{m}\left(\hat{\theta}_{1}, \hat{\theta}_{2}, \ldots, \hat{\theta}_{m}\right)= & M_{m} .
\end{aligned}
$$

Contoh 3.1 Misalkan $X_{1}, X_{2}, \ldots, X_{n}$ adalah sampel acak dari populasi $X$ dengan fungsi kepekatan peluang

$$
f(x ; \theta)=\frac{1}{\theta} \mathbf{I}(0<x<\theta)
$$

Tentukan penduga bagi $\theta$ dengan menggunakan metode momen.

Jawab. Berdasarkan fungsi kepekatan peluang $f(x ; \theta)$, maka $X \sim$ seragam $(0, \theta)$, sehingga $E(X)=\frac{\theta}{2}=g_{1}(\theta)$. Dengan menggunakan metode momen diperoleh

$$
\begin{aligned}
g_{1}(\hat{\theta}) & =M_{1}, \\
\frac{\hat{\theta}}{2} & =\bar{X} .
\end{aligned}
$$

Jadi, penduga bagi $\theta$ ialah

$$
\hat{\theta}=2 \bar{X}
$$

Contoh 3.2 Misalkan $X \sim N\left(\mu, \sigma^{2}\right)$ dan $X_{1}, X_{2}, \ldots, X_{n}$ adalah contoh acak dari populasi $X$. Tentukan penduga bagi $\mu$ dan $\sigma^{2}$ dengan menggunakan metode momen. 
376

377

Jawab. Karena $X \sim N\left(\mu, \sigma^{2}\right)$, maka

$$
\begin{aligned}
E(X) & =\mu \\
E\left(X^{2}\right) & =\sigma^{2}+\mu^{2},
\end{aligned}
$$

sehingga

$$
\begin{aligned}
& g_{1}\left(\mu, \sigma^{2}\right)=\mu \\
& g_{2}\left(\mu, \sigma^{2}\right)=\sigma^{2}+\mu^{2} .
\end{aligned}
$$

Dengan metode momen,

$$
\begin{aligned}
& g_{1}\left(\hat{\mu}, \hat{\sigma}^{2}\right)=M_{1} \\
& g_{2}\left(\hat{\mu}, \hat{\sigma}^{2}\right)=M_{2},
\end{aligned}
$$

sehingga

$$
\begin{aligned}
\hat{\mu} & =\frac{1}{n} \sum_{i=1}^{n} X_{i}=\bar{X}, \\
\hat{\sigma}^{2}+\hat{\mu}^{2} & =\frac{1}{n} \sum_{i=1}^{n} X_{i}^{2} \\
\hat{\sigma}^{2} & =\frac{1}{n} \sum_{i=1}^{n} X_{i}^{2}-\hat{\mu}^{2} \\
& =\frac{1}{n} \sum_{i=1}^{n} X_{i}^{2}-\bar{X}^{2} \\
& =\frac{1}{n} \sum_{i=1}^{n}\left(X_{i}-\bar{X}\right)^{2} .
\end{aligned}
$$

Jadi, penduga bagi parameter $\mu$ dan $\sigma^{2}$ secara berturut-turut ialah $\hat{\mu}=\bar{X}$ $\operatorname{dan} \hat{\sigma}^{2}=\frac{1}{n} \sum_{i=1}^{n}\left(X_{i}-\bar{X}\right)^{2}$

Contoh 3.3 Misalkan $X_{1}, X_{2}, \ldots, X_{n}$ adalah sampel acak dari populasi $X$ dengan fungsi kepekatan peluang

$$
f(x ; \theta)=\theta x^{\theta-1} \mathbf{I}(0<x<1)
$$

di mana $0<\theta<\infty$ ialah parameter yang tidak diketahui. Dengan menggunakan metode momen, tentukan penduga bagi $\theta$. Jika $x_{1}=0.2, x_{2}=0.6$, $x_{3}=0.5, x_{4}=0.3$ adalah nilai amatan dari empat sampel acak, maka tentukan dugaan bagi $\theta$. 
Jawab. Nilai harapan bagi $X$ dengan $f(x ; \theta)=\theta x^{\theta-1} \mathbf{I}(0<x<1)$ ialah

$$
\begin{aligned}
E(X) & =\int_{0}^{1} x f(x ; \theta) d x \\
& =\int_{0}^{1} x \theta x^{\theta-1} d x \\
& =\frac{\theta}{\theta+1},
\end{aligned}
$$

sehingga

$$
g_{1}(\theta)=\frac{\theta}{\theta+1}
$$

Dengan metode momen,

$$
\begin{aligned}
M_{1} & =g_{1}(\hat{\theta}) \\
\bar{X} & =\frac{\hat{\theta}}{\hat{\theta}+1} \\
\hat{\theta} & =\frac{\bar{X}}{1-\bar{X}},
\end{aligned}
$$

dengan $\bar{X}$ adalah rata-rata dari sampel. Dengan demikian, statistik $\frac{\bar{X}}{1-\bar{X}}$ adalah penduga bagi $\theta$,

$$
\hat{\theta}=\frac{\bar{X}}{1-\bar{X}} .
$$

Karena $x_{1}=0.2, x_{2}=0.6, x_{3}=0.5, x_{4}=0.3$, diperoleh $\bar{x}=0.4$, sehingga dugaan bagi $\theta$ ialah

$$
\frac{0.4}{1-0.4}=\frac{2}{3} \text {. }
$$

Contoh 3.4 Misalkan $X_{1}, X_{2}, \ldots, X_{n}$ adalah sampel acak dari sebaran seragam $(\alpha, \beta), \alpha<\beta$. Dengan menggunakan metode momen, tentukan penduga bagi $\alpha$ dan $\beta$. Untuk ukuran sampel $n=9$ dengan nilai-nilai amatan 0.5, 0.6, 0.1, 0.9, 1.3, 1.6, 0.7, 0.9, dan 1.0, tentukanlah dugaan bagi $\alpha$ dan $\beta$. 
Jawab. Karena $E(X)=\frac{\alpha+\beta}{2}=g_{1}(\alpha, \beta) \operatorname{dan} E\left(X^{2}\right)=\frac{1}{3}\left(\alpha^{2}+\alpha \beta+\beta^{2}\right)=$ $g_{2}(\alpha, \beta)$, maka dengan metode momen diperoleh

$$
\begin{aligned}
\frac{\hat{\alpha}+\hat{\beta}}{2} & =\frac{1}{n} \sum_{i=1}^{n} X_{i}=Q_{1}, \\
\frac{1}{3}\left(\hat{\alpha}^{2}+\hat{\alpha} \hat{\beta}+\hat{\beta}^{2}\right) & =\frac{1}{n} \sum_{i=1}^{n} X_{i}^{2}=Q_{2} .
\end{aligned}
$$

Dari persamaan 3.1 dan 3.2, diperoleh

$$
\begin{aligned}
& \hat{\alpha}+\hat{\beta}=2 Q_{1} \\
\Leftrightarrow & \hat{\alpha}=2 Q_{1}-\hat{\beta} \\
& \hat{\alpha}^{2}+\hat{\alpha} \hat{\beta}+\hat{\beta}^{2}=3 Q_{2} \\
\Leftrightarrow & \left(2 Q_{1}-\hat{\beta}\right)^{2}+\left(2 Q_{1}-\hat{\beta}\right) \hat{\beta}+\hat{\beta}^{2}=3 Q_{2} \\
\Leftrightarrow & \hat{\beta}^{2}-2 \hat{\beta} Q_{1}+4 Q_{1}^{2}-3 Q_{2}=0 \\
\Leftrightarrow & \hat{\beta}_{1,2}=\frac{2 Q_{1} \pm \sqrt{4 Q_{1}^{2}-4\left(4 Q_{1}^{2}-3 Q_{2}\right)}}{2} \\
\Leftrightarrow & \hat{\beta}_{1,2}=Q_{1} \pm \sqrt{3\left(Q_{2}-Q_{1}^{2}\right)} \\
\Leftrightarrow & \hat{\alpha}_{1,2}=Q_{1} \mp \sqrt{3\left(Q_{2}-Q_{1}^{2}\right)} .
\end{aligned}
$$

Karena $\hat{\alpha}<\hat{\beta}$, maka

$$
\begin{aligned}
& \hat{\alpha}=Q_{1}-\sqrt{3\left(Q_{2}-Q_{1}^{2}\right)} \\
& \hat{\beta}=Q_{1}+\sqrt{3\left(Q_{2}-Q_{1}^{2}\right)} .
\end{aligned}
$$

Untuk ukuran sampel $n=9$ dengan nilai-nilai amatan 0.5, 0.6, 0.1, 0.9, 1.3, 1.6, 0.7, 0.9, dan 1.0 akan diperoleh dugaan bagi $Q_{1}$ sebesar 0.84 dan dugaan bagi $Q_{2}$ sebesar 0.89 serta dugaan bagi $\alpha$ sebesar 0.096 dan dugaan bagi $\beta$ sebesar 1.584 .

Dari Contoh 3.4, dugaan yang diperoleh dengan metode momen tidak memberikan dugaan yang layak, karena untuk menduga $\beta$ yang seharusnya bernilai lebih besar sama dengan 1.6, diperoleh dugaannya sebesar 1.584 .

\subsubsection{Metode Kemungkinan Maksimum}

Definisi 3.3 Misalkan $X_{1}, X_{2}, \ldots, X_{n}$ adalah sampel acak dari populasi $X$ dengan fungsi kepekatan peluang $f(x ; \theta)$, di mana $\theta$ adalah parameter yang 
tidak diketahui dalam ruang parameter $\Omega$. Fungsi kemungkinan atau likelihood function, $L(\theta ; \mathbf{x})$, didefinisikan sebagai berikut

$$
L(\theta ; \mathbf{x})=\prod_{i=1}^{n} f\left(x_{i} ; \theta\right) .
$$

Catatan : L $(\theta ; \mathbf{x})$ adalah fungsi kepekatan bersama dari sampel. Karena $L(\theta ; \mathbf{x})$ merupakan fungsi dari $\theta$, maka kita juga dapat menggunakan notasi $L(\theta)$.

Definisi 3.4 Suatu fungsi dari $\mathbf{X}$, katakanlah $\hat{\theta}=\hat{\theta}(\mathbf{X})$ disebut penduga kemungkinan maksimum bagi $\theta$ bila

$$
\hat{\theta}=\operatorname{Arg} \sup _{\theta \in \Omega} L(\theta ; \mathbf{X}) .
$$

Berikut merupakan langkah-langkah untuk menentukan penduga kemungkinan maksimum.

1. Definisikan fungsi kemungkinan $L(\theta)$ untuk amatan sampel $x_{1}, x_{2}, \ldots$, $x_{n}$

$$
L(\theta)=\prod_{i=1}^{n} f\left(x_{i} ; \theta\right) .
$$

2. Perhatikan bahwa setiap nilai $\theta$ yang memaksimumkan $L(\theta)$ juga akan memaksimumkan fungsi log-kemungkinan $\ln L(\theta)$, sehingga untuk memudahkan perhitungan kita tentukan $\theta$ yang memaksimumkan $\ln L(\theta)$.

3. Nyatakan $\theta$ sebagai $\hat{\theta}$ untuk memperoleh penduga kemungkinan maksimum bagi $\theta$ dengan menggantikan amatan sampel dengan peubah acaknya.

Contoh 3.5 Misalkan dan $X_{1}, X_{2}, \ldots, X_{n}$ adalah sampel acak dari populasi $X$ dengan fungsi kepekatan peluang

$$
f(x ; \theta)=\frac{1}{\theta} \mathbf{I}(0<x<\theta) .
$$

Tentukan penduga bagi $\theta$ dengan menggunakan metode kemungkinan maksimum. 
418

Jawab. Fungsi kemungkinan dari contoh ialah

$$
\begin{aligned}
L(\theta) & =\prod_{i=1}^{n} f\left(x_{i} ; \theta\right) \\
& =\prod_{i=1}^{n} \frac{1}{\theta}, \theta>x_{i}(i=1,2, \ldots, n) \\
& =\left(\frac{1}{\theta}\right)^{n}, \theta>\max \left\{x_{1}, \ldots, x_{n}\right\} \\
\ln L(\theta) & =\ln \left(\frac{1}{\theta}\right)^{n} \\
& =-n \ln \theta .
\end{aligned}
$$

Ruang parameter $\theta$ terhadap $L(\theta)$ ialah

$$
\Omega=\left\{\theta \in \mathbb{R} \mid x_{\max }<\theta<\infty\right\}=\left(x_{\max }, \infty\right) .
$$

Selanjutnya, tentukan $\theta$ yang memaksimumkan $\ln L(\theta)$. Turunan pertama dari $\ln L(\theta)$ ialah

$$
\begin{aligned}
\frac{d \ln L(\theta)}{d \theta} & =\frac{d}{d \theta}[-n \ln \theta] \\
& =-\frac{n}{\theta}<0
\end{aligned}
$$

Karena $\frac{d \ln L(\theta)}{d \theta}<0$, maka $\ln L(\theta)$ merupakan fungsi turun. Dengan demikian, $\theta=x_{\max }$ memaksimumkan fungsi $\ln L(\theta)$. Jadi, penduga kemungkinan maksimum bagi $\theta$ ialah

$$
\hat{\theta}=X_{(n)},
$$

${ }_{421}$ di mana $X_{(n)}$ adalah statistik tataan ke- $n$ dari sampel.

Contoh 3.6 Jika $X_{1}, X_{2}, \ldots, X_{n}$ adalah sampel acak dengan fungsi kepekatan peluang

$$
f(x ; \theta)=\theta e^{-\theta x} \mathbf{I}(x>0),
$$

maka tentukan penduga kemungkinan maksimum bagi $\theta$. 
423

Jawab. Fungsi kemungkinan dari sampel ialah

$$
\begin{aligned}
L(\theta) & =\prod_{i=1}^{n} f\left(x_{i} ; \theta\right) \\
\ln L(\theta) & =\ln \left[\prod_{i=1}^{n} f\left(x_{i} ; \theta\right)\right] \\
& =\sum_{i=1}^{n} \ln f\left(x_{i} ; \theta\right) \\
& =\sum_{i=1}^{n} \ln \left(\theta e^{-\theta x_{i}}\right) \\
& =\sum_{i=1}^{n}\left[\ln \theta-\theta x_{i}\right] \\
& =n \ln \theta-\theta \sum_{i=1}^{n} x_{i} .
\end{aligned}
$$

${ }_{424}$ Kemudian, tentukan nilai maksimum dari $\ln L(\theta)$.

$$
\begin{aligned}
\frac{d \ln L(\theta)}{d \theta} & =0 \\
\frac{d}{d \theta}\left[n \ln \theta-\theta \sum_{i=1}^{n} x_{i}\right] & =0 \\
\frac{n}{\theta}-\sum_{i=1}^{n} x_{i} & =0 \\
\frac{n}{\theta} & =\sum_{i=1}^{n} x_{i} \\
\theta & =\frac{1}{\bar{x}} .
\end{aligned}
$$

${ }_{425}$ Turunan kedua bagi $\ln L(\theta)$ ialah

$$
\begin{aligned}
& \frac{d^{2} \ln L(\theta)}{d \theta^{2}}=-\frac{n}{\theta^{2}} \\
& \frac{d^{2} \ln L(\theta)}{d \theta^{2}}=-n \bar{x}^{2}<0 .
\end{aligned}
$$

Dengan demikian, penduga kemungkinan maksimum bagi $\theta$ ialah

$$
\hat{\theta}=\frac{1}{\bar{X}}
$$


Contoh 3.7 Jika $X_{1}, X_{2}, \ldots, X_{n}$ adalah sampel acak dengan fungsi kepekatan peluang

$$
f(x ; \theta)=(1-\theta) x^{-\theta} \mathbf{I}(0<x<1),
$$

427

maka tentukan penduga kemungkinan maksimum bagi $\theta$.

428

Jawab. Fungsi kemungkinan dari sampel ialah

$$
\begin{aligned}
L(\theta) & =\prod_{i=1}^{n} f\left(x_{i} ; \theta\right) \\
\ln L(\theta) & =\ln \left[\prod_{i=1}^{n} f\left(x_{i} ; \theta\right)\right] \\
& =\sum_{i=1}^{n} \ln f\left(x_{i} ; \theta\right) \\
& =\sum_{i=1}^{n} \ln \left[(1-\theta) x_{i}^{-\theta}\right] \\
& =n \ln (1-\theta)-\theta \sum_{i=1}^{n} \ln x_{i}
\end{aligned}
$$

${ }_{429}$ Kemudian, tentukan nilai maksimum dari $\ln L(\theta)$.

$$
\begin{aligned}
\frac{d \ln L(\theta)}{d \theta} & =0 \\
\frac{d}{d \theta}\left[n \ln (1-\theta)-\theta \sum_{i=1}^{n} \ln x_{i}\right] & =0 \\
-\frac{n}{1-\theta}-\sum_{i=1}^{n} \ln x_{i} & =0 \\
\frac{1}{1-\theta} & =-\frac{1}{n} \sum_{i=1}^{n} \ln x_{i} \\
\theta & =1+\frac{n}{\sum_{i=1}^{n} \ln x_{i}} .
\end{aligned}
$$

${ }_{430}$ Turunan kedua bagi $\ln L(\theta)$ ialah

$$
\begin{aligned}
\frac{d^{2} \ln L(\theta)}{d \theta^{2}} & =-\frac{n}{(1-\theta)^{2}} \\
& =-\frac{\left(\sum_{i=1}^{n} \ln x_{i}\right)^{2}}{n}<0 .
\end{aligned}
$$


Dengan demikian, $L(\theta)$ maksimum bila

$$
\theta=1+\frac{n}{\sum_{i=1}^{n} \ln x_{i}},
$$

sehingga penduga kemungkinan maksimum bagi $\theta$ ialah

$$
\hat{\theta}=1+\frac{n}{\sum_{i=1}^{n} \ln X_{i}} .
$$

Contoh 3.8 Misalkan dan $X_{1}, X_{2}, \ldots, X_{n}$ adalah sampel acak dari populasi $X$ yang menyebar $N\left(\theta_{1}, \theta_{2}\right)$. Tentukan penduga bagi $\theta_{1}$ dan $\theta_{2}$ dengan menggunakan metode kemungkinan maksimum.

Jawab. Fungsi kemungkinan dari sampel tersebut ialah

$$
\begin{aligned}
L\left(\theta_{1}, \theta_{2}\right) & =\prod_{i=1}^{n} f\left(x_{i} ; \theta_{1}, \theta_{2}\right) \\
& =\prod_{i=1}^{n} \frac{1}{\sqrt{2 \pi \theta_{2}}} \exp \left[-\frac{\left(x_{i}-\theta_{1}\right)^{2}}{2 \theta_{2}}\right] \\
& =\left(2 \pi \theta_{2}\right)^{-n / 2} \exp \left[-\frac{\sum_{i=1}^{n}\left(x_{i}-\theta_{1}\right)^{2}}{2 \theta_{2}}\right] \\
\ln L\left(\theta_{1}, \theta_{2}\right) & =-\frac{n}{2} \ln (2 \pi)-\frac{n}{2} \ln \theta_{2}-\frac{\sum_{i=1}^{n}\left(x_{i}-\theta_{1}\right)^{2}}{2 \theta_{2}} .
\end{aligned}
$$


${ }_{436}$ Kemudian, tentukan nilai maksimum dari $\ln L\left(\theta_{1}, \theta_{2}\right)$.

$$
\begin{aligned}
& \frac{\partial \ln L\left(\theta_{1}, \theta_{2}\right)}{\partial \theta_{1}}=0 \\
& \frac{2 \sum_{i=1}^{n}\left(x_{i}-\theta_{1}\right)}{2 \theta_{2}}=0 \\
& \theta_{1}=\frac{\sum_{i=1}^{n} x_{i}}{n} \\
& \theta_{1}=\bar{x}, \\
& \hat{\theta}_{1}=\bar{X}, \\
& \frac{\partial \ln L\left(\theta_{1}, \theta_{2}\right)}{\partial \theta_{2}}=0 \\
& -\frac{n}{2 \theta_{2}}+\frac{\sum_{i=1}^{n}\left(x_{i}-\theta_{1}\right)^{2}}{2\left(\theta_{2}\right)^{2}}=0 \\
& \frac{\sum_{i=1}^{n}\left(x_{i}-\theta_{1}\right)^{2}}{2\left(\theta_{2}\right)^{2}}=\frac{n}{2 \theta_{2}} \\
& \theta_{2}=\frac{\sum_{i=1}^{n}\left(x_{i}-\theta_{1}\right)^{2}}{n} \text {. }
\end{aligned}
$$

Selanjutnya, substitusikan 3.3 pada 3.4 untuk menentukan penduga kemungkinan maksimum bagi $\theta_{2}$, yaitu

$$
\hat{\theta}_{2}=\frac{\sum_{i=1}^{n}\left(X_{i}-\bar{X}\right)^{2}}{n} .
$$

Contoh 3.9 Misalkan dan $X_{1}, X_{2}, \ldots, X_{n}$ adalah sampel acak dari populasi $X$ yang menyebar gamma dengan parameter $\alpha$ dan $\beta$. Tentukan penduga bagi $\alpha$ dan $\beta$ dengan menggunakan metode kemungkinan maksimum. 
$441 \quad$ Jawab. Fungsi kemungkinan dari sampel tersebut ialah

$$
\begin{aligned}
L(\alpha, \beta) & =\prod_{i=1}^{n} f\left(x_{i} ; \alpha, \beta\right) \\
& =\prod_{i=1}^{n} \frac{1}{\Gamma(\alpha) \beta^{\alpha}} x_{i}^{\alpha-1} e^{-x_{i} / \beta} \\
& =\frac{1}{[\Gamma(\alpha)]^{n} \beta^{n \alpha}}\left(\prod_{i=1}^{n} x_{i}\right)^{\alpha-1} \exp \left(-\frac{1}{\beta} \sum_{i=1}^{n} x_{i}\right) \\
\ln L(\alpha, \beta) & =-n \ln \Gamma(\alpha)-n \alpha \ln \beta+(\alpha-1) \sum_{i=1}^{n} \ln x_{i}-\frac{1}{\beta} \sum_{i=1}^{n} x_{i} .
\end{aligned}
$$

${ }_{442}$ Kemudian, tentukan nilai maksimum dari $\ln L(\alpha, \beta)$.

$$
\begin{aligned}
\frac{\partial \ln L(\alpha, \beta)}{\partial \beta} & =0 \\
-\frac{n \alpha}{\beta}+\frac{\sum_{i=1}^{n} x_{i}}{\beta^{2}} & =0 \\
n \alpha & =\frac{\sum_{i=1}^{n} x_{i}}{\beta} \\
\beta & =\frac{\bar{x}}{\alpha}, \\
\frac{\partial \ln L(\alpha, \beta)}{\partial \alpha} & =0 \\
-\frac{n}{\Gamma(\alpha)} \Gamma^{\prime}(\alpha)-n \ln \beta+\sum_{i=1}^{n} \ln x_{i} & =0 \\
-\frac{\Gamma^{\prime}(\alpha)}{\Gamma(\alpha)}-\ln \beta+\frac{1}{n} \sum_{i=1}^{n} \ln x_{i} & =0 \\
\frac{\Gamma^{\prime}(\alpha)}{\Gamma(\alpha)}+\ln \beta & =\frac{1}{n} \sum_{i=1}^{n} \ln x_{i} .
\end{aligned}
$$

${ }_{443}$ Selanjutnya, substitusikan 3.5 pada 3.6 untuk menentukan penduga kemu- 
444

ngkinan maksimum bagi $\alpha$,

$$
\begin{aligned}
\frac{\Gamma^{\prime}(\alpha)}{\Gamma(\alpha)}+\ln \beta & =\frac{1}{n} \sum_{i=1}^{n} \ln x_{i} \\
\frac{\Gamma^{\prime}(\alpha)}{\Gamma(\alpha)}+\ln \frac{\bar{x}}{\alpha} & =\frac{1}{n} \sum_{i=1}^{n} \ln x_{i} \\
\frac{\Gamma^{\prime}(\alpha)}{\Gamma(\alpha)}+\ln \bar{x}-\ln \alpha & =\frac{1}{n} \sum_{i=1}^{n} \ln x_{i} \\
\frac{\Gamma^{\prime}(\alpha)}{\Gamma(\alpha)}-\ln \alpha & =\frac{1}{n} \sum_{i=1}^{n} \ln x_{i}-\ln \bar{x}
\end{aligned}
$$

Jawab. Berdasarkan Contoh 3.6, diperoleh penduga kemungkinan maksimum dari $\theta$ ialah

$$
\hat{\theta}=\frac{1}{\bar{X}},
$$


maka dengan menggunakan Teorema 3.1, penduga kemungkinan maksimum bagi $\sqrt{\theta^{2}+5}$ ialah

$$
\sqrt{\frac{1}{\bar{X}^{2}}+5}
$$

\subsection{Sifat-Sifat Penduga}

Secara umum, perbedaan penggunaan metode pendugaan akan menghasilkan penduga yang berbeda. Seperti pada Contoh 3.1 dan Contoh 3.5, jika $X \sim$ seragam $(0, \theta)$ dan $X_{1}, X_{2}, \ldots, X_{n}$ adalah sampel acak dari populasi $X$, maka penduga yang diperoleh dengan metode momen ialah

$$
\hat{\theta}_{1}=2 \bar{X},
$$

sedangkan penduga yang diperoleh dengan metode kemungkinan maksimum ialah

$$
\hat{\theta}_{2}=X_{(n)} .
$$

Definisi 3.5 Misalkan $X$ adalah peubah acak dengan fungsi kepekatan atau fungsi massa peluang $f(x ; \theta), \theta \in \Omega$. Misalkan pula $X_{1}, X_{2}, \ldots, X_{n}$ adalah sampel acak dari $X$ dan $T$ merupakan suatu statistik. $T$ dikatakan penduga takbias bagi $\theta$ jika

$$
E(T)=\theta, \forall \theta \in \Omega .
$$

Jika $E(T) \neq \theta$, maka $T$ disebut penduga bias bagi $\theta$. Bias dari $\hat{\theta}$, yang dinotasikan $B(\hat{\theta}, \theta)$, didefinisikan sebagai

$$
B(\hat{\theta}, \theta)=E(\hat{\theta})-\theta
$$

Jika

$$
\lim _{n \rightarrow \infty} B(\hat{\theta}, \theta)=0 \text { atau } \lim _{n \rightarrow \infty} E(T)=\theta,
$$

maka $\hat{\theta}$ merupakan penduga takbias asimtotik bagi $\theta$. 

ialah

Jawab. Berdasarkan Contoh 3.2, penduga bagi $\mu$ dan $\sigma^{2}$ berturut-turut

$$
\hat{\mu}=\bar{X} \operatorname{dan} \hat{\sigma}^{2}=\frac{1}{n} \sum_{i=1}^{n}\left(X_{i}-\bar{X}\right)^{2} .
$$

${ }_{468}$ Karena $\bar{X} \sim N\left(\mu, \frac{\sigma^{2}}{n}\right)$, maka $E(\bar{X})=\mu$. Jadi, $\bar{X}$ adalah penduga takbias 469 bagi $\mu$.

$$
\begin{aligned}
E\left[\hat{\sigma}^{2}\right] & =E\left[\frac{1}{n} \sum_{i=1}^{n}\left(X_{i}-\bar{X}\right)^{2}\right] \\
& =E\left[\frac{n-1}{n} \frac{1}{n-1} \sum_{i=1}^{n}\left(X_{i}-\bar{X}\right)^{2}\right] \\
& =\frac{n-1}{n} E\left[\frac{1}{n-1} \sum_{i=1}^{n}\left(X_{i}-\bar{X}\right)^{2}\right] \\
& =\frac{n-1}{n} E\left[S^{2}\right] \\
& =\frac{\sigma^{2}}{n} E\left[\frac{n-1}{\sigma^{2}} S^{2}\right],
\end{aligned}
$$

${ }_{470}$ Karena $\frac{n-1}{\sigma^{2}} S^{2} \sim \chi^{2}(n-1)$, maka persamaan 3.9 menjadi

$$
\begin{aligned}
E\left(\hat{\sigma}^{2}\right) & =\frac{\sigma^{2}}{n}(n-1) \\
& =\frac{n-1}{n} \sigma^{2} \\
& \neq \sigma^{2} .
\end{aligned}
$$

${ }_{471}$ Jadi, $\hat{\sigma}^{2}=\frac{1}{n} \sum_{i=1}^{n}\left(X_{i}-\bar{X}\right)^{2}$ merupakan penduga bias bagi $\sigma^{2}$. 
Pada Contoh 3.11,

$$
\begin{aligned}
B\left(\hat{\sigma}^{2}, \sigma^{2}\right) & =E\left(\hat{\sigma}^{2}\right)-\sigma^{2} \\
& =\frac{n-1}{n} \sigma^{2}-\sigma^{2} \\
\lim _{n \rightarrow \infty} B\left(\hat{\sigma}^{2}, \sigma^{2}\right) & =\lim _{n \rightarrow \infty}\left(\frac{n-1}{n} \sigma^{2}-\sigma^{2}\right) \\
& =\lim _{n \rightarrow \infty}-\frac{\sigma^{2}}{n} \\
& =0 .
\end{aligned}
$$

Karena $\lim _{n \rightarrow \infty} B\left(\hat{\sigma}^{2}, \sigma^{2}\right)=0$, maka $\hat{\sigma}^{2}$ merupakan penduga takbias asimtotik bagi $\sigma^{2}$. Selanjutnya, berdasarkan fakta bahwa $\frac{n-1}{\sigma^{2}} S^{2} \sim \chi^{2}(n-1)$, maka

$$
E\left(\frac{n-1}{\sigma^{2}} S^{2}\right)=n-1,
$$

yang berarti bahwa

$$
E\left(S^{2}\right)=\frac{\sigma^{2}}{n-1} \times(n-1)=\sigma^{2}
$$

Jadi,

$$
S^{2}=\frac{1}{n-1} \sum_{i=1}^{n}\left(X_{i}-\bar{X}\right)^{2}
$$

merupakan penduga takbias bagi $\sigma^{2}$.

Penduga takbias kadang dapat memberi dugaan yang tidak layak seperti pada contoh berikut.

Contoh 3.12 Misalkan $X \sim \operatorname{Poisson}(\theta), \theta>0$ dengan

$$
f(x ; \theta)=\frac{e^{-\theta} \theta^{x}}{x !} \mathbf{I}(x=0,1,2, \ldots) .
$$

Ingin diperoleh penduga takbias bagi $e^{-3 \theta}$. Untuk peubah acak tersebut, berikan penduga bagi fungsi parameter $g(\theta)=e^{-3 \theta}$.

J78 Jawab. Untuk sampel acak berukuran satu, yaitu $X, T(X)=(-2)^{X}$, 
479

diperoleh

$$
\begin{aligned}
E(T(X)) & =E\left((-2)^{X}\right) \\
& =\sum_{x=0}^{\infty}\left[(-2)^{x} \cdot \frac{e^{-\theta} \theta^{x}}{x !}\right] \\
& =e^{-\theta} \sum_{x=1}^{n} \frac{(-2 \theta)^{x}}{x !} \\
& =e^{-\theta} e^{-2 \theta} \\
& =e^{-3 \theta} .
\end{aligned}
$$

Contoh 3.13 Misalkan $X_{1}, X_{2}, X_{3}$ adalah tiga sampel acak dari populasi dengan nilai harapan $\mu$ dan ragam $\sigma^{2}>0$. Jika statistik $\bar{X}$ dan

$$
Y=\frac{X_{1}+2 X_{2}+3 X_{3}}{6}
$$

Definisi 3.6 Misalkan $\hat{\theta}_{1}$ dan $\hat{\theta}_{2}$ adalah dua penduga takbias bagi $\theta$. Penduga $\hat{\theta}_{1}$ dikatakan lebih efisien daripada $\hat{\theta}_{2}$ jika $\operatorname{Var}\left(\hat{\theta}_{1}\right)<\operatorname{Var}\left(\hat{\theta}_{2}\right)$. Rasio $\eta$ didefinisikan sebagai berikut

$$
\eta\left(\hat{\theta}_{1}, \hat{\theta}_{2}\right)=\frac{\operatorname{Var}\left(\hat{\theta}_{2}\right)}{\operatorname{Var}\left(\hat{\theta}_{1}\right)},
$$

merupakan efisiensi relatif dari $\hat{\theta}_{1}$ terhadap $\hat{\theta}_{2}$.

adalah dua penduga takbias bagi $\mu$, maka penduga manakah yang lebih efisien? 
487

488

dan

$$
\begin{aligned}
\operatorname{Var}(Y) & =\operatorname{Var}\left(\frac{X_{1}+2 X_{2}+3 X_{3}}{6}\right) \\
& =\frac{1}{36}\left[\operatorname{Var}\left(X_{1}\right)+4 \operatorname{Var}\left(X_{2}\right)+9 \operatorname{Var}\left(X_{3}\right)\right] \\
& =\frac{1}{36}\left(14 \sigma^{2}\right) \\
& =\frac{14}{36} \sigma^{2} .
\end{aligned}
$$

$$
\begin{aligned}
\operatorname{Var}(\bar{X}) & =\operatorname{Var}\left(\frac{X_{1}+X_{2}+X_{3}}{3}\right) \\
& =\frac{1}{9}\left[\operatorname{Var}\left(X_{1}\right)+\operatorname{Var}\left(X_{2}\right)+\operatorname{Var}\left(X_{3}\right)\right] \\
& =\frac{1}{9}\left(3 \sigma^{2}\right) \\
& =\frac{1}{3} \sigma^{2}=\frac{12}{36} \sigma^{2}
\end{aligned}
$$

Jadi, $\frac{12}{36} \sigma^{2}=\operatorname{Var}(\bar{X})<\operatorname{Var}(Y)=\frac{14}{36} \sigma^{2}$, sehingga $\bar{X}$ merupakan penduga yang lebih efisien daripada $Y$. Efisiensi relatif dari $\bar{X}$ terhadap $Y$ ialah

$$
\eta(\bar{X}, Y)=\frac{14}{12}=\frac{7}{6}
$$

Jawab. Ragam dari $\bar{X}$ dan $Y$ ialah

\subsubsection{Efisiensi dan Pertaksamaan Rao-Cramèr}

Pada subbab sebelumnya dibahas efisiensi relatif dari dua penduga takbias dengan cara membandingkan ragamnya. Berdasarkan definisi efisiensi relatif penduga tersebut, timbul pertanyaan apakah terdapat penduga yang paling efisien di antara beberapa penduga takbias tersebut? Untuk mengetahui hal tersebut, kita dapat menentukan apakah ada penduga yang paling efisien berdasarkan batas bawah pertaksamaan Rao-Cramèr. Jika suatu penduga memiliki ragam yang nilainya sama dengan batas bawah pertaksamaan RaoCramèr, maka penduga tersebut adalah penduga yang paling efisien. 
Definisi 3.7 Misalkan $X$ adalah peubah acak dengan fungsi kepekatan peluang $f(x ; \theta)$. Andaikan $f(x ; \theta)$ kontinu dan terturunkan dua kali, maka informasi Fisher, dinotasikan $I(\theta)$, didefinisikan sebagai

$$
I(\theta)=\int_{-\infty}^{\infty}\left[\frac{d \ln f(x ; \theta)}{d \theta}\right]^{2} f(x ; \theta) d x .
$$

Dengan kata lain, $I(\theta)$ adalah nilai harapan dari peubah acak $\left[\frac{d \ln f(X ; \theta)}{d \theta}\right]^{2}$, yaitu

$$
I(\theta)=E\left(\left[\frac{d \ln f(X ; \theta)}{d \theta}\right]^{2}\right) .
$$

499

Lema berikut adalah formula alternatif untuk informasi Fisher.

Lema 3.1 Informasi Fisher I $(\theta)$ juga dapat didefinisikan sebagai

$$
I(\theta)=-E\left(\frac{d^{2} \ln f(X ; \theta)}{d \theta^{2}}\right) .
$$

500

Bukti. Karena $f(x ; \theta)$ adalah fungsi kepekatan peluang, maka

$$
\int_{-\infty}^{\infty} f(x ; \theta) d x=1 .
$$

Turunkan persamaan 3.10 terhadap $\theta$,

$$
\frac{d}{d \theta} \int_{-\infty}^{\infty} f(x ; \theta) d x=0 .
$$

se

Selanjutnya, persamaan 3.11 dapat ditulis menjadi

$$
\begin{aligned}
& \int_{-\infty}^{\infty} \frac{d f(x ; \theta)}{d \theta} \frac{1}{f(x ; \theta)} f(x ; \theta) d x=0 \\
& \int_{-\infty}^{\infty} \frac{d \ln f(x ; \theta)}{d \theta} f(x ; \theta) d x=0 \\
& \int_{-\infty}^{\infty}\left[\frac{d^{2} \ln f(x ; \theta)}{d \theta^{2}} f(x ; \theta)+\frac{d \ln f(x ; \theta)}{d \theta} \frac{d f(x ; \theta)}{d \theta}\right] d x=0 \\
& \int_{-\infty}^{\infty}\left[\frac{d^{2} \ln f(x ; \theta)}{d \theta^{2}} f(x ; \theta)+\frac{d \ln f(x ; \theta)}{d \theta} \frac{d f(x ; \theta)}{d \theta} \frac{1}{f(x ; \theta)} f(x ; \theta)\right] d x=0 \\
& \int_{-\infty}^{\infty}\left[\frac{d^{2} \ln f(x ; \theta)}{d \theta^{2}} f(x ; \theta)+\left[\frac{d \ln f(x ; \theta)}{d \theta}\right]^{2} f(x ; \theta)\right] d x=0
\end{aligned}
$$


Jadi, berdasarkan persamaan di atas diperoleh

$$
\int_{-\infty}^{\infty}\left[\frac{d \ln f(x ; \theta)}{d \theta}\right]^{2} f(x ; \theta) d x=-\int_{-\infty}^{\infty} \frac{d^{2} \ln f(x ; \theta)}{d \theta^{2}} f(x ; \theta) d x .
$$

Dengan demikian, berdasarkan Definisi 3.7 diperoleh

$$
I(\theta)=-\int_{-\infty}^{\infty} \frac{d^{2} \ln f(x ; \theta)}{d \theta^{2}} f(x ; \theta) d x .
$$

504

Lema 3.2 Jika $X_{1}, X_{2}, \ldots, X_{n}$ adalah sampel acak dari sebaran $X$ dengan fungsi kepekatan peluang $f(x ; \theta)$, maka informasi Fisher dari sampel berukuran $n$ ialah

$$
I_{n}(\theta)=n I(\theta) .
$$

505

Bukti. Dengan menggunakan Definisi 3.7,

$$
\begin{aligned}
I_{n}(\theta) & =-E\left(\frac{d^{2} \ln f\left(X_{1}, X_{2}, \ldots, X_{n} ; \theta\right)}{d \theta^{2}}\right) \\
& =-E\left(\frac{d^{2}}{d \theta^{2}}\left[\ln f\left(X_{1} ; \theta\right)+\ldots+\ln f\left(X_{n} ; \theta\right)\right]\right) \\
& =-E\left(\frac{d^{2} \ln f\left(X_{1} ; \theta\right)}{d \theta^{2}}\right)-\ldots-E\left(\frac{d^{2} \ln f\left(X_{n} ; \theta\right)}{d \theta^{2}}\right) \\
& =I(\theta)+\ldots+I(\theta) \\
& =n I(\theta) .
\end{aligned}
$$

506

Contoh 3.14 Misalkan X adalah peubah acak dari sebaran eksponensial dengan fungsi kepekatan peluang

$$
f(x ; \theta)=\frac{1}{\theta} e^{-x / \theta} \mathbf{I}(0 \leq x<\infty), \theta>0 .
$$

Tentukan I $(\theta)$ dengan menggunakan Definisi 3.7 dan Lema 3.1.

508

509

Jawab. Karena $f(x ; \theta)=\frac{1}{\theta} e^{-x / \theta}$, maka $\ln f(x ; \theta)=-\ln \theta-\frac{x}{\theta}$. Turunan pertama dari ln $f(x ; \theta)$ terhadap $\theta$ ialah

$$
\begin{aligned}
\frac{d \ln f(x ; \theta)}{d \theta} & =-\frac{1}{\theta}+\frac{x}{\theta^{2}} \\
\left(\frac{d \ln f(x ; \theta)}{d \theta}\right)^{2} & =\frac{1}{\theta^{2}}-\frac{2 x}{\theta^{3}}+\frac{x^{2}}{\theta^{4}} .
\end{aligned}
$$


510 511

Dengan demikian,

$$
\begin{aligned}
I(\theta) & =-E\left[\frac{d^{2} \ln f(X ; \theta)}{d \theta^{2}}\right] \\
& =-E\left[\frac{1}{\theta^{2}}-\frac{2 X}{\theta^{3}}\right] \\
& =-\left[\frac{1}{\theta^{2}}-\frac{2 \theta}{\theta^{3}}\right] \\
& =\frac{1}{\theta^{2}} .
\end{aligned}
$$
terhadap $\theta$, yaitu

$$
\frac{d^{2} \ln f(x ; \theta)}{d \theta^{2}}=\frac{1}{\theta^{2}}-\frac{2 x}{\theta^{3}}
$$

Jika menggunakan Lema 3.1, maka diperlukan turunan kedua dari $\ln f(x ; \theta)$

513

Contoh 3.15 Misalkan $X_{1}, X_{2}, \ldots, X_{n}$ adalah sampel acak dari sebaran normal dengan parameter $\mu$ dan $\sigma^{2}$. Tentukan informasi Fisher $I_{n}(\mu)$.

Jawab. Misalkan $X \sim N\left(\mu, \sigma^{2}\right)$, maka

$$
\begin{aligned}
\ln f(x ; \mu) & =\ln \left(\frac{1}{\sqrt{2 \pi \sigma^{2}}} \exp \left[-\frac{(x-\mu)^{2}}{2 \sigma^{2}}\right]\right) \\
& =\ln \left(\frac{1}{\sqrt{2 \pi \sigma^{2}}}\right)-\frac{(x-\mu)^{2}}{2 \sigma^{2}},
\end{aligned}
$$

517 sehingga turunan pertama dan kedua dari $\ln f(x ; \mu)$ ialah

$$
\begin{aligned}
\frac{d \ln f(x ; \mu)}{d \mu} & =\frac{x-\mu}{\sigma^{2}} \\
\frac{d^{2} \ln f(x ; \mu)}{d \mu^{2}} & =-\frac{1}{\sigma^{2}} .
\end{aligned}
$$


518

Jadi,

$$
\begin{aligned}
I_{n}(\mu) & =n I(\mu) \\
& =n \times-E\left(\frac{d^{2} \ln f(X ; \mu)}{d \mu^{2}}\right) \\
& =n \times \frac{1}{\sigma^{2}} .
\end{aligned}
$$

519

$m a k a$

$$
\operatorname{Var}(Y) \geq \frac{\left(k^{\prime}(\theta)\right)^{2}}{n I(\theta)} .
$$

Bukti. Nilai harapan $E(Y)=k(\theta)$ dapat dituliskan menjadi

$$
\begin{aligned}
k(\theta) & =\int_{-\infty}^{\infty} \cdots \int_{-\infty}^{\infty} u\left(x_{1}, x_{2}, \ldots, x_{n}\right) f\left(x_{1} ; \theta\right) \cdots f\left(x_{n} ; \theta\right) d x_{1} \cdots d x_{n} \\
& =\int_{-\infty}^{\infty} \cdots \int_{-\infty}^{\infty} u\left(x_{1}, x_{2}, \ldots, x_{n}\right) L(\theta) d x_{1} \cdots d x_{n}
\end{aligned}
$$

${ }_{525}$ Turunkan $k(\theta)$ terhadap $\theta$, sehingga

$$
\begin{aligned}
k^{\prime}(\theta) & =\int_{-\infty}^{\infty} \cdots \int_{-\infty}^{\infty} u\left(x_{1}, x_{2}, \ldots, x_{n}\right) \frac{d L(\theta)}{d \theta} \cdot \frac{1}{L(\theta)} \cdot L(\theta) d x_{1} \cdots d x_{n} \\
& =\int_{-\infty}^{\infty} \cdots \int_{-\infty}^{\infty} u\left(x_{1}, x_{2}, \ldots, x_{n}\right) \frac{d \ln L(\theta)}{d \theta} \cdot L(\theta) d x_{1} \cdots d x_{n} \\
& =\int_{-\infty}^{\infty} \cdots \int_{-\infty}^{\infty} u\left(x_{1}, x_{2}, \ldots, x_{n}\right)\left[\sum_{i=1}^{n} \frac{1}{f\left(x_{i} ; \theta\right)} \cdot \frac{d f\left(x_{i} ; \theta\right)}{d \theta}\right] L(\theta) d x_{1} \cdots d x_{n} \\
& =\int_{-\infty}^{\infty} \cdots \int_{-\infty}^{\infty} u\left(x_{1}, x_{2}, \ldots, x_{n}\right)\left[\sum_{i=1}^{n} \frac{d \ln f\left(x_{i} ; \theta\right)}{d \theta}\right] L(\theta) d x_{1} \cdots d x_{n} .(3.12)
\end{aligned}
$$


Definisikan peubah acak $Z$ sebagai

$$
Z=\sum_{i=1}^{n} \frac{d \ln f\left(X_{i} ; \theta\right)}{d \theta},
$$

maka $E(Z)=0$ dan $\operatorname{Var}(Z)=n I(\theta)$. Persamaan 3.12 dapat ditulis menjadi

$$
k^{\prime}(\theta)=E(Y Z)=E(Y) E(Z)+\rho \sigma_{Y} \sqrt{n I(\theta)}
$$

dengan $\rho$ adalah koefisien korelasi antara $Y$ dan $Z$. Karena $E(Z)=0$ dan $\rho^{2} \leq 1$, maka

$$
\rho=\frac{k^{\prime}(\theta)}{\sigma_{Y} \sqrt{n I(\theta)}}
$$

dan

$$
\frac{\left[k^{\prime}(\theta)\right]^{2}}{\sigma_{Y}^{2} n I(\theta)} \leq 1 .
$$

Dengan demikian, terbukti bahwa

$$
\sigma_{Y}^{2} \geq \frac{\left[k^{\prime}(\theta)\right]^{2}}{n I(\theta)}
$$

Definisi 3.8 Misalkan $Y$ adalah penduga takbias bagi parameter $\theta$. Statistik $Y$ disebut penduga efisien jika ragam dari $Y$ sama dengan batas bawah pertaksamaan Rao-Cramèr. Efisiensi penduga takbias $Y$ bagi parameter $\theta$ didefinisikan sebagai

$$
\frac{\left[k^{\prime}(\theta)\right]^{2}}{n I(\theta) \operatorname{Var}(Y)} \times 100 \% \text {. }
$$

Jika

$$
\lim _{n \rightarrow \infty} \frac{\left[k^{\prime}(\theta)\right]^{2}}{n I(\theta) \operatorname{Var}(Y)}=1,
$$

maka penduga takbias $Y$ disebut sebagai penduga efisien asimtotik.

Akibat 3.1 Berdasarkan asumsi pada Teorema 3.2, jika $Y=u\left(X_{1}, X_{2}, \ldots, X_{n}\right)$ adalah penduga takbias bagi $\theta, k(\theta)=\theta$, maka pertaksamaan Rao-Cramèr menjadi

$$
\operatorname{Var}(Y) \geq \frac{1}{n I(\theta)}
$$


Contoh 3.16 Misalkan $X_{1}, X_{2}, \ldots, X_{n}$ adalah sampel acak dari sebaran Poisson dengan nilai harapan $\theta>0$. Tunjukkan bahwa $\bar{X}$ adalah penduga efisien bagi $\theta$.

Jawab.

$$
\begin{aligned}
\frac{d \ln f(x ; \theta)}{d \theta} & =\frac{d}{d \theta}(x \ln \theta-\theta-\ln x !) \\
& =\frac{x}{\theta}-1 \\
& =\frac{x-\theta}{\theta} \\
I(\theta) & =E\left[\left(\frac{d \ln f(X ; \theta)}{d \theta}\right)^{2}\right] \\
& =\frac{E(X-\theta)^{2}}{\theta^{2}} \\
& =\frac{\sigma^{2}}{\theta^{2}} \\
& =\frac{\theta}{\theta^{2}} \\
& =\frac{1}{\theta} .
\end{aligned}
$$

Karena $X \sim \operatorname{Poisson}(\theta)$, maka

$$
\operatorname{Var}(\bar{X})=\frac{\operatorname{Var}(X)}{n}=\frac{\theta}{n} .
$$

Batas bawah Rao-Cramèr:

$$
\frac{1}{n I(\theta)}=\frac{\theta}{n}=\operatorname{Var}(\bar{X})
$$

sehingga $\bar{X}$ merupakan penduga efisien bagi $\theta$. Efisiensi penduga $\bar{X}$ bagi $\theta$ sebesar

$$
\frac{1 /[n I(\theta)]}{\operatorname{Var}(\bar{X})} \times 100 \%=\frac{\theta / n}{\theta / n} \times 100 \%=100 \% .
$$

Contoh 3.17 Misalkan $X_{1}, X_{2}, \ldots, X_{n}$ adalah sampel acak dari sebaran normal dengan nilai harapan $\mu$ dan ragam $\theta$. Tentukan efisiensi bagi penduga takbias $\theta$, yaitu

$$
S^{2}=\frac{\sum_{i=1}^{n}\left(X_{i}-\bar{X}\right)^{2}}{n-1} .
$$


$533 \quad$ Jawab

$$
\begin{aligned}
\frac{d \ln f(x ; \theta)}{d \theta} & =\frac{d}{d \theta}\left(-\frac{1}{2} \ln 2 \pi-\frac{1}{2} \ln \theta-\frac{1}{2 \theta}(x-\mu)^{2}\right) \\
& =-\frac{1}{2 \theta}+\frac{1}{2 \theta^{2}}(x-\mu)^{2} \\
\frac{d^{2} \ln f(x ; \theta)}{d \theta^{2}} & =\frac{1}{2 \theta^{2}}-\frac{1}{\theta^{3}}(x-\mu)^{2} \\
I(\theta) & =-E\left[\frac{d^{2} \ln f(X ; \theta)}{d \theta^{2}}\right] \\
& =\frac{1}{2 \theta^{2}}-\frac{1}{\theta^{3}} E(X-\mu)^{2} \\
& =\frac{1}{2 \theta^{2}}-\frac{1}{\theta^{3}} \cdot \theta \\
& =\frac{1}{2 \theta^{2}} .
\end{aligned}
$$

Batas bawah pertaksamaan Rao-Cramèr:

$$
\frac{1}{n I(\theta)}=\frac{1}{n \frac{1}{2 \theta^{2}}}=\frac{2 \theta^{2}}{n} \text {. }
$$

534 Karena $Y=\frac{\sum_{i=1}^{n}\left(X_{i}-\bar{X}\right)^{2}}{\theta} \sim \chi^{2}(n-1)$, maka $\operatorname{Var}(Y)=2(n-1)$ dan

$$
\begin{aligned}
S^{2} & =\frac{\theta}{(n-1)} Y, \\
\operatorname{Var}\left(S^{2}\right) & =\frac{\theta^{2}}{(n-1)^{2}} \operatorname{Var}(Y) \\
& =\frac{\theta^{2}}{(n-1)^{2}} \cdot 2(n-1) \\
& =\frac{2 \theta^{2}}{(n-1)} .
\end{aligned}
$$

Dengan demikian,

$$
\operatorname{Var}\left(S^{2}\right)=\frac{2 \theta^{2}}{(n-1)}>\frac{1}{n I(\theta)}=\frac{2 \theta^{2}}{n} .
$$

Efisiensi penduga $S^{2}$ bagi $\theta$ sebesar

$$
\frac{1 /[n I(\theta)]}{\operatorname{Var}\left(S^{2}\right)} \times 100 \%=\frac{n-1}{n} \times 100 \%
$$


Definisi 3.9 Misalkan $X_{1}, X_{2}, \ldots, X_{n}$ adalah sampel acak dari populasi $X$ dengan fungsi kepekatan peluang $f(x ; \theta)$. Barisan penduga $\left\{\hat{\theta}_{n}\right\}$ disebut konsisten jika barisan $\left\{\hat{\theta}_{n}\right\}$ konvergen dalam peluang ke $\theta$, yaitu

$$
\forall \varepsilon>0, \quad \lim _{n \rightarrow \infty} P\left(\left|\hat{\theta}_{n}-\theta\right| \geq \varepsilon\right)=0 .
$$

Teorema 3.3 Misalkan $X_{1}, X_{2}, \ldots, X_{n}$ adalah sampel acak dari sebaran $X$ dengan fungsi kepekatan peluang $f(x ; \theta)$ dan $\left\{\hat{\theta}_{n}\right\}$ merupakan barisan penduga bagi $\theta$ berdasarkan sampel. Jika ragam dari $\hat{\theta}_{n}$ ada untuk setiap $n$ dan berhingga, serta

$$
\lim _{n \rightarrow \infty} E\left(\left(\hat{\theta}_{n}-\theta\right)^{2}\right)=0
$$

$m a k a$

$$
\forall \varepsilon>0, \quad \lim _{n \rightarrow \infty} P\left(\left|\hat{\theta}_{n}-\theta\right| \geq \varepsilon\right)=0
$$

Bukti. Berdasarkan pertaksamaan Markov diperoleh

$$
P\left(\left(\hat{\theta}_{n}-\theta\right)^{2} \geq \varepsilon^{2}\right) \leq \frac{E\left(\left(\hat{\theta}_{n}-\theta\right)^{2}\right)}{\varepsilon^{2}}
$$

untuk setiap $\varepsilon>0$. Karena $\left(\hat{\theta}_{n}-\theta\right)^{2} \geq \varepsilon^{2}$ equivalen dengan $\left|\hat{\theta}_{n}-\theta\right| \geq \varepsilon$, maka

$$
P\left(\left(\hat{\theta}_{n}-\theta\right)^{2} \geq \varepsilon^{2}\right)=P\left(\left|\hat{\theta}_{n}-\theta\right| \geq \varepsilon\right) \leq \frac{E\left(\left(\hat{\theta}_{n}-\theta\right)^{2}\right)}{\varepsilon^{2}}
$$


untuk setiap $n \in \mathbb{N}$. Perhatikan bahwa jika

$$
\lim _{n \rightarrow \infty} E\left(\left(\hat{\theta}_{n}-\theta\right)^{2}\right)=0
$$

maka

$$
\lim _{n \rightarrow \infty} P\left(\left|\hat{\theta}_{n}-\theta\right| \geq \varepsilon\right)=0
$$

543

Bias bagi penduga $\theta$ ialah $B(\hat{\theta}, \theta)=E\left(\hat{\theta}_{n}\right)-\theta$. Jika penduga yang diperoleh merupakan penduga takbias, maka $B(\hat{\theta}, \theta)=0$. Selanjutnya, akan ditunjukkan bahwa

$$
E\left((\hat{\theta}-\theta)^{2}\right)=\operatorname{Var}(\hat{\theta})+[B(\hat{\theta}, \theta)]^{2} .
$$

Perhatikan bahwa

$$
\begin{aligned}
E\left((\hat{\theta}-\theta)^{2}\right) & =E\left(\hat{\theta}^{2}-2 \hat{\theta} \theta+\theta^{2}\right) \\
& =E\left(\hat{\theta}^{2}\right)-2 \theta E(\hat{\theta})+\theta^{2} \\
& =E\left(\hat{\theta}^{2}\right)-[E(\hat{\theta})]^{2}+[E(\hat{\theta})]^{2}-2 \theta E(\hat{\theta})+\theta^{2} \\
& =\operatorname{Var}(\hat{\theta})+[E(\hat{\theta})]^{2}-2 \theta E(\hat{\theta})+\theta^{2} \\
& =\operatorname{Var}(\hat{\theta})+\left[E\left(\hat{\theta}_{n}\right)-\theta\right]^{2} \\
& =\operatorname{Var}(\hat{\theta})+[B(\hat{\theta}, \theta)]^{2}
\end{aligned}
$$

Jika

$$
\lim _{n \rightarrow \infty} \operatorname{Var}(\hat{\theta})=0 \operatorname{dan} \lim _{n \rightarrow \infty} B(\hat{\theta}, \theta)=0,
$$

maka berdasarkan persamaan 3.13,

$$
\lim _{n \rightarrow \infty} E\left((\hat{\theta}-\theta)^{2}\right)=0
$$

Dengan kata lain, untuk menunjukkan bahwa suatu penduga konsisten, kita cukup menunjukkan persamaan 3.14. 
Contoh 3.18 Misalkan $X_{1}, X_{2}, \ldots, X_{n}$ adalah sampel acak dari populasi normal dengan nilai harapan $\mu$ dan ragam $\sigma^{2}>0$. Tentukan apakah penduga bagi $\sigma^{2}$, yaitu

$$
\hat{\sigma}^{2}=\frac{1}{n} \sum_{i=1}^{n}\left(X_{i}-\bar{X}\right)^{2}
$$

551

merupakan penduga konsisten bagi $\sigma^{2}$ ?

Jawab. Karena $\hat{\sigma}^{2}$ bergantung terhadap $n$, maka notasikan $\hat{\sigma}^{2}$ sebagai $\hat{\sigma}_{n}^{2}$, sehingga

$$
\hat{\sigma}_{n}^{2}=\frac{1}{n} \sum_{i=1}^{n}\left(X_{i}-\bar{X}\right)^{2} .
$$

${ }_{552}$ Ragam bagi $\hat{\sigma}_{n}^{2}$ ialah

$$
\begin{aligned}
\operatorname{Var}\left(\hat{\sigma}_{n}^{2}\right) & =\operatorname{Var}\left(\frac{1}{n} \sum_{i=1}^{n}\left(X_{i}-\bar{X}\right)^{2}\right) \\
& =\frac{1}{n^{2}} \operatorname{Var}\left(\sigma^{2} \frac{(n-1) S^{2}}{\sigma^{2}}\right) \\
& =\frac{\sigma^{4}}{n^{2}} \operatorname{Var}\left(\frac{(n-1) S^{2}}{\sigma^{2}}\right) ; \frac{(n-1) S^{2}}{\sigma^{2}} \sim \chi^{2}(n-1) \\
& =\frac{2(n-1) \sigma^{4}}{n^{2}} \\
& =\left[\frac{1}{n}-\frac{1}{n^{2}}\right] 2 \sigma^{4}, \\
\lim _{n \rightarrow \infty} \operatorname{Var}\left(\hat{\sigma}_{n}^{2}\right) & =\lim _{n \rightarrow \infty}\left[\frac{1}{n}-\frac{1}{n^{2}}\right] 2 \sigma^{4}=0 .
\end{aligned}
$$


553

$\operatorname{Bias} B\left(\hat{\sigma}_{n}^{2}, \sigma^{2}\right)$ ialah

$$
\begin{aligned}
B\left(\hat{\sigma}_{n}^{2}, \sigma^{2}\right) & =E\left(\hat{\sigma}_{n}^{2}\right)-\sigma^{2} \\
& =E\left(\frac{1}{n} \sum_{i=1}^{n}\left(X_{i}-\bar{X}\right)^{2}\right)-\sigma^{2} \\
& =\frac{1}{n} E\left(\sigma^{2} \frac{(n-1) S^{2}}{\sigma^{2}}\right)-\sigma^{2} \\
& =\frac{\sigma^{2}}{n} E\left(\frac{(n-1) S^{2}}{\sigma^{2}}\right)-\sigma^{2} \\
& =\frac{(n-1) \sigma^{2}}{n}-\sigma^{2} \\
& =-\frac{\sigma^{2}}{n}, \\
\lim _{n \rightarrow \infty} B\left(\hat{\sigma}_{n}^{2}, \sigma^{2}\right) & =-\lim _{n \rightarrow \infty} \frac{\sigma^{2}}{n}=0 .
\end{aligned}
$$

${ }_{554}$ Jadi, $\frac{1}{n} \sum_{i=1}^{n}\left(X_{i}-\bar{X}\right)^{2}$ adalah penduga konsisten bagi $\sigma^{2}$.

\subsection{Penduga Selang}

Definisi 3.10 Misalkan $X_{1}, X_{2}, \ldots, X_{n}$ adalah sampel acak dari populasi $X$ dengan fungsi kepekatan peluang $f(x, \theta)$, di mana $\theta$ adalah parameter yang tidak diketahui. Penduga selang bagi $\theta$ dengan peluang $(1-\alpha)$ adalah selang statistik $\left[L\left(X_{1}, X_{2}, \ldots, X_{n}\right), U\left(X_{1}, X_{2}, \ldots, X_{n}\right)\right]$ dengan $L \leq U$ sedemikian sehingga

$$
P\left(\left[L\left(X_{1}, X_{2}, \ldots, X_{n}\right) \leq \theta \leq U\left(X_{1}, X_{2}, \ldots, X_{n}\right)\right]\right)=1-\alpha
$$

dengan $0<\alpha<1$.

Pada persamaan 3.15, $P(L \leq \theta \leq U)$ menyatakan bahwa peluang parameter $\theta$ berada di antara selang acak tersebut adalah sebesar $(1-\alpha)$, di mana $(1-\alpha)$ disebut sebagai koefisien kepercayaan. Setelah diperoleh titik atau amatan sampel, maka selang $\left[L\left(x_{1}, x_{2}, \ldots, x_{n}\right), U\left(x_{1}, x_{2}, \ldots, x_{n}\right)\right]$ disebut sebagai selang kepercayaan $100(1-\alpha) \%$ bagi $\theta$. Selang

$$
\left[L\left(x_{1}, x_{2}, \ldots, x_{n}\right), U\left(x_{1}, x_{2}, \ldots, x_{n}\right)\right]
$$

tentunya dapat mencakup atau tidak mencakup nilai $\theta$ yang sebenarnya, tetapi bila sampel ini diperoleh sebanyak $m$ kali, maka harapan kita $(1-\alpha) \times$ $m$ kali selang ini akan mencakup nilai $\theta$. 
Contoh 3.19 Misalkan $X_{1}, X_{2}, \ldots, X_{n}$ adalah sampel acak dari sebaran $N\left(\mu, \sigma^{2}\right)$, dengan asumsi $\sigma^{2}>0$ diketahui. Misalkan pula $\bar{X}$ merupakan nilai tengah dari sampel, maka peubah acak $(\bar{X}-\mu) /(\sigma / \sqrt{n})$ memiliki sebaran normal baku. Dengan kata lain,

$$
\frac{(\bar{X}-\mu)}{\sigma / \sqrt{n}} \sim N(0,1) .
$$

Tentukan selang kepercayaan $100(1-\alpha) \%$ bagi $\mu$.

Jawab. Untuk $0<\alpha<1$, definisikan bahwa

$$
P\left(\frac{(\bar{X}-\mu)}{\sigma / \sqrt{n}}>z_{\alpha / 2}\right)=\frac{\alpha}{2}
$$

566

sedemikian sehingga

$$
\begin{aligned}
1-\alpha & =P\left(-z_{\alpha / 2}<\frac{(\bar{X}-\mu)}{\sigma / \sqrt{n}}<z_{\alpha / 2}\right) \\
& =P\left(-\frac{\sigma}{\sqrt{n}} z_{\alpha / 2}<\bar{X}-\mu<\frac{\sigma}{\sqrt{n}} z_{\alpha / 2}\right) \\
& =P\left(\bar{X}-\frac{\sigma}{\sqrt{n}} z_{\alpha / 2}<\mu<\bar{X}+\frac{\sigma}{\sqrt{n}} z_{\alpha / 2}\right) .
\end{aligned}
$$

Jadi, selang kepercayaan $100(1-\alpha) \%$ bagi $\mu$ ialah

$$
\left(\bar{x}-\frac{\sigma}{\sqrt{n}} z_{\alpha / 2}, \bar{x}+\frac{\sigma}{\sqrt{n}} z_{\alpha / 2}\right),
$$

di mana

$$
\bar{x}=\frac{1}{n} \sum_{i=1}^{n} x_{i}
$$

Contoh 3.20 Misalkan $X_{1}, X_{2}, \ldots, X_{n}$ adalah sampel acak dari sebaran $N\left(\mu, \sigma^{2}\right)$, dengan asumsi $\sigma^{2}$ tidak diketahui. Misalkan $\bar{X}$ dan $S^{2}$ merupakan nilai tengah dan ragam dari sampel. Tentukan selang kepercayaan $100(1-\alpha) \%$ bagi $\mu$.

Jawab. Karena $X_{1}, X_{2}, \ldots, X_{n} \sim N\left(\mu, \sigma^{2}\right)$, maka

$$
\bar{X} \sim N\left(\mu, \frac{\sigma^{2}}{n}\right) \text { dan } \frac{n-1}{\sigma^{2}} S^{2} \sim \chi^{2}(n-1),
$$


dengan $\bar{X}$ dan $\frac{n-1}{n} S^{2}$ saling bebas. Oleh karena itu, peubah acak

$$
T=\frac{(\bar{X}-\mu)}{S / \sqrt{n}} \sim t(n-1) .
$$

${ }_{572}$ Untuk $0<\alpha<1$, definisikan bahwa $P\left(\frac{(\bar{X}-\mu)}{S / \sqrt{n}}>t_{\alpha / 2}\right)=\frac{\alpha}{2}$ sedemikian 573 sehingga

$$
\begin{aligned}
1-\alpha & =P\left(-t_{\alpha / 2}<\frac{(\bar{X}-\mu)}{S / \sqrt{n}}<t_{\alpha / 2}\right) \\
& =P\left(-\frac{S}{\sqrt{n}} t_{\alpha / 2}<\bar{X}-\mu<\frac{S}{\sqrt{n}} t_{\alpha / 2}\right) \\
& =P\left(\bar{X}-\frac{S}{\sqrt{n}} t_{\alpha / 2}<\mu<\bar{X}+\frac{S}{\sqrt{n}} t_{\alpha / 2}\right) .
\end{aligned}
$$

Jadi, selang kepercayaan $100(1-\alpha) \%$ bagi $\mu$ ialah

$$
\left(\bar{x}-\frac{s}{\sqrt{n}} t_{\alpha / 2}, \bar{x}+\frac{s}{\sqrt{n}} t_{\alpha / 2}\right)
$$

di mana

$$
\bar{x}=\frac{1}{n} \sum_{i=1}^{n} x_{i} \text { dan } s^{2}=\frac{1}{n-1} \sum_{i=1}^{n}\left(x_{i}-\bar{x}\right)^{2} .
$$

Contoh 3.21 Misalkan $X_{1}, X_{2}, \ldots, X_{n}$ adalah sampel acak dari sebaran $N\left(\mu, \sigma^{2}\right)$, dengan asumsi $\sigma^{2}$ tidak diketahui. Misalkan $\bar{X}$ dan $S^{2}$ merupakan nilai tengah dan ragam dari sampel. Tentukan selang kepercayaan $100(1-\alpha) \%$ bagi $\sigma^{2}$.

Jawab. Karena $X_{1}, X_{2}, \ldots, X_{n} \sim N\left(\mu, \sigma^{2}\right)$, maka

$$
\frac{n-1}{\sigma^{2}} S^{2} \sim \chi_{\alpha / 2}^{2}(n-1) .
$$

Untuk $0<\alpha<1$, definisikan bahwa

$$
P\left(\frac{n-1}{\sigma^{2}} S^{2}<\chi_{\alpha / 2}^{2}(n-1)\right)=\frac{\alpha}{2}
$$


579

sedemikian sehingga

$$
\begin{aligned}
1-\alpha & =P\left(\chi_{\alpha / 2}^{2}(n-1)<\frac{n-1}{\sigma^{2}} S^{2}<\chi_{1-\alpha / 2}^{2}(n-1)\right) \\
& =P\left(\frac{\chi_{\alpha / 2}^{2}(n-1)}{(n-1) S^{2}}<\frac{1}{\sigma^{2}}<\frac{\chi_{1-\alpha / 2}^{2}(n-1)}{(n-1) S^{2}}\right) \\
& =P\left(\frac{(n-1) S^{2}}{\chi_{1-\alpha / 2}^{2}(n-1)}<\sigma^{2}<\frac{(n-1) S^{2}}{\chi_{\alpha / 2}^{2}(n-1)}\right) .
\end{aligned}
$$

Jadi, selang kepercayaan $100(1-\alpha) \%$ bagi $\sigma^{2}$ ialah

$$
\left(\frac{(n-1) s^{2}}{\chi_{1-\alpha / 2}^{2}(n-1)}, \frac{(n-1) s^{2}}{\chi_{\alpha / 2}^{2}(n-1)}\right) \text {, }
$$

di mana

$$
s^{2}=\frac{1}{n-1} \sum_{i=1}^{n}\left(x_{i}-\bar{x}\right)^{2} .
$$

Contoh 3.22 Misalkan X adalah peubah acak Bernoulli dengan peluang sukses sebesar $p$ dan $X_{1}, X_{2}, \ldots, X_{n}$ adalah sampel acak dari sebaran $X$. Misalkan $\hat{p}=\bar{X}$ adalah proporsi sampel yang menyatakan sukses, dengan $\hat{p}=$ $\frac{1}{n} \sum_{i=1}^{n} X_{i}$ merupakan nilai tengah dan $\operatorname{Var}(\hat{p})=p(1-p) / n$. Tentukan selang kepercayaan bagi $p$.

Jawab. Berdasarkan Teorema Limit Pusat, sebaran dari peubah acak

$$
Z=\frac{\hat{p}-p}{\sqrt{p(1-p) / n}}
$$

mendekati sebaran $N(0,1)$. Bila $p(1-p)$ diganti dengan penduganya, yaitu $\hat{p}(1-\hat{p})$, maka

$$
\begin{aligned}
1-\alpha & =P\left(-z_{\alpha / 2}<\frac{\hat{p}-p}{\sqrt{\hat{p}(1-\hat{p}) / n}}<z_{\alpha / 2}\right) \\
& =P\left(-z_{\alpha / 2} \sqrt{\hat{p}(1-\hat{p}) / n}<\hat{p}-p<z_{\alpha / 2} \sqrt{\hat{p}(1-\hat{p}) / n}\right) \\
& =P\left(\hat{p}-z_{\alpha / 2} \sqrt{\hat{p}(1-\hat{p}) / n}<p<\hat{p}+z_{\alpha / 2} \sqrt{\hat{p}(1-\hat{p}) / n}\right)
\end{aligned}
$$

Jadi, selang kepercayaan $100(1-\alpha) \%$ bagi $\mu$ ialah

$$
\left(\bar{p}-z_{\alpha / 2} \sqrt{\bar{p}(1-\bar{p}) / n}, \bar{p}+z_{\alpha / 2} \sqrt{\bar{p}(1-\bar{p}) / n}\right),
$$




\subsubsection{Selang Kepercayaan Beda Dua Nilai Tengah}

Misalkan $X_{1}, X_{2}, \ldots, X_{m}$ adalah sampel acak dari sebaran $X$ dan $Y_{1}, Y_{2}, \ldots, Y_{n}$ adalah sampel acak dari sebaran $Y$. Asumsikan bahwa masing-masing sampel saling bebas dan ragam dari $X$ dan $Y$ berhingga, dinotasikan dengan $\sigma_{1}^{2}=$ $\operatorname{Var}(X)$ dan $\sigma_{2}^{2}=\operatorname{Var}(Y)$. Misalkan $\bar{X}=\frac{1}{m} \sum_{i=1}^{m} X_{i}$ dan $\bar{Y}=\frac{1}{n} \sum_{i=1}^{n} Y_{i}$ adalah nilai tengah sampel dari sebaran $X$ dan $Y$. Dengan demikian, $\bar{X}-\bar{Y}$ memiliki sebaran dengan

$$
E(\bar{X}-\bar{Y})=\mu_{x}-\mu_{y} \operatorname{dan} \operatorname{Var}(\bar{X}-\bar{Y})=\frac{\sigma_{1}^{2}}{m}+\frac{\sigma_{2}^{2}}{n}
$$

Berdasarkan asumsi kebebasan sampel dan Teorema Limit Pusat, peubah acak

$$
Z=\frac{(\bar{X}-\bar{Y})-\left(\mu_{x}-\mu_{y}\right)}{\sqrt{\frac{S_{1}^{2}}{m}+\frac{S_{2}^{2}}{n}}} \dot{\sim} N(0,1) .
$$

Jadi, selang kepercayaan $100(1-\alpha) \%$ bagi $\mu_{x}-\mu_{y}$ ialah

$$
\left((\bar{x}-\bar{y})-z_{\alpha / 2} \sqrt{\frac{s_{1}^{2}}{m}+\frac{s_{2}^{2}}{n}},(\bar{x}-\bar{y})+z_{\alpha / 2} \sqrt{\frac{s_{1}^{2}}{m}+\frac{s_{2}^{2}}{n}}\right)
$$

dengan

$$
\begin{aligned}
& s_{1}^{2}=\frac{1}{m-1} \sum_{i=1}^{m}\left(x_{i}-\bar{x}\right)^{2}, \\
& s_{2}^{2}=\frac{1}{n-1} \sum_{i=1}^{n}\left(y_{i}-\bar{y}\right)^{2} .
\end{aligned}
$$

Selang kepercayaan bagi beda dua nilai tengah yang dihasilkan pada persamaan 3.16 merupakan suatu pendekatan. Berikut ini akan dijelaskan hasil eksak untuk selang kepercayaan bagi beda dua nilai tengah jika diasumsikan bahwa sebaran $X$ dan $Y$ adalah normal dengan ragam yang sama, yaitu $\sigma_{1}^{2}=\sigma_{2}^{2}$. Asumsikan $X \sim N\left(\mu_{x}, \sigma^{2}\right)$ dan $Y \sim N\left(\mu_{y}, \sigma^{2}\right)$ saling bebas. Misalkan $n=n_{1}+n_{2}$ adalah total dari ukuran sampel. Misalkan pula $X_{1}, X_{2}, \ldots, X_{n_{1}}$ adalah sampel acak dari sebaran $X$ dan $Y_{1}, Y_{2}, \ldots, Y_{n_{2}}$ adalah sampel acak dari sebaran $Y$.

Penduga bagi $\mu_{x}-\mu_{y}$ adalah $\bar{X}-\bar{Y}$ dengan $E(\bar{X}-\bar{Y})=\mu_{x}-\mu_{y}$ dan $\operatorname{Var}(\bar{X}-\bar{Y})=\frac{\sigma^{2}}{n_{1}}+\frac{\sigma^{2}}{n_{2}}$. Karena $\bar{X}$ dan $\bar{Y}$ saling bebas, maka

$$
\frac{(\bar{X}-\bar{Y})-\left(\mu_{x}-\mu_{y}\right)}{\sigma \sqrt{\frac{1}{n_{1}}+\frac{1}{n_{2}}}} \sim N(0,1) .
$$


Misalkan

$$
S_{p}^{2}=\frac{\left(n_{1}-1\right) S_{1}^{2}+\left(n_{2}-1\right) S_{2}^{2}}{n_{1}+n_{2}-2} .
$$

Perhatikan bahwa $S_{p}^{2}$ merupakan penduga tak bias bagi $\sigma^{2}$. Karena

$$
\left(n_{1}-1\right) S_{1}^{2} / \sigma^{2} \sim \chi^{2}\left(n_{1}-1\right) \text { dan }\left(n_{2}-1\right) S_{2}^{2} / \sigma^{2} \sim \chi^{2}\left(n_{2}-1\right),
$$

602

\subsubsection{Selang Kepercayaan Nisbah Dua Ragam}

Misalkan $X_{1}, X_{2}, \ldots, X_{n}$ adalah sampel acak dari sebaran $X \sim N\left(\mu_{x}, \sigma_{x}^{2}\right)$, maka

$$
V=\frac{\sum_{i=1}^{n}\left(X_{i}-\bar{X}\right)^{2}}{\sigma_{x}^{2}} \sim \chi^{2}(n-1) .
$$

Misalkan pula $Y_{1}, Y_{2}, \ldots, Y_{m}$ adalah sampel acak dari sebaran $Y \sim N\left(\mu_{y}, \sigma_{y}^{2}\right)$, maka

$$
W=\frac{\sum_{i=1}^{m}\left(Y_{i}-\bar{Y}\right)^{2}}{\sigma_{y}^{2}} \sim \chi^{2}(m-1) .
$$


Karena peubah acak $V$ dan $W$ saling bebas, maka

$$
\frac{W /(m-1)}{V /(n-1)} \sim F(m-1, n-1),
$$

604

sehingga untuk $0<\alpha<1$,

$$
\begin{aligned}
1-\alpha & =P\left(F_{\alpha / 2}(m-1, n-1) \leq \frac{\sum_{i=1}^{m}\left(Y_{i}-\bar{Y}\right) / \sigma_{y}^{2}(m-1)}{\sum_{i=1}^{n}\left(X_{i}-\bar{X}\right) / \sigma_{x}^{2}(n-1)} \leq F_{1-\alpha / 2}(m-1, n-1)\right) \\
& =P\left(F_{\alpha / 2}(m-1, n-1) \leq \frac{S_{y}^{2} / \sigma_{y}^{2}}{S_{x}^{2} / \sigma_{x}^{2}} \leq F_{1-\alpha / 2}(m-1, n-1)\right) \\
& =P\left(F_{\alpha / 2}(m-1, n-1) \frac{S_{x}^{2}}{S_{y}^{2}} \leq \frac{\sigma_{x}^{2}}{\sigma_{y}^{2}} \leq F_{1-\alpha / 2}(m-1, n-1) \frac{S_{x}^{2}}{S_{y}^{2}}\right) .
\end{aligned}
$$

Jadi, selang kepercayaan $100(1-\alpha) \%$ bagi $\frac{\sigma_{x}^{2}}{\sigma_{y}^{2}}$ ialah

$$
\left(F_{\alpha / 2}(m-1, n-1) \frac{s_{x}^{2}}{s_{y}^{2}}, F_{1-\alpha / 2}(m-1, n-1) \frac{s_{x}^{2}}{s_{y}^{2}}\right)
$$

605

dengan

$$
\begin{aligned}
& s_{x}^{2}=\frac{1}{n-1} \sum_{i=1}^{n}\left(x_{i}-\bar{x}\right)^{2}, \\
& s_{y}^{2}=\frac{1}{m-1} \sum_{i=1}^{m}\left(y_{i}-\bar{y}\right)^{2} .
\end{aligned}
$$

Catatan: Misalkan

$$
Z=\frac{W /(m-1)}{V /(n-1)} \sim F(m-1, n-1)
$$

atau

$$
\frac{1}{Z}=\frac{V /(n-1)}{W /(m-1)} \sim F(n-1, m-1)
$$

maka

$$
F_{\alpha / 2}(m-1, n-1)=\frac{1}{F_{1-\alpha / 2}(n-1, m-1)} .
$$

Bukti. Karena $Z \sim F(m-1, n-1)$, maka

$$
\begin{aligned}
& P\left(Z \leq F_{\alpha / 2}(m-1, n-1)\right)=\frac{\alpha}{2} \\
\Leftrightarrow \quad & P\left(\frac{1}{Z} \geq \frac{1}{F_{\alpha / 2}(m-1, n-1)}\right)=\frac{\alpha}{2} .
\end{aligned}
$$


Karena $\frac{1}{Z} \sim F(n-1, m-1)$, maka

$$
\begin{gathered}
F_{1-\alpha / 2}(n-1, m-1)=\frac{1}{F_{\alpha / 2}(m-1, n-1)} \\
\Leftrightarrow \quad F_{\alpha / 2}(m-1, n-1)=\frac{1}{F_{1-\alpha / 2}(n-1, m-1)} .
\end{gathered}
$$

\subsection{Latihan}

1. Misalkan $X_{1}, X_{2}, \ldots, X_{n}$ adalah sampel acak dari sebaran dengan fungsi kepekatan peluang

$$
f(x ; \theta)=\frac{1}{\beta-\alpha} \mathbf{I}(\alpha<x<\beta)
$$

Tentukan penduga dari $\alpha$ dan $\beta$ dengan menggunakan metode momen.

2. Misalkan $X_{1}, X_{2}, \ldots, X_{n}$ adalah sampel acak dari sebaran dengan fungsi kepekatan peluang

$$
f(x ; \theta)=\sqrt{\frac{2}{\pi}} \exp \left[-\frac{1}{2}(x-\theta)^{2}\right] \mathbf{I}(x \geq \theta)
$$

Tentukan penduga kemungkinan maksimum bagi $\theta$.

3. Andaikan $X_{1}, X_{2}, \ldots, X_{n}$ merupakan sampel acak dari sebaran dengan fungsi kepekatan peluang

$$
f(x ; \theta)=\mathbf{I}(\theta-0.5 \leq x \leq \theta+0.5)
$$

dan $Y_{1}<Y_{2}<\ldots<Y_{n}$ merupakan statistik-statistik tataan (order statistics)-nya. Carilah penduga bagi $\theta$ dengan menggunakan:

(a) metode momen,

(b) metode kemungkinan maksimum. Jelaskan bahwa $\left(Y_{1}+Y_{n}\right) / 2$ dan $\left(4 Y_{1}+2 Y_{n}+1\right) / 6$ masing-masing merupakan penduga kemungkinan maksimum bagi $\theta$.

4. Misalkan $X_{1}, X_{2}, \ldots, X_{n}$ adalah sampel acak dari sebaran $\Gamma(2, \theta)$, di mana $\theta$ merupakan parameter yang tidak diketahui. 
(a) Carilah sebaran dari $Y$ jika $Y=\sum_{i=1}^{n} X_{i}$ dan tentukan konstanta $c$ sedemikian sehingga $c Y$ adalah penduga tak bias bagi $\theta$.

(b) Jika $n=5$, tunjukkan bahwa $P\left(9.59<\frac{2 Y}{\theta}<34.2\right)=0.95$.

5. Misalkan $X_{1}, X_{2}, \ldots, X_{n}$ adalah sampel acak dari sebaran dengan fungsi kepekatan peluang

$$
f(x ; \theta)=e^{-(x-\theta)} \mathbf{I}(x>\theta)
$$

di mana $-\infty<\theta<\infty$. Periksa apakah penduga $X_{(1)}$ dan $\bar{X}-1$ merupakan penduga tak bias bagi $\theta$ ? Di antara penduga tersebut, manakah penduga yang lebih efisien?

6. Misalkan $X_{1}, X_{2}, \ldots, X_{n}$ adalah sampel acak dari sebaran $X \sim \operatorname{Poisson}(\lambda)$ dengan $\lambda>0$. Tentukan penduga bagi $\lambda$ dan periksa apakah penduga tersebut merupakan penduga konsisten bagi $\lambda$.

7. Misalkan $X_{1}, X_{2}, \ldots, X_{n}$ adalah sampel acak dari sebaran dengan fungsi kepekatan peluang

$$
f(x ; \theta)=\theta e^{-\theta x} \mathbf{I}(x>0)
$$

di mana $\theta>0$.

(a) Tentukanlah $I(\theta)$, informasi Fisher bagi $\theta$.

(b) Berikanlah penduga takbias bagi $\theta$.

(c) Berikanlah batas bawah pertaksamaan Rao-Cramèr untuk penduga yang diperoleh dari butir b.

(d) Carilah efisiensi penduga yang diperoleh dari butir b.

8. Andaikan fungsi kepekatan peluang $f(x ; \theta)=\theta \exp (-\theta x) \mathbf{I}(x>0)$ dan $Y=\left(X_{1}+X_{2}+\ldots+X_{n}\right) / n$, maka :

(a) Tunjukkanlah bahwa $W=2 n Y / \theta$ memiliki sebaran Khi-kuadrat dengan derajat bebas $2 n$.

(b) Berikanlah selang kepercayaan $(1-\alpha)$ bagi $\theta$.

9. Misalkan $X_{1}, X_{2}, \ldots, X_{11}$ adalah sampel acak dari sebaran normal dengan nilai tengah $\mu$ (tidak diketahui) dan ragam $\sigma^{2}=9.9$. Jika $\sum_{i=1}^{11} x_{i}=$ 132, tentukanlah konstanta $k$ sedemikian sehingga $90 \%$ selang kepercayaan bagi $\mu$ ialah $[12-k \sqrt{0.9}, 12+k \sqrt{0.9}]$. 
10. Misalkan $\bar{X}$ dan $\bar{Y}$ adalah nilai tengah dari dua sampel acak yang saling bebas dari sebaran $N\left(\mu_{x}, \sigma^{2}\right)$ dan $N\left(\mu_{y}, \sigma^{2}\right)$ dengan asumsi ragam tidak diketahui. Tentukan $n$ sedemikian sehingga

$$
P\left(\bar{X}-\bar{Y}-\sigma / 5<\mu_{x}-\mu_{y}<\bar{X}-\bar{Y}+\sigma / 5\right)=0.90 .
$$




\section{BAB 4}

\section{" Kecukupan}

\section{${ }_{644} 4.1 \quad$ Statistik Cukup}

Definisi 4.1 Misalkan $X_{1}, X_{2}, \ldots, X_{n}$ adalah sampel acak dari populasi $X$ dengan fungsi kepekatan peluang atau fungsi massa peluang $f(x ; \theta), \theta \in \Omega$. Andaikan $Y=u\left(X_{1}, X_{2}, \ldots, X_{n}\right)$ merupakan statistik dengan fungsi kepekatan peluang atau fungsi massa peluang $g_{Y}(y ; \theta), \theta \in \Omega$, maka $Y$ adalah statistik cukup bagi $\theta$ jika

$$
\frac{f\left(x_{1}, \ldots, x_{n} ; \theta\right)}{g_{Y}\left(u\left(x_{1}, \ldots, x_{n}\right) ; \theta\right)}=H\left(x_{1}, \ldots, x_{n}\right)
$$

dengan $H\left(x_{1}, \ldots, x_{n}\right)$ tidak bergantung pada $\theta \in \Omega$.

Contoh 4.1 Misalkan $X_{1}, X_{2}, \ldots, X_{n}$ adalah sampel acak dari sebaran dengan $f(x ; \theta)=\theta^{x}(1-\theta)^{1-x} \mathbf{I}(x=0,1)$ di mana $0<\theta<1$. Tunjukkan bahwa $Y=\sum_{i=1}^{n} X_{i}$ adalah statistik cukup bagi $\theta$.

Jawab.

$$
\begin{aligned}
f\left(x_{1}, \ldots, x_{n} ; \theta\right) & =\prod_{i=1}^{n} \theta^{x_{i}}(1-\theta)^{1-x_{i}} \mathbf{I}\left(x_{i}=0,1\right) \\
& =\theta^{\Sigma_{i=1}^{n} x_{i}}(1-\theta)^{n-\Sigma_{i=1}^{n} x_{i}} \prod_{i=1}^{n} \mathbf{I}\left(x_{i}=0,1\right)
\end{aligned}
$$

Karena $X_{i} \sim \operatorname{Bernoulli}(\theta)$, maka $Y=\sum_{i=1}^{n} X_{i} \sim \operatorname{binomial}(n, \theta)$ sehingga

$$
g_{Y}(y ; \theta)=\left(\begin{array}{l}
n \\
y
\end{array}\right) \theta^{y}(1-\theta)^{n-y} \mathbf{I}(y=0,1, \ldots, n) .
$$


650

Sebaran bersyarat dari $X_{1}, X_{2}, \ldots, X_{n}$ untuk $Y=\sum_{i=1}^{n} X_{i}=y$ ialah

$$
\begin{aligned}
\frac{f\left(x_{1}, \ldots, x_{n} ; \theta\right)}{g_{Y}(y ; \theta)} & =\frac{\theta^{\sum_{i=1}^{n} x_{i}}(1-\theta)^{n-\Sigma_{i=1}^{n} x_{i}}}{\left(\begin{array}{c}
n \\
\sum_{i=1}^{n} x_{i}
\end{array}\right) \theta^{\sum_{i=1}^{n} x_{i}}(1-\theta)^{n-\Sigma_{i=1}^{n} x_{i}}} \\
& =\frac{1}{\left(\begin{array}{c}
n \\
\sum_{i=1}^{n} x_{i}
\end{array}\right)} \\
& =\frac{1}{\left(\begin{array}{l}
n \\
y
\end{array}\right)}
\end{aligned}
$$

Teorema 4.1 (Faktorisasi Neyman) Misalkan $X_{1}, X_{2}, \ldots, X_{n}$ adalah sampel acak dari sebaran dengan fungsi kepekatan peluang atau fungsi massa

$$
\begin{aligned}
g_{Y}(y ; \theta) & =n f(y ; \theta)[1-F(y)]^{n-1} \mathbf{I}(y>\theta) \\
& =n e^{-(y-\theta)}\left[1-\left(\int_{\theta}^{y} e^{-(x-\theta)} d x\right)\right]^{n-1} \\
& =n e^{-(y-\theta)}\left[1-\left(1-e^{-(y-\theta)}\right)\right]^{n-1} \\
& =n e^{-(y-\theta)}\left[e^{-(y-\theta)}\right]^{n-1} \\
& =n e^{-n(y-\theta)} \mathbf{I}(y>\theta) .
\end{aligned}
$$

Sebaran bersyarat dari $X_{1}, X_{2}, \ldots, X_{n}$ untuk $Y=X_{(1)}=\min \left(X_{i}\right)$ ialah

$$
\begin{aligned}
\frac{f\left(x_{1}, \ldots, x_{n} ; \theta\right)}{g_{Y}(y ; \theta)} & =\frac{\prod_{i=1}^{n} e^{-\left(x_{i}-\theta\right)}}{n e^{-n\left(\min \left(x_{i}\right)-\theta\right)}} \\
& =\frac{\exp \left(n \theta-\sum_{i=1}^{n} x_{i}\right)}{n \exp \left(-n\left(\min \left(x_{i}\right)-\theta\right)\right)} \\
& =\frac{\exp \left(-\sum_{i=1}^{n} x_{i}\right)}{n \exp \left(-n \min \left(x_{i}\right)\right)}
\end{aligned}
$$

(tidak bergantung pada parameter $\theta$ ). Jadi, $Y=X_{(1)}$ merupakan statistik cukup bagi $\theta$. 
peluang $f(x ; \theta), \theta \in \Omega$. Statistik $Y_{1}=u_{1}\left(X_{1}, X_{2}, \ldots, X_{n}\right)$ merupakan statistik cukup bagi $\theta$ jika dan hanya jika terdapat dua fungsi nonnegatif $k_{1}$ dan $k_{2}$ sehingga

$$
\prod_{i=1}^{n} f\left(x_{i} ; \theta\right)=k_{1}\left(u_{1}\left(x_{1}, x_{2}, \ldots, x_{n}\right) ; \theta\right) \cdot k_{2}\left(x_{1}, x_{2}, \ldots, x_{n}\right)
$$

dengan $k_{2}\left(x_{1}, x_{2}, \ldots, x_{n}\right)$ tidak bergantung pada $\theta$.

Bukti. $(\Rightarrow)$ Jika $Y_{1}$ adalah statistik cukup, maka

$$
\begin{aligned}
f\left(x_{1}, x_{2}, \ldots, x_{n} ; \theta\right) & =g_{Y_{1}}\left(u_{1}\left(x_{1}, x_{2}, \ldots, x_{n}\right) ; \theta\right) \cdot H\left(x_{1}, x_{2}, \ldots, x_{n}\right) \\
\prod_{i=1}^{n} f\left(x_{i} ; \theta\right) & =k_{1}\left(u\left(x_{1}, x_{2}, \ldots, x_{n}\right) ; \theta\right) \cdot k_{2}\left(x_{1}, x_{2}, \ldots, x_{n}\right) .
\end{aligned}
$$

$(\Leftarrow)$ Misalkan $X$ merupakan peubah acak kontinu. Dalam pembuktian ini, peubah $y_{1}=u_{1}\left(x_{1}, x_{2}, \ldots, x_{n}\right), y_{2}=u_{2}\left(x_{1}, x_{2}, \ldots, x_{n}\right), \ldots, y_{n}=$ $u_{n}\left(x_{1}, x_{2}, \ldots, x_{n}\right)$ ditransformasikan satu-satu. Peubah $y_{1}, y_{2}, \ldots$ dan $y_{n}$ memiliki invers $x_{1}=w_{1}\left(y_{1}, y_{2}, \ldots, y_{n}\right), x_{2}=w_{2}\left(y_{1}, y_{2}, \ldots, y_{n}\right), \ldots, x_{n}=w_{n}\left(y_{1}, y_{2}, \ldots, y_{n}\right)$ dan determinan matriks Jacobi $J$. Fungsi kepekatan peluang bagi $Y_{1}, Y_{2}, \ldots$ dan $Y_{n}$ ialah

$$
g\left(y_{1}, y_{2}, \ldots, y_{n} ; \theta\right)=k_{1}\left(y_{1} ; \theta\right) \cdot k_{2}\left(w_{1}, w_{2}, \ldots, w_{n}\right) \cdot|J|
$$

di mana $w_{i}=w_{i}\left(y_{1}, y_{2}, \ldots, y_{n}\right), i=1,2, \ldots, n$. Fungsi kepekatan peluang bagi $Y_{1}$ ialah

$$
\begin{aligned}
g_{Y_{1}}\left(y_{1} ; \theta\right) & =\int_{-\infty}^{\infty} \ldots \int_{-\infty}^{\infty} g\left(y_{1}, y_{2}, \ldots, y_{n} ; \theta\right) d y_{2} \ldots d y_{n} \\
& =k_{1}\left(y_{1} ; \theta\right) \int_{-\infty}^{\infty} \ldots \int_{-\infty}^{\infty} k_{2}\left(w_{1}, w_{2}, \ldots, w_{n}\right) \cdot|J| d y_{2} \ldots d y_{n} .
\end{aligned}
$$

Misalkan $m\left(y_{1}\right)=\int_{-\infty}^{\infty} \ldots \int_{-\infty}^{\infty} k_{2}\left(w_{1}, w_{2}, \ldots, w_{n}\right) \cdot|J| d y_{2} \ldots d y_{n}$, maka

$$
g_{Y_{1}}\left(y_{1} ; \theta\right)=k_{1}\left(y_{1} ; \theta\right) m\left(y_{1}\right) \text {. }
$$

Jika $m\left(y_{1}\right)=0$, maka $g_{Y_{1}}\left(y_{1} ; \theta\right)=0$. Jika $m\left(y_{1}\right)>0$, maka fungsi $k_{1}\left(y_{1} ; \theta\right)$ dapat dituliskan menjadi

$$
k_{1}\left(u_{1}\left(x_{1}, x_{2}, \ldots, x_{n}\right) ; \theta\right)=\frac{g_{Y_{1}}\left(u_{1}\left(x_{1}, x_{2}, \ldots, x_{n}\right) ; \theta\right)}{m\left(u_{1}\left(x_{1}, x_{2}, \ldots, x_{n}\right)\right)}
$$

dan faktorisasinya menjadi

$$
\prod_{i=1}^{n} f\left(x_{i} ; \theta\right)=g_{Y_{1}}\left(u_{1}\left(x_{1}, x_{2}, \ldots, x_{n}\right) ; \theta\right) \frac{k_{2}\left(x_{1}, x_{2}, \ldots, x_{n}\right)}{m\left(u_{1}\left(x_{1}, x_{2}, \ldots, x_{n}\right)\right)},
$$


di mana fungsi $k_{2}$ dan $m$ tidak bergantung pada $\theta$. Dengan demikian, berdasarkan definisinya dengan

$$
H\left(x_{1}, \ldots, x_{n}\right)=\frac{k_{2}\left(x_{1}, x_{2}, \ldots, x_{n}\right)}{m\left(u_{1}\left(x_{1}, x_{2}, \ldots, x_{n}\right)\right)},
$$

maka $Y_{1}$ merupakan statistik cukup bagi $\theta$.

Contoh 4.3 Misalkan $X_{1}, X_{2}, \ldots, X_{n}$ adalah sampel acak dari sebaran $N\left(\theta, \sigma^{2}\right)$, $-\infty<\theta<\infty$, di mana $\sigma^{2}>0$ diketahui. Dengan menggunakan Teorema 4.1 (Faktorisasi Neyman), tunjukkan bahwa $\bar{X}$ adalah statistik cukup bagi $\theta$.

Jawab. Jika $\bar{x}=\frac{\sum_{i=1}^{n} x_{i}}{n}$, maka

$$
\begin{aligned}
\sum_{i=1}^{n}\left(x_{i}-\theta\right)^{2} & =\sum_{i=1}^{n}\left(x_{i}-\bar{x}+\bar{x}-\theta\right)^{2} \\
& =\sum_{i=1}^{n}\left[\left(x_{i}-\bar{x}\right)^{2}+2\left(x_{i}-\bar{x}\right)(\bar{x}-\theta)+(\bar{x}-\theta)^{2}\right] \\
& =\sum_{i=1}^{n}\left(x_{i}-\bar{x}\right)^{2}+n(\bar{x}-\theta)^{2},
\end{aligned}
$$

karena $(\bar{x}-\theta) \sum_{i=1}^{n}\left(x_{i}-\bar{x}\right)=0$. Fungsi kepekatan peluang bersama bagi $X_{1}, X_{2}, \ldots, X_{n}$ ialah

$$
\begin{aligned}
f\left(x_{1}, x_{2}, \ldots, x_{n} ; \theta\right) & =\prod_{i=1}^{n} f\left(x_{i} ; \theta\right) \\
& =\left(\frac{1}{\sigma \sqrt{2 \pi}}\right)^{n} \exp \left[-\frac{\sum_{i=1}^{n}\left(x_{i}-\theta\right)^{2}}{2 \sigma^{2}}\right] \\
& =\left\{\exp \left[-\frac{n(\bar{x}-\theta)^{2}}{2 \sigma^{2}}\right]\right\} \times\left\{\frac{\exp \left[-\sum_{i=1}^{n}\left(x_{i}-\bar{x}\right)^{2} / 2 \sigma^{2}\right]}{(\sigma \sqrt{2 \pi})^{n}}\right\} \\
& =k_{1}(\bar{x} ; \theta) \times k_{2}\left(x_{1}, x_{2}, \ldots, x_{n}\right) .
\end{aligned}
$$

Karena $\prod_{i=1}^{n} f\left(x_{i} ; \theta\right)$ dapat difaktorkan menjadi $k_{1}$ dan $k_{2}$ di mana $k_{2}$ tidak bergantung pada parameter $\theta$, maka berdasarkan Teorema 4.1, $\bar{X}$ merupakan statistik cukup bagi $\theta$.

Akibat 4.1 Jika $Y$ adalah statistik cukup bagi $\theta$, maka penduga kemungkinan maksimum bagi $\theta$ adalah fungsi dari $Y$. 


$$
\begin{aligned}
E\left[\left(Y_{2}-\varphi\left(Y_{1}\right)\right)\left(\varphi\left(Y_{1}\right)-\theta\right)\right] & =\iint\left(y_{2}-\varphi\left(y_{1}\right)\right)\left(\varphi\left(y_{1}\right)-\theta\right) f\left(y_{1}, y_{2} ; \theta\right) d y_{1} d y_{2} \\
& =\iint\left(y_{2}-\varphi\left(y_{1}\right)\right)\left(\varphi\left(y_{1}\right)-\theta\right) f\left(y_{2} \mid y_{1}\right) f_{Y_{1}}\left(y_{1} ; \theta\right) d y_{1} d y_{2} \\
& =\int\left(\varphi\left(y_{1}\right)-\theta\right)\left(\int\left(y_{2}-\varphi\left(y_{1}\right)\right) f\left(y_{2} \mid y_{1}\right) d y_{2}\right) f_{Y_{1}}\left(y_{1} ; \theta\right) d y_{1} \\
& =\int\left(\varphi\left(y_{1}\right)-\theta\right)\left(\varphi\left(y_{1}\right)-\varphi\left(y_{1}\right)\right) f_{Y_{1}}\left(y_{1} ; \theta\right) d y_{1} \\
& =0
\end{aligned}
$$


689

$$
\begin{aligned}
\operatorname{Var}\left(Y_{2}\right)= & E\left(Y_{2}-\theta\right)^{2} \\
= & E\left(Y_{2}-\varphi\left(Y_{1}\right)+\varphi\left(Y_{1}\right)-\theta\right)^{2} \\
= & E\left(Y_{2}-\varphi\left(Y_{1}\right)\right)^{2}+2 E\left[\left(Y_{2}-\varphi\left(Y_{1}\right)\right)\left(\varphi\left(Y_{1}\right)-\theta\right)\right] \\
& +E\left(\varphi\left(Y_{1}\right)-\theta\right)^{2} \\
= & E\left(Y_{2}-\varphi\left(Y_{1}\right)\right)^{2}+E\left(\varphi\left(Y_{1}\right)-\theta\right)^{2} \\
= & E\left(Y_{2}-\varphi\left(Y_{1}\right)\right)^{2}+\operatorname{Var}\left(\varphi\left(Y_{1}\right)\right) .
\end{aligned}
$$

Karena $E\left(Y_{2}-\varphi\left(Y_{1}\right)\right)^{2} \geq 0$, maka persamaan 4.1 menjadi

$$
\operatorname{Var}\left(Y_{2}\right) \geq \operatorname{Var}\left(\varphi\left(Y_{1}\right)\right) \text {. }
$$

Berdasarkan Teorema 4.2, jika $Y_{1}$ adalah statistik cukup untuk suatu parameter $\theta$, maka untuk mendapatkan penduga takbias dengan ragam minimum atau Minimum Variance Unbiased Estimator (MVUE), cukup dengan mencari fungsi dari statistik $Y_{1}, \varphi\left(Y_{1}\right)$, sedemikian sehingga $E\left(\varphi\left(Y_{1}\right)\right)=\theta$.

Contoh 4.4 Misalkan $X_{1}, X_{2}, \ldots, X_{n}$ adalah sampel acak dengan $f(x ; \theta)=$ $\frac{1}{\theta} e^{-x / \theta} \mathbf{I}(x>0)$. Tentukan MVUE bagi $\theta$.

Jawab.

$$
\begin{aligned}
L(\theta) & =\prod_{i=1}^{n} f\left(x_{i}, \theta\right) \\
L(\theta) & =\theta^{-n} \exp \left[-\frac{\sum_{i=1}^{n} x_{i}}{\theta}\right] .
\end{aligned}
$$

Berdasarkan Teorema 4.1, statistik $Y_{1}=\sum_{i=1}^{n} X_{i}$ merupakan statistik cukup. Fungsi log-likelihood dari persamaan 4.2 adalah

$$
\ln L(\theta)=-n \ln \theta-\frac{1}{\theta} \sum_{i=1}^{n} x_{i},
$$

sehingga diperoleh penduga kemungkinan maksimum bagi $\theta$ adalah $\bar{X}=\frac{Y_{1}}{n}$. Karena $X_{i} \sim \Gamma(1, \theta)$, maka $Y_{1}=\sum_{i=1}^{n} x_{i} \sim \Gamma(n, \theta)$.

$$
E(\bar{X})=E\left(\frac{Y_{1}}{n}\right)=\frac{1}{n} E\left(Y_{1}\right)=\frac{1}{n} \cdot n \theta=\theta,
$$

sehingga $\bar{X}$ merupakan MVUE bagi $\theta$. 
Misalkan $\varphi\left(Y_{1}\right)=E\left(Y_{2} \mid Y_{1}\right)$ adalah penduga takbias yang memiliki ragam lebih kecil daripada penduga takbias bagi $\theta$, yaitu $Y_{2}$. Misalkan pula suatu fungsi dari suatu statistik $Y_{3}$, dinotasikan dengan $\Upsilon\left(Y_{3}\right)$ dan amatannya didefinisikan sebagai $\Upsilon\left(y_{3}\right)=E\left(\varphi\left(Y_{1}\right) \mid Y_{3}=y_{3}\right)$, di mana $Y_{3}$ bukan statistik cukup. Berdasarkan Teorema 4.2 (Rao-Blackwell), $E\left(\Upsilon\left(Y_{3}\right)\right)=\theta$ dan $\Upsilon\left(Y_{3}\right)$ memiliki ragam lebih kecil daripada $\varphi\left(Y_{1}\right)$. Oleh karena itu, seharusnya $\Upsilon\left(Y_{3}\right)$ merupakan penduga takbias yang lebih baik jika dibandingkan dengan $\varphi\left(Y_{1}\right)$. Namun, hal ini tidak benar karena $Y_{3}$ bukan statistik cukup, sehingga sebaran bersyarat dari $Y_{1}$ jika diketahui $Y_{3}=y_{3}$ dan nilai harapan bersyarat dari $Y_{3}$ masih mengandung $\theta$. Jadi, meskipun $E\left(\Upsilon\left(Y_{3}\right)\right)=\theta$, $\Upsilon\left(Y_{3}\right)$ bukanlah suatu statistik karena masih bergantung pada paramater $\theta$ yang tidak diketahui. Sebagai contoh, misalkan $X_{1}, X_{2}, X_{3}$ adalah sampel acak dari sebaran eksponensial dengan nilai harapan $\theta>0$, maka fungsi kepekatan peluang bersama dari sampel acak tersebut ialah

$$
f\left(x_{1}, x_{2}, x_{3} ; \theta\right)=\left(\frac{1}{\theta}\right)^{3} \exp \left(-\frac{x_{1}+x_{2}+x_{3}}{\theta}\right) \prod_{i=1}^{3} \mathbf{I}\left(0<x_{i}<\infty\right) .
$$

Berdasarkan Teorema 4.1, $Y_{1}=X_{1}+X_{2}+X_{3}$ merupakan statistik cukup bagi $\theta$. Nilai harapan dari $Y_{1}$ ialah

$$
E\left(Y_{1}\right)=E\left(X_{1}+X_{2}+X_{3}\right)=3 \theta,
$$

dan $Y_{1} / 3=\bar{X}$ ialah fungsi dari statistik cukup yang merupakan penduga takbias bagi $\theta$.

Misalkan $Y_{2}=X_{2}+X_{3}$ dan $Y_{3}=X_{3}$. Transformasi satu-satu $x_{1}=y_{1}-y_{2}$, $x_{2}=y_{2}-y_{3}, x_{3}=y_{3}$ memiliki determinan matriks Jacobi sama dengan

$$
\begin{aligned}
J & =\operatorname{det}\left(\frac{\partial \mathbf{x}}{\partial \mathbf{y}^{\prime}}\right) \\
& =\left|\begin{array}{rrr}
1 & -1 & 0 \\
0 & 1 & -1 \\
0 & 0 & 1
\end{array}\right| \\
& =1
\end{aligned}
$$

dan fungsi kepekatan peluang bersama bagi $Y_{1}, Y_{2}$, dan $Y_{3}$ ialah

$$
g\left(y_{1}, y_{2}, y_{3} ; \theta\right)=\left(\frac{1}{\theta}\right)^{3} \exp \left(-\frac{y_{1}}{\theta}\right) \mathbf{I}\left(0<y_{3}<y_{2}<y_{1}<\infty\right) .
$$


703

706

Fungsi kepekatan peluang marginal bagi $Y_{1}$ dan $Y_{3}$ ialah

$$
\begin{aligned}
g_{13}\left(y_{1}, y_{3} ; \theta\right) & =\int_{y_{3}}^{y_{1}}\left(\frac{1}{\theta}\right)^{3} \exp \left(-\frac{y_{1}}{\theta}\right) d y_{2} \\
& =\left(\frac{1}{\theta}\right)^{3}\left(y_{1}-y_{3}\right) \exp \left(-\frac{y_{1}}{\theta}\right) \mathbf{I}\left(0<y_{3}<y_{1}<\infty\right) .
\end{aligned}
$$

Karena $Y_{3}=X_{3}$, maka fungsi kepekatan peluang bagi $Y_{3}$ ialah

$$
g_{3}\left(y_{3} ; \theta\right)=\frac{1}{\theta} \exp \left(-\frac{y_{3}}{\theta}\right) \mathbf{I}\left(0<y_{3}<\infty\right),
$$

sehingga fungsi kepekatan peluang bersyarat bagi $Y_{1}$ jika diketahui $Y_{3}=y_{3}$ ialah

$$
\begin{aligned}
g_{1 \mid 3}\left(y_{1} \mid y_{3}\right) & =\frac{g_{13}\left(y_{1}, y_{3} ; \theta\right)}{g_{3}\left(y_{3} ; \theta\right)} \\
& =\left(\frac{1}{\theta}\right)^{2}\left(y_{1}-y_{3}\right) \exp \left(-\frac{1}{\theta}\left(y_{1}-y_{3}\right)\right) \mathbf{I}\left(0<y_{3}<y_{1}<\infty\right) .
\end{aligned}
$$

$$
\begin{aligned}
E\left(\frac{Y_{1}}{3} \mid y_{3}\right) & =E\left(\frac{Y_{1}-Y_{3}}{3} \mid y_{3}\right)+E\left(\frac{Y_{3}}{3} \mid y_{3}\right) \\
& =\frac{1}{3} \int_{y_{3}}^{\infty}\left(\frac{1}{\theta}\right)^{2}\left(y_{1}-y_{3}\right)^{2} \exp \left(-\frac{1}{\theta}\left(y_{1}-y_{3}\right)\right) d y_{1}+\frac{y_{3}}{3} \\
& =\frac{1}{3} \frac{\Gamma(3) \theta^{3}}{\theta^{2}}+\frac{y_{3}}{3} \\
& =\frac{2 \theta}{3}+\frac{y_{3}}{3} \\
& =\Upsilon\left(y_{3}\right) .
\end{aligned}
$$

Jelas bahwa $E\left(\Upsilon\left(Y_{3}\right)\right)=\theta$ dan $\operatorname{Var}\left(\Upsilon\left(Y_{3}\right)\right) \leq \operatorname{Var}\left(Y_{1} / 3\right)$, tetapi $\Upsilon\left(Y_{3}\right)$ bukan statistik karena bergantung pada parameter $\theta$ dan tidak dapat digunakan sebagai penduga bagi $\theta$.

\subsection{Kelengkapan dan Kekhasan}

Definisi 4.2 Misalkan $Z$ adalah peubah acak dengan fungsi kepekatan atau fungsi massa peluang $h(z ; \theta), \theta \in \Omega$. Jika $E(u(Z))=0, \forall \theta \in \Omega$ memerlukan $u(Z)=0$ kecuali pada himpunan berpeluang nol untuk setiap $h(z ; \theta), \theta \in \Omega$, maka famili $\{h(z ; \theta): \theta \in \Omega\}$ disebut famili lengkap dari fungsi kepekatan atau fungsi massa peluang. 
Berikut merupakan beberapa contoh famili lengkap dan famili tak lengkap.

Contoh 4.5 Misalkan $X_{1}, X_{2}, \ldots, X_{n}$ adalah sampel acak dari sebaran Poisson dengan parameter $\theta>0$. Tunjukkan bahwa $Y_{1}=\sum_{i=1}^{n} X_{i}$ adalah statistik cukup bagi $\theta$ dan himpunan fungsi massa peluang bagi $Y_{1}$ merupakan famili lengkap.

Jawab. Karena $X_{i} \sim$ Poisson $(\theta)$, maka

$$
\begin{aligned}
\prod_{i=1}^{n} f\left(x_{i} ; \theta\right) & =\prod_{i=1}^{n} \frac{\theta^{x_{i}} e^{-\theta}}{x_{i} !} \mathbf{I}\left(x_{i}=0,1,2, \ldots\right) \\
& =\frac{\theta^{\Sigma x_{i}} e^{-n \theta}}{\prod_{i=1}^{n}\left(x_{i} !\right)} \prod_{i=1}^{n} \mathbf{I}\left(x_{i}=0,1,2, \ldots\right) \\
& =\theta^{\Sigma x_{i}} e^{-n \theta} \times \frac{1}{\prod_{i=1}^{n}\left(x_{i} !\right)} \\
& =k_{1}\left(y_{1} ; \theta\right) \times k_{2}\left(x_{1}, x_{2}, \ldots, x_{n}\right)
\end{aligned}
$$

Berdasarkan Teorema 4.1, $Y_{1}=\sum_{i=1}^{n} X_{i}$ merupakan statistik cukup bagi $\theta$.

Kemudian, fungsi massa peluang bagi $Y_{1}$ ialah

$$
g\left(y_{1} ; \theta\right)=\frac{(n \theta)^{y_{1}} e^{-n \theta}}{y_{1} !} \mathbf{I}\left(y_{1}=0,1,2, \ldots\right) .
$$

Misalkan $\left\{g\left(y_{1} ; \theta\right): \theta>0\right\}$ merupakan famili dari fungsi massa peluang. Misalkan pula $u\left(Y_{1}\right)$ adalah fungsi dari $Y_{1}$ sedemikian sehingga $E\left(u\left(Y_{1}\right)\right)=$ 0 . Akan ditunjukkan bahwa bila $E\left(u\left(Y_{1}\right)\right)=0$ memerlukan $u\left(Y_{1}\right)=0$ kecuali pada himpunan berpeluang nol untuk setiap $g\left(y_{1} ; \theta\right), \theta>0$.

$$
\begin{gathered}
E\left(u\left(Y_{1}\right)\right)=0 \\
\sum_{y_{1}=0}^{\infty} u\left(y_{1}\right) \frac{(n \theta)^{y_{1}} e^{-n \theta}}{y_{1} !}=0 \\
e^{-n \theta}\left[u(0)+u(1) \frac{n \theta}{1 !}+u(2) \frac{(n \theta)^{2}}{2 !}+\cdots\right]=0 .
\end{gathered}
$$

Karena $e^{-n \theta} \neq 0$, maka

$$
u(0)+[n u(1)] \theta+\left[\frac{n^{2} u(2)}{2}\right] \theta^{2}+\cdots=0 .
$$


Catatan: Jika suatu deret (pangkat) takhingga konvergen ke nol untuk setiap $\theta>0$, maka setiap koefisiennya sama dengan nol.

Dengan demikian,

$$
u(0)=0, n u(1)=0, \frac{n^{2} u(2)}{2}=0, \cdots .
$$

Artinya, $u(0)=u(1)=u(2)=\cdots=0$. Jadi, $\left\{g\left(y_{1} ; \theta\right): \theta>0\right\}$ merupakan famili lengkap.

Contoh 4.6 Misalkan $Z$ adalah peubah acak dari famili $\{h(z ; \theta): \theta \in \Omega\}$ di mana

$$
h(z ; \theta)=\frac{1}{\theta} e^{-z / \theta} \mathbf{I}(0<z<\infty) .
$$

Tunjukkan bahwa famili $\{h(z ; \theta): \theta \in \Omega\}$ merupakan famili lengkap.

Jawab. Misalkan pula $u(Z)$ adalah fungsi dari peubah acak $Z$ sedemikian sehingga $E(u(Z))=0$, yaitu

$$
\frac{1}{\theta} \int_{0}^{\infty} u(z) e^{-z / \theta} d z=0, \theta>0 .
$$

Catatan: Misalkan $£$ merupakan operator transformasi Laplace. Bila $£ f=$ $£ g$, maka $f=g$ pada titik-titik kekontinuannya. Dengan kata lain,

$$
\int_{0}^{\infty} f(t) e^{-s t} d t=\int_{0}^{\infty} g(t) e^{-s t} d t \Rightarrow f(t)=g(t) .
$$

Karena ruas kiri pada persamaan 4.3 merupakan transformasi Laplace bagi fungsi $u(z)$, maka $u(z)=0$ pada titik-titik kekontinuannya. Jadi,

$$
\{h(z ; \theta): \theta \in \Omega\}
$$

merupakan famili lengkap.

Contoh 4.7 Tunjukkan bahwa famili yang anggotanya sebagai berikut bukan merupakan famili lengkap.

a. $f(x ; \theta)=\frac{1}{2 \theta} \mathbf{I}(|x|=1,2, \ldots, \theta), \theta \in \mathbb{N}$.

b. $f(x ; \theta)=\frac{1}{2 \theta} \mathbf{I}(|x|<\theta)$.

Jawab. 
a. Karena peubah acak $X$ memiliki fungsi massa peluang

$$
f(x ; \theta)=\frac{1}{2 \theta} \mathbf{I}(|x|=1,2, \ldots, \theta), \theta \in \mathbb{N},
$$

maka

$$
\begin{aligned}
E(X) & =\sum_{x=-\theta}^{\theta} x f(x ; \theta) \\
& =\sum_{x=-\theta}^{\theta} x\left(\frac{1}{2 \theta}\right) \\
& =0,
\end{aligned}
$$

tetapi tidak mengharuskan $X=0$ sehingga $f(x ; \theta)$ bukan anggota famili lengkap.

b. Karena peubah acak $X$ memiliki fungsi kepekatan peluang

$$
f(x ; \theta)=\frac{1}{2 \theta} \mathbf{I}(|x|<\theta)
$$

maka

$$
\begin{aligned}
E(X) & =\int_{-\theta}^{\theta} x f(x ; \theta) d x \\
& =\int_{-\theta}^{\theta} x\left(\frac{1}{2 \theta}\right) d x \\
& =0,
\end{aligned}
$$

tetapi tidak mengharuskan $X=0$ sehingga $f(x ; \theta)$ bukan anggota famili lengkap.

Misalkan $X_{1}, X_{2}, \ldots, X_{n}$ adalah sampel acak dengan fungsi kepekatan atau fungsi massa peluang $f(x ; \theta)$ dan $Y_{1}=u\left(X_{1}, X_{2}, \ldots, X_{n}\right)$ adalah statistik cukup bagi $\theta$. Misalkan pula $\varphi\left(Y_{1}\right)$ dan $\psi\left(Y_{1}\right)$ masing-masing adalah fungsi dari statistik cukup $Y_{1}$ (tidak bergantung pada $\theta$ ) sedemikian sehingga $E\left(\varphi\left(Y_{1}\right)\right)=\theta$ dan $E\left(\psi\left(Y_{1}\right)\right)=\theta, \forall \theta \in \Omega$. Nilai harapan dari selisih kedua fungsi tersebut ialah

$$
E\left(\varphi\left(Y_{1}\right)-\psi\left(Y_{1}\right)\right)=0, \theta \in \Omega
$$


Jika famili $\left\{f_{Y_{1}}\left(y_{1} ; \theta\right): \theta \in \Omega\right\}$ merupakan famili lengkap, maka $\varphi\left(y_{1}\right)-$ $\psi\left(y_{1}\right)=0$ kecuali pada himpunan yang berpeluang nol. Dengan kata lain, untuk setiap penduga takbias $\psi\left(Y_{1}\right)$ bagi $\theta$,

$$
\varphi\left(y_{1}\right)=\psi\left(y_{1}\right)
$$

kecuali pada himpunan yang berpeluang nol. Dengan demikian, $\varphi\left(Y_{1}\right)$ merupakan fungsi dari statistik cukup $Y_{1}$ yang khas dan memiliki ragam minimum jika dibandingkan dengan penduga takbias lainnya (Teorema 4.2). Hal tersebut dinyatakan dalam teorema berikut.

Teorema 4.3 (Lehmann dan Scheffé) Misalkan $X_{1}, X_{2}, \ldots, X_{n}$ adalah sampel acak dengan fungsi kepekatan atau fungsi massa peluang $f(x ; \theta)$. Misalkan pula $Y_{1}=u\left(X_{1}, X_{2}, \ldots, X_{n}\right)$ adalah statistik cukup bagi $\theta$ dan famili $\left\{f_{Y_{1}}\left(y_{1} ; \theta\right): \theta \in \Omega\right\}$ merupakan famili lengkap. Jika terdapat fungsi $Y_{1}$ yang merupakan penduga takbias bagi $\theta$, maka fungsi $Y_{1}$ merupakan penduga takbias dengan ragam minimum yang khas atau Unique Minimum Variance Unbiased Estimator (UMVUE).

\subsection{Kelas Eksponen}

Definisi 4.3 Suatu fungsi kepekatan atau fungsi massa peluang

$$
f(x ; \theta)=\exp [p(\theta) K(x)+S(x)+q(\theta)] \mathbf{I}(x \in W), \gamma<\theta<\delta
$$

disebut sebagai anggota kelas eksponen biasa fungsi kepekatan peluang kontinu atau fungsi massa peluang diskret jika

1. $W$ tak bergantung pada parameter $\theta$.

2. $p(\theta)$ fungsi kontinu nontrivial dari $\theta$.

3. a. Jika $X$ peubah acak kontinu, maka setiap $K^{\prime}(x) \neq 0$ dan $S(x)$ fungsi kontinu dari $x, x \in W$.

b. Jika $X$ peubah acak diskret, maka $K(x)$ adalah fungsi nontrivial dari $x \in W$.

Contoh 4.8 Misalkan $X \sim N(0, \theta)$. Apakah anggota dari famili

$$
\{f(x ; \theta): 0<\theta<\infty\}
$$

merupakan anggota kelas eksponen biasa fungsi kepekatan peluang kontinu? 
764

Jawab.

$$
\begin{aligned}
f(x ; \theta) & =\frac{1}{\sqrt{2 \pi \theta}} e^{-x^{2} / 2 \theta} \\
& =\exp [\ln f(x ; \theta)] \\
& =\exp \left[-\frac{1}{2 \theta} x^{2}-\ln \sqrt{2 \pi \theta}\right] \mathbf{I}(-\infty<x<\infty) .
\end{aligned}
$$

Berdasarkan persamaan $4.5, W=(-\infty, \infty)$ tidak bergantung pada parameter $\theta$,

$$
\begin{gathered}
f(x ; \theta)=\exp [p(\theta) K(x)+S(x)+q(\theta)] \\
=\exp \left[-\frac{1}{2 \theta} x^{2}-\ln \sqrt{2 \pi \theta}\right] \\
p(\theta)=-\frac{1}{2 \theta}, K(x)=x^{2}, S(x)=0, q(\theta)=-\ln \sqrt{2 \pi \theta},
\end{gathered}
$$

$K^{\prime}(x)=2 x \neq 0$ dan $S(x)$ merupakan fungsi kontinu pada $x \in(-\infty, \infty)$. Jadi, $N(0, \theta)$ anggota kelas eksponen biasa fungsi kepekatan peluang kontinu. 幽

Contoh 4.9 Misalkan $X \sim$ Poisson $(\theta)$. Apakah anggota dari famili

$$
\{f(x ; \theta): 0<\theta<\infty\}
$$

merupakan anggota kelas eksponen biasa fungsi massa peluang diskret?

\section{Jawab.}

$$
\begin{aligned}
f(x ; \theta) & =e^{-\theta} \frac{\theta^{x}}{x !} \mathbf{I}(x=0,1,2, \ldots) \\
& =\exp [\ln f(x ; \theta)] \mathbf{I}(x=0,1,2, \ldots) \\
& =\exp \left[(\ln \theta) x+\ln \left(\frac{1}{x !}\right)-\theta\right] \mathbf{I}(x=0,1,2, \ldots)
\end{aligned}
$$

Berdasarkan persamaan $4.6, W=\{0,1,2, \ldots\}$ tidak bergantung pada parameter $\theta$,

$$
\begin{aligned}
f(x ; \theta) & =\exp [p(\theta) K(x)+S(x)+q(\theta)] \\
& =\exp \left[(\ln \theta) x+\ln \left(\frac{1}{x !}\right)-\theta\right] \mathbf{I}(x=0,1,2, \ldots) \\
p(\theta)= & \ln \theta, K(x)=x, S(x)=\ln \left(\frac{1}{x !}\right), q(\theta)=-\theta
\end{aligned}
$$


dan $K(x)=x$ merupakan fungsi nontrivial dari $x \in W$. Jadi,

$$
f(x ; \theta)=e^{-\theta} \frac{\theta^{x}}{x !} \mathbf{I}(x=0,1,2, \ldots)
$$

anggota kelas eksponen biasa fungsi massa peluang diskret.

Misalkan $X \sim \operatorname{seragam}(0, \theta)$, maka $f(x ; \theta)=\frac{1}{\theta} \mathbf{I}(0<x<\theta)$ juga dapat dituliskan seperti persamaan 4.6. Namun, perhatikan bahwa interval $(0, \theta)$ bergantung pada parameter $\theta$ sehingga fungsi kepekatan peluang sebaran seragam $(0, \theta)$ bukan anggota kelas eksponen biasa fungsi kepekatan peluang kontinu.

Misalkan $X_{1}, X_{2}, \ldots, X_{n}$ adalah sampel acak dari sebaran yang merupakan anggota kelas eksponen biasa. Fungsi kepekatan atau fungsi massa peluang bersama dari $X_{1}, X_{2}, \ldots, X_{n}$ ialah

$$
\begin{aligned}
\prod_{i=1}^{n} f\left(x_{i} ; \theta\right) & =\prod_{i=1}^{n} \exp \left[\ln f\left(x_{i} ; \theta\right)\right] \\
& =\exp \left[p(\theta) \sum_{i=1}^{n} K\left(x_{i}\right)+\sum_{i=1}^{n} S\left(x_{i}\right)+n q(\theta)\right] \\
& =\exp \left[p(\theta) \sum_{i=1}^{n} K\left(x_{i}\right)+n q(\theta)\right] \exp \left[\sum_{i=1}^{n} S\left(x_{i}\right)\right] \prod_{i=1}^{n} \mathbf{I}\left(x_{i} \in W\right) .
\end{aligned}
$$

Berdasarkan Teorema 4.1, $Y_{1}=\sum_{i=1}^{n} K\left(x_{i}\right)$ merupakan statistik cukup bagi parameter $\theta$. Selanjutnya, teorema berikut ini menyatakan kelengkapan dari statistik cukup $Y_{1}$ tersebut.

Teorema 4.4 Misalkan $f(x ; \theta), \gamma<\theta<\delta$, adalah fungsi kepekatan atau fungsi massa peluang dari peubah acak $X$ yang merupakan anggota kelas eksponen biasa. Jika $X_{1}, X_{2}, \ldots, X_{n}$ adalah contoh acak dari sebaran $X$, maka

$$
Y_{1}=\sum_{i=1}^{n} K\left(x_{i}\right)
$$

merupakan statistik cukup bagi $\theta$ dan famili $\left\{f_{Y_{1}}\left(y_{1} ; \theta\right): \gamma<\theta<\delta\right\}$ dari fungsi kepekatan atau fungsi massa peluang $Y_{1}$ adalah famili lengkap. Dengan kata lain, $Y_{1}$ adalah statistik cukup lengkap.

Contoh 4.10 Misalkan $X_{1}, X_{2}, \ldots, X_{n}$ adalah sampel acak dari sebaran normal $N\left(\theta, \sigma^{2}\right),-\infty<\theta<\infty, \sigma^{2}>0$. Tunjukkan bahwa $Y_{1}=\sum_{i=1}^{n} X_{i}$ merupakan statistik cukup lengkap dan $Y_{1} / n$ merupakan UMVUE bagi $\theta$. 
Jawab. Karena $X \sim N\left(\theta, \sigma^{2}\right)$, maka fungsi kepekatan peluangnya ialah

$$
f(x ; \theta)=\frac{1}{\sigma \sqrt{2 \pi}} \exp \left[-\frac{(x-\theta)^{2}}{2 \sigma^{2}}\right] \mathbf{I}(-\infty<x<\infty)
$$

atau

$$
f(x ; \theta)=\exp \left[\frac{\theta}{\sigma^{2}} x-\frac{x^{2}}{2 \sigma^{2}}-\ln \sqrt{2 \pi \sigma^{2}}-\frac{\theta^{2}}{2 \sigma^{2}}\right] \mathbf{I}(-\infty<x<\infty),
$$

sehingga

$$
p(\theta)=\frac{\theta}{\sigma^{2}}, K(x)=x, S(x)=-\frac{x^{2}}{2 \sigma^{2}}-\ln \sqrt{2 \pi \sigma^{2}}, q(\theta)=-\frac{\theta^{2}}{2 \sigma^{2}} .
$$

Berdasarkan Teorema 4.4, $Y_{1}=\sum_{i=1}^{n} X_{i}$ merupakan statistik cukup lengkap. Karena $E\left(Y_{1}\right)=n \theta$, maka $\varphi\left(Y_{1}\right)=Y_{1} / n=\bar{X}$ adalah penduga takbias khas bagi $\theta$ dan fungsi dari statistik cukup $Y_{1}$ yang memiliki ragam minimum. Dengan demikian, $\bar{X}$ merupakan UMVUE bagi $\theta$.

Contoh 4.11 Misalkan $X_{1}, X_{2}, \ldots, X_{n}$ adalah sampel acak dari sebaran binomial dengan parameter $(1, \theta), 0<\theta<1$. Tentukan UMVUE bagi $\theta$ dan UMVUE bagi $\operatorname{Var}(\bar{X})$.

Jawab.

$$
\begin{aligned}
& f(x ; \theta)=\theta^{x}(1-\theta)^{1-x} \mathbf{I}(x=0,1) \\
&=\left(\frac{\theta}{1-\theta}\right)^{x}(1-\theta) \mathbf{I}(x=0,1) \\
&=\exp \left[x \ln \frac{\theta}{1-\theta}+\ln (1-\theta)\right] \mathbf{I}(x=0,1) \\
& p(\theta)=\ln \frac{\theta}{1-\theta}, K(x)=x, S(x)=0, q(\theta)=\ln (1-\theta) .
\end{aligned}
$$

Karena $K(x)=x$ adalah fungsi nontrivial dari $x \in\{0,1\}$, maka $b(1, \theta)$ anggota kelas eksponen biasa fungsi massa peluang diskret. Dengan demikian, $Y=\sum_{i=1}^{n} X_{i}$ merupakan statistik cukup lengkap bagi $\theta$ dan $Y \sim b(n, \theta)$, sehingga nilai harapan dan ragam dari $Y$ ialah

$$
\begin{aligned}
E(Y) & =n \theta \text { dan } \operatorname{Var}(Y)=n \theta(1-\theta), \\
E\left(\frac{Y}{n}\right) & =\theta \text { dan } \operatorname{Var}\left(\frac{Y}{n}\right)=\frac{\theta}{n}(1-\theta) .
\end{aligned}
$$


di mana c adalah suatu konstanta.

Jawab. Misalkan $u\left(X_{1}\right)$ adalah fungsi dari $X_{1}$. Kemudian, hitung nilai harapan bersyarat dari statistik takbias jika diketahui statistik cukup $\bar{X}$, yaitu

$$
E\left(u\left(X_{1}\right) \mid \bar{X}=\bar{x}\right)=\varphi(\bar{x}) .
$$


811 812

Dengan pemisalan peubah $z=\sqrt{n}\left(x_{1}-\bar{x}\right) / \sqrt{n-1}$, maka nilai harapan bersyarat tersebut menjadi

$$
\varphi(\bar{x})=\int_{-\infty}^{c^{\prime}} \frac{1}{\sqrt{2 \pi}} e^{-z^{2} / 2} d z=\Phi\left(c^{\prime}\right)
$$

di mana $c^{\prime}=\sqrt{n}(c-\bar{x}) / \sqrt{n-1}$. Dengan demikian, UMVUE bagi $\Phi(c-\theta)$ untuk setiap konstanta $c$ ialah

$$
\varphi(\bar{X})=\Phi\left(\frac{\sqrt{n}(c-\bar{X})}{\sqrt{n-1}}\right)
$$
Selanjutnya akan ditentukan fungsi kepekatan peluang bersama bagi $X_{1}$ dan $\bar{X}$ serta fungsi kepekatan peluang bersyarat dari $X_{1}$ jika diketahui $\bar{X}$. Dari fungsi kepekatan peluang bersyarat tersebut, dapat ditentukan nilai harapan bersyarat $E\left(u\left(X_{1}\right) \mid \bar{X}=\bar{x}\right)=\varphi(\bar{x})$. Fungsi kepekatan peluang bersama bagi $X_{1}$ dan $\bar{X}$ adalah normal bivariat dengan vektor nilai harapan $(\theta, \theta)$ dan ragam $\sigma_{1}^{2}=1, \sigma_{2}^{2}=1 / n$, serta koefisien korelasi $\rho=1 / \sqrt{n}$, sehingga fungsi kepekatan peluang bersyarat dari $X_{1}$ jika diketahui $\bar{X}=\bar{x}$ adalah normal dengan nilai harapan

$$
\theta+\frac{\rho \sigma_{1}}{\sigma_{2}}(\bar{x}-\theta)=\bar{x}
$$

dan ragam

$$
\sigma_{1}^{2}\left(1-\rho^{2}\right)=\frac{n-1}{n} .
$$

Jadi, nilai harapan bersyarat dari $u\left(X_{1}\right)$ jika diketahui statistik cukup $\bar{X}=\bar{x}$

$$
\begin{aligned}
\varphi(\bar{x}) & =\int_{-\infty}^{\infty} u\left(x_{1}\right) \sqrt{\frac{n-1}{n}} \frac{1}{\sqrt{2 \pi}} \exp \left[-\frac{n\left(x_{1}-\bar{x}\right)}{2(n-1)}\right] d x_{1} \\
& =\int_{-\infty}^{c} \sqrt{\frac{n-1}{n}} \frac{1}{\sqrt{2 \pi}} \exp \left[-\frac{n\left(x_{1}-\bar{x}\right)}{2(n-1)}\right] d x_{1} .
\end{aligned}
$$




\subsection{Latihan}

1. Misalkan $X_{1}, X_{2}, \ldots, X_{n}$ adalah sampel acak dari sebaran dengan fungsi kepekatan peluang

$$
f(x ; \theta)=\frac{\theta}{(1+x)^{\theta+1}} \mathbf{I}(x \geq 0), \theta>0 .
$$

Tentukan statistik cukup bagi parameter $\theta$.

2. Misalkan $X_{1}, X_{2}, \ldots, X_{n}$ adalah sampel acak dari sebaran dengan fungsi kepekatan peluang $f(x ; \theta)=\theta e^{-\theta x} \mathbf{I}(x>0), \theta>0 . Y=\sum_{i=1}^{n} X_{i}$ merupakan statistik cukup bagi $\theta$. Tunjukkan bahwa $(n-1) / Y$ adalah MVUE bagi $\theta$.

3. Misalkan $\{h(x ; \theta): \theta \in \Omega\}$ merupakan famili dari fungsi kepekatan peluang, di mana $h(x ; \theta)=\frac{1}{\theta} \mathbf{I}(x>0)$. Tunjukkan bahwa famili tersebut tidak lengkap jika $\Omega=\{\theta: \theta>1\}$.

4. Misalkan $X_{1}, X_{2}, \ldots, X_{n}$ adalah sampel acak dari sebaran dengan fungsi kepekatan peluang $f(x ; \theta)=\theta^{2} x e^{-\theta x} \mathbf{I}(0<x<\infty), \theta>0$.

(a) Tunjukkan bahwa $Y=\sum_{i=1}^{n} X_{i}$ merupakan statistik cukup lengkap bagi $\theta$.

(b) Hitung $E(1 / Y)$ dan carilah fungsi dari $Y$ yang merupakan UMVUE bagi $\theta$.

5. Andaikan peubah acak $X$ dengan fungsi kepekatan peluang $f(x ; \theta)=$ $B(\theta) h(x) \exp [Q(\theta) R(x)] \mathbf{I}(a<x<b)$ merupakan anggota kelas eksponen biasa. Tunjukkanlah bahwa

$$
E[R(X)]=-B^{\prime}(\theta) /\left[\left(B(\theta) Q^{\prime}(\theta)\right] .\right.
$$




\section{BA 5}

\section{« Pendugaan Bayes}

\subsection{Prinsip Minimax}

Misalkan $X_{1}, X_{2}, \ldots, X_{n}$ merupakan sampel acak dari sebaran yang memiliki fungsi kepekatan atau fungsi massa peluang $f(x ; \theta), \theta \in \Omega$. Misalkan pula $Y=U\left(X_{1}, X_{2}, \ldots, X_{n}\right)$ merupakan statistik yang digunakan untuk menduga parameter $\theta$ dan $\delta(y)$ merupakan fungsi nilai amatan dari statistik $Y$ yang menjadi dugaan titik bagi parameter $\theta$. Fungsi $\delta$ disebut juga sebagai fungsi keputusan. Suatu nilai dari fungsi keputusan, sebut saja $\delta(y)$, disebut sebagai putusan. Putusan tersebut dapat benar atau salah. Hal tersebut dapat menjadi ukuran dari perbedaan, jika ada, antara nilai sebenarnya dari $\theta$ dengan dugaan titik $\delta(y)$. Oleh karena itu, definisikan $£[\theta, \delta(y)]$ sebagai fungsi kehilangan (loss function). Nilai harapan dari fungsi kehilangan disebut sebagai fungsi risiko (risk function), dinotasikan dengan $R(\theta, \delta)$. Jika $Y$ merupakan peubah acak kontinu dengan $f_{Y}(y ; \theta), \theta \in \Omega$, merupakan fungsi kepekatan peluang dari $Y$, maka fungsi risiko dapat dihitung sebagai berikut

$$
R(\theta, \delta)=E(£[\theta, \delta(Y)])=\int_{-\infty}^{\infty} £[\theta, \delta(y)] f_{Y}(y ; \theta) d y
$$

Contoh 5.1 Misalkan $X_{1}, X_{2}, \ldots, X_{25}$ merupakan sampel acak dari sebaran $N(\theta, 1),-\infty<\theta<\infty$. Misalkan $Y=\bar{X}$, nilai tengah dari sampel acak, dan misalkan $£[\theta, \delta(y)]=[\theta-\delta(y)]^{2}$. Bandingkanlah dua fungsi keputusan berikut:

$$
\text { - } \delta_{1}(y)=y \text {, }
$$$$
\text { - } \delta_{2}(y)=0 \text {. }
$$ 
Jawab. Fungsi risiko untuk masing-masing $\delta_{1}(y)$ dan $\delta_{2}(y)$ ialah

$$
\begin{aligned}
& R\left(\theta, \delta_{1}\right)=E\left((\theta-Y)^{2}\right)=\frac{1}{25} \\
& R\left(\theta, \delta_{2}\right)=E\left((\theta-0)^{2}\right)=\theta^{2} .
\end{aligned}
$$

Jelas bahwa jika pada kenyataannya $\theta=0$, maka $\delta_{2}(y)=0$ adalah keputusan yang tepat dan $R\left(0, \delta_{2}\right)=0$. Tetapi, jika $\theta \neq 0$, maka $\delta_{2}(y)=0$ adalah keputusan yang kurang tepat. Sebagai contoh, misalkan pada kenyataannya $\theta=2$, maka $R\left(2, \delta_{2}\right)=4>R\left(2, \delta_{1}\right)=\frac{1}{25}$. Secara umum, $R\left(\theta, \delta_{2}\right)<$ $R\left(\theta, \delta_{1}\right)$ jika $-\frac{1}{5}<\theta<\frac{1}{5}$ dan untuk $\theta$ selainnya $R\left(\theta, \delta_{2}\right) \geq R\left(\theta, \delta_{1}\right)$. Dengan demikian, kadang kala suatu fungsi keputusan lebih baik daripada fungsi keputusan lainnya untuk beberapa nilai $\theta$ dan fungsi keputusan lainnya lebih baik untuk nilai $\theta$ lainnya, sehingga jika kita membatasi fungsi keputusan $\delta$, seperti $E(\delta(Y))=\theta$ untuk setiap nilai $\theta, \theta \in \Omega$, maka $\delta_{2}(y)=0$ tidak termasuk ke dalam pertimbangan sebagai fungsi keputusan. Berdasarkan hal tersebut, fungsi risiko merupakan ragam dari penduga takbias $\delta(Y)$.

Misalkan kita tidak ingin membatasi sendiri fungsi keputusan $\delta$, seperti $E(\delta(Y))=\theta$ untuk setiap nilai $\theta, \theta \in \Omega$. Misalkan kita katakan bahwa fungsi keputusan yang meminimumkan fungsi risiko yang maksimum merupakan fungsi keputusan terbaik. Karena pada contoh ini $R\left(\theta, \delta_{2}\right)=\theta^{2}$ tak terbatas, maka berdasarkan kriteria tersebut, $\delta_{2}(y)=0$ bukanlah fungsi keputusan terbaik. Dengan demikian, kita peroleh

$$
\max _{\theta} R\left(\theta, \delta_{1}\right)=\max _{\theta}\left(\frac{1}{25}\right)=\frac{1}{25} .
$$

Oleh karena itu, $\delta_{1}(y)=y=\bar{x}$ merupakan fungsi keputusan terbaik berdasarkan kriteria minimax karena $\frac{1}{25}$ nilainya terkecil.

Berdasarkan Contoh 5.1, dapat disimpulkan bahwa

- tanpa pemberian batasan pada fungsi keputusan, sulit untuk mencari fungsi keputusan yang memiliki fungsi risiko yang secara umum lebih kecil daripada fungsi risiko dari putusan yang lain,

- suatu prinsip mengenai pemilihan fungsi keputusan terbaik disebut sebagai prinsip minimax. Prinsip tersebut dapat dinyatakan sebagai berikut:

Misalkan diberikan fungsi keputusan $\delta_{0}(y)$, untuk setiap $\theta \in \Omega$,

$$
\max _{\theta} R\left(\theta, \delta_{0}(y)\right) \leq \max _{\theta} R(\theta, \delta(y))
$$


untuk setiap fungsi keputusan $\delta(y)$, maka $\delta(y)$ disebut sebagai fungsi keputusan minimax (minimax decision function).

Dengan pemberian batasan bahwa $E(\delta(Y))=\theta$ dan fungsi kehilangan $£[\theta, \delta(y)]=[\theta-\delta(y)]^{2}$, fungsi keputusan yang meminimumkan fungsi risiko menghasilkan penduga takbias dengan ragam minimum.

\subsection{Sebaran Prior dan Posterior}

Definisi 5.1 Misalkan $X_{1}, X_{2}, \ldots, X_{n}$ adalah sampel acak dengan sebaran $f(x \mid \theta)$, di mana $\theta$ adalah parameter yang tidak diketahui. Fungsi kepekatan peluang dari peubah acak $\Theta$ disebut sebaran prior bagi $\Theta$, dinotasikan dengan $h(\theta)$.

Definisi 5.2 Misalkan $X_{1}, X_{2}, \ldots, X_{n}$ adalah sampel acak dengan sebaran $f(x \mid \theta)$, di mana $\theta$ adalah parameter yang tidak diketahui. Fungsi kepekatan peluang bersyarat dari peubah acak $\Theta$ jika diberikan sampel $x_{1}, x_{2}, \ldots, x_{n}$ disebut sebaran posterior bagi $\Theta$, dinotasikan dengan $k\left(\theta \mid x_{1}, x_{2}, \ldots, x_{n}\right)$.

Catatan 5.1 Jika $X_{1}, X_{2}, \ldots, X_{n}$ adalah sampel acak dari populasi yang memiliki fungsi kepekatan peluang $f(x \mid \theta)$, maka fungsi kepekatan peluang bersama antara sampel dan parameter ialah

$$
g\left(x_{1}, \ldots, x_{n}, \theta\right)=L\left(x_{1}, \ldots, x_{n} \mid \theta\right) h(\theta)
$$

dengan $L\left(x_{1}, \ldots, x_{n} \mid \theta\right)=\prod_{i=1}^{n} f\left(x_{i} \mid \theta\right)$. Fungsi kepekatan peluang marginal bagi $\mathbf{X}$ ialah

$$
g_{1}\left(x_{1}, \ldots, x_{n}\right)=\int_{-\infty}^{\infty} g\left(x_{1}, \ldots, x_{n}, \theta\right) d \theta .
$$

Selanjutnya, dengan menggunakan formula Bayes diperoleh

$$
\begin{aligned}
k\left(\theta \mid x_{1}, x_{2}, \ldots, x_{n}\right) & =\frac{g\left(x_{1}, \ldots, x_{n}, \theta\right)}{g_{1}\left(x_{1}, \ldots, x_{n}\right)} \\
& =\frac{L\left(x_{1}, \ldots, x_{n} \mid \theta\right) h(\theta)}{g_{1}\left(x_{1}, \ldots, x_{n}\right)} .
\end{aligned}
$$

Contoh 5.2 Misalkan $X_{i} \mid \theta \stackrel{b s i}{\sim} \operatorname{Poisson}(\theta)$ dan $\Theta \sim \Gamma(\alpha, \beta)$, $\alpha$ dan $\beta$ diketahui. Tentukan sebaran posterior bagi $\theta$. 
Jawab. Misalkan $\mathbf{X}^{\prime}=\left(X_{1}, X_{2}, \ldots, X_{n}\right)$ dan $\mathbf{x}^{\prime}=\left(x_{1}, x_{2}, \ldots, x_{n}\right)$.

$$
L(\mathbf{x} \mid \theta)=\prod_{i=1}^{n}\left(\frac{\theta^{x_{i}} e^{-\theta}}{x_{i} !}\right) \mathbf{I}\left(x_{i}=0,1,2, \ldots\right), \theta>0
$$

dan sebaran prior bagi $\Theta$ ialah

$$
h(\theta)=\frac{\theta^{\alpha-1} e^{-\theta / \beta}}{\Gamma(\alpha) \beta^{\alpha}} \mathbf{I}(\theta>0) .
$$

Pada Contoh 5.2 terlihat bahwa tidak perlu menentukan fungsi kepekatan peluang marginal $g_{1}(\mathbf{x})$ untuk mencari sebaran posterior $k(\theta \mid \mathbf{x})$. Jika kita membagi $L(\mathbf{x} \mid \theta) h(\theta)$ dengan $g_{1}(\mathbf{x})$, maka diperoleh faktor yang bergantung pada amatan peubah, $\mathbf{x}$, tetapi tidak bergantung pada $\theta$, misalkan disebut $c(\mathbf{x})$, dan $\theta^{\Sigma x_{i}+\alpha-1} e^{-\theta[\beta /(n \beta+1)]}$, yaitu

$$
k(\theta \mid \mathbf{x})=c(\mathbf{x}) \theta^{\Sigma x_{i}+\alpha-1} \exp \left(-\frac{\theta}{\beta /(n \beta+1)}\right) \mathbf{I}(\theta>0)
$$

dengan $x_{i}=0,1,2, \ldots$ dan $i=1,2, \ldots, n$. Faktor $c(\mathbf{x})$ tersebut harus berupa konstanta sedemikian sehingga membuat $k(\theta \mid \mathbf{x})$ sebagai suatu fungsi kepekatan peluang, yaitu

$$
c(\mathbf{x})=\frac{1}{\Gamma\left(\sum_{i=1}^{n} x_{i}+\alpha\right)[\beta /(n \beta+1)]^{\Sigma x_{i}+\alpha}} .
$$


Dugaan Bayes adalah fungsi keputusan $\delta$ yang meminimumkan

$$
E\{£[\Theta, \delta(\mathbf{x})] \mid \mathbf{X}=\mathbf{x}\}=\int_{-\infty}^{\infty} £[\theta, \delta(\mathbf{x})] k(\theta \mid \mathbf{x}) d \theta
$$

Selanjutnya, tentukan konstanta $c(\mathbf{x})$ sedemikian sehingga membuat $k(\theta \mid \mathbf{x})$ sebagai suatu fungsi kepekatan peluang. Jelas bahwa $k(\theta \mid \mathbf{x})$ harus berupa fungsi kepekatan peluang dari sebaran $\Gamma\left(\sum_{i=1}^{n} x_{i}+\alpha, \beta /(n \beta+1)\right)$, sehingga

$$
c(\mathbf{x})=\frac{1}{\Gamma\left(\sum_{i=1}^{n} x_{i}+\alpha\right)[\beta /(n \beta+1)]^{\Sigma x_{i}+\alpha}} .
$$

Misalkan terdapat statistik cukup $Y=u(\mathbf{X})$ untuk parameter $\theta$ sehingga

$$
L(\mathbf{x} \mid \theta)=g[u(\mathbf{x}) \mid \theta] H(\mathbf{x}),
$$

di mana $g(y \mid \theta)$ adalah fungsi kepekatan peluang dari $Y$, jika diketahui $\Theta=\theta$. Karena faktor $H(\mathbf{x})$ tidak bergantung pada $\theta$, maka dapat kita abaikan, sehingga

$$
k(\theta \mid \mathbf{x}) \propto g[u(\mathbf{x}) \mid \theta] h(\theta) .
$$

Dengan demikian, jika statistik $Y$ untuk parameter $\theta$ ada, maka kita dapat memulai dengan fungsi kepekatan peluang $Y$ dan menuliskan

$$
k(\theta \mid y) \propto g[y \mid \theta] h(\theta),
$$

di mana $k(\theta \mid y)$ adalah fungsi kepekatan peluang bersyarat dari $\Theta \mid Y=y$. Dalam kasus statistik cukup $Y$, kita juga akan menggunakan $g_{1}(y)$, fungsi kepekatan peluang marginal dari $Y$, yaitu

$$
g_{1}(y)=\int_{-\infty}^{\infty} g[y \mid \theta] h(\theta) d \theta .
$$

\subsection{Metode Pendugaan Bayes}


jika $\Theta$ adalah peubah acak kontinu, yaitu

$$
\delta(\mathbf{x})=\operatorname{Arg} \min \int_{-\infty}^{\infty} £[\theta, \delta(\mathbf{x})] k(\theta \mid \mathbf{x}) d \theta,
$$

di mana $£[\theta, \delta(\mathbf{x})]$ adalah fungsi kehilangan. Peubah acak terkait $\delta(\mathbf{X})$ disebut penduga Bayes bagi $\theta$. Jika fungsi kehilangan yang diberikan ialah

$$
£[\theta, \delta(\mathbf{x})]=[\theta-\delta(\mathbf{x})]^{2},
$$

maka dugaan Bayes ialah $\delta(\mathbf{x})=E[\Theta \mid \mathbf{x}]$, nilai harapan dari sebaran bersyarat $\Theta \mid \mathbf{X}=\mathbf{x}$. Hal tersebut berdasarkan fakta bahwa $E\left[(W-b)^{2}\right]$ (jika ada) adalah minimum ketika $b=E(W)$. Jika fungsi kehilangan yang diberikan ialah

$$
£[\theta, \delta(\mathbf{x})]=|\theta-\delta(\mathbf{x})|,
$$

maka dugaan Bayes ialah median dari sebaran bersyarat $\Theta \mid \mathbf{X}=\mathbf{x}$. Hal tersebut berdasarkan fakta bahwa $E(|W-b|)$ (jika ada) adalah minimum ketika $b=\operatorname{median}(W)$.

Secara umum, misalkan $\xi(\theta)$ adalah suatu fungsi dari $\theta$. Untuk fungsi kehilangan $£[\xi(\theta), \delta(\mathbf{x})]$, dugaan Bayes dari $\xi(\theta)$ adalah fungsi keputusan $\delta$ yang meminimumkan

$$
E\{£[\Theta, \delta(\mathbf{x})] \mid \mathbf{X}=\mathbf{x}\}=\int_{-\infty}^{\infty} £[\xi(\theta), \delta(\mathbf{x})] k(\theta \mid \mathbf{x}) d \theta .
$$

Peubah acak $\delta(\mathbf{X})$ disebut penduga Bayes bagi $\xi(\theta)$.

Nilai harapan bersyarat dari $£[\Theta, \delta(\mathbf{x})] \mid \mathbf{X}=\mathbf{x}$ mendefinisikan peubah acak yang merupakan fungsi dari contoh $\mathbf{X}$. Nilai harapan fungsi dari $\mathbf{X}$ (dalam kasus kontinu) diberikan sebagai berikut

$$
\begin{aligned}
& \int_{-\infty}^{\infty}\left\{\int_{-\infty}^{\infty} £[\theta, \delta(\mathbf{x})] k(\theta \mid \mathbf{x}) d \theta\right\} g_{1}(\mathbf{x}) d \mathbf{x} \\
= & \int_{-\infty}^{\infty}\left\{\int_{-\infty}^{\infty} £[\theta, \delta(\mathbf{x})] L(\mathbf{x} \mid \theta) d \mathbf{x}\right\} h(\theta) d \theta,
\end{aligned}
$$

di mana $\int_{-\infty}^{\infty} £[\theta, \delta(\mathbf{x})] L(\mathbf{x} \mid \theta) d \mathbf{x}$ adalah fungsi risiko yang dinotasikan dengan $R(\theta, \delta)$. Oleh karena itu, persamaan 5.4 adalah nilai harapan dari risiko. Karena dugaan Bayes $\delta(\mathbf{x})$ meminimumkan

$$
\int_{-\infty}^{\infty} £[\theta, \delta(\mathbf{x})] k(\theta \mid \mathbf{x}) d \theta
$$

untuk setiap $\mathbf{x}$ di mana $g(\mathbf{x})>0$, maka $\delta(\mathbf{x})$ juga meminimumkan nilai harapan dari risiko. 
Contoh 5.3 Diketahui sebaran

$$
\begin{gathered}
X_{i} \mid \theta \stackrel{b s i}{\sim} \text { binomial }(1, \theta) \\
\Theta \sim \operatorname{beta}(\alpha, \beta) .
\end{gathered}
$$

901

Tentukan dugaan Bayes bagi $\theta$ jika $£[\theta, \delta(\mathbf{x})]=[\theta-\delta(\mathbf{x})]^{2}$.

Jawab. Sebaran prior bagi $\Theta$ ialah

$$
h(\theta)=\frac{\Gamma(\alpha+\beta)}{\Gamma(\alpha) \Gamma(\beta)} \theta^{\alpha-1}(1-\theta)^{\beta-1} \mathbf{I}(0<\theta<1),
$$

di mana $\alpha$ dan $\beta$ adalah konstanta positif. Statistik cukup $Y=\sum_{i=1}^{n} x_{i}$ menyebar $\operatorname{binomial}(n, \theta)$, sehingga fungsi kepekatan bersyarat $Y \mid \Theta=\theta$ ialah

$$
g(y \mid \theta)=\left(\begin{array}{l}
n \\
y
\end{array}\right) \theta^{y}(1-\theta)^{n-y} \mathbf{I}(y=0,1, \ldots, n) .
$$

Dengan menggunakan 5.3,

$$
k(\theta \mid y) \propto \theta^{y}(1-\theta)^{n-y} \theta^{\alpha-1}(1-\theta)^{\beta-1} \mathbf{I}(0<\theta<1),
$$

sehingga sebaran posterior $\Theta \mid Y=y$ menyebar beta dengan parameter $(\alpha+y, \beta+n-y)$ dan fungsi kepekatan peluangnya ialah

$k(\theta \mid y)=\frac{\Gamma(n+\alpha+\beta)}{\Gamma(\alpha+y) \Gamma(n+\beta-y)} \theta^{\alpha+y-1}(1-\theta)^{\beta+n-y-1} \mathbf{I}(0<\theta<1, y=0,1, \ldots, n)$.

Dugaan Bayes yang diperoleh ini merupakan rata-rata terbobot antara dugaan yang diperoleh dari sebaran prior, yaitu $\frac{\alpha}{\alpha+\beta}$ dengan dugaan yang diperoleh dari sebaran bersyarat $Y \mid \theta$, yaitu $\frac{y}{n}$.

Contoh 5.4 Diketahui sebaran

$$
\begin{gathered}
X_{i} \mid \theta \stackrel{b s i}{\sim} N\left(\theta, \sigma^{2}\right), \text { di mana } \sigma^{2} \text { diketahui } \\
\Theta \sim N\left(\theta_{0}, \sigma_{0}^{2}\right), \text { di mana } \theta_{0} \text { dan } \sigma_{0}^{2} \text { diketahui. }
\end{gathered}
$$

Tentukan dugaan Bayes bagi $\theta$ jika $£[\theta, \delta(\mathbf{x})]=[\theta-\delta(\mathbf{x})]^{2}$. 
Jawab. Karena $Y=\bar{X}$ adalah statistik cukup bagi $\theta$, maka

$$
\begin{gathered}
Y \mid \theta \stackrel{b s i}{\sim} N\left(\theta, \sigma^{2} / n\right), \text { di mana } \sigma^{2} \text { diketahui } \\
\Theta \sim N\left(\theta_{0}, \sigma_{0}^{2}\right), \text { di mana } \theta_{0} \text { dan } \sigma_{0}^{2} \text { diketahui. }
\end{gathered}
$$

Sebaran prior bagi $\Theta$ ialah

$$
h(\theta)=\frac{1}{\sqrt{2 \pi \sigma_{0}^{2}}} \exp \left\{-\frac{1}{2 \sigma_{0}^{2}}\left(\theta-\theta_{0}\right)^{2}\right\} \mathbf{I}(-\infty<\theta<\infty) .
$$

Dengan menggunakan 5.3,

$$
\begin{aligned}
k(\theta \mid y) & \propto \frac{1}{\sqrt{2 \pi} \sigma / \sqrt{n}} \frac{1}{\sqrt{2 \pi} \sigma_{0}} \exp \left[-\frac{(y-\theta)^{2}}{2\left(\sigma^{2} / n\right)}-\frac{\left(\theta-\theta_{0}\right)^{2}}{2 \sigma_{0}^{2}}\right] \\
& \propto \exp \left[-\frac{\left(\sigma_{0}^{2}+\sigma^{2} / n\right) \theta^{2}-2\left(y \sigma_{0}^{2}+\theta_{0} \sigma^{2} / n\right) \theta}{2\left(\sigma^{2} / n\right) \sigma_{0}^{2}}\right] \\
& \propto \exp \left[-\frac{\left.\left(\theta-\frac{y \sigma_{0}^{2}+\theta_{0} \sigma^{2} / n}{\sigma_{0}^{2}+\sigma^{2} / n}\right)^{2}\right]}{\frac{2\left(\sigma^{2} / n\right) \sigma_{0}^{2}}{\sigma_{0}^{2}+\sigma^{2} / n}}\right]
\end{aligned}
$$

sehingga sebaran posterior $\Theta \mid Y=y$ menyebar normal dengan parameter

$$
\left(\frac{y \sigma_{0}^{2}+\theta_{0} \sigma^{2} / n}{\sigma_{0}^{2}+\sigma^{2} / n}, \frac{\left(\sigma^{2} / n\right) \sigma_{0}^{2}}{\sigma_{0}^{2}+\sigma^{2} / n}\right)
$$

Untuk $£[\theta, \delta(\mathbf{x})]=[\theta-\delta(\mathbf{x})]^{2}$, maka $\delta(y)$ merupakan nilai harapan dari sebaran normal dengan parameter 5.5, yaitu

$$
\begin{aligned}
\delta(y) & =\frac{y \sigma_{0}^{2}+\theta_{0} \sigma^{2} / n}{\sigma_{0}^{2}+\sigma^{2} / n} \\
& =\left(\frac{\sigma_{0}^{2}}{\sigma_{0}^{2}+\sigma^{2} / n}\right) y+\left(\frac{\sigma^{2} / n}{\sigma_{0}^{2}+\sigma^{2} / n}\right) \theta_{0} .
\end{aligned}
$$

Dugaan Bayes yang diperoleh ini merupakan rata-rata terbobot antara dugaan yang diperoleh dari sebaran prior, yaitu $\theta_{0}$ dengan dugaan yang diperoleh dari sebaran bersyarat $Y \mid \theta$, yaitu $y$. 
Berikut ini merupakan contoh yang membandingkan penggunaan prinsip minimax dan metode pendugaan Bayes. Misalkan diketahui sebaran prior bagi peubah acak $\Theta$ ialah sebagai berikut:

$$
\begin{aligned}
& P\left(\Theta=\theta_{1}\right)=0.6 \\
& P\left(\Theta=\theta_{2}\right)=0.4
\end{aligned}
$$

Misalkan $\theta_{1}$ menyatakan Bogor hujan di sore hari dan $\theta_{2}$ menyatakan Bogor tidak hujan di sore hari. Kemudian, terdapat tambahan informasi $Y$ mengenai kondisi cuaca di Gunung Salak, yaitu

$$
\begin{array}{lll}
y_{1}: & \text { Gunung Salak cerah } \\
y_{2}: & \text { Gunung Salak berawan } \\
y_{3}: & \text { Gunung Salak gelap }
\end{array}
$$

dengan peluang bersyarat $Y \mid \theta$ ialah sebagai berikut:

\begin{tabular}{|l|c|c|c|}
\hline$P(Y \mid \theta)$ & $y_{1}$ & $y_{2}$ & $y_{3}$ \\
\hline$\theta_{1}$ & 0.05 & 0.25 & 0.7 \\
\hline$\theta_{2}$ & 0.425 & 0.375 & 0.2 \\
\hline
\end{tabular}

Selanjutnya, misalkan fungsi kehilangan $£[\theta, \delta(y)]$ diberikan sebagai berikut:

\begin{tabular}{|c|c|c|c|c|}
\hline Putusan $(\delta)$ & $\Theta \backslash Y$ & $y_{1}$ & $y_{2}$ & $y_{3}$ \\
\hline$\delta_{1}$ & $\theta_{1}$ & 6 & 3 & 1 \\
\cline { 2 - 5 } (membawa payung) & $\theta_{2}$ & 12 & 5 & 2 \\
\hline \multirow{2}{*}{$\begin{array}{c}\delta_{1} \\
\text { (tidak membawa payung) }\end{array}$} & $\theta_{1}$ & 10 & 15 & 20 \\
\cline { 2 - 5 } & $\theta_{2}$ & 0 & 2 & 4 \\
\hline
\end{tabular}

- Prinsip minimax

$R\left(\theta_{j}, \delta_{j}\right)=\sum_{i=1}^{3} £\left[\theta_{j}, \delta_{j}\left(y_{i}\right)\right] P\left(Y=y_{i} \mid \theta_{j}\right), j=1,2$.

\begin{tabular}{|c|c|c|c|c|c|}
\hline Putusan $(\delta)$ & & $y_{1}$ & $y_{2}$ & $y_{1}$ & $R(\theta, \delta)$ \\
\hline \multirow{4}{*}{$\begin{array}{c}\text { Membawa } \\
\text { payung }\end{array}$} & $\theta_{1}$ & 0.05 & 0.25 & 0.7 & 1.75 \\
\cline { 2 - 5 } & $£\left[\theta_{1}, \delta_{1}(y)\right]$ & 6 & 3 & 1 & \\
\cline { 2 - 5 } & $\theta_{2}$ & 0.425 & 0.375 & 0.2 & 7.375 \\
\cline { 2 - 5 }$\delta_{2}\left[\theta_{2}, \delta_{1}(y)\right]$ & 12 & 5 & 2 & \\
\hline \multirow{4}{*}{$\begin{array}{c}\text { Tidak membawa } \\
\text { payung }\end{array}$} & $\theta_{1}$ & 0.05 & 0.25 & 0.7 & 18.25 \\
\cline { 2 - 5 } & $£\left[\theta_{1}, \delta_{2}(y)\right]$ & 10 & 15 & 20 & \\
\cline { 2 - 5 } & $\theta_{2}$ & 0.425 & 0.375 & 0.2 & 1.033 \\
\cline { 2 - 5 } & $£\left[\theta_{2}, \delta_{2}(y)\right]$ & 0 & 2 & 4 & \\
\hline
\end{tabular}

Putusan minimax: $\delta=\arg \min \max R(\theta, \delta)=\delta_{1}$. 
Sebaran bersama dan sebaran marginal bagi peubah acak $\Theta$ dan $Y$ diperoleh sebagai berikut:

\begin{tabular}{|c|c|c|c|c|}
\hline$P(\Theta, Y)$ & $y_{1}$ & $y_{2}$ & $y_{3}$ & $P\left(\theta_{j}\right)$ \\
\hline$\theta_{1}$ & 0.03 & 0.15 & 0.42 & 0.6 \\
\hline$\theta_{2}$ & 0.17 & 0.15 & 0.08 & 0.4 \\
\hline$P\left(y_{i}\right)$ & 0.2 & 0.3 & 0.5 & 1 \\
\hline
\end{tabular}

di mana

$$
\begin{aligned}
P(\Theta=\theta, Y=y) & =P(Y=y \mid \Theta=\theta) P(\Theta=\theta) \\
P\left(\theta_{j}\right) & =\sum_{i=1}^{3} P\left(\Theta=\theta_{j}, Y=y_{i}\right), j=1,2 \\
P\left(y_{i}\right) & =\sum_{j=1}^{2} P\left(\Theta=\theta_{j}, Y=y_{i}\right), i=1,2,3 .
\end{aligned}
$$

Sebaran posterior $\Theta \mid Y$ ialah

\begin{tabular}{|c|c|c|c|}
\hline$P(\Theta \mid Y)$ & $y_{1}$ & $y_{2}$ & $y_{3}$ \\
\hline$\theta_{1}$ & 0.15 & 0.5 & 0.84 \\
\hline$\theta_{2}$ & 0.85 & 0.5 & 0.16 \\
\hline
\end{tabular}

- Pendugaan Bayes

\begin{tabular}{|c|c|rl|}
\hline Amatan & Putusan & $E_{\Theta \mid y}(£[\Theta, \delta(y)])$ & \\
\hline \multirow{2}{*}{$y_{1}$} & $\delta_{1}$ & $(6 \times 0.15)+(12 \times 0.85)$ & $=11.1$ \\
\cline { 2 - 4 } & $\delta_{2}$ & $(10 \times 0.15)+(0 \times 0.85)$ & $=1.5$ \\
\hline \multirow{2}{*}{$y_{2}$} & $\delta_{1}$ & $(3 \times 0.5)+(5 \times 0.5)$ & $=4$ \\
\cline { 2 - 4 } & $\delta_{2}$ & $(15 \times 0.5)+(2 \times 0.5)$ & $=8.5$ \\
\hline \multirow{2}{*}{$y_{3}$} & $\delta_{1}$ & $(1 \times 0.84)+(2 \times 0.16)$ & $=1.16$ \\
\cline { 2 - 4 } & $\delta_{2}$ & $(20 \times 0.84)+(4 \times 0.16)$ & $=17.44$ \\
\hline
\end{tabular}

Jadi, putusan Bayes bergantung pada amatan $Y$ yang diperoleh. Jika $Y$ yang diperoleh $y_{1}$, maka putusan Bayes ialah $\delta_{2}$, sedangkan jika $Y$ yang diperoleh $y_{2}$ atau $y_{3}$, maka putusan Bayes ialah $\delta_{1}$.

\subsection{Latihan}

1. Misalkan $X$ adalah peubah acak sedemikian sehingga $E\left[(X-b)^{2}\right]$ ada untuk setiap bilangan Real $b$. Tunjukkan bahwa $E\left[(X-b)^{2}\right]$ minimum ketika $b=E(X)$. 
2. Misalkan $X$ adalah suatu peubah acak kontinu. Tunjukkan bahwa

$$
E(|X-b|)=E(|X-m|)+2 \int_{m}^{b}(b-x) f(x) d x
$$

di mana $m$ adalah median dari sebaran $X$.

3. Andaikan $Y_{n}$ merupakan statistik tataan ke-n dari suatu sampel acak berukuran $n$ dari sebaran dengan fungsi kepekatan peluang $f(x ; \theta)=$ $\theta^{-1} \mathbf{I}(0<x<\theta)$. Andai pula $\theta$ merupakan amatan dari peubah acak $\Theta$ dengan fungsi kepekatan peluang $h(\theta)=\theta^{-\beta-1} \beta \alpha^{\beta} \mathbf{I}(\theta>\alpha), \alpha>$ $0, \beta>0$. Bila fungsi kehilangan $£\left[\theta, \delta\left(y_{n}\right)\right]=\left[\theta-\delta\left(y_{n}\right)\right]^{2}$, maka tentukanlah solusi Bayes $\delta\left(y_{n}\right)$ yang merupakan dugaan titik bagi $\theta$.

4. Misalkan $\theta$ merupakan nilai amatan dari peubah acak $\Theta$ dengan fungsi kepekatan peluang

$$
h(\theta)=\left(\Gamma(\alpha) \beta^{\alpha}\right)^{-1} \theta^{\alpha-1} e^{-\theta / \beta} \mathbf{I}(\theta>0)
$$

dan $\alpha>0, \beta>0$ merupakan bilangan yang diketahui. Misalkan pula bahwa $X_{1}, X_{2}, \ldots, X_{n}$ merupakan sampel acak dari sebaran Poisson dengan nilai tengah $\theta$. Bila $Y=\sum_{i=1}^{n} X i$ dan fungsi kehilangannya ialah $£[\theta, \delta(y)]=[\theta-\delta(y)]^{2}$, maka tentukan solusi Bayes $\delta(y)$ sebagai dugaan titik bagi $\theta$.

5. Misalkan $\theta$ merupakan nilai amatan dari peubah acak $\Theta$ bersebaran $N(a, b), a$ dan $b$ masing-masing merupakan konstanta yang diketahui, $a \in R$ dan $b>0$. Misalkan pula $Y$ merupakan rata-rata dari sampel acak $X_{1}, X_{2}, \ldots, X_{n}$ yang bersebaran $N(\theta, 25), \theta \in R$. Bila fungsi kerugian $£[\theta, \delta(y)]=|\theta-\delta(y)|$ maka berikan dugaan Bayes $\delta(y)$ sebagai dugaan titik bagi $\theta$. 


\section{BAB 6}

\section{Pengujian Hipotesis}

Misalkan $X$ peubah acak untuk suatu populasi dengan parameter $\theta$ yang tidak diketahui, di mana $\theta \in \Omega$. Misalkan pula $X_{1}, X_{2}, \ldots, X_{n}$ ialah sampel acak dari sebaran peubah acak $X$ yang memiliki fungsi kepekatan atau fungsi massa peluang $f(x, \theta)$. Suatu hipotesis statistika adalah pernyataan tentang sebaran dari populasi $X$. Pernyataan tersebut biasanya berkaitan dengan parameter $\theta$ jika kita sedang berhadapan dengan statistika parametrik, selain itu pernyataan tersebut ialah berkaitan dengan bentuk sebaran $X$. Hipotesis statistika disebut sebagai hipotesis sederhana jika hipotesis tersebut secara keseluruhan menunjukkan sebaran suatu populasi, sebaliknya disebut sebagai hipotesis majemuk.

Definisikan suatu hipotesis sebagai berikut

$$
\begin{aligned}
& H_{0}: \theta \in \omega_{0} \\
& H_{1}: \theta \in \omega_{1}
\end{aligned}
$$

di mana $\omega_{0}$ dan $\omega_{1}$ ialah himpunan bagian dari $\Omega$ dan $\omega_{0} \cup \omega_{1}=\Omega$. Hipotesis $H_{0}$ disebut sebagai hipotesis nul dan $H_{1}$ disebut sebagai hipotesis alternatif atau hipotesis tandingan.

Misalkan $D$ adalah ruang dari sampel, yaitu $D=\operatorname{ruang}\left\{\left(X_{1}, X_{2}, \ldots, X_{n}\right)\right\}$. Pengujian $H_{0}$ lawan $H_{1}$ tersebut berdasarkan himpunan bagian $C$ dari $D$. Himpunan bagian $C$ disebut sebagai daerah kritis dan himpunan tersebut berpadanan dengan aturan sebagai berikut:

Tolak $H_{0}$ (Terima $H_{1}$ ), jika $\left(X_{1}, X_{2}, \ldots, X_{n}\right) \in C$ Tidak Tolak $H_{0}$ (Tolak $H_{1}$ ), jika $\left(X_{1}, X_{2}, \ldots, X_{n}\right) \in C^{c}$.

Penerimaan suatu hipotesis tidak berarti bahwa hipotesis tersebut benar, tetapi karena tidak ada bukti yang cukup untuk menolak atau menafikannya. 
Dalam pengujian hipotesis, ada dua kemungkinan kesalahan yang dapat kita lakukan, yaitu:

1. Kesalahan untuk menolak $H_{0}$, sedangkan kenyataanya $H_{0}$ benar.

2. Kesalahan untuk tidak menolak $H_{0}$, sedangkan kenyataanya $H_{0}$ salah.

Kesalahan menolak $H_{0}$ yang benar disebut sebagai kesalahan jenis I dan kesalahan tidak menolak $H_{0}$ yang salah disebut kesalahan jenis II. Peluang terjadinya salah jenis I dinotasikan dengan $\alpha$, sedangkan peluang terjadinya salah jenis II dinotasikan dengan $\beta$.

\begin{tabular}{|l|l|l|}
\hline & \multicolumn{1}{|c|}{$H_{0}$ benar } & \multicolumn{1}{c|}{$H_{0}$ salah } \\
\hline Tolak $H_{0}$ & Salah Jenis I & Putusan benar \\
\hline Tidak Tolak $H_{0}$ & Putusan benar & Salah Jenis II \\
\hline
\end{tabular}

Ukuran atau taraf nyata dari suatu uji hipotesis adalah peluang dari salah jenis I, yaitu

$$
\alpha=\max _{\theta \in \omega_{0}} P_{\theta}\left[\left(X_{1}, X_{2}, \ldots, X_{n}\right) \in C\right] .
$$

$P_{\theta}\left[\left(X_{1}, X_{2}, \ldots, X_{n}\right) \in C\right]$ merupakan peluang bahwa $\left(X_{1}, X_{2}, \ldots, X_{n}\right) \in C$ ketika $\theta$ adalah parameter yang benar. Berdasarkan semua kemungkinan daerah kritis $C$ berukuran $\alpha$, kita menginginkan daerah kritis dengan peluang salah jenis II yang minimum atau daerah kritis dengan peluang dari komplemen salah jenis II maksimum. Komplemen salah jenis II ialah menolak $H_{0}$ ketika $H_{1}$ benar, di mana hal tersebut adalah putusan yang benar. Dengan demikian, untuk $\theta \in \omega_{1}$, kita ingin memaksimumkan

$$
1-P_{\theta}[\text { Salah jenis II }]=P_{\theta}\left[\left(X_{1}, X_{2}, \ldots, X_{n}\right) \in C\right] .
$$

Peluang pada ruas kanan persamaan 6.1 disebut sebagai kuasa dari uji pada $\theta$. Jadi, meminimumkan peluang salah jenis II sama dengan memaksimumkan kuasa. Selanjutnya, definisikan fungsi kuasa dari daerah kritis $C$ sebagai

$$
\gamma_{C}(\theta)=P_{\theta}\left[\left(X_{1}, X_{2}, \ldots, X_{n}\right) \in C\right] ; \quad \theta \in \Omega .
$$

Untuk $H_{0}$ sederhana lawan $H_{1}$ sederhana, yaitu

$$
\begin{aligned}
& H_{0}: \theta=\theta^{\prime} \\
& H_{1}: \theta=\theta^{\prime \prime}
\end{aligned}
$$

fungsi kuasanya ialah $\gamma_{C}\left(\theta^{\prime}\right)=\alpha$ dan $\gamma_{C}\left(\theta^{\prime \prime}\right)=1-\beta$. Misalkan terdapat dua daerah kritis $C_{1}$ dan $C_{2}$ yang berukuran $\alpha . C_{1}$ dikatakan lebih baik dari $C_{2}$ jika $\gamma_{C_{1}}(\theta) \geq \gamma_{C_{2}}(\theta)$ untuk setiap $\theta \in \omega_{1}$. 
Contoh 6.2 Misalkan $X_{1}, X_{2}, \ldots, X_{10}$ adalah sampel acak dari sebaran Poisson dengan nilai harapan $\theta$. Daerah kritis untuk pengujian $H_{0}: \theta=0.1$ lawan $H_{1}: \theta>0.1$ diberikan sebagai berikut

$$
Y=\sum_{i=1}^{10} X_{i} \geq 3 .
$$

Statistisk $Y$ memiliki sebaran dengan nilai harapan $10 \theta$, sehingga bila $\theta=0.1$, nilai harapan $Y$ ialah 1. Taraf nyata dari uji ini ialah

$$
\alpha=P(Y \geq 3)=1-P(Y \leq 2)=1-0.920=0.080 .
$$

Jika daerah kritis didefinisikan sebagai $\sum_{i=1}^{10} X_{i} \geq 4$, maka taraf nyatanya ialah

$$
\alpha=P(Y \geq 4)=1-P(Y \leq 3)=1-0.981=0.019 .
$$


Sebagai contoh, jika taraf nyata yang diinginkan ialah $\alpha=0.05$, maka hal tersebut dapat disesuaikan dengan cara sebagai berikut. Misalkan $W$ merupakan peubah acak yang menyebar Bernoulli dengan peluang sukses sebesar

$$
P(W=1)=\frac{0.050-0.019}{0.080-0.019}=\frac{31}{61} .
$$

Asumsikan bahwa $W$ dipilih secara bebas dari sampel. Perhatikan aturan penolakan berikut :

$$
\text { Tolak } H_{0} \text { jika } \sum_{i=1}^{10} x_{i} \geq 4 \text { atau jika } \sum_{i=1}^{10} x_{i}=3 \text { dan } W=1 \text {. }
$$

Berdasarkan aturan penolakan tersebut, diperoleh taraf nyata sebesar

$$
\begin{aligned}
P_{H_{0}}(Y \geq 4)+P_{H_{0}}(\{Y=3\} \cap\{W=1\}) & =P_{H_{0}}(Y \geq 4)+P_{H_{0}}(Y=3) P(W=1) \\
& =0.019+0.061 \times \frac{31}{61} \\
& =0.05 .
\end{aligned}
$$

Proses melakukan percobaan tambahan untuk memutuskan apakah akan menolak $H_{0}$ atau tidak ketika $Y=3$ disebut sebagai uji acak (randomized test).

\subsection{Uji Paling Kuasa}

Misalkan $f(x ; \theta)$ adalah fungsi kepekatan atau fungsi massa peluang dari suatu peubah acak $X$ di mana $\theta \in \Omega=\left\{\theta^{\prime}, \theta^{\prime \prime}\right\}$. Misalkan pula $\omega_{0}=\left\{\theta^{\prime}\right\}$ dan $\omega_{1}=\left\{\theta^{\prime \prime}\right\}$, serta $\mathbf{X}^{\prime}=\left(X_{1}, X_{2}, \ldots, X_{n}\right)$ adalah sampel acak dari sebaran peubah acak $X$. Selanjutnya, definisikan daerah kritis terbaik untuk uji hipotesis sederhana antara hipotesis nul $H_{0}$ dan hipotesis alternatif $H_{1}$.

Definisi 6.1 Misalkan $C$ adalah himpunan bagian dari ruang sampel. $C$ disebut sebagai daerah kritis terbaik berukuran $\alpha$ untuk uji hipotesis sederhana $H_{0}: \theta=\theta^{\prime}$ dan $H_{1}: \theta=\theta^{\prime \prime}$ jika $P_{\theta^{\prime}}[\mathbf{X} \in C]=\alpha$ dan untuk setiap himpunan bagian $A$ dari ruang sampel,

$$
P_{\theta^{\prime}}[\mathbf{X} \in A]=\alpha \Rightarrow P_{\theta^{\prime \prime}}[\mathbf{X} \in C] \geq P_{\theta^{\prime \prime}}[\mathbf{X} \in A] .
$$

Teorema 6.1 (Neyman-Pearson) Misalkan $X_{1}, X_{2}, \ldots, X_{n}$ adalah sampel acak dari sebaran yang memiliki fungsi massa atau kepekatan peluang $f(x ; \theta)$, maka fungsi kemungkinan dari $X_{1}, X_{2}, \ldots, X_{n}$ ialah

$$
L(\theta ; \mathbf{x})=\prod_{i=1}^{n} f\left(x_{i} ; \theta\right), \text { untuk } \mathbf{x}^{\prime}=\left(x_{1}, x_{2}, \ldots, x_{n}\right) .
$$


Misalkan $\theta^{\prime}$ dan $\theta^{\prime \prime}$ adalah nilai dari $\theta$ sedemikian sehingga $\Omega=\left\{\theta: \theta=\theta^{\prime}, \theta^{\prime \prime}\right\}$ dan $k$ adalah bilangan positif. Misalkan pula $C$ adalah himpunan bagian dari ruang sampel sedemikian sehingga: $(a) \frac{L\left(\theta^{\prime} ; \mathbf{x}\right)}{L\left(\theta^{\prime \prime} ; \mathbf{x}\right)} \leq k$ untuk setiap $\mathbf{x} \in C$, (b) $\frac{L\left(\theta^{\prime} ; \mathbf{x}\right)}{L\left(\theta^{\prime \prime} ; \mathbf{x}\right)} \geq k$ untuk setiap $\mathbf{x} \in C^{c}$, dan $(c) \alpha=P_{H_{0}}[\mathbf{X} \in C]$, maka $C$ adalah daerah kritis terbaik berukuran $\alpha$ untuk pengujian hipotesis sederhana $H_{0}: \theta=\theta^{\prime}$ dan $H_{1}: \theta=\theta^{\prime \prime}$.

Bukti. Misalkan $X$ adalah peubah acak kontinu. Jika $C$ adalah satusatunya daerah kritis berukuran $\alpha$, maka teorema tersebut terbukti. Untuk penyederhanaan, misalkan $\int{ }_{R} \int L\left(\theta ; x_{1}, x_{2}, \ldots, x_{n}\right) d x_{1} d x_{2} \ldots d x_{n}$ menjadi $\int_{R} L(\theta)$. Jika terdapat daerah kritis berukuran $\alpha$ yang lain, misalkan daerah tersebut adalah $A$, maka

$$
\int_{A} L\left(\theta^{\prime}\right)=\int_{C} L\left(\theta^{\prime}\right)=\alpha
$$

Kemudian yang ingin dibuktikan ialah

$$
\int_{C} L\left(\theta^{\prime \prime}\right)-\int_{A} L\left(\theta^{\prime \prime}\right) \geq 0
$$

Karena $C$ adalah gabungan dari himpunan saling lepas $C \cap A$ dan $C \cap A^{c}$, maka

$$
\begin{aligned}
& \int_{C} L\left(\theta^{\prime \prime}\right)-\int_{A} L\left(\theta^{\prime \prime}\right) \\
= & \int_{C \cap A} L\left(\theta^{\prime \prime}\right)+\int_{C \cap A^{c}} L\left(\theta^{\prime \prime}\right)-\int_{A \cap C} L\left(\theta^{\prime \prime}\right)-\int_{A \cap C^{c}} L\left(\theta^{\prime \prime}\right) \\
= & \int_{C \cap A^{c}} L\left(\theta^{\prime \prime}\right)-\int_{A \cap C^{c}} L\left(\theta^{\prime \prime}\right) .
\end{aligned}
$$

Berdasarkan hipotesis pada teorema tersebut, $L\left(\theta^{\prime \prime}\right) \geq(1 / k) L\left(\theta^{\prime}\right)$ untuk setiap $\mathbf{x} \in C$, juga untuk setiap $\mathbf{x} \in C \cap A^{c}$, sehingga

$$
\int_{C \cap A^{c}} L\left(\theta^{\prime \prime}\right) \geq \frac{1}{k} \int_{C \cap A^{c}} L\left(\theta^{\prime}\right)
$$

dan $L\left(\theta^{\prime \prime}\right) \leq(1 / k) L\left(\theta^{\prime}\right)$ untuk setiap $\mathbf{x} \in C^{c}$, juga untuk setiap $\mathbf{x} \in A \cap C^{c}$, sehingga

$$
\int_{A \cap C^{c}} L\left(\theta^{\prime \prime}\right) \leq \frac{1}{k} \int_{A \cap C^{c}} L\left(\theta^{\prime}\right) .
$$

Berdasarkan pertaksamaan tersebut diperoleh

$$
\int_{C \cap A^{c}} L\left(\theta^{\prime \prime}\right)-\int_{A \cap C^{c}} L\left(\theta^{\prime \prime}\right) \geq \frac{1}{k} \int_{C \cap A^{c}} L\left(\theta^{\prime}\right)-\frac{1}{k} \int_{A \cap C^{c}} L\left(\theta^{\prime}\right) ;
$$


dan dari persamaan 6.2 diperoleh

$$
\int_{C} L\left(\theta^{\prime \prime}\right)-\int_{A} L\left(\theta^{\prime \prime}\right) \geq \frac{1}{k}\left[\int_{C \cap A^{c}} L\left(\theta^{\prime}\right)-\int_{A \cap C^{c}} L\left(\theta^{\prime}\right)\right] .
$$

1017

Dengan demikian,

$$
\begin{aligned}
& \int_{C \cap A^{c}} L\left(\theta^{\prime \prime}\right)-\int_{A \cap C^{c}} L\left(\theta^{\prime \prime}\right) \\
= & \int_{C \cap A} L\left(\theta^{\prime \prime}\right)+\int_{C \cap A^{c}} L\left(\theta^{\prime \prime}\right)-\int_{A \cap C} L\left(\theta^{\prime \prime}\right)-\int_{A \cap C^{c}} L\left(\theta^{\prime \prime}\right) \\
= & \int_{C} L\left(\theta^{\prime \prime}\right)-\int_{A} L\left(\theta^{\prime \prime}\right) \\
= & \alpha-\alpha=0 .
\end{aligned}
$$

Jika hasil tersebut disubstitusi ke pertaksamaan 6.3, maka diperoleh

$$
\int_{C} L\left(\theta^{\prime \prime}\right)-\int_{A} L\left(\theta^{\prime \prime}\right) \geq 0 .
$$

Jawab.

$$
\begin{aligned}
\frac{L\left(\theta^{\prime} ; \mathbf{x}\right)}{L\left(\theta^{\prime \prime} ; \mathbf{x}\right)} & =\frac{(1 / \sqrt{2 \pi})^{n} \exp \left(-\sum_{i=1}^{n} x_{i}^{2} / 2\right)}{(1 / \sqrt{2 \pi})^{n} \exp \left(-\sum_{i=1}^{n}\left(x_{i}-1\right)^{2} / 2\right)} \\
& =\exp \left(-\sum_{i=1}^{n} x_{i}+\frac{n}{2}\right) .
\end{aligned}
$$

$$
\begin{aligned}
& H_{0}: \theta=\theta^{\prime}=0 \\
& H_{1}: \theta=\theta^{\prime \prime}=1 .
\end{aligned}
$$

$$
f(x ; \theta)=\frac{1}{\sqrt{2 \pi}} \exp \left(-\frac{(x-\theta)^{2}}{2}\right),-\infty<x<\infty .
$$


Jika $k>0$, maka himpunan dari semua titik $\left(x_{1}, x_{2}, \ldots, x_{n}\right)$ sedemikian sehingga

$$
\begin{aligned}
& \exp \left(-\sum_{i=1}^{n} x_{i}+\frac{n}{2}\right) \leq k \\
\Leftrightarrow \quad & -\sum_{i=1}^{n} x_{i}+\frac{n}{2} \leq \log k \\
\Leftrightarrow \quad & \sum_{i=1}^{n} x_{i} \geq \frac{n}{2}-\log k=c
\end{aligned}
$$

adalah daerah kritis terbaik, yaitu $C=\left\{\left(x_{1}, x_{2}, \ldots, x_{n}\right): \sum_{i=1}^{n} x_{i} \geq c\right\}$, di mana $c$ adalah suatu konstanta yang dapat ditentukan sedemikian sehingga daerah kritis tersebut berukuran $\alpha$. Kejadian $\sum_{i=1}^{n} X_{i} \geq c$ ekuivalen dengan kejadian $\bar{X} \geq c / n=c_{1}$. Sebagai contoh, misalkan uji hipotesis tersebut berdasarkan statistik $\bar{X}$. Jika $H_{0}$ benar, $\theta=\theta^{\prime}=0$, maka $\bar{X} \sim N(0,1 / n)$. Berdasarkan ukuran contoh $n$ dan taraf nyata $\alpha$, konstanta $c_{1}$ dapat ditentukan dengan melihat tabel sebaran normal sedemikian sehingga

$$
P_{H_{0}}\left(\bar{X} \geq c_{1}\right)=\alpha .
$$

Dengan demikian, jika nilai dari $X_{1}, X_{2}, \ldots, X_{n}$ berturut-turut adalah $x_{1}, x_{2}, \ldots, x_{n}$, maka $\bar{x}=\sum_{i=1}^{n} x_{i} / n$. Jika $\bar{x} \geq c_{1}$, maka hipotesis $H_{0}$ ditolak pada taraf nyata $\alpha$; jika $\bar{x} \leq c_{1}$, maka hipotesis $H_{0}$ tidak ditolak. Peluang menolak $H_{0}$ padahal $H_{0}$ benar ialah $\alpha$; peluang menolak $H_{0}$ ketika $H_{0}$ salah adalah nilai dari kuasa uji hipotesis pada $\theta=\theta^{\prime \prime}=1$, yaitu

$$
P_{H_{1}}\left(\bar{X} \geq c_{1}\right)=\int_{c_{1}}^{\infty} \frac{1}{\sqrt{2 \pi} \sqrt{1 / n}} \exp \left(-\frac{(\bar{x}-1)^{2}}{2(1 / n)}\right) d \bar{x} .
$$

Misalkan $n=25$ dan $\alpha=0.05$, maka berdasarkan tabel sebaran normal $c_{1}=1.645 / \sqrt{25}=0.329$ dan kuasa dari uji terbaik $H_{0}$ lawan $H_{1}$ ialah 0.05 ketika $H_{0}$ benar dan

$$
\begin{aligned}
\int_{0.329}^{\infty} \frac{1}{\sqrt{2 \pi} \sqrt{1 / 25}} \exp \left(-\frac{(\bar{x}-1)^{2}}{2(1 / 25)}\right) d \bar{x} & =\int_{-3.355}^{\infty} \frac{1}{\sqrt{2 \pi}} e^{-w^{2} / 2} d w \\
& =P(Z \geq-3.355) \\
& =0.9996
\end{aligned}
$$

ketika $H_{1}$ benar.

\subsection{Uji Selalu Paling Kuasa}

Uji selalu paling kuasa atau uniformly most powerful test ini digunakan untuk menguji hipotesis nul sederhana dengan hipotesis alternatif majemuk. Berikut merupakan contoh dari pengujian tersebut. 
Contoh 6.4 Misalkan $X_{1}, X_{2}$ adalah sampel acak dari sebaran yang memiliki fungsi kepekatan peluang

$$
f(x ; \theta)=\frac{1}{\theta} e^{-x / \theta} \mathbf{I}(x>0) .
$$

1035

1036

1037

1038

sehingga daerah kritis $C=\left\{\left(x_{1}, x_{2}\right):\left(x_{1}+x_{2}\right) \geq k_{3}\right\}$.

$$
\begin{aligned}
\alpha & =P\left(\mathbf{X} \in C \mid H_{0}\right) \\
0.05 & =P_{\theta=2}\left(X_{1}+X_{2} \geq k_{2}\right) \\
0.05 & =1-P\left(X_{1}+X_{2}<k_{2}\right) \\
0.05 & =1-\int_{0}^{k_{3}} \int_{0}^{k_{3}-x_{1}} \frac{1}{4} \exp \left[-\left(x_{1}+x_{2}\right) / 2\right] d x_{2} d x_{1} \\
0.05 & =e^{-k_{3} / 2}\left(1+\frac{k_{3}}{2}\right) \\
k_{3} & =9.5 .
\end{aligned}
$$

Jika $k>0$, maka himpunan dari semua titik $\left(x_{1}, x_{2}\right)$ sedemikian sehingga

$$
\frac{\frac{1}{2^{2}} \exp \left[-\left(x_{1}+x_{2}\right) / 2\right]}{\frac{1}{\left(\theta^{*}\right)^{2}} \exp \left[-\left(x_{1}+x_{2}\right) / \theta^{*}\right]} \leq k
$$

$$
\begin{aligned}
& \frac{\frac{1}{2^{2}} \exp \left[-\left(x_{1}+x_{2}\right) / 2\right]}{\frac{1}{\left(\theta^{*}\right)^{2}} \exp \left[-\left(x_{1}+x_{2}\right) / \theta^{*}\right]} \leq k \\
& \Leftrightarrow \quad-\log 4-\left(x_{1}+x_{2}\right) / 2+\log \left(\theta^{*}\right)^{2}+\left(x_{1}+x_{2}\right) / \theta^{*} \leq \log k \\
& \Leftrightarrow \quad\left(x_{1}+x_{2}\right)\left(\frac{1}{\theta^{*}}-\frac{1}{2}\right) \leq k_{1} \\
& \Leftrightarrow \quad\left(x_{1}+x_{2}\right)\left(\frac{1}{2}-\frac{1}{\theta^{*}}\right) \geq k_{2},
\end{aligned}
$$

karena $\forall \theta^{*}>2,\left(\frac{1}{2}-\frac{1}{\theta^{*}}\right)>0$, maka pertaksamaan 6.4 dapat ditulis menjadi

$$
\left(x_{1}+x_{2}\right) \geq k_{3},
$$


Misalkan peubah acak $X$ memiliki fungsi kepekatan atau massa peluang $f(x ; \boldsymbol{\theta})$, di mana $\boldsymbol{\theta}$ adalah vektor dari parameter pada $\Omega$. Misalkan $\omega \subset \Omega$ dan

$$
H_{0}: \theta \in \omega \text { lawan } H_{1}: \theta \in \Omega \cap \omega^{c} .
$$


Prinsip dari rasio kemungkinan untuk menolak $H_{0}$ adalah jika dan hanya jika $\Lambda \leq \lambda_{0}<1$, di mana

$$
\Lambda(x)=\frac{\sup _{\boldsymbol{\theta} \in \omega} L(\omega)}{\sup _{\boldsymbol{\theta} \in \Omega} L(\Omega)}=\frac{L(\hat{\omega})}{L(\hat{\Omega})},
$$

dengan taraf nyata dari uji tersebut ialah $\alpha=\max _{\theta \in \omega} P_{H_{0}}\left[\Lambda(X) \leq \lambda_{0}\right]$.

Contoh 6.6 Misalkan $X_{1}, X_{2}, \ldots, X_{n}$ merupakan sampel acak dari sebaran $N\left(\theta_{1}, \theta_{2}\right)$ di mana $\theta_{1}$ adalah nilai tengah dan $\theta_{2}$ adalah ragam yang tidak diketahui, sehingga $\Omega=\left\{\left(\theta_{1}, \theta_{2}\right) \in \mathbb{R} \times \mathbb{R}^{+}\right\}$. Hipotesis yang diuji ialah

$$
\begin{aligned}
& H_{0}: \theta_{1}=0, \theta_{2}>0 \\
& H_{1}: \theta_{1} \neq 0, \theta_{2}>0,
\end{aligned}
$$

sehingga $\omega=\left\{\theta_{1}=0, \theta_{2} \in \mathbb{R}^{+}\right\}$. Tentukan statistik dan sebaran yang terkait hipotesis tersebut, serta berikan daerah kritis pada taraf nyata $\alpha$.

Jawab. Dalam hal ini sampel acak $X_{1}, X_{2}, \ldots, X_{n}$ saling bebas, sehingga fungsi kemungkinannya ialah

$$
L(\Omega)=\left(2 \pi \theta_{2}\right)^{-n / 2} \exp \left[-\frac{1}{2 \theta_{2}} \sum_{i=1}^{n}\left(x_{i}-\theta_{1}\right)^{2}\right]
$$

dan

$$
L(\omega)=\left(2 \pi \theta_{2}\right)^{-n / 2} \exp \left[-\frac{1}{2 \theta_{2}} \Sigma_{i=1}^{n} x_{i}^{2}\right] .
$$

Jika $\partial \ln L(\omega) / \partial \theta_{2}=0$, maka

$$
\begin{aligned}
\frac{-n}{2 \theta_{2}}+\frac{1}{\theta_{2}} & =0 \\
\theta_{2} & =\frac{\sum_{i=1}^{n} x_{i}^{2}}{n},
\end{aligned}
$$

di mana $\theta_{2}$ memaksimumkan $L(\omega)$. Jadi, penduga kemungkinan maksimum bagi $\theta_{2}$ ialah

$$
\hat{\theta}_{2}=\frac{\sum_{i=1}^{n} X_{i}^{2}}{n}
$$

Jika $\partial \ln L(\Omega) / \partial \theta_{1}$ dan $\partial \ln L(\Omega) / \partial \theta_{2}$ dibuat sama dengan nol, maka penduga kemungkinan maksimum bagi $\theta_{1}$ dan $\theta_{2}$ ialah

$$
\begin{aligned}
& \hat{\theta}_{1}=\bar{X} \\
& \hat{\theta}_{2}=\frac{\sum_{i=1}^{n}\left(X_{i}-\bar{X}\right)^{2}}{n} .
\end{aligned}
$$


Dengan demikian,

$$
\begin{aligned}
L(\hat{\Omega}) & =\left[2 \pi \times \frac{\sum_{i=1}^{n}\left(x_{i}-\bar{x}\right)^{2}}{n}\right]^{-n / 2} e^{-n / 2} \\
L(\hat{\omega}) & =\left[2 \pi \times \frac{\sum_{i=1}^{n} x_{i}^{2}}{n}\right]^{-n / 2} e^{-n / 2},
\end{aligned}
$$

sehingga

$$
\Lambda(x)=\frac{L(\hat{\omega})}{L(\hat{\Omega})}=\left[\frac{\sum_{i=1}^{n}\left(x_{i}-\bar{x}\right)^{2}}{\sum_{i=1}^{n} x_{i}^{2}}\right]^{n / 2} .
$$

Karena $\sum_{i=1}^{n}\left(x_{i}-\bar{x}\right)^{2}=\sum_{i=1}^{n} x_{i}^{2}-n \bar{x}^{2}$, maka

$$
\begin{aligned}
& \Lambda(x)=\left[\frac{\sum_{i=1}^{n}\left(x_{i}-\bar{x}\right)^{2}}{\sum_{i=1}^{n}\left(x_{i}-\bar{x}\right)^{2}+n \bar{x}^{2}}\right]^{n / 2} \leq \lambda_{0} \\
\Leftrightarrow & \frac{1}{n \bar{x}^{2}} \leq \lambda_{0}^{2 / n} \\
\Leftrightarrow & 1+\frac{n \bar{x}^{2}}{\sum_{i=1}^{n}\left(x_{i}-\bar{x}\right)^{2}} \\
\Leftrightarrow & \frac{n \bar{x}^{2}\left(x_{i}-\bar{x}\right)^{2}}{\sum_{i=1}^{n}\left(x_{i}-\bar{x}\right)^{2}} \geq \lambda_{0}^{-2 / n}-1=\lambda_{0}^{*} \\
\Leftrightarrow & \frac{n \bar{x}^{2} / \theta_{2}}{\sum_{i=1}^{n}\left(x_{i}-\bar{x}\right)^{2} / \theta_{2} \times \frac{1}{n-1}} \geq \lambda_{0}^{*}(n-1) \\
\Leftrightarrow & \frac{\sqrt{n}|\bar{x}| / \sqrt{\theta_{2}}}{\sqrt{\sum_{i=1}^{n}\left(x_{i}-\bar{x}\right)^{2} / \theta_{2} \times \frac{1}{n-1}}} \geq \sqrt{\lambda_{0}^{*}(n-1)}=\lambda_{0}^{* *} .
\end{aligned}
$$

Karena $\bar{X} \sim N\left(\theta_{1}, \theta_{2}\right)$ dan $\Sigma_{i=1}^{n}\left(X_{i}-\bar{X}\right)^{2} / \theta_{2} \sim \chi^{2}(n-1)$, maka

$$
T=\frac{\sqrt{n}\left(\bar{X}-\theta_{1}\right)}{\sqrt{\sum_{i=1}^{n}\left(X_{i}-\bar{X}\right)^{2} /(n-1)}} \sim \mathrm{t}-\operatorname{Student}(n-1)
$$

dan bila $H_{0}$ benar,

$$
T=\frac{\sqrt{n} \bar{X}}{\sqrt{\sum_{i=1}^{n}\left(X_{i}-\bar{X}\right)^{2} /(n-1)}} \sim \mathrm{t}-\operatorname{Student}(n-1) .
$$


1066

Dengan demikian, daerah kritis $C$ ialah

$$
\begin{aligned}
C & =\left\{\mathbf{x} ; \frac{\sqrt{n}|\bar{x}|}{\sqrt{\sum_{i=1}^{n}\left(x_{i}-\bar{x}\right)^{2} /(n-1)}} \geq t_{\alpha / 2}(n-1)\right\} \\
& =\left\{\mathbf{x} ;|\bar{x}| \geq \frac{S}{\sqrt{n}} t_{\alpha / 2}(n-1)\right\} .
\end{aligned}
$$

1067

$$
\begin{aligned}
& H_{0}: \theta_{1}=\theta_{2}, \theta_{3}>0 \\
& H_{1}: \theta_{1} \neq \theta_{2}, \theta_{3}>0,
\end{aligned}
$$

sehingga $\omega=\left\{\left(\theta_{1}, \theta_{2}, \theta_{3}\right): \theta_{1}=\theta_{2} \in \mathbb{R}, \theta_{3} \in \mathbb{R}^{+}\right\}$. Tentukan statistik dan sebaran yang terkait hipotesis tersebut, serta berikan daerah kritis pada taraf nyata $\alpha$.

Jawab. Dalam hal ini $X_{1}, X_{2}, \ldots, X_{n}, Y_{1}, Y_{2}, \ldots, Y_{m}$ adalah $n+m>2$ sampel acak saling bebas, sehingga fungsi kemungkinannya ialah

$$
L(\Omega)=\left(2 \pi \theta_{3}\right)^{-(n+m) / 2} \exp \left[-\frac{1}{2 \theta_{3}}\left\{\sum_{i=1}^{n}\left(x_{i}-\theta_{1}\right)^{2}+\sum_{i=1}^{m}\left(y_{i}-\theta_{2}\right)^{2}\right\}\right]
$$

dan

$$
L(\omega)=\left(2 \pi \theta_{3}\right)^{-(n+m) / 2} \exp \left[-\frac{1}{2 \theta_{3}}\left\{\Sigma_{i=1}^{n}\left(x_{i}-\theta_{1}\right)^{2}+\Sigma_{i=1}^{m}\left(y_{i}-\theta_{1}\right)^{2}\right\}\right] .
$$

Jika $\partial \ln L(\omega) / \partial \theta_{1}$ dan $\partial \ln L(\omega) / \partial \theta_{3}$ dibuat sama dengan nol, maka

$$
\begin{aligned}
\sum_{i=1}^{n}\left(x_{i}-\theta_{1}\right)+\sum_{i=1}^{m}\left(y_{i}-\theta_{1}\right) & =0 \\
\frac{1}{\theta_{3}}\left[\sum_{i=1}^{n}\left(x_{i}-\theta_{1}\right)^{2}+\sum_{i=1}^{m}\left(y_{i}-\theta_{1}\right)^{2}\right] & =n+m .
\end{aligned}
$$

Solusi dari persamaan di atas untuk $\theta_{1}$ dan $\theta_{3}$ berturut-turut ialah

$$
\begin{aligned}
& \theta_{1 \omega}=(n+m)^{-1}\left\{\sum_{i=1}^{n} x_{i}+\sum_{i=1}^{m} y_{i}\right\} \\
& \theta_{3 \omega}=(n+m)^{-1}\left\{\sum_{i=1}^{n}\left(x_{i}-\theta_{1 \omega}\right)^{2}+\sum_{i=1}^{m}\left(y_{i}-\theta_{1 \omega}\right)^{2}\right\},
\end{aligned}
$$


di mana $\theta_{1 \omega}$ dan $\theta_{3 \omega}$ memaksimumkan $L(\omega)$. Selanjutnya, jika $\partial \ln L(\Omega) / \partial \theta_{1}$, $\partial \ln L(\Omega) / \partial \theta_{2}$, dan $\partial \ln L(\Omega) / \partial \theta_{3}$ dibuat sama dengan nol, maka

$$
\begin{aligned}
& \sum_{i=1}^{n}\left(x_{i}-\theta_{1}\right)=0 \\
& \sum_{i=1}^{m}\left(y_{i}-\theta_{2}\right)=0 \\
&-(n+m)+\frac{1}{\theta_{3}}\left[\sum_{i=1}^{n}\left(x_{i}-\theta_{1}\right)^{2}+\sum_{i=1}^{m}\left(y_{i}-\theta_{1}\right)^{2}\right]=0 .
\end{aligned}
$$

Solusi dari persamaan di atas untuk $\theta_{1}, \theta_{2}$ dan $\theta_{3}$ berturut-turut ialah

$$
\begin{gathered}
\theta_{1}=\bar{x} \\
\theta_{2}=\bar{y} \\
\theta_{3}=(n+m)^{-1}\left\{\sum_{i=1}^{n}\left(x_{i}-\theta_{1}\right)^{2}+\sum_{i=1}^{m}\left(y_{i}-\theta_{2}\right)^{2}\right\}
\end{gathered}
$$

1078

di mana $\theta_{1}, \theta_{2}$ dan $\theta_{3}$ memaksimumkan $L(\Omega)$. Dengan demikian,

$$
\begin{aligned}
L(\hat{\Omega}) & =\left[\frac{e^{-1}}{2 \pi \theta_{3}}\right]^{(n+m) / 2} \\
L(\hat{\omega}) & =\left[\frac{e^{-1}}{2 \pi \theta_{3 \omega}}\right]^{(n+m) / 2},
\end{aligned}
$$

1079 sehingga

$$
\begin{aligned}
\Lambda(x) & =\frac{L(\hat{\omega})}{L(\hat{\Omega})}=\left[\frac{\theta_{3}}{\theta_{3 \omega}}\right]^{(n+m) / 2} \\
\Lambda^{2 /(n+m)}(X) & =\frac{\hat{\theta}_{3}}{\hat{\theta}_{3 \omega}} \\
& =\frac{\sum_{i=1}^{n}\left(X_{i}-\bar{X}\right)^{2}+\sum_{i=1}^{m}\left(Y_{i}-\bar{Y}\right)^{2}}{\sum_{i=1}^{n}\left(X_{i}-\frac{n \bar{X}+m \bar{Y}}{n+m}\right)^{2}+\sum_{i=1}^{m}\left(Y_{i}-\frac{n \bar{X}+m \bar{Y}}{n+m}\right)^{2}} .
\end{aligned}
$$

1080

Karena

$$
\begin{aligned}
\sum_{i=1}^{n}\left(X_{i}-\frac{n \bar{X}+m \bar{Y}}{n+m}\right)^{2} & =\sum_{i=1}^{n}\left(\left[X_{i}-\bar{X}\right]+\left[\bar{X}-\frac{n \bar{X}+m \bar{Y}}{n+m}\right]\right)^{2} \\
& =\sum_{i=1}^{n}\left(X_{i}-\bar{X}\right)^{2}+n\left(\bar{X}-\frac{n \bar{X}+m \bar{Y}}{n+m}\right)^{2} \\
& =\sum_{i=1}^{n}\left(X_{i}-\bar{X}\right)^{2}+\frac{m^{2} n}{(n+m)^{2}}(\bar{X}-\bar{Y})^{2}
\end{aligned}
$$


1081

dan

$$
\begin{aligned}
\sum_{i=1}^{m}\left(Y_{i}-\frac{n \bar{X}+m \bar{Y}}{n+m}\right)^{2} & =\sum_{i=1}^{m}\left(\left[Y_{i}-\bar{Y}\right]+\left[\bar{Y}-\frac{n \bar{X}+m \bar{Y}}{n+m}\right]\right)^{2} \\
& =\sum_{i=1}^{m}\left(Y_{i}-\bar{Y}\right)^{2}+m\left(\bar{Y}-\frac{n \bar{X}+m \bar{Y}}{n+m}\right)^{2} \\
& =\sum_{i=1}^{m}\left(Y_{i}-\bar{Y}\right)^{2}+\frac{n^{2} m}{(n+m)^{2}}(\bar{X}-\bar{Y})^{2}
\end{aligned}
$$

1082

maka

$$
\begin{aligned}
\Lambda^{2 /(n+m)}(X) & =\frac{\sum_{i=1}^{n}\left(X_{i}-\bar{X}\right)^{2}+\sum_{i=1}^{m}\left(Y_{i}-\bar{Y}\right)^{2}}{\sum_{i=1}^{n}\left(X_{i}-\bar{X}\right)^{2}+\sum_{i=1}^{m}\left(Y_{i}-\bar{Y}\right)^{2}+[n m /(n+m)](\bar{X}-\bar{Y})^{2}} \\
& =\frac{1}{1+\frac{[n m /(n+m)](\bar{X}-\bar{Y})^{2}}{\sum_{i=1}^{n}\left(X_{i}-\bar{X}\right)^{2}+\sum_{i=1}^{m}\left(Y_{i}-\bar{Y}\right)^{2}}} .
\end{aligned}
$$

Jika hipotesis $H_{0}: \theta_{1}=\theta_{2}$ benar, maka peubah acak

$T=\sqrt{\frac{n m}{n+m}}(\bar{X}-\bar{Y})\left\{(n+m-2)^{-1}\left[\sum_{i=1}^{n}\left(X_{i}-\bar{X}\right)^{2}+\sum_{i=1}^{m}\left(Y_{i}-\bar{Y}\right)^{2}\right]\right\}^{-1 / 2}$

memiliki sebaran t-Student dengan derajat bebas $n+m-2$. Dengan demikian, peubah acak $\Lambda^{2 /(n+m)}(X)$ dapat dituliskan menjadi

$$
\frac{n+m-2}{(n+m-2)+T^{2}}
$$

sehingga daerah kritis $C$ ialah $C=\left\{|t| \geq t_{\alpha / 2}(n+m-2)\right\}$, di mana $t$ adalah nilai amatan dari peubah acak $T$.

Definisi 6.3 Misalkan peubah acak $Z \sim N(\delta, 1)$ dan peubah acak $U \sim$ $\chi^{2}(r)$, serta dua peubah acak tersebut saling bebas, maka peubah acak

$$
T=\frac{Z}{\sqrt{U / r}}
$$

dikatakan memiliki sebaran $t$ takterpusat dengan derajat bebas $r$ dan parameter takterpusat $\delta$. Jika $\delta=0$, maka $T$ disebut memiliki sebaran terpusat $t$. 
Kedua peubah acak tersebut saling bebas dan

$$
\begin{aligned}
& Z_{2} \sim N\left(\sqrt{n m /(n+m)}\left(\theta_{1}-\theta_{2}\right) / \sigma, 1\right) \\
& U_{2} \sim \chi^{2}(n+m-2) .
\end{aligned}
$$

Dengan demikian, jika $\theta_{1} \neq \theta_{2}$, maka $T$ memiliki sebaran $t$ takterpusat dengan derajat bebas $n+m-2$ dan parameter takterpusatnya

$$
\delta_{2}=\sqrt{n m /(n+m)}\left(\theta_{1}-\theta_{2}\right) / \sigma .
$$


Misalkan suatu statistik $-2 \ln \Lambda(X)$ dengan

$$
\Lambda(x)=\frac{L(\hat{\omega})}{L(\hat{\Omega})} .
$$

Berdasarkan prinsip dari uji rasio kemungkinan, $H_{0}$ ditolak jika dan hanya jika $\Lambda \leq \lambda_{0}$, sehingga untuk statistik $-2 \ln \Lambda, H_{0}$ ditolak jika $-2 \ln \Lambda>\lambda_{1}$ untuk suatu konstanta $\lambda_{1}$. Dengan demikian, uji rasio kemungkinan ekuivalen dengan uji yang menggunakan statistik $-2 \ln \Lambda$. Berikut ini merupakan teorema yang menyatakan sebaran asimtotik bagi $-2 \ln \Lambda$.

Teorema 6.2 Misalkan $X_{1}, X_{2}, \ldots, X_{n}$ adalah sampel acak dengan fungsi kepekatan peluang $f(\mathbf{x} ; \theta), \theta \in \Omega$, di mana $\Omega$ merupakan himpunan bagian berdimensi $r$ dari $\mathbb{R}^{r}$ dan misalkan $\omega$ merupakan himpunan bagian berdimensi $m$ dari $\Omega$. Misalkan pula himpunan positif dari fungsi kepekatan peluang tidak bergantung pada $\theta$, maka sebaran asimtotik dari $-2 \ln \Lambda$ ialah $\chi^{2}(r-m)$, asalkan $\theta \in \omega$, yaitu saat $n \rightarrow \infty$,

$$
P_{\theta}(-2 \ln \Lambda \leq x) \rightarrow G(x), x \geq 0, \forall \theta \in \omega,
$$

dengan $G$ adalah fungsi sebaran dari sebaran $\chi^{2}(r-m)$.

\subsection{Uji Rasio Peluang Bersekuens}

Pada Teorema 6.1 diberikan suatu metode untuk menentukan daerah kritis terbaik untuk pengujian hipotesis sederhana lawan hipotesis alternatif sederhana. Misalkan $X_{1}, X_{2}, \ldots, X_{n}$ adalah sampel acak dengan ukuran contoh $n$ yang tetap, yang berasal dari sebaran dengan fungsi massa atau kepekatan peluang $f(x ; \theta)$, di mana $\theta=\left\{\theta: \theta=\theta^{\prime}, \theta^{\prime \prime}\right\}$ dan $\theta^{\prime}, \theta^{\prime \prime}$ diketahui nilainya. Fungsi kemungkinan dari $X_{1}, X_{2}, \ldots, X_{n}$ ialah

$$
L(\theta ; n)=f\left(x_{1} ; \theta\right) f\left(x_{2} ; \theta\right) \cdots f\left(x_{n} ; \theta\right) .
$$

Jika $H_{0}: \theta=\theta^{\prime}$ ditolak dan $H_{1}: \theta=\theta^{\prime \prime}$ diterima ketika

$$
\frac{L\left(\theta^{\prime} ; n\right)}{L\left(\theta^{\prime \prime} ; n\right)} \leq k
$$

di mana $k>0$, maka berdasarkan Teorema 6.1, hal tersebut merupakan uji terbaik dari $H_{0}$ lawan $H_{1}$.

Selanjutnya, misalkan ukuran sampel $n$ merupakan suatu peubah acak. Misalkan $N$ adalah peubah acak yang menyatakan ukuran sampel dengan 
ruang sampel $\{1,2,3, \ldots\}$. Prosedur untuk pengujian hipotesis sederhana $H_{0}$ : $\theta=\theta^{\prime}$ lawan $H_{1}: \theta=\theta^{\prime \prime}$ ialah sebagai berikut: misalkan $k_{0}$ dan $k_{1}$ merupakan konstanta positif dengan $k_{0}<k_{1}$. Amati nilai dari $X_{1}, X_{2}, \ldots, X_{n}$ pada suatu sekuens, sebagai contoh $x_{1}, x_{2}, x_{3} \ldots$ dan hitung

$$
\frac{L\left(\theta^{\prime} ; 1\right)}{L\left(\theta^{\prime \prime} ; 1\right)}, \frac{L\left(\theta^{\prime} ; 2\right)}{L\left(\theta^{\prime \prime} ; 2\right)}, \frac{L\left(\theta^{\prime} ; 3\right)}{L\left(\theta^{\prime \prime} ; 3\right)}, \cdots
$$

Hipotesis $H_{0}$ ditolak jika dan hanya jika terdapat bilangan bulat positif $n$ sedemikian sehingga $\mathbf{x}_{n}=\left(x_{1}, x_{2}, \ldots, x_{n}\right)$ merupakan anggota dari himpunan

$$
C_{n}=\left\{\mathbf{x}_{n}: k_{0}<\frac{L\left(\theta^{\prime} ; j\right)}{L\left(\theta^{\prime \prime} ; j\right)}<k_{1}, j=1,2, \ldots, n-1 \text { dan } \frac{L\left(\theta^{\prime} ; n\right)}{L\left(\theta^{\prime \prime} ; n\right)} \leq k_{0}\right\} .
$$

Di samping itu, hipotesis $H_{0}$ diterima jika dan hanya jika terdapat bilangan bulat positif $n$ sedemikian sehingga $\mathbf{x}_{n}=\left(x_{1}, x_{2}, \ldots, x_{n}\right)$ merupakan anggota dari himpunan

$$
A_{n}=\left\{\mathbf{x}_{n}: k_{0}<\frac{L\left(\theta^{\prime} ; j\right)}{L\left(\theta^{\prime \prime} ; j\right)}<k_{1}, j=1,2, \ldots, n-1 \text { dan } \frac{L\left(\theta^{\prime} ; n\right)}{L\left(\theta^{\prime \prime} ; n\right)} \geq k_{1}\right\},
$$

Dengan kata lain, pengamatan contoh dilanjutkan selama

$$
k_{0}<\frac{L\left(\theta^{\prime} ; n\right)}{L\left(\theta^{\prime \prime} ; n\right)}<k_{1}
$$

dan berhenti jika:

1. Dengan penolakan $H_{0}: \theta=\theta^{\prime}$,

$$
\frac{L\left(\theta^{\prime} ; n\right)}{L\left(\theta^{\prime \prime} ; n\right)} \leq k_{0}
$$

2. Dengan penerimaan $H_{0}: \theta=\theta^{\prime}$,

$$
\frac{L\left(\theta^{\prime} ; n\right)}{L\left(\theta^{\prime \prime} ; n\right)} \geq k_{1}
$$

Pengujian hipotesis tersebut disebut uji rasio peluang bersekuens Wald (Wald's sequential probability ratio test). Seringkali, pertaksamaan 6.5 dituliskan menjadi

$$
c_{0}(n)<u\left(x_{1}, x_{2}, \ldots, x_{n}\right)<c_{1}(n)
$$

di mana $u\left(X_{1}, X_{2}, \ldots, X_{n}\right)$ adalah suatu statistik dan $c_{0}(n), c_{1}(n)$ adalah konstanta yang bergantung terhadap $k_{0}, k_{1}, \theta^{\prime}, \theta^{\prime \prime}$, dan $n$, sehingga pengamatan dihentikan serta putusan ditentukan ketika

$$
u\left(x_{1}, x_{2}, \ldots, x_{n}\right) \leq c_{0}(n) \text { atau } u\left(x_{1}, x_{2}, \ldots, x_{n}\right) \geq c_{1}(n) .
$$


Contoh 6.8 Misalkan X memiliki fungsi massa peluang

$$
f(x ; \theta)=\theta^{x}(1-\theta)^{1-x} \mathbf{I}(x=0,1) .
$$

1109

Tentukan daerah kritis bagi hipotesis

$$
\begin{aligned}
& H_{0}: \quad \theta=\frac{1}{3} \\
& H_{1}: \quad \theta=\frac{2}{3}
\end{aligned}
$$

dengan menggunakan uji rasio peluang bersekuens Wald.

Jawab.

$$
\frac{L\left(\frac{1}{3} ; n\right)}{L\left(\frac{2}{3} ; n\right)}=\frac{\left(\frac{1}{3}\right)^{\Sigma x_{i}}\left(\frac{2}{3}\right)^{n-\Sigma x_{i}}}{\left(\frac{2}{3}\right)^{\Sigma x_{i}}\left(\frac{1}{3}\right)^{n-\Sigma x_{i}}}=2^{n-2 \Sigma x_{i}},
$$

di mana $\Sigma x_{i}=\sum_{i=1}^{n} x_{i}$.

$$
\begin{gathered}
k_{0}<\frac{L\left(\frac{1}{3} ; n\right)}{L\left(\frac{2}{3} ; n\right)}<k_{1} \\
\log _{2} k_{0}<n-2 \sum_{i=1}^{n} x_{i}<\log _{2} k_{1} \\
c_{0}(n)=\frac{n}{2}-\frac{1}{2} \log _{2} k_{1}<\sum_{i=1}^{n} x_{i}<\frac{n}{2}-\frac{1}{2} \log _{2} k_{0}=c_{1}(n) .
\end{gathered}
$$

Perhatikan bahwa $L\left(\frac{1}{3} ; n\right) / L\left(\frac{2}{3} ; n\right) \leq k_{0}$ jika dan hanya jika $c_{1}(n) \leq \sum_{i=1}^{n} x_{i}$ dan $L\left(\frac{1}{3} ; n\right) / L\left(\frac{2}{3} ; n\right) \geq k_{1}$ jika dan hanya jika $c_{0}(n) \geq \sum_{i=1}^{n} x_{i}$. Dengan demikian, pengamatan contoh dilanjutkan selama

$$
c_{0}(n)<\sum_{i=1}^{n} x_{i}<c_{1}(n) .
$$

Daerah penolakan $H_{0}: \theta=\frac{1}{3}$ ialah $\sum_{i=1}^{n} x_{i} \geq c_{1}(n)$ dan daerah penerimaan $H_{0}: \theta=\frac{1}{3}$ ialah $\sum_{i=1}^{n} x_{i} \leq c_{0}(n)$.

Pada subbab ini, kuasa dari uji ketika $H_{0}$ benar dinotasikan $\alpha$ dan kuasa dari uji ketika $H_{1}$ benar dinotasikan $1-\beta$. Dengan demikian, $\alpha$ adalah peluang terjadinya kesalahan jenis I (penolakan $H_{0}$ padahal $H_{0}$ benar) dan $\beta$ adalah peluang terjadinya kesalahan jenis II (penerimaan $H_{0}$ padahal $H_{0}$ salah), sehingga (dalam kasus kontinu)

$$
\alpha=\sum_{n=1}^{\infty} \int_{C_{n}} L\left(\theta^{\prime} ; n\right), \quad(1-\beta)=\sum_{n=1}^{\infty} \int_{C_{n}} L\left(\theta^{\prime \prime} ; n\right) .
$$


Karena peluang bernilai satu ketika prosedur berakhir, maka

$$
1-\alpha=\sum_{n=1}^{\infty} \int_{A_{n}} L\left(\theta^{\prime} ; n\right), \quad \beta=\sum_{n=1}^{\infty} \int_{A_{n}} L\left(\theta^{\prime \prime} ; n\right) .
$$

Jika $\left(x_{1}, x_{2}, \ldots, x_{n}\right) \in C_{n}$, maka $L\left(\theta^{\prime} ; n\right) \leq k_{0} L\left(\theta^{\prime \prime} ; n\right)$, sehingga jelas bahwa

$$
\alpha=\sum_{n=1}^{\infty} \int_{C_{n}} L\left(\theta^{\prime} ; n\right) \leq \sum_{n=1}^{\infty} \int_{C_{n}} k_{0} L\left(\theta^{\prime \prime} ; n\right)=k_{0}(1-\beta) .
$$

Karena $L\left(\theta^{\prime} ; n\right) \geq k_{1} L\left(\theta^{\prime \prime} ; n\right)$ pada setiap titik dari himpunan $A_{n}$, maka

$$
1-\alpha=\sum_{n=1}^{\infty} \int_{A_{n}} L\left(\theta^{\prime} ; n\right) \geq \sum_{n=1}^{\infty} \int_{A_{n}} k_{1} L\left(\theta^{\prime \prime} ; n\right)=k_{1} \beta .
$$

1113 Oleh karena itu,

$$
\frac{\alpha}{1-\beta} \leq k_{0}, \quad k_{1} \leq \frac{1-\alpha}{\beta}
$$

1114 asalkan $\beta$ tidak bernilai 0 atau 1 .

Misalkan $\alpha_{0}$ dan $\beta_{0}$ adalah nilai yang ditetapkan sebelumnya. Jika kita mengambil

$$
k_{0}=\frac{\alpha_{0}}{1-\beta_{0}} \text { dan } k_{1}=\frac{1-\alpha_{0}}{\beta_{0}},
$$

maka pertaksamaan 6.6 menjadi

$$
\frac{\alpha}{1-\beta} \leq \frac{\alpha_{0}}{1-\beta_{0}}, \quad \frac{1-\alpha_{0}}{\beta_{0}} \leq \frac{1-\alpha}{\beta}
$$

1115

atau ekuivalen dengan

$$
\alpha\left(1-\beta_{0}\right) \leq \alpha_{0}(1-\beta), \quad \beta\left(1-\alpha_{0}\right) \leq \beta_{0}(1-\alpha) .
$$

Apabila kedua pertaksamaan 6.7 dijumlahkan, maka diperoleh

$$
\alpha+\beta \leq \alpha_{0}+\beta_{0}
$$

Dengan demikian, diperoleh batas atas dari $\alpha$ dan $\beta$ ialah

$$
\alpha \leq \frac{\alpha_{0}}{1-\beta_{0}}, \beta \leq \frac{\beta_{0}}{1-\alpha_{0}},
$$

1116 serta secara empiris

$$
\begin{aligned}
& \alpha \approx \alpha_{0}, \\
& \beta \approx \beta_{0} .
\end{aligned}
$$


$1117 \quad$ Pada Contoh 6.8, bila $\alpha=0.01$ dan $\beta=0.05$, maka

$$
\begin{aligned}
& k_{0}=\frac{0.01}{1-0.05}=\frac{1}{95} \\
& k_{1}=\frac{1-0.01}{0.05}=\frac{99}{5},
\end{aligned}
$$

sehingga tolak $H_{0}$ bila

$$
\sum_{i=1}^{n} x_{i} \geq \frac{n}{2}-\frac{1}{2} \log _{2} \frac{1}{95}=c_{1}(n)
$$

dan terima $H_{1}$ bila

$$
\sum_{i=1}^{n} x_{i} \leq \frac{n}{2}-\frac{1}{2} \log _{2} \frac{99}{5}=c_{0}(n) .
$$

Catatan 6.1 Peluang bahwa prosedur dari pengujian tersebut terus berlanjut sampai $n \rightarrow \infty$ ialah nol. Jika $\theta=\theta^{\prime}$ atau $\theta=\theta^{\prime \prime}$, maka

$$
\begin{aligned}
& E\left(N \mid H_{0}\right)=\frac{1}{E\left(Z \mid H_{0}\right)}\left[\alpha \ln k_{0}+(1-\alpha) \ln k_{1}\right], \\
& E\left(N \mid H_{1}\right)=\frac{1}{E\left(Z \mid H_{1}\right)}\left[(1-\beta) \ln k_{0}+\beta \ln k_{1}\right],
\end{aligned}
$$

di mana

$$
Z=\ln \frac{f\left(X ; \theta^{\prime}\right)}{f\left(X ; \theta^{\prime \prime}\right)}
$$

dan $N$ merupakan peubah acak yang menyatakan ukuran sampel.

Contoh 6.9 Misalkan $X$ memiliki sebaran $N \sim(\mu, 1)$. Gunakan uji rasio peluang bersekuens Wald untuk menentukan rata-rata ukuran contoh yang diharapkan untuk sampai pada suatu putusan bila diketahui hipotesis sebagai berikut :

$$
\begin{aligned}
& H_{0}: \quad \mu=0 \\
& H_{1}: \quad \mu=1
\end{aligned}
$$

dengan $\alpha=\beta=0.01$ 
1126 Jawab.

$$
\begin{aligned}
k_{0} & =\frac{0.01}{1-0.01}=\frac{1}{99} \\
k_{1} & =\frac{1-0.01}{0.01}=99 \\
Z & =\ln \frac{f\left(X ; \theta^{\prime}\right)}{f\left(X ; \theta^{\prime \prime}\right)} \\
& =\ln \left[\frac{\exp \left(-\frac{1}{2} X^{2}\right)}{\exp \left(-\frac{1}{2}[X-1]^{2}\right)}\right] \\
& =-\frac{1}{2}\left[X^{2}-(X-1)^{2}\right] \\
& =\frac{1}{2}-X
\end{aligned}
$$

1127

$$
\begin{aligned}
E\left(Z \mid H_{0}\right) & =E\left(\frac{1}{2}-X \mid H_{0}\right) \\
& =\frac{1}{2}-E(X \mid \mu=0) \\
& =\frac{1}{2} \\
E\left(Z \mid H_{1}\right) & =E\left(\frac{1}{2}-X \mid H_{1}\right) \\
& =\frac{1}{2}-E(X \mid \mu=1) \\
& =\frac{1}{2}-1 \\
& =-\frac{1}{2}
\end{aligned}
$$

1128

$$
\begin{aligned}
& E\left(N \mid H_{0}\right)=\frac{1}{1 / 2}\left[0.01 \ln \left(\frac{1}{99}\right)+0.99 \ln (99)\right]=9 \\
& E\left(N \mid H_{1}\right)=\frac{1}{-1 / 2}\left[0.99 \ln \left(\frac{1}{99}\right)+0.01 \ln (99)\right]=9
\end{aligned}
$$


1129 Sebagai pembanding, gunakan uji terbaiknya.

$$
\begin{aligned}
\alpha & =P\left(\bar{X}>k \mid H_{0}\right) \\
0.01 & =P\left(\frac{\bar{X}}{\sqrt{\frac{1}{n}}}>\frac{k}{\sqrt{\frac{1}{n}}}\right) \\
0.01 & =P\left(Z>\frac{k}{\sqrt{\frac{1}{n}}}\right) \\
0.01 & =P(Z>2.325),
\end{aligned}
$$

1130 sehingga

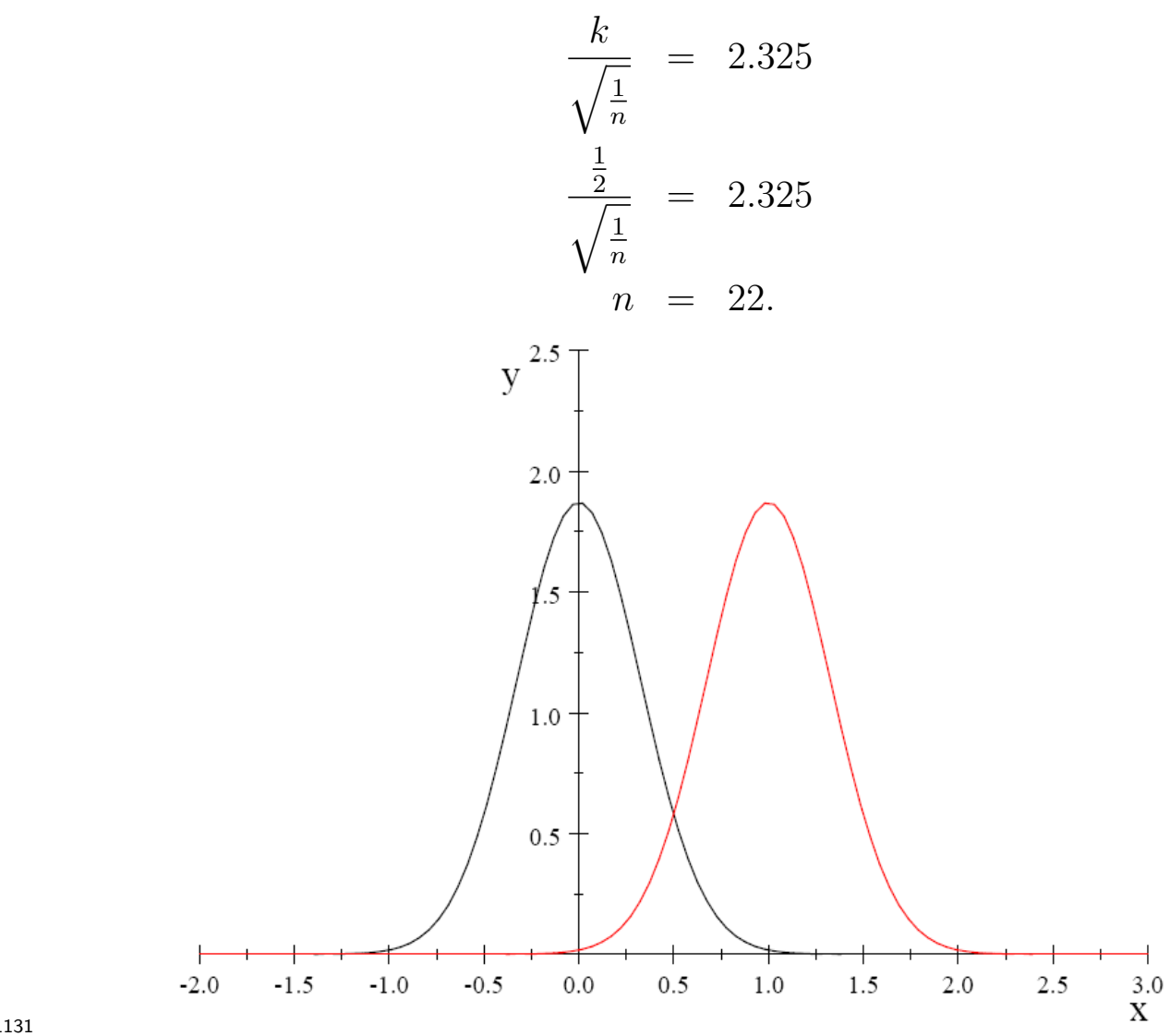

1132

巫

${ }_{1133} 6.5$ Latihan

1134 1. Misalkan $X_{1}, X_{2}, \ldots, X_{n}$ merupakan sampel acak dari sebaran $N(\theta, 25)$. 
(a) Tunjukkanlah bahwa $C=\left\{\left(x_{1}, x_{2}, \ldots, x_{n}\right): \frac{\sum_{i=1}^{n} x_{i}}{n} \geq c\right\}$ merupakan daerah kritis terbaik untuk pengujian $H_{0}: \theta=10$ lawan $H_{1}: \theta=12$.

(b) Tentukan pula $n$ dan $c$ sehingga $\alpha=0.05$ dan $1-\beta=0.90$.

\section{Catatan:}

Bila $Z^{\sim} N(0,1)$, maka $P(Z \geq 1.645)=0.05$ dan $P(Z \geq 1.285)=0.10$.

2. Misalkan $X_{1}, X_{2}, \ldots, X_{10}$ merupakan sampel acak dari sebaran $N(0, \theta)$ untuk pengujian

$$
H_{0}: \theta=5 \text { lawan } H_{1}: \theta>5 .
$$

(a) Tunjukkanlah bahwa ada Uji Selalu Paling Kuasa (UMPT, Uniformly Most Powerful Test) dalam pengujian ini.

(b) Bila $\alpha=0.05$ maka berikanlah daerah kritis dan fungsi kuasanya.

3. Misalkan $X_{1}, X_{2}, \ldots, X_{n}$ merupakan sampel acak dari sebaran $N(5, \theta)$, $\theta>0$, untuk pengujian

$$
H_{0}: \theta=\theta_{0} \text { lawan } H_{1}: \theta \neq \theta_{0}
$$

(a) Apakah dapat diperoleh uji selalu paling kuasa (Uniformly Most Powerful Test)? Jelaskan.

(b) Tunjukkanlah bahwa uji rasio kemungkinan (LRT, Likelihood Ratio Test) $H_{0}: \theta=\theta_{0}$ lawan $H_{1}: \theta \neq \theta_{0}$ dapat didasarkan pada statistik $W=\sum_{i=1}^{n}\left(X_{i}-5\right)^{2} / \theta_{0}$. Tentukan sebaran dari $W$ bila $H_{0}$ benar dan berikan daerah kritisnya untuk taraf nyata (level of significance) $\alpha$.

4. Berikut fungsi massa peluang peubah acak $\mathrm{Z}$ dengan $0<\theta<1$ :

\begin{tabular}{cccc}
\hline Amatan $(z)$ & $f\left(z ; \theta_{0}\right)$ & $f(z ; \theta)$ & $f\left(z ; \theta_{0}\right) / \sup f(z ; \theta)$ \\
\hline$z_{1}$ & $1 / 12$ & $\theta / 3$ & $\cdots$ \\
$z_{2}$ & $1 / 12$ & $(1 / 3)(1-\theta)$ & $\cdots$ \\
$z_{3}$ & $1 / 6$ & $1 / 2$ & $\cdots$ \\
$z_{4}$ & $2 / 3$ & $1 / 6$ & $\cdots$ \\
\hline
\end{tabular}

Isilah nilai $f\left(z ; \theta_{0}\right) / \sup f(z ; \theta)$ pada tabel di atas dan berikanlah uji rasio kemungkinan (LRT, Likelihood Ratio Test) untuk pengujian $H_{0}$ : $\theta=\theta_{0}$ lawan $H_{1}: \theta \neq \theta_{0}$ dengan amatan tunggal untuk $\alpha=1 / 6$. Berikan pula kuasa uji-nya $(1-\beta)$. 
1155

1156

1157

1158

1159

5. Misalkan peubah acak $X$ bersebaran $N(0, \theta)$. Berikanlah uji rasio peluang bersekuens (SPRT, Sequential Probability Ratio Test) bagi $H_{0}: \theta=4$ lawan $H_{1}: \theta=9$ dengan $\alpha=0.05$ dan $\beta=0.10$. Berikan pula rata-rata ukuran contoh yang diharapkan untuk sampai pada suatu putusan. 


\section{LAMPIRAN}

1. Terdapat 7 karyawan di departemen Aktuaria dan 6 karyawan di departemen Market Management. Akan dibentuk suatu tim khusus untuk melakukan analisa terhadap suatu produk asuransi yang akan diluncurkan. Hitunglah banyaknya cara untuk membentuk tim khusus dengan memilih 3 karyawan dari departemen Aktuaria dan 2 karyawan dari departemen Market Management.

Jawab:

Banyaknya cara untuk membentuk tim khusus dengan memilih 3 karyawan dari departemen Aktuaria dan 2 karyawan dari departemen Market Management adalah

$$
\left(\begin{array}{l}
7 \\
3
\end{array}\right) \times\left(\begin{array}{l}
6 \\
2
\end{array}\right)=35 \times 15=525
$$


1168

1169

1170

1171

1172

1173

1174

1175

2. Dari soal nomor 1, hitunglah probabilitas bahwa tim khusus dari 5 karyawan yang dipilih secara acak tersebut, terdiri dari 3 karyawan dari departemen Aktuaria dan 2 karyawan dari departemen Market Management.

Jawab:

$$
\begin{aligned}
& \left(\begin{array}{l}
7 \\
0
\end{array}\right) \times\left(\begin{array}{l}
6 \\
5
\end{array}\right)=1 \times 6=6 \\
& \left(\begin{array}{l}
7 \\
1
\end{array}\right) \times\left(\begin{array}{l}
6 \\
4
\end{array}\right)=7 \times 15=105 \\
& \left(\begin{array}{l}
7 \\
2
\end{array}\right) \times\left(\begin{array}{l}
6 \\
3
\end{array}\right)=21 \times 20=420 \\
& \left(\begin{array}{l}
7 \\
3
\end{array}\right) \times\left(\begin{array}{l}
6 \\
2
\end{array}\right)=35 \times 15=525 \\
& \left(\begin{array}{l}
7 \\
4
\end{array}\right) \times\left(\begin{array}{l}
6 \\
1
\end{array}\right)=35 \times 6=210 \\
& \left(\begin{array}{l}
7 \\
5
\end{array}\right) \times\left(\begin{array}{l}
6 \\
0
\end{array}\right)=21 \times 1=21
\end{aligned}
$$

Jadi probabilitas bahwa tim khusus dari 5 karyawan yang dipilih secara acak tersebut, terdiri dari 3 karyawan dari departemen Aktuaria dan 2 karyawan dari departemen Market Management adalah

$$
\frac{525}{6+105+420+525+210+21}=\frac{525}{1287}=0,41 .
$$


1176

1177

1178

1179

1180

1181

1182

3. Di sebuah perusahaan asuransi terdapat 3 sub bagian di bagian product development yang akan diisi oleh 7 karyawan baru yang telah memenuhi seleksi. Sub bagian pertama tersedia 2 posisi, sub bagian kedua tersedia 2 posisi, dan sub bagian ketiga tersedia 3 posisi. Hitunglah banyaknya cara yang mungkin untuk menempatkan karyawan tersebut ke dalam posisi yang tersedia.

Jawab:

Banyaknya cara yang mungkin untuk menempatkan karyawan tersebut ke dalam posisi yang tersedia adalah

$$
\left(\begin{array}{lll} 
& 7 & \\
2 & 2 & 3
\end{array}\right)=\frac{7 !}{2 ! 2 ! 3 !}=210 .
$$


1183

4. Misalkan $N$ adalah jumlah klaim per bulan, dengan

$$
\operatorname{Pr}(N=n)=\frac{1}{(n+1)(n+2)}
$$

1184

1185

1186

1187

1188 bulan tersebut.

Jawab:

dimana $0 \leq n$. Tentukanlah probabilitas dari sedikitnya satu klaim selama bulan tertentu, diberikan paling banyak empat klaim selama

Probabilitas dari sedikitnya satu klaim selama bulan tertentu adalah

$$
\begin{aligned}
\operatorname{Pr}(N \geq 1 \mid N \leq 4) & =\frac{\operatorname{Pr}(1 \leq N \leq 4)}{\operatorname{Pr}(N \leq 4)} \\
& =\frac{\Sigma_{1}^{4} \frac{1}{(n+1)(n+2)}}{\sum_{0}^{4} \frac{1}{(n+1)(n+2)}} \\
& =\frac{2}{5} \\
& =0,4 .
\end{aligned}
$$


5. Misalkan kejadian $A$ dan $B$ saling bebas dengan $\operatorname{Pr}\left(A \cap B^{c}\right)=0,2$ dan $\operatorname{Pr}\left(A^{c} \cap B\right)=0,3$.

Hitunglah $\operatorname{Pr}(A \cup B)$.

Jawab:

Karena kejadian $A$ dan $B$ saling bebas maka diperoleh

$$
\begin{aligned}
\operatorname{Pr}(A \cap B) & =\operatorname{Pr}(A) \cdot \operatorname{Pr}(B) \\
\operatorname{Pr}(A \cap B) & =\left(\operatorname{Pr}\left(A \cap B^{c}\right)+\operatorname{Pr}(A \cap B)\right)\left(\operatorname{Pr}\left(A^{c} \cap B\right)+\operatorname{Pr}(A \cap B)\right) \\
x & =(0,2+x)(0,3+x) \\
x & =0,06+0,5 x+x^{2} \\
0 & =x^{2}-0,5 x+0,06 .
\end{aligned}
$$

Nilai $\operatorname{Pr}(A \cap B)=x$ yang memenuhi persamaan di atas adalah 0,2 atau 0, 3. Karena $\operatorname{Pr}(A \cup B)=\operatorname{Pr}\left(A \cap B^{c}\right)+\operatorname{Pr}\left(A^{c} \cap B\right)+\operatorname{Pr}(A \cap B)$ maka nilai $\operatorname{Pr}(A \cup B)$ yang mungkin adalah 0,7 atau 0,8 . 
6. Sebuah perusahaan asuransi menentukan bahwa N, jumlah klaim yang diterima dalam satu minggu, memenuhi $\operatorname{Pr}[N=n]=\frac{1}{2^{n+1}}$, dimana $n \geq 0$. Perusahaan juga menentukan bahwa jumlah klaim yang diterima dalam satu minggu adalah saling bebas dari jumlah klaim yang diterima dalam minggu yang lain. Tentukanlah probabilitas bahwa tepatnya tujuh klaim akan diterima selama periode dua minggu.

Jawab:

Probabilitas bahwa tepatnya tujuh klaim akan diterima selama periode dua minggu adalah

$$
\begin{aligned}
& 2(\operatorname{Pr}(N=0) \operatorname{Pr}(N=7)+\operatorname{Pr}(N=1) \operatorname{Pr}(N=6)+\operatorname{Pr}(N=2) \operatorname{Pr}(N=5) \\
& +\operatorname{Pr}(N=3) \operatorname{Pr}(N=4)) \\
& =2\left(\frac{1}{2^{1}} \frac{1}{2^{8}}+\frac{1}{2^{2}} \frac{1}{2^{7}}+\frac{1}{2^{3}} \frac{1}{2^{6}}+\frac{1}{2^{4}} \frac{1}{2^{5}}\right) \\
& =2 \times 4 \times \frac{1}{2^{9}} \\
& =\frac{1}{64} .
\end{aligned}
$$


7. Sebuah polis asuransi memberikan manfaat individu sebesar 100 per hari untuk biaya perawatan sampai 3 hari dan 25 per hari untuk biaya perawatan setelah 3 hari seterusnya. Jumlah hari perawatan, X, adalah variabel acak diskrit dengan fungsi probabilitas

$$
P(X=k)= \begin{cases}\frac{6-k}{15} & \text { untuk } k=1,2,3,4,5 \\ 0 & \text { lainnya }\end{cases}
$$

Hitunglah nilai variansi pembayaran biaya perawatan dari polis asuransi tersebut.

Jawab:

Misal $B$ merupakan variabel acak yang menyatakan biaya perawatan, maka diperoleh:

$$
B(x)=\left\{\begin{array}{lll}
100 x & ; & x=1,2,3 \\
25 x & ; & x=4,5
\end{array}\right.
$$

Jadi,

$$
\begin{aligned}
E[B(x)] & =\sum_{k=1}^{k=5} B(k) P(X=k) \\
& =100 \cdot\left(1 \cdot \frac{6-1}{15}+2 \cdot \frac{6-2}{15}+3 \cdot \frac{6-3}{15}\right)+25 \cdot\left(4 \cdot \frac{6-4}{15}+5 \cdot \frac{6-5}{15}\right) \\
& =168,33 . \\
E\left[B^{2}(x)\right] & =\sum_{k=1}^{k=5} B^{2}(k) P(X=k) \\
& =100^{2} \cdot\left(1^{2} \cdot \frac{6-1}{15}+2^{2} \cdot \frac{6-2}{15}+3^{2} \cdot \frac{6-3}{15}\right)+25^{2} \cdot\left(4^{2} \cdot \frac{6-4}{15}+5^{2} \cdot \frac{6-5}{15}\right) \\
& =34375 . \\
\operatorname{Var}[B(x)] & =E\left[B^{2}(x)\right]-(E[B(x)])^{2} \\
& =34375-(168,33)^{2} \\
& =6038,9 .
\end{aligned}
$$


1207

1208

1209

1210

1211

1212

1213

1214

1215

8. Misalkan $X$ adalah variabel acak diskrit dengan distribusi probabilitas sebagai berikut:

\begin{tabular}{|c|c|c|c|c|c|}
\hline$x$ & 2 & 4 & 6 & 7 & 12 \\
\hline $\operatorname{Pr}(X=x)$ & $3 / 7$ & $1 / 7$ & $1 / 7$ & $1 / 7$ & $1 / 7$ \\
\hline
\end{tabular}

Hitunglah nilai persentil ke-60 dari $X$.

Jawab:

Karena $60=\frac{100 i}{8}$ sehingga $i=4,8$. Berdasarkan data di atas, dengan mengasumsikan bahwa data di atas sebanyak 7 data, kita ketahui bahwa data ke-empat, $x_{4}=4$, dan data ke-lima, $x_{5}=6$. Oleh karena itu persentil ke-60 dari data di atas adalah $80 \%$ dari 4 ke 6 atau

$$
4+(6-4) *(0,8)=5,6 .
$$


9. Distribusi probabilitas dari ukuran klaim untuk sebuah polis asuransi diberikan dalam tabel berikut.

\begin{tabular}{|c|c|c|c|c|c|c|c|}
\hline Ukuran klaim & 20 & 30 & 40 & 50 & 60 & 70 & 80 \\
\hline Probabilitas & 0,15 & 0,10 & 0,05 & 0,20 & 0,10 & 0,10 & 0,30 \\
\hline
\end{tabular}

Tentukanlah persentase dari klaim yang terletak dalam nilai satu standar deviasi dari rata-rata ukuran klaim.

Jawab:

Rata-rata ukuran klaim

$=20 \cdot 0,15+30 \cdot 0,10+40 \cdot 0,05+50 \cdot 0,20+60 \cdot 0,10+70 \cdot 0,10+80 \cdot 0,30$

$=3+3+2+10+6+7+24$

$=55$

Rata-rata ukuran klaim kuadrat

$=20^{2} \cdot 0,15+30^{2} \cdot 0,10+40^{2} \cdot 0,05+50^{2} \cdot 0,20+60^{2} \cdot 0,10+70^{2} \cdot 0,10+80^{2} \cdot 0,30$

$=60+90+80+500+360+490+1920$

$=3500$

Standar deviasi ukuran klaim $=\sqrt{3500-3025}=\sqrt{475}=21,8$ Jadi persentase dari klaim yang terletak dalam nilai satu standar deviasi dari rata-rata ukuran klaim (ukuran klaim yang terletak pada interval $[55-21,8 ; 22+21,8]=[33,2 ; 76,8])$ adalah $45 \%$. 
1232

10. Misalkan dipilih sebuah angka $W$ yang merupakan variabel acak dari 50, 55, 60, 65, 70. Hitunglah $\operatorname{Pr}[W \geq 55]$.

Petunjuk: $W=5 X+45$, dimana $X$ mempunyai distribusi uniform diskrit pada $1,2,3,4,5$.

Jawab:

Karena $X$ mempunyai distribusi uniform diskrit pada 1, 2, 3, 4, 5, maka

$$
\begin{aligned}
\operatorname{Pr}[X=k]= & \frac{1}{5} \text { untuk } k=1,2,3,4,5 \\
\operatorname{Pr}[W \geq 55] & =1-\operatorname{Pr}[W<55] \\
& =1-\operatorname{Pr}[W=50] \\
& =1-\operatorname{Pr}[5 X+45=50] \\
& =1-\operatorname{Pr}[X=1] \\
& =1-\frac{1}{5} \\
& =\frac{4}{5} .
\end{aligned}
$$


11. Misalkan $X$ adalah variabel acak yang mempunyai distribusi binomial dengan $n=10$ dan $\operatorname{Var}[X]=0,25 E[X]$.

Hitunglah probabilitas untuk $X=7$.

Jawab:

Karena $X$ adalah variabel acak yang mempunyai distribusi binomial dengan $n=10$ maka $E[X]=10 p$ dan $\operatorname{Var}[X]=10 p(1-p)$ dengan $p$ merupakan peluang sukses.

Karena $\operatorname{Var}[X]=0,25 E[X]$ maka diperoleh $10 p(1-p)=0,25 \cdot 10 p$. Nilai $p$ yang memenuhi adalah $p=0,75$.

Jadi

$$
\operatorname{Pr}[X=7]=\left(\begin{array}{c}
10 \\
7
\end{array}\right)(0,75)^{7}(0,25)^{3}=0,25 .
$$


1237

1238

1239

12. Misalkan $Z \sim \operatorname{Poisson}(\lambda)$ dan $E\left[Z^{2}\right]=12$.

Hitunglah $\operatorname{Pr}(Z=1)$.

Jawab:

Pertama akan ditentukan parameter $\lambda$.

Karena $Z \sim \operatorname{Poisson}(\lambda)$ maka $E[Z]=\operatorname{Var}[Z]=\lambda$.

Karena $\operatorname{Var}[Z]=E\left[Z^{2}\right]-E[Z]^{2}$ maka diperoleh $\lambda^{2}+\lambda-12=0$ atau $\lambda=3$.

Jadi,

$$
\operatorname{Pr}[Z=1]=\frac{3^{1} e^{-3}}{1 !}=0,149 .
$$


13. Masa beroperasi dari sebuah bagian mesin mempunyai distribusi kontinu pada interval $[0,40]$ dengan fungsi probabilitas densitas, $f(x)$, yang proporsional dengan $(10+x)^{-2}$. Hitunglah probabilitas untuk masa beroperasi dari sebuah bagian mesin yang lebih kecil dari 5 .

Jawab:

Misal $f(x)=k(10+x)^{-2}$ untuk $x$ pada interval $[0,40]$.

Karena $\int_{0}^{40} k(10+x)^{-2} d x=1$ maka diperoleh $k=12,5$.

Jadi

$$
\begin{aligned}
\operatorname{Pr}[X<5] & =\int_{0}^{5} 12,5(10+x)^{-2} d x \\
& =-\left.\frac{12,5}{10+x}\right|_{0} ^{5} \\
& =-0,83+1,25 \\
& =0,42 .
\end{aligned}
$$


14. Misalkan $X$ adalah variabel acak yang mempunyai fungsi distribusi kumulatif

$$
F(x)=\left\{\begin{array}{cl}
0 & , x<1 \\
\frac{x^{2}-2 x+2}{2} & , 1 \leq x<2 \\
1 & , x \geq 2
\end{array}\right.
$$

1248

1249

1250

1251

1252

1253

1254

Hitunglah variansi dari $X$.

Jawab:

Berdasarkan fungsi distribusi kumulatif di atas, maka diperoleh fkp sebagai berikut:

$$
f(x)=x-1, \quad 1 \leq x<2
$$

$$
\begin{aligned}
E[X] & =\int_{1}^{2} x(x-1) d x \\
& =\int_{1}^{2}\left(x^{2}-x\right) d x \\
& =\left.\left(\frac{1}{3} x^{3}-\frac{1}{2} x^{2}\right)\right|_{1} ^{2} \\
& =\frac{7}{3}-\frac{3}{2} \\
& =\frac{5}{6}
\end{aligned}
$$

$$
\begin{aligned}
E\left[X^{2}\right] & =\int_{1}^{2} x^{2}(x-1) d x \\
& =\int_{1}^{2}\left(x^{3}-x^{2}\right) d x \\
& =\left.\left(\frac{1}{4} x^{4}-\frac{1}{3} x^{3}\right)\right|_{1} ^{2} \\
& =\frac{15}{4}-\frac{7}{3} \\
& =\frac{17}{12}
\end{aligned}
$$

$$
\begin{aligned}
\operatorname{Var}[X] & =E\left[X^{2}\right]-(E[X])^{2} \\
& =\frac{17}{12}-\frac{25}{36} \\
& =\frac{13}{18}
\end{aligned}
$$


15. Misalkan $X_{1}, X_{2}, X_{3}$ adalah sampel acak dari distribusi diskrit dengan fungsi probabilitas

$$
p(x)= \begin{cases}\frac{1}{3} & , x=0 \\ \frac{2}{3} & , x=1 \\ 0 & , \text { lainnya }\end{cases}
$$

1255

1256

1257

1258

1259
Tentukanlah fungsi pembangkit momen, $M_{Y}(t)$, dari perkalian $Y=$ $X_{1} \cdot X_{2} \cdot X_{3}$.

Jawab:

\begin{tabular}{|c|c|c|c|c|c|}
\hline$X_{1}$ & $X_{2}$ & $X_{3}$ & $e^{t Y}$ & $p(y)$ & $e^{t Y} p(y)$ \\
\hline 0 & 0 & 0 & 1 & $\frac{1}{27}$ & $\frac{1}{27}$ \\
\hline 0 & 0 & 1 & 1 & $\frac{2}{27}$ & $\frac{2}{27}$ \\
\hline 0 & 1 & 0 & 1 & $\frac{2}{27}$ & $\frac{2}{27}$ \\
\hline 0 & 1 & 1 & 1 & $\frac{4}{27}$ & $\frac{4}{27}$ \\
\hline 1 & 0 & 0 & 1 & $\frac{2}{27}$ & $\frac{2}{27}$ \\
\hline 1 & 0 & 1 & 1 & $\frac{4}{27}$ & $\frac{4}{27}$ \\
\hline 1 & 1 & 0 & 1 & $\frac{4}{27}$ & $\frac{4}{27}$ \\
\hline 1 & 1 & 1 & $e^{t}$ & $\frac{8}{27}$ & $e^{t} \frac{8}{27}$ \\
\hline
\end{tabular}

Jadi diperoleh

$$
E\left[e^{t Y}\right]=\Sigma e^{t y} p(y)=\frac{19}{27}+\frac{8}{27} e^{t} .
$$


16. Pemilik kendaraan mengasuransikan kendaraannya dari kerusakan dengan membeli sebuah polis asuransi dengan pemotongan 250 dari total klaim yang dibayar. Dalam kejadian bahwa kendaraan mengalami kerusakan, biaya perbaikan dapat dimodelkan dengan variabel acak uniform pada interval $[0,1500]$. Hitunglah standar deviasi dari manfaat polis asuransi untuk kejadian bahwa kendaraan tersebut mengalami kerusakan.

Jawab:

Misal $X$ adalah variabel acak yang menyatakan biaya perbaikan, $X \sim$ uniform $[0,1500]$ sehingga $f(x)=\frac{1}{1500}, x \in[0,1500]$.

$$
\begin{aligned}
E[X] & =\int_{0}^{1500} \frac{1}{1500} x d x \\
& =\left.\frac{1}{3000} x^{2}\right|_{0} ^{1500} \\
& =\frac{1}{3000} 1500^{2} \\
& =750 . \\
E\left[X^{2}\right] & =\int_{0}^{1500} \frac{1}{1500} x^{2} d x \\
& =\left.\frac{1}{4500} x^{3}\right|_{0} ^{1500} \\
& =\frac{1}{4500} 1500^{3} \\
& =750000 . \\
\sigma(X) & \sqrt{E\left[X^{2}\right]-(E[X])^{2}} \\
= & \sqrt{750000-750^{2}} \\
= & 433 .
\end{aligned}
$$


1274

$$
\begin{aligned}
E\left[X^{4}\right] & =\int_{0}^{\infty} x^{4} \frac{1}{3} e^{-\frac{1}{3} x} d x \\
& =-\left.\frac{1}{3}\left(3 x^{4}+36 x^{3}+324 x^{2}+1944 x+5832\right) e^{-\frac{1}{3} x}\right|_{0} ^{\infty} \\
& =\frac{1}{3} \times 5832 \\
& =1944 .
\end{aligned}
$$


18. Misalkan $X$ adalah variabel acak dengan mean $\mu_{x}$ dan variansi $\sigma_{x}^{2}$. $X$ disebut sebagai variabel acak populasi. Misalkan $X_{1}, X_{2}, \ldots X_{n}$ adalah pengamatan-pengamatan yang berdistribusi identik dan saling bebas dari $X$.

$X_{1}, X_{2}, \ldots X_{n}$ adalah sampel acak dari $X$. Misalkan $S=\sum_{i=1}^{n} X_{i}$ dan $\bar{X}=\frac{1}{n} \sum_{i=1}^{n} X_{i} . \bar{X}$ adalah mean dari sampel.

Manakah dari pernyataan berikut yang benar.

(i) $E(S)=\mu_{X}$

(ii) $\operatorname{Var}(S)=n \cdot \sigma_{X}^{2}$

(iii) $E(X)=n \cdot \mu_{X}$

(iv) $\operatorname{Var}(\bar{X})=\frac{\sigma_{X}^{2}}{n}$

Jawab:

Pernyataan yang benar adalah (ii) dan (iv). 
1293

1294

1295

1296

19. Sebuah koin yang kedua sisinya seimbang dilempar sebanyak dua kali. Misalkan $X$ adalah banyaknya sisi pertama yang terlihat pada lemparan pertama. Misalkan $Y$ adalah banyaknya sisi pertama yang terlihat pada dua lemparan pertama. Hitunglah $\operatorname{Var}(X+Y)$.

Jawab:

\begin{tabular}{c|cc|c|c} 
Luaran & $X$ & $Y$ & $Z=X+Y$ & $\operatorname{Pr}(Z=z)$ \\
\hline$S_{1} S_{1}$ & 1 & 2 & 3 & $1 / 4$ \\
$S_{1} S_{2}$ & 1 & 1 & 2 & $1 / 4$ \\
$S_{2} S_{1}$ & 0 & 1 & 1 & $1 / 4$ \\
$S_{2} S_{2}$ & 0 & 0 & 0 & $1 / 4$
\end{tabular}

$$
\begin{aligned}
& E(Z)=\frac{1}{4}(0+1+2+3)=3 / 2 \\
& E\left(Z^{2}\right)=\frac{1}{4}(0+1+4+9)=7 / 2 \\
& \operatorname{Var}(X+Y)=\operatorname{Var}(Z)=E\left(Z^{2}\right)-(E(Z))^{2}=\frac{7}{2}-\left(\frac{3}{2}\right)^{2}=\frac{5}{4}=1,25 .
\end{aligned}
$$


1297 20. Dari soal nomor 19 , hitunglah $E(Y \mid X=1)$.

1298 Jawab:

1299

\begin{tabular}{|c|c|c|c|c|}
\hline$x \downarrow, y \longrightarrow$ & 0 & 1 & 2 & $p_{X}(x)$ \\
\hline 0 & $1 / 4$ & $1 / 4$ & 0 & $1 / 2$ \\
\hline 1 & 0 & $1 / 4$ & $1 / 4$ & $1 / 2$ \\
\hline$p_{Y}(y)$ & $1 / 4$ & $1 / 2$ & $1 / 4$ & 1 \\
\hline
\end{tabular}

$$
\begin{aligned}
E(Y \mid X=1) & =\Sigma y \cdot p(y \mid x=1) \\
& =0 \cdot p(0 \mid x=1)+1 \cdot p(1 \mid x=1)+2 \cdot p(2 \mid x=1) \\
& =0 \cdot \frac{p(1,0)}{p_{X}(1)}+1 \cdot \frac{p(1,1)}{p_{X}(1)}+2 \cdot \frac{p(1,2)}{p_{X}(1)} \\
& =0 \cdot \frac{0}{1 / 2}+1 \cdot \frac{1 / 4}{1 / 2}+2 \cdot \frac{1 / 4}{1 / 2} \\
& =0+\frac{1}{2}+1 \\
& =\frac{3}{2}=1,50 .
\end{aligned}
$$


21. Misalkan $N_{1}$ dan $N_{2}$ mewakili banyaknya klaim yang diajukan ke sebuah perusahaan asuransi di bulan April dan Mei. Fungsi probabilitas bersama dari $N_{1}$ dan $N_{2}$ adalah

$p\left(n_{1}, n_{2}\right)=\left\{\begin{array}{cl}\frac{1}{3}\left(\frac{1}{4}\right)^{n_{1}-1} e^{-n_{1}}\left(1-e^{-n_{1}}\right)^{n_{2}-1} & , n_{1}=1,2,3, \ldots n_{2}=1,2,3, \ldots \\ 0 & \text {, lainnya }\end{array}\right.$

1304

Hitunglah nilai ekspektasi banyaknya klaim yang akan diajukan ke perusahaan asuransi di bulan Mei jika tepatnya 2 klaim diajukan di bulan April.

Jawab:

$$
\begin{aligned}
E\left[N_{2} \mid N_{1}=2\right] & =\Sigma_{n_{2}=1}^{\infty} n_{2} p\left(n_{2} \mid N_{1}=2\right) \\
& =\Sigma_{n_{2}=1}^{\infty} n_{2} \frac{p\left(2, n_{2}\right)}{p\left(N_{1}=2\right)}
\end{aligned}
$$

$$
\begin{aligned}
p\left(N_{1}=2\right) & =\Sigma_{n_{2}=1}^{\infty}\left(\frac{1}{3} \frac{1}{4} e^{-2}\left(1-e^{-2}\right)^{n_{2}-1}\right) \\
& =\frac{1}{12 e^{2}} \Sigma_{n_{2}=0}^{\infty}\left(1-e^{-2}\right)^{n_{2}} \\
& =\frac{1}{12 e^{2}} \frac{1}{1-\left(1-e^{-2}\right)} \\
& =\frac{1}{12}
\end{aligned}
$$

Oleh karena itu diperoleh

$$
\begin{aligned}
E\left[N_{2} \mid N_{1}=2\right] & =\sum_{n_{2}=1}^{\infty} n_{2} \frac{\frac{1}{3} \frac{1}{4} e^{-2}\left(1-e^{-2}\right)^{n_{2}-1}}{\frac{1}{12}} \\
& =\sum_{n_{2}=1}^{\infty} n_{2} e^{-2}\left(1-e^{-2}\right)^{n_{2}-1} \\
& =\Sigma_{n_{2}=0}^{\infty} n_{2} e^{-2}\left(1-e^{-2}\right)^{n_{2}}
\end{aligned}
$$

Perhatikan bahwa nilai ekspektasi di atas adalah nilai ekspektasi untuk peubah acak geometri $N_{2}$. Maka diperoleh

$$
\begin{aligned}
E\left[N_{2} \mid N_{1}=1\right] & =\frac{1-e^{-2}}{e^{-2}} \\
& =e^{2}-1 .
\end{aligned}
$$


Jawab:

Karena $X \sim \exp (\lambda=1)$ maka diperoleh $f_{X}(x)=e^{-x}$. Karena $Y=10 \cdot X^{0,8}$ adalah fungsi naik, maka

$$
\begin{aligned}
f(y)=f_{Y}(y) & =f_{X}(x) \frac{d x}{d y} \\
& =e^{-x \frac{d x}{d y}} \\
& =e^{-(0,1 y)^{1,25}}\left(0,125(0,1 y)^{0,25}\right) \\
& =0,125(0,1 y)^{0,25} \exp \left(-(0,1 y)^{1,25}\right) .
\end{aligned}
$$


23. Misalkan variabel acak $X$ berdistribusi uniform pada interval $[2,6]$. Misalkan variabel acak $Y=\frac{1}{X}$. Tentukanlah fungsi probabilitas densitas untuk variabel acak Y pada interval $[1 / 6,1 / 2]$.

Jawab:

Karena $X \sim$ uniform $[2,6]$ maka diperoleh $f_{X}(x)=\frac{1}{4}, x \in[2,6]$.

Karena $Y=\frac{1}{X}$ adalah fungsi turun maka

$$
\begin{aligned}
f(y)=f_{Y}(y) & =-f_{X}(x) \frac{d x}{d y} \\
& =-\frac{1}{4} \frac{d x}{d y} \\
& =-\frac{1}{4}\left(-\frac{1}{y^{2}}\right) \\
& =\frac{1}{4 y^{2}} .
\end{aligned}
$$


1324

1325

24. Misalkan $S$ adalah variabel acak yang berdistribusi eksponensial dengan mean 1 dan $T$ adalah variabel acak yang berdistribusi eksponensial dengan mean 2. Tentukanlah fungsi probabilitas densitas untuk $f_{X}(x)$, dimana $X=S+T$.

Jawab:

Perhatikan bahwa

$$
S \sim f_{S}(s)=e^{-s}
$$

dan

$$
T \sim f_{T}(t)=\frac{1}{2} e^{-\frac{1}{2} t} .
$$

Sehingga diperoleh

$$
\begin{aligned}
& f_{X}(x) \\
& =\int_{0}^{x} f_{S}(s) f_{T}(x-s) d s \\
& =\int_{0}^{x} e^{-s} \frac{1}{2} e^{-\frac{1}{2}(x-s)} d s \\
& =\frac{1}{2} e^{-\frac{1}{2} x} \int_{0}^{x} e^{-\frac{1}{2} s} d s \\
& =e^{-\frac{1}{2} x}\left(1-e^{-\frac{1}{2} x}\right) \\
& =e^{-\frac{1}{2} x}-e^{-x} .
\end{aligned}
$$


25. Suatu populasi mempunyai mean 100 dan standar deviasi 16 . Hitunglah probabilitas bahwa mean sampel berada dalam interval \pm 3 dari mean populasi jika ukuran sampel $n=100$.

Jawab:

$$
\begin{aligned}
& \operatorname{Pr}(|\bar{X}-100| \leq 3) \\
& =\operatorname{Pr}(-3 \leq \bar{X}-100 \leq 3) \\
& =\operatorname{Pr}\left(\frac{-3}{16 / \sqrt{100}} \leq \frac{\bar{X}-100}{16 / \sqrt{100}} \leq \frac{3}{16 / \sqrt{100}}\right) \\
& =\operatorname{Pr}\left(\frac{-3}{16 / \sqrt{100}} \leq Z \leq \frac{3}{16 / \sqrt{100}}\right) \\
& =\operatorname{Pr}\left(|Z| \leq \frac{3 \sqrt{100}}{16}\right) \\
& =\operatorname{Pr}(|Z| \leq 1,875) \\
& =2 \operatorname{Pr}(0 \leq Z \leq 1,875) \\
& =0,9392
\end{aligned}
$$


26. Variabel acak $Y$ diketahui mempunyai distribusi normal. Sampel acak berukuran $n=14$ menghasilkan nilai $\bar{Y}=-43,2$ dan $S_{Y}=17,9$. Hitunglah interval kepercayaan $98 \%$ untuk mean populasi.

Jawab:

$$
\varepsilon=t_{\alpha / 2}(n-1) \frac{S_{Y}}{\sqrt{n}} \longrightarrow \varepsilon=t_{0,01}(13) \frac{17,9}{\sqrt{14}}=12,7 .
$$

Jadi interval kepercayaan $98 \%$ untuk mean populasi adalah

$$
(-43,2-12,7 ;-43,2+12,7)=(-55,9 ;-30,5) \text {. }
$$


27. Sampel acak dari 9 pengamatan diambil dari populasi normal menghasilkan statistik

$$
\bar{X}=5 \text { dan } \frac{1}{8} \Sigma_{i=1}^{9}\left(X_{i}-\bar{X}\right)^{2}=36 .
$$

Tentukanlah batas kepercayaan $95 \%$ simetris untuk mean populasi.

Jawab:

$$
\varepsilon=t_{\alpha / 2}(n-1) \frac{S_{X}}{\sqrt{n}} \longrightarrow \varepsilon=t_{0,025}(8) \frac{6}{\sqrt{9}}=4,6 .
$$

Jadi batas kepercayaan $95 \%$ simetris untuk mean populasi adalah $5 \pm$ 4,6 . 
28. Diberikan informasi sampel acak sebagai berikut:

- $Y=X_{1}+\ldots+X_{n}$ dimana ukuran sampel $n$ sama dengan 25 dan variabel acak saling bebas dan berdistribusi identik.

- $X_{i}$ berdistribusi Poisson dengan parameter $\lambda$

- $H_{0}: \lambda=0,1$

- $H_{0}: \lambda<0,1$

- Daerah kritis untuk menolak $H_{0}$ adalah $Y \leq 2$

Hitunglah tingkat signifikansi dari uji tersebut.

Jawab:

Tingkat signifikansi dari uji di atas adalah peluang menolak $H_{0}$ jika $H_{0}$ benar, yaitu diberikan sebagai berikut:

$$
P(Y \leq 2 \mid \lambda=0,1)
$$

Karena $Y$ adalah jumlah dari peubah acak Poisson yang saling bebas dengan rata-rata 0,1 maka rata-rata $Y$ adalah $25 \times(0,1)=2,5$. Oleh karena itu diperoleh:

$P(Y \leq 2)=P(Y=0 ; 1 ; 2)=e^{-2,5}+e^{-2,5} \frac{2.5}{1 !}+e^{-2,5} \frac{2.5^{2}}{2 !}=0.5438$.

Jadi tingkat signifikansi uji di atas sedikitnya 0,50 dan lebih kecil dari 0,6 . 
29. Sampel acak dari 21 pengamatan dari distribusi normal memberikan hasil sebagai berikut:

$$
\bar{X}=3,5 \quad \frac{1}{20} \Sigma_{i=1}^{21}\left(X_{i}-\bar{X}\right)^{2}=0,445
$$

Digunakan uji dua arah

$$
\begin{aligned}
& H_{0}: \mu=3 \\
& H_{1}: \mu \neq 3
\end{aligned}
$$

Hitunglah nilai p (probabilitas uji statistik) dari uji tersebut.

Jawab:

Nilai p (probabilitas uji statistik) dari uji di atas adalah:

$$
\begin{aligned}
P\left(t(n-1) \geq \frac{|\bar{X}-\mu|}{\frac{S}{\sqrt{n}}}\right) & =P\left(t(n-1) \geq \frac{0,5}{\frac{\sqrt{0,445}}{\sqrt{21}}}\right) \\
& =P(t(n-1) \geq 3,43) \\
& =1-P(t(n-1) \leq 3,43) \\
& =1-0,997423 \\
& =0,002577 .
\end{aligned}
$$


30. Misalkan $X_{1}, \ldots, X_{12}$ adalah variabel-variabel acak yang masing-masing berdistribusi normal dengan mean 0 dan variansi $\sigma^{2}>0$. Dengan nilai $\mathrm{p}=0,025$ untuk uji hipotesis:

$$
\begin{aligned}
& H_{0}: \sigma^{2}=10 \\
& H_{1}: \sigma^{2}<10
\end{aligned}
$$

Tentukanlah daerah penolakan untuk uji hipotesis tersebut.

Jawab:

Perhatikan bahwa

$$
\chi^{2}(n-1)=\frac{(n-1) S^{2}}{\sigma^{2}} .
$$

Diperoleh

$$
\chi^{2}(11)=\frac{\sum_{i=1}^{12}\left(X_{i}-0\right)^{2}}{10}=\frac{\sum_{i=1}^{12} X_{i}^{2}}{10} .
$$

Daerah penolakan untuk uji hipotesis di atas adalah

$$
\chi^{2}(11)<\chi_{0,975}^{2}(11)=3,816
$$

atau

$$
\Sigma_{i=1}^{12} X_{i}^{2}<38,16 .
$$


31. Kode peserta ujian dari suatu ujian profesi aktuaris terdiri dari satu digit angka, tiga huruf, dan 3 digit angka (contohnya 1SAM123), kecuali huruf I, O, dan Q tidak dimasukkan pada posisi alphabet pertama dan ketiga. Hitunglah banyaknya kode peserta ujian yang mungkin dari ujian profesi aktuaris tersebut.

Jawab:

Misalkan $K_{1} K_{2} K_{3} K_{4} K_{5} K_{6} K_{7}$ menyatakan kode yang mungkin dari ujian profesi aktuaris tersebut.

Karena $K_{1}, K_{5}, K_{6}$ dan $K_{7}$ merupakan digit-digit angka maka 10 kemungkinan untuk masing-masing digit $K_{1}, K_{5}, K_{6}$ dan $K_{7}$.

Sedangkan $K_{2}$ dan $K_{4}$ merupakan digit-digit huruf A,B, .., Z kecuali I,O dan Q, sehingga ada 23 kemungkinan untuk masing-masing digit $K_{2}$ dan $K_{4}$.

Untuk $K_{3}$ mempunyai 26 kemungkinan.

Dengan menggunakan prinsip perkalian maka diperoleh banyaknya kode yang mungkin dari ujian profesi aktuaris tersebut adalah:

$10 \times 23 \times 26 \times 23 \times 10 \times 10 \times 10=137.540 .000$ 
32. Banyaknya kombinasi dari $r$ obyek yang dipilih dari kumpulan $n$ obyek yang berbeda diberikan oleh $\left(\begin{array}{c}n \\ r\end{array}\right)$. Tentukanlah persamaan yang tepat dari $\left(\begin{array}{c}n \\ r\end{array}\right)$.

Jawab:

$$
\begin{aligned}
& \left(\begin{array}{c}
n \\
r
\end{array}\right)=\frac{n !}{r !(n-r) !} \\
& \left(\begin{array}{l}
n \\
r
\end{array}\right)=\frac{(n-1) ! n}{r !(n-r-1) !(n-r)} \\
& \left(\begin{array}{c}
n \\
r
\end{array}\right)=\frac{(n-1) !}{r !((n-1)-r) !} \frac{n}{n-r} \\
& \left(\begin{array}{c}
n \\
r
\end{array}\right)=\frac{(n-1) !}{r !((n-1)-r) !} \frac{(n-r)+r}{n-r} \\
& \left(\begin{array}{c}
n \\
r
\end{array}\right)=\frac{(n-1) !}{r !((n-1)-r) !}\left(1+\frac{r}{n-r}\right) \\
& \left(\begin{array}{c}
n \\
r
\end{array}\right)=\frac{(n-1) !}{r !((n-1)-r) !}+\frac{(n-1) ! r}{r !((n-1)-r) !(n-r)} \\
& \left(\begin{array}{c}
n \\
r
\end{array}\right)=\frac{(n-1) !}{r !((n-1)-r) !}+\frac{(n-1) ! r}{(r-1) !((n-r)-1) ! r(n-r)} \\
& \left(\begin{array}{c}
n \\
r
\end{array}\right)=\frac{(n-1) !}{r !((n-1)-r) !}+\frac{(n-1) !}{(r-1) !(n-r) !} \\
& \left(\begin{array}{c}
n \\
r
\end{array}\right)=\frac{(n-1) !}{r !((n-1)-r) !}+\frac{(n-1) !}{(r-1) !((n-1)-(r-1)) !} \\
& \left(\begin{array}{c}
n \\
r
\end{array}\right)=\left(\begin{array}{c}
n-1 \\
r
\end{array}\right)+\left(\begin{array}{c}
n-1 \\
r-1
\end{array}\right)
\end{aligned}
$$


1392

1393

1394

1395

33. Tentukanlah ekspansi dari $(x-2 y)^{3}$.

Jawab:

Berdasarkan Teorema Multinomial, diperoleh:

$$
(a x+b y)^{n}=\left(\begin{array}{c}
n \\
0
\end{array}\right) a^{n} b^{0} x^{n} y^{0}+\left(\begin{array}{c}
n \\
1
\end{array}\right) a^{n-1} b^{1} x^{n-1} y^{1}+\ldots+\left(\begin{array}{c}
n \\
n
\end{array}\right) a^{0} b^{n} x^{0} y^{n} .
$$

Jadi ekspansi dari $(x-2 y)^{3}$ adalah

$$
\begin{aligned}
(x-2 y)^{3}= & \left(\begin{array}{l}
3 \\
0
\end{array}\right) 1^{3}(-2)^{0} x^{3} y^{0}+\left(\begin{array}{l}
3 \\
1
\end{array}\right) 1^{2}(-2)^{1} x^{2} y^{1}+\left(\begin{array}{l}
3 \\
2
\end{array}\right) 1^{1}(-2)^{2} x^{1} y^{2} \\
& +\left(\begin{array}{l}
3 \\
3
\end{array}\right) 1^{0}(-2)^{0} x^{2} y^{3} \\
= & x^{3}-6 x^{2} y+12 x y^{2}-8 y^{3} .
\end{aligned}
$$


34. Misalkan himpunan universal adalah $U=\{1,2, \pi$, Jamaal, water, gum $\}$. Misalkan $A=\{1,2, \pi\}$ dan $B=\{1,2$, Jamaal,gum $\}$. Tentukanlah $(A \cup B)^{c}$.

Jawab:

Karena $A=\{1,2, \pi\}$ dan $B=\{1,2$, Jamaal,gum $\}$ maka

$$
A \cup B=\{1,2, \pi, \text { Jamaal,gum }\}
$$

Oleh karena itu diperoleh

$$
\begin{aligned}
(A \cup B)^{c} & =U-(A \cup B) \\
& =\{1,2, \pi, \text { Jamaal,water, gum }\}-\{1,2, \pi, \text { Jamaal, gum }\} \\
& =\{\text { water }\}
\end{aligned}
$$


35. Misalkan $\operatorname{Pr}(A \cup B)=0,7, \operatorname{Pr}\left(A^{c}\right)=0,6$, dan $\operatorname{Pr}\left(A \cap B^{c}\right)=0,3$. Hitunglah $\operatorname{Pr}(B)$.

Jawab:

Kita ketahui bahwa

$$
\operatorname{Pr}(A)=1-\operatorname{Pr}\left(A^{c}\right)=1-0,6=0,4 .
$$

Karena $\operatorname{Pr}(A)=\operatorname{Pr}(A \cap B)+\operatorname{Pr}\left(A \cap B^{c}\right)$ maka diperoleh

$$
\operatorname{Pr}(A \cap B)=\operatorname{Pr}(A)-\operatorname{Pr}\left(A \cap B^{c}\right)=0,4-0,3=0,1 .
$$

Berdasarkan aturan peluang, diketahui:

$$
\begin{aligned}
\operatorname{Pr}(A \cup B) & =\operatorname{Pr}(A)+\operatorname{Pr}(B)-\operatorname{Pr}(A \cap B) \\
0,7 & =0,4+\operatorname{Pr}(B)-0,1
\end{aligned}
$$

sehingga diperoleh $\operatorname{Pr}(B)=0,4$. 
1409 36. Dari soal nomor 35, hitunglah $\operatorname{Pr}(A \cap B)$.

$1410 \quad$ Jawab:

$1411 \quad$ Kita ketahui bahwa

$$
\operatorname{Pr}(A)=1-\operatorname{Pr}\left(A^{c}\right)=1-0,6=0,4 .
$$

1412

$$
\begin{gathered}
\text { Karena } \operatorname{Pr}(A)=\operatorname{Pr}(A \cap B)+\operatorname{Pr}\left(A \cap B^{c}\right) \text { maka diperoleh } \\
\qquad \begin{array}{l}
\operatorname{Pr}(A \cap B)=\operatorname{Pr}(A)-\operatorname{Pr}\left(A \cap B^{c}\right)=0,4-0,3=0,1 .
\end{array}
\end{gathered}
$$


37. Sebuah polis asuransi memberikan manfaat individu sebesar 100 per hari untuk biaya perawatan sampai 3 hari dan 50 per hari untuk biaya perawatan setelah 3 hari seterusnya. Jumlah hari perawatan, $X$, adalah variabel acak diskrit dengan fungsi probabilitas

$$
P(X=k)= \begin{cases}\frac{6-k}{15} & \text { untuk } k=1,2,3,4,5 \\ 0 & \text { lainnya }\end{cases}
$$

Hitunglah nilai variansi pembayaran biaya perawatan dari polis asuransi tersebut.

Jawab:

Misal $B(x)$ menyatakan biaya perawatan ,

1417

$$
\begin{aligned}
& B(X=k)= \begin{cases}100 k & , k=1,2,3 \\
300+50(k-3) & , k=4,5\end{cases} \\
E[B(x)]= & \sum_{k=1}^{k=5} B(k) P(X=k) \\
= & 100 \cdot \frac{6-1}{15}+200 \cdot \frac{6-2}{15}+300 \cdot \frac{6-3}{15}+350 \cdot \frac{6-4}{15}+400 \cdot \frac{6-5}{15} \\
= & 220 . \\
E\left[(B(x))^{2}\right]= & \sum_{k=1}^{k=5}(B(k))^{2} P(X=k) \\
= & 100^{2} \cdot \frac{6-1}{15}+200^{2} \cdot \frac{6-2}{15}+300^{2} \cdot \frac{6-3}{15}+350^{2} \cdot \frac{6-4}{15}+400^{2} \cdot \frac{6-5}{15} \\
= & 59000 . \\
& \operatorname{Var}[B(x)]=E\left[(B(x))^{2}\right]-(E[B(x)])^{2} \\
= & 59000-220^{2} \\
= & 10600 .
\end{aligned}
$$


38. Misalkan $X$ adalah variabel acak diskrit dengan distribusi probabilitas sebagai berikut:

\begin{tabular}{|c|c|c|c|c|c|}
\hline$x$ & 2 & 4 & 6 & 7 & 12 \\
\hline $\operatorname{Pr}(X=x)$ & $6 / 11$ & $2 / 11$ & $1 / 11$ & $1 / 11$ & $1 / 11$ \\
\hline
\end{tabular}

Hitunglah nilai kuartil ketiga dari $X$.

Jawab:

Misalkan $Q_{3}$ menyatakan kuartil ketiga dari data di atas. Dengan mengasumsikan bahwa data di atas sebanyak 11 data, maka diperoleh:

$$
Q_{3}=x_{\frac{3}{4} \cdot 12}=x_{9}=6 \text {. }
$$


39. Distribusi probabilitas dari ukuran klaim untuk sebuah polis asuransi diberikan dalam tabel berikut.

\begin{tabular}{|c|c|c|c|c|c|c|c|}
\hline Ukuran klaim & 30 & 40 & 50 & 60 & 70 & 80 & 90 \\
\hline Probabilitas & 0,15 & 0,10 & 0,05 & 0,20 & 0,10 & 0,1 & 0,30 \\
\hline
\end{tabular}

Tentukanlah persentase dari klaim yang terletak dalam nilai satu standar deviasi dari median ukuran klaim.

Jawab:

Median ukuran klaim $=\frac{60+70}{2}=65$. Rata-rata ukuran klaim

$=30 \cdot 0,15+40 \cdot 0,10+50 \cdot 0,05+60 \cdot 0,20+70 \cdot 0,10+80 \cdot 0,10+90 \cdot 0,30$

$=4,5+4+2,5+12+7+8+27$

$=65$

Rata-rata ukuran klaim kuadrat

$$
=30^{2} \cdot 0,15+40^{2} \cdot 0,10+50^{2} \cdot 0,05+60^{2} \cdot 0,20+70^{2} \cdot 0,10+80^{2} \cdot 0,10+90^{2} \cdot 0,30
$$$$
=135+160+125+720+490+640+2430
$$$$
=4700
$$

Standar deviasi ukuran klaim $=\sqrt{4700-4225}=\sqrt{475}=21,8$ Jadi persentase dari klaim yang terletak dalam nilai satu standar deviasi dari median ukuran klaim (ukuran klaim yang terletak pada interval $[65-21,8 ; 65+21,8]=[43,2 ; 86,8])$ adalah $45 \%$. 
40. Misalkan $X$ adalah variabel acak yang berdistribusi uniform dari bilangan asli yang dipilih acak dari 1 sampai 100. Tentukanlah nilai modus dari $X$.

Jawab:

Karena $\operatorname{Pr}(X=x)=\frac{1}{100}$ maka peluang untuk setiap variabel acak adalah sama. Hal ini berarti modus dari $X$ tidak ada. 
1441

1442

1443

1444

1445

1446

1447

1448

1449

1450

41. Misalkan seorang peserta pertandingan memanah mempunyai kemampuan tepat mengenai sasaran adalah $65 \%$ dan mengambil $n=5$ percobaan memanah sasaran. Misalkan $X$ menunjukkan banyaknya percobaan memanah sasaran dimana $X$ mempunyai distribusi binomial. Hitunglah $\operatorname{Pr}(X>E[X])$.

Jawab:

Misalkan $p$ menyatakan peluang perserta tersebut sukses memanah sasaran, maka diperoleh $p=65 \%=0,65$. Karena $E[X]=n \cdot p$ maka untuk $n=5$ diperoleh $E[X]=5 \cdot(0,65)=3,25$.

Jadi

$$
\begin{aligned}
\operatorname{Pr}(X>E[X]) & =\operatorname{Pr}(X>3,25) \\
& =\operatorname{Pr}(X=4)+\operatorname{Pr}(X=5) \\
& =\left(\begin{array}{l}
5 \\
4
\end{array}\right)(0,65)^{4}(1-0,65)^{1}+\left(\begin{array}{l}
5 \\
5
\end{array}\right)(0,65)^{5}(1-0,65)^{0} \\
& =0,4284 .
\end{aligned}
$$


42. Misalkan $X$ adalah variabel acak yang mempunyai distribusi geometrik dan standar deviasi $\sigma_{X}=\frac{\sqrt{15}}{2}$. Hitunglah $\operatorname{Pr}(X<E[X])$.

Jawab:

Misalkan $p$ menyatakan peluang sukses. Karena $\sigma_{X}=\sqrt{\frac{1-p}{p^{2}}}$ dan $\sigma_{X}=$ $\frac{\sqrt{15}}{2}$ maka diperoleh $15 p^{2}+4 p-4=0$. Sedangkan $0 \leq p \leq 1$ maka nilai $p$ yang memenuhi adalah $p=\frac{2}{5}=0,4$.

Karena $E[X]=\frac{1-p}{p}$ maka diperoleh $E[X]=1,5$. Jadi

$$
\begin{aligned}
\operatorname{Pr}(X<E[X]) & =\operatorname{Pr}(X<1,5) \\
& =\operatorname{Pr}(X=0)+\operatorname{Pr}(X=1) \\
& =p(1-p)^{0}+p(1-p)^{1} \\
& =0,4(1-0,4)^{0}+0,4(1-0,4)^{1} \\
& =0,4+0,24 \\
& =0,64 .
\end{aligned}
$$


1458

43. Fungsi probabilitas densitas untuk variabel acak $X$ diberikan oleh

$$
f(x)=k(10+x)^{-2} ; \quad 0 \leq x<\infty .
$$

1459

1460

1461

1462

$$
\begin{aligned}
\operatorname{Pr}(X \leq 15) & =\int_{0}^{15} 10 k(10+x)^{-2} d x \\
& =-\left.10(10+x)^{-1}\right|_{x=0} ^{x=15} \\
& =-\frac{10}{25}+1 \\
& =\frac{15}{25} \\
& =0,6
\end{aligned}
$$


44. Kerugian yang disebabkan oleh kebakaran pada sebuah bangunan dimodelkan dengan variabel acak $X$ yang mempunyai fungsi probabilitas densitas

$$
f(x)=\left\{\begin{array}{cl}
0,005(20-x) & , 0<x<20 \\
0 & , \text { lainnya }
\end{array}\right.
$$

Diberikan bahwa kerugian kebakaran melebihi 8, hitunglah probabilitas bahwa kerugian kebakaran melebihi 16 .

$$
\begin{aligned}
P(X>8) & =P(8<X<20) \\
& =\int_{8}^{20} 0,005(20-x) d x \\
& =0,\left.005\left(20 x-\frac{1}{2} x^{2}\right)\right|_{x=8} ^{x=20} \\
& =0,36 . \\
& =P(16<X<20) \\
= & \int_{16}^{20} 0,005(20-x) d x \\
= & 0,\left.005\left(20 x-\frac{1}{2} x^{2}\right)\right|_{x=16} ^{x=20} \\
= & 0,04 \\
& \\
P(X>16) & =\frac{P(X>16 \cap X>8)}{P(X>8)} \\
& =\frac{0,04}{0,36} \\
& =\frac{1}{9} .
\end{aligned}
$$


45. Misalkan X berdistribusi uniform pada interval [-2,6] dengan fungsi probabilitas densitas

$$
f(x)= \begin{cases}\frac{1}{8} & ,-2 \leq x \leq 6 \\ 0 & , \text { lainnya }\end{cases}
$$

Hitunglah nilai ekspektasi $g(X)=X^{3}+\sqrt{X+2}$.

1467

Jawab:

$$
\begin{aligned}
E[g(X)] & =\int_{-2}^{6} g(x) \cdot f(x) d x \\
& =\int_{-2}^{6}\left(x^{3}+\sqrt{x+2}\right) \cdot \frac{1}{8} \\
& =\frac{1}{8}\left[\left(\frac{1}{4} x^{4}+\frac{2}{3}(x+2)^{3 / 2}\right]_{-2}^{6}\right. \\
& =41,89 .
\end{aligned}
$$


46. Misalkan variabel acak $Y$ berdistribusi uniform kontinu pada interval $[-2,5]$. Hitunglah $\operatorname{Pr}(Y=1)$.

Jawab:

Karena $Y$ berdistribusi uniform kontinu pada interval [-2,5] maka

$$
\operatorname{Pr}(Y=1)=\int_{1}^{1} \frac{1}{5-(-2)} d y=0
$$


47. Usia dari sebuah mesin cetak dengan harga 200 mempunyai distribusi eksponensial dengan mean 2 tahun. Pabrik yang memproduksi mesin cetak akan membayar full refund kepada pembeli jika mesin cetak rusak selama tahun pertama dan one-half refund jika mesin cetak rusak selama tahun kedua. Jika pabrik tersebut menjual 100 mesin cetak, hitunglah nilai harapan dari refund yang akan dibayar.

Jawab:

Misal $X$ adalah variabel acak yang menyatakan usia sebuah mesin cetak. Karena $X \sim$ eksponensial $(1 / 2)$ maka diperoleh $f(x)=\frac{1}{2} e^{-\frac{1}{2} x}$. Misal $R(x)$ menyatakan refund yang akan dibayar untuk satu mesin cetak, maka diperoleh

$$
\begin{aligned}
R(X & =x)= \begin{cases}200 & , 0 \leq x \leq 1 \\
100 & , 1<x \leq 2 \\
0 & , \text { selainnya }\end{cases} \\
E[R(X)] & =\int_{0}^{1} 200 \frac{1}{2} e^{-\frac{1}{2} x}+\int_{1}^{2} 100 \frac{1}{2} e^{-\frac{1}{2} x} \\
& =200\left[-e^{-\frac{1}{2} x}\right]_{0}^{1}+100\left[-e^{-\frac{1}{2} x}\right]_{1}^{2} \\
& =200\left(1-e^{-\frac{1}{2}}\right)+100\left(e^{-\frac{1}{2}}-e^{-1}\right) \\
& =102,56 .
\end{aligned}
$$

Jadi jika pabrik tersebut menjual 100 mesin cetak, maka nilai harapan dari refund yang akan dibayar adalah

$$
E[100 R(X)]=100 \cdot E[R(X)]=10256 .
$$


1485

1486

1487

48. Misalkan $Z$ adalah variabel acak yang berdistribusi normal standar. Hitunglah $\operatorname{Pr}(|Z|>2,05)$.

Jawab:

$$
\begin{aligned}
\operatorname{Pr}(|Z|>2,05) & =1-\operatorname{Pr}(|Z| \leq 2,05) \\
& =1-2 \operatorname{Pr}(0 \leq Z \leq 2,05) \\
& =1-2(0,4798) \\
& =0,0404 .
\end{aligned}
$$


49. Sebuah uji diagnostik mengenai ada atau tidaknya suatu penyakit mempunyai dua hasil yang mungkin: 1 untuk ada penyakit dan 0 untuk tidak ada penyakit. Misalkan $X$ menunjukkan adanya atau tidaknya penyakit berdasarkan pernyataan pasien, dan $Y$ menunjukkan hasil dari uji diagnostik. Fungsi probabilitas bersama dari $X$ dan $Y$ diberikan oleh

$$
\begin{array}{ll}
\operatorname{Pr}(X=0, Y=0)=0,800 & \operatorname{Pr}(X=1, Y=0)=0,050 \\
\operatorname{Pr}(X=0, Y=1)=0,025 & \operatorname{Pr}(X=1, Y=1)=0,125
\end{array}
$$

Hitunglah $\operatorname{Var}(X+Y)$.

Jawab:

\begin{tabular}{cc|cc|c} 
& & $\mathrm{Y}$ & & \\
& & 0 & 1 & $\operatorname{Pr}(X=x)$ \\
\hline $\mathrm{X}$ & 0 & 0,800 & 0,025 & 0,825 \\
& 1 & 0,050 & 0,125 & 0,175 \\
\hline $\operatorname{Pr}(Y=y)$ & & 0,850 & 0,150 & 1
\end{tabular}

\begin{tabular}{cc|c|c}
$X$ & $Y$ & $Z=X+Y$ & $\operatorname{Pr}(Z=z)$ \\
\hline 0 & 0 & 0 & 0,800 \\
0 & 1 & 1 & 0,025 \\
1 & 0 & 1 & 0,050 \\
1 & 1 & 2 & 0,125
\end{tabular}

$$
\begin{aligned}
& E(Z)=0 \cdot 0,800+1 \cdot(0,025+0,050)+2 \cdot 0,125=0,325 \\
& E\left(Z^{2}\right)=0^{2} \cdot 0,800+1^{2} \cdot(0,025+0,050)+2^{2} \cdot 0,125=0,575 \\
& \operatorname{Var}(X+Y)=\operatorname{Var}(Z)=E\left(Z^{2}\right)-(E(Z))^{2}=0,575-(0,325)^{2}=0,4694
\end{aligned}
$$


1497 50. Dari soal nomor 49, hitunglah $\operatorname{Var}(Y \mid X=1)$.

1498 Jawab:

$$
\begin{aligned}
& \operatorname{Pr}(Y=0 \mid X=1)=\frac{\operatorname{Pr}(X=1, Y=0)}{\operatorname{Pr}(X=1)}=\frac{0,050}{0,175}=0,286 \\
& \operatorname{Pr}(Y=1 \mid X=1)=\frac{\operatorname{Pr}(X=1, Y=1)}{\operatorname{Pr}(X=1)}=\frac{0,125}{0,175}=0,714 \\
& E(Y \mid X=1)=\operatorname{Pr}(Y=1 \mid X=1)=0,714 \\
& E\left(Y^{2} \mid X=1\right)=\operatorname{Pr}(Y=1 \mid X=1)=0,714 \\
& \operatorname{Var}(Y \mid X=1)=E\left(Y^{2} \mid X=1\right)-(E(Y \mid X=1))^{2}=0,714-(0,714)^{2}=0,20 .
\end{aligned}
$$


51. Misalkan $X$ dan $Y$ adalah variabel-variabel acak. Diberikan persamaan sebagai berikut:

(i) $\operatorname{Cov}[X, Y]=E[X \cdot Y]-E[X] E[Y]$

(ii) $\operatorname{Cov}[X, Y]=a \cdot \operatorname{Var}[X]$ jika $Y=a \cdot X+b$

(iii) $\operatorname{Cov}[X, Y]=\operatorname{Var}[Y]$

Manakah yang benar dari tiga persamaan diatas?

Jawab:

Yang benar adalah persamaan (i) dan (ii). 
52. Sebuah investasi memberikan tingkat bunga tahunan $R$ yang mengikuti distribusi uniform pada interval $(0,04 ; 0,08)$. Untuk investasi awal sebesar 10.000 akan memberikan hasil setelah satu tahun mengikuti variabel acak $V=10.000 e^{R}$. Tentukanlah fungsi distribusi kumulatif, $F(v)$, untuk nilai $v$ yang memenuhi $0<F(v)<1$.

Jawab:

Karena $R$ mengikuti distribusi uniform pada interval $(0,04 ; 0,08)$ maka diperoleh $f(r)=\frac{1}{0,04}$.

$$
\begin{aligned}
\operatorname{Pr}(R \leq r) & =\int_{0,04}^{r} f(s) d s \\
& =\int_{0,04}^{r} \frac{1}{0,04} d s \\
& =\frac{1}{0,04} r-1 .
\end{aligned}
$$

Dengan demikian, diperoleh

$$
\begin{aligned}
F(v) & =\operatorname{Pr}(V \leq v) \\
& =\operatorname{Pr}\left(10.000 e^{R} \leq v\right) \\
& =\operatorname{Pr}(\ln 10.000+R \leq \ln v) \\
& =\operatorname{Pr}(R \leq \ln v-\ln 10.000) \\
& =\operatorname{Pr}\left(R \leq \ln \left(\frac{v}{10000}\right)\right) \\
& =\frac{1}{0,04} \ln \left(\frac{v}{10000}\right)-1 \\
& =25\left[\ln \left(\frac{v}{10000}\right)-0,04\right] .
\end{aligned}
$$


1520

1521

53. Misalkan $X_{1}$ dan $X_{2}$ adalah variabel-variabel acak dari distribusi normal standar. Tentukanlah fungsi densitas probabilitas dari $Y_{1}=\frac{X_{1}}{X_{2}}$.

Jawab:

$$
X_{1} \sim f_{X_{1}}\left(x_{1}\right)=\frac{1}{\sqrt{2 \pi}} e^{-x_{1}^{2} / 2}, \quad-\infty<x_{1}<\infty
$$

$$
X_{2} \sim f_{X_{2}}\left(x_{2}\right)=\frac{1}{\sqrt{2 \pi}} e^{-x_{2}^{2} / 2},-\infty<x_{2}<\infty
$$

$$
\begin{aligned}
g_{1}\left(y_{1}\right) & =2 \int_{0}^{\infty} f_{X_{2}}\left(x_{2}\right) f_{X_{1}}\left(x_{2} y_{1}\right) x_{2} d x_{2} \\
& =2 \int_{0}^{\infty} \frac{1}{\sqrt{2 \pi}} e^{-\frac{x_{2}^{2}}{2}} \frac{1}{\sqrt{2 \pi}} e^{-\frac{x_{2}^{2} y_{1}^{2}}{2}} x_{2} d x_{2} \\
& =\frac{1}{\pi} \int_{0}^{\infty} e^{-\frac{x_{2}^{2}\left(1+y_{1}^{2}\right)}{2}} x_{2} d x_{2} \\
& =\left.\frac{1}{\pi} \frac{1}{\left(1+y_{1}^{2}\right)} e^{-\frac{x_{2}^{2}\left(1+y_{1}^{2}\right)}{2}}\right|_{-\infty} ^{0} \\
& =\frac{1}{\pi\left(1+y_{1}^{2}\right)} .
\end{aligned}
$$


1522 54. Dari soal nomor 53, tentukanlah mean dari variabel acak $Y_{1}$.

$1523 \quad$ Jawab:

$$
E\left[Y_{1}\right]=\int_{-\infty}^{\infty} y_{1} \frac{1}{\pi\left(1+y_{1}^{2}\right)} d y_{1}
$$

1524 Karena $f\left(y_{1}\right)=\frac{y_{1}}{\pi\left(1+y_{1}^{2}\right)}$ adalah fungsi ganjil, maka

$$
E\left[Y_{1}\right]=0
$$


55. Suatu populasi mempunyai mean 100 dan standar deviasi 16 . Hitunglah probabilitas bahwa mean sampel berada dalam interval \pm 3 dari mean populasi jika ukuran sampel $n=200$.

Jawab:

$$
\begin{aligned}
& \operatorname{Pr}(|\bar{X}-100| \leq 3) \\
& =\operatorname{Pr}\left(|Z| \leq \frac{3 \sqrt{200}}{16}\right) \\
& =\operatorname{Pr}(|Z| \leq 2,652) \\
& =2 \operatorname{Pr}(0 \leq Z \leq 2,652) \\
& =0,992
\end{aligned}
$$




$$
\begin{aligned}
\sum_{i=1}^{n}\left(X_{i}-\bar{X}\right)^{2} & =\sum_{i=1}^{n}\left(\left(X_{i}-\mu_{X}\right)-\left(\bar{X}-\mu_{X}\right)\right)^{2} \\
& =\sum_{i=1}^{n}\left(\left(X_{i}-\mu_{X}\right)^{2}-2\left(X_{i}-\mu_{X}\right)\left(\bar{X}-\mu_{X}\right)+\left(\bar{X}-\mu_{X}\right)^{2}\right) \\
& =\sum_{i=1}^{n}\left(X_{i}-\mu_{X}\right)^{2}-2\left(\bar{X}-\mu_{X}\right) \Sigma_{i=1}^{n}\left(X_{i}-\mu_{X}\right)+\Sigma_{i=1}^{n}\left(\bar{X}-\mu_{X}\right)^{2} \\
& =\sum_{i=1}^{n}\left(X_{i}-\mu_{X}\right)^{2}-2\left(\bar{X}-\mu_{X}\right)\left(n \bar{X}-n \mu_{X}\right)+n\left(\bar{X}-\mu_{X}\right)^{2} \\
& =\sum_{i=1}^{n}\left(X_{i}-\mu_{X}\right)^{2}-2 n\left(\bar{X}-\mu_{X}\right)^{2}+n\left(\bar{X}-\mu_{X}\right)^{2} \\
& =\sum_{i=1}^{n}\left(X_{i}-\mu_{X}\right)^{2}-n\left(\bar{X}-\mu_{X}\right)^{2} .
\end{aligned}
$$


57. Variabel acak $Y$ diketahui mempunyai distribusi normal. Sampel acak berukuran $n=14$ menghasilkan $\sum_{i=1}^{n} Y_{i}=-602$ dan $S_{Y}=18$. Tentukanlah interval kepercayaan $95 \%$ untuk mean populasi.

Jawab:

$$
\varepsilon=t_{\alpha / 2}(n-1) \frac{S_{Y}}{\sqrt{n}} \longrightarrow \varepsilon=t_{0,025}(13) \frac{18}{\sqrt{14}}=10,4 .
$$

Jadi Hitunglah interval kepercayaan 95\% untuk mean populasi adalah

$$
(-43-10,4 ;-43+10,4)=(-53,4 ;-32,6) .
$$


58. Diberikan sampel acak dari distribusi loss normal:

- Mean sampel adalah 42.000

- Standar deviasi sampel adalah 8.000

- Terdapat 25 loss pengamatan dalam sampel

Dengan menggunakan uji dua arah dengan

$$
H_{0}: \mu=45.000 \quad H_{1}: \mu \neq 45.000 \text {. }
$$

Tentukanlah nilai $\alpha$ yang akan menolak $H_{0}$.

Jawab:

$$
t(n-1)=\frac{\bar{X}-\mu_{X}}{\frac{S}{\sqrt{n}}} \longrightarrow t(24)=\frac{42-45}{\frac{8}{\sqrt{25}}}=-1,875 .
$$

$\alpha=0,01: t_{0,005}(24)=2,797$.

$\alpha=0,02: t_{0,01}(24)=2,492$.

$\alpha=0,05: t_{0,025}(24)=2,064$.

$\alpha=0,1: t_{0,05}(24)=1,711$.

Karena daerah penolakan untuk $\alpha$ adalah $|t(24)|>t_{\alpha / 2}(24)$ maka kesimpulannya, menolak $H_{0}$ pada $\alpha=0,1$ dan tidak menolak $H_{0}$ pada $\alpha=0,01 ; \alpha=0,02 ;$ dan $\alpha=0,05$. 
59. Laporan survei menyebutkan biaya rata-rata dari kamar hotel di suatu kota lebih kecil dari 49,21. Untuk menguji ini, peneliti memilih sampel dari 24 kamar hotel dan memperoleh biaya rata-rata sampel adalah 47,37 dengan standar deviasi adalah 3,42. Pada $\alpha=0,01$, berilah kesimpulan dari uji tersebut.

Jawab:

Dengan menggunakan uji satu arah:

$$
\begin{array}{ll}
H_{0} & : \quad \mu=49,21 \\
H_{1} & : \quad \mu<49,21
\end{array}
$$

Perhatikan bahwa

$$
t(23)=\frac{47,37-49,21}{\frac{3,42}{\sqrt{24}}}=-2,636
$$

dan daerah penolakan untuk $\alpha=0,01$ adalah $t(24)<t_{0,005}(24)=$ 2,807 maka kesimpulannya menolak $H_{0}$ pada $\alpha=0,01$. Jadi, biaya kamar di kota tersebut lebih kecil dari 49,21 pada $\alpha=0,01$. 
60. Misalkan $X_{1}, X_{2}, X_{3}, X_{4}$ adalah sampel acak dari distribusi normal dengan mean $\mu$ yang tidak diketahui dan variansi $\sigma^{2}$ yang tidak diketahui. Significance level $\alpha=0,05$ menggunakan statistik Student- $t$ untuk uji hipotesis:

$$
\begin{aligned}
& H_{0}: \mu=10 \\
& H_{1}: \mu \neq 10
\end{aligned}
$$

Diketahui $\bar{X}=15,84$ dan $S^{2}=\frac{\Sigma_{i=1}^{4}\left(X_{i}-\bar{X}\right)^{2}}{3}=16$. Tentukanlah critical $t$-value dan keputusan yang diperoleh.

Jawab:

Perhatikan bahwa

$$
t(3)=\frac{15,84-10}{\frac{4}{\sqrt{4}}}=2,92
$$

dan daerah penolakan untuk $\alpha=0,05$ adalah $|t(4)|>t_{0,025}(4)=2,78$. Dengan critical t-value $t=2,78$ maka kesimpulannya menolak $H_{0}$ pada $\alpha=0,05$. 


\section{ERRATA}

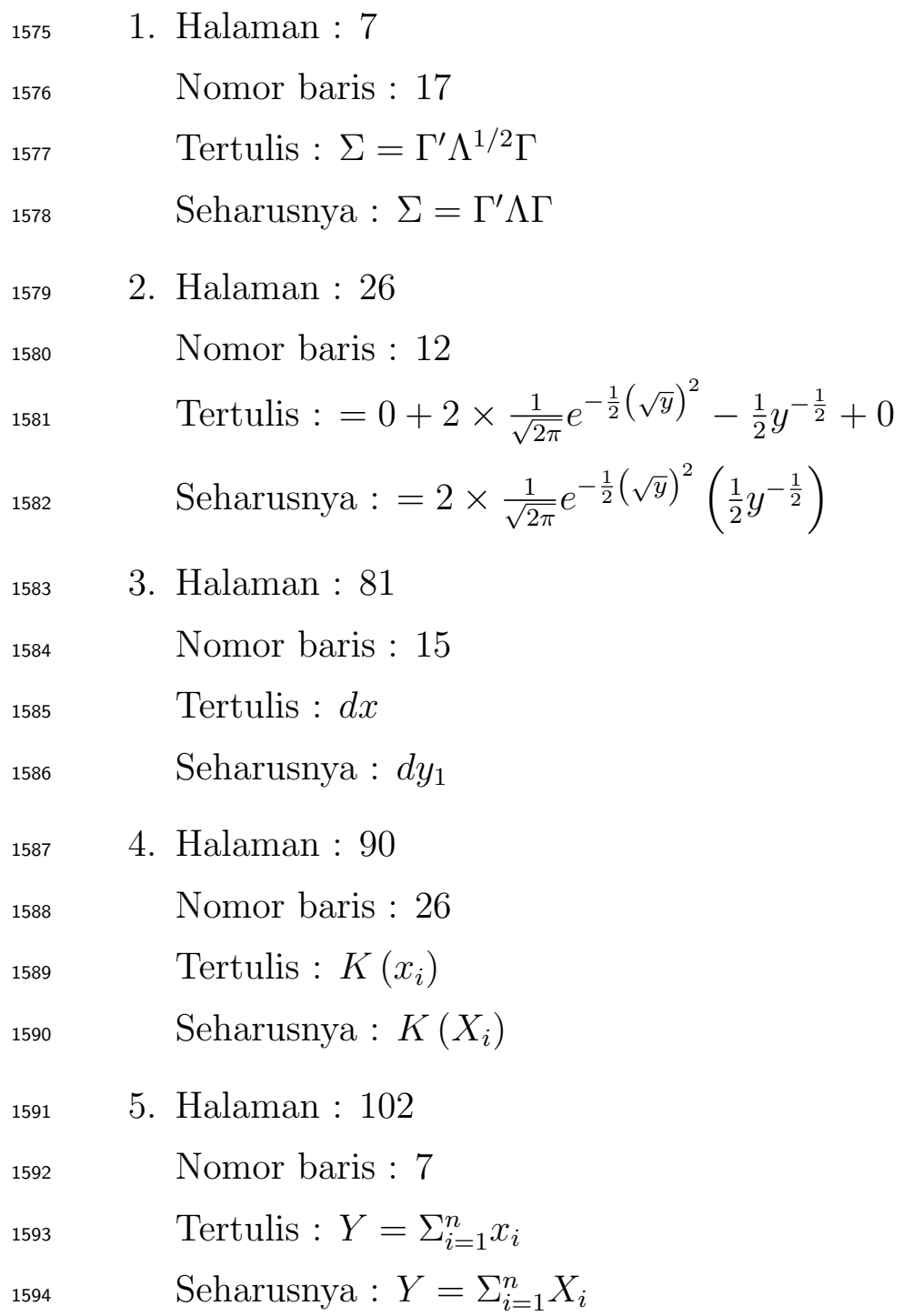


6. Halaman : 104

Nomor baris : 20

Tertulis : $\delta_{1}$

Seharusnya : $\delta_{2}$

7. Halaman : 114

Nomor baris : 21 dan 22

Tertulis : $k_{2}$

Seharusnya : $k_{3}$

8. Halaman : 115

Nomor baris : 17 dan 18

Tertulis : $=\left(5-\theta^{*}\right) \sum_{i=1}^{n} x_{i}+n\left(\theta^{*}\right)^{2}-\frac{25 n}{2} \leq k_{1}$

Seharusnya $:=\left(5-\theta^{*}\right) \sum_{i=1}^{n} x_{i}+\frac{n\left(\theta^{*}\right)^{2}}{2}-\frac{25 n}{2} \leq k_{1}$

9. Halaman : 115

Nomor baris : 18

Tertulis : $=\left(5-\theta^{*}\right) \sum_{i=1}^{n} x_{i} \leq n\left(\theta^{*}\right)^{2}-\frac{25 n}{2}+k_{1}$

Seharusnya $:=\left(5-\theta^{*}\right) \sum_{i=1}^{n} x_{i} \leq \frac{n\left(\theta^{*}\right)^{2}}{2}-\frac{25 n}{2}+k_{1}$

10. Halaman : 118

Nomor baris : 3

Tertulis : $S$

Seharusnya : $s$ 


\section{${ }^{105}$ Daftar Pustaka}

[1] Hogg RV, McKean J, Craig AT. 2005. Introduction to Mathematical Statistics. Sixth Edition. New Jersey: Pearson Education, Inc.

[2] Hogg RV, McKean J, Craig AT. 2014. Introduction to Mathematical Statistics. Seventh Edition. New Jersey: Pearson Education, Inc.

[3] Lindgren BW. 1976. Statistical Theory. Third Edition. New York: Macmillan Publishing Co, Inc.

[4] Rice JA. 2007. Mathematical Statistics and Data Analysis. Duxbury: Thomson Brooks/Cole.

[5] Roussas GG. 1973. A First Course in Mathematical Statistics. Boston: Addison-Wesley Publishing Company. 
INDEX

\begin{tabular}{|c|c|c|}
\hline & Istilah di buku & $\begin{array}{l}\text { Muncul pertama di } \\
\text { Bab }\end{array}$ \\
\hline $\begin{array}{l}\text { Alternative hypothesis, } 244,255-256,373,439,446, \\
448,476,563\end{array}$ & Hipotesis alternatif & \\
\hline 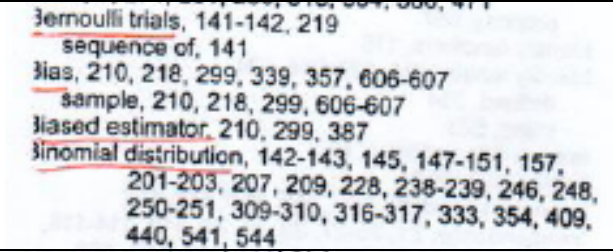 & $\begin{array}{l}\text { Bernoulli trials } \\
\text { Bias } \\
\text { Bias Estimator } \\
\text { Binomial (Distribusi) }\end{array}$ & \\
\hline $\begin{array}{l}\text { eentral limit theorem, } 170,220,225,248,313,317 \\
323-324,340,342,354,370,448,456,463, \\
541,552,570,605,616\end{array}$ & Teorema Limit Pusat & \\
\hline hi-square diatribution, 161, 167-168, 192, 259, & Ch-Squared (Distribusi) & \\
\hline $\begin{array}{l}\text { Composite null hypothesis, } 457,544 \\
\text { Conditional probability, 21.24, } 28,30-32,96-97,121, \\
150,169,178,186,189,389-390 \\
\text { Conditional probabilty density funclions, } 121\end{array}$ & $\begin{array}{l}\text { Hipotesis Null-Komposit } \\
\text { Peluang Bersyarat } \\
\text { Fungsi Kepekatan Peluang } \\
\text { Bersyarat }\end{array}$ & \\
\hline $\begin{array}{l}\text { Confidence intervals, } 207,218-219,221-223,227, \\
238,244,248,254,267,269,277,281, \\
2831-284,286,291,315,342,347,2383,410, \\
501-502,513,515-516,537,542,561,565\end{array}$ & Selang Kepercayaan & \\
\hline $\begin{array}{c}\text { Continuous random variable, 33-34, 44,-47, } 52,63,97 . \\
169-171,211,213,238-239,272,301,405, \\
417,538,540,570,607\end{array}$ & Peubah acak kontinu & \\
\hline $\begin{array}{l}\text { Convergence, 54, 295-296, 298, 300-304, 306-307, } \\
321-323,343,401\end{array}$ & Konvergensi & \\
\hline $\begin{array}{r}\text { Corfelation, } 104-106,108-111,116,118,128,138-139, \\
147,157,184,186,189,240,337,443,415, \\
421,433,401,516-519,521,577,594-600 \\
\end{array}$ & Korelasi & \\
\hline 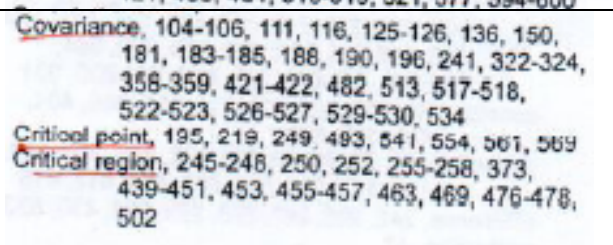 & $\begin{array}{l}\text { Kovarians } \\
\text { Titik Kritis } \\
\text { Daerah Kritis }\end{array}$ & \\
\hline $\begin{array}{c}\text { Data, } 28-29,176,212-213,215-218,223-224, \\
235-240,243-244,249-250,256-257,261, \\
264-265,279,282-284,286-288,373-374, \\
377,379-380,387,389,423,433,444,466, \\
468,496,510,514-516,518,541-543,550, \\
552,556-557,560,565,570-571,578-579 \\
582-564,587-588,590-591,596-601 \\
606-607,612-613,615,629 \\
\end{array}$ & Data & \\
\hline 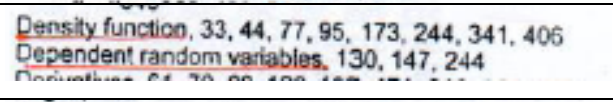 & $\begin{array}{l}\text { Fungsi Kepekatan } \\
\text { Peubah acak (Dependent) }\end{array}$ & \\
\hline $\begin{array}{c}\text { Discrete random variable, } 32,34,40-41,45,53,58, \\
61,176,211,227,406\end{array}$ & Peubah Acak Diskret & \\
\hline Distribution, $11,32-36,41-52,54,57-67,69-71,76$. & Distribusi & \\
\hline
\end{tabular}




\begin{tabular}{|c|c|}
\hline 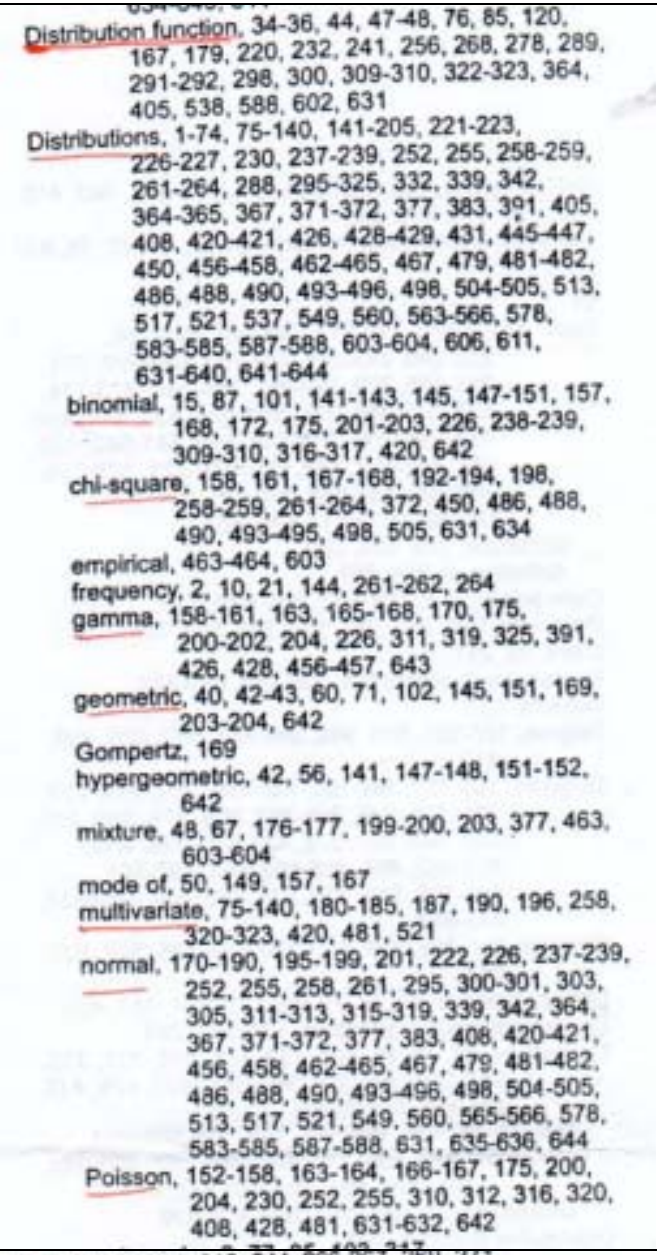 & $\begin{array}{l}\text { Fungsi Distribusi } \\
\text { Distribusi } \\
\text { Binomial } \\
\text { Chi-kuadrat } \\
\text { Empirik } \\
\text { Frekuensi } \\
\text { Gamma } \\
\text { Geometrik } \\
\text { Gompertz } \\
\text { Hipergeometrik } \\
\text { Campuran } \\
\text { mode (??) } \\
\text { Multivariat } \\
\text { Normal } \\
\text { Poisson }\end{array}$ \\
\hline 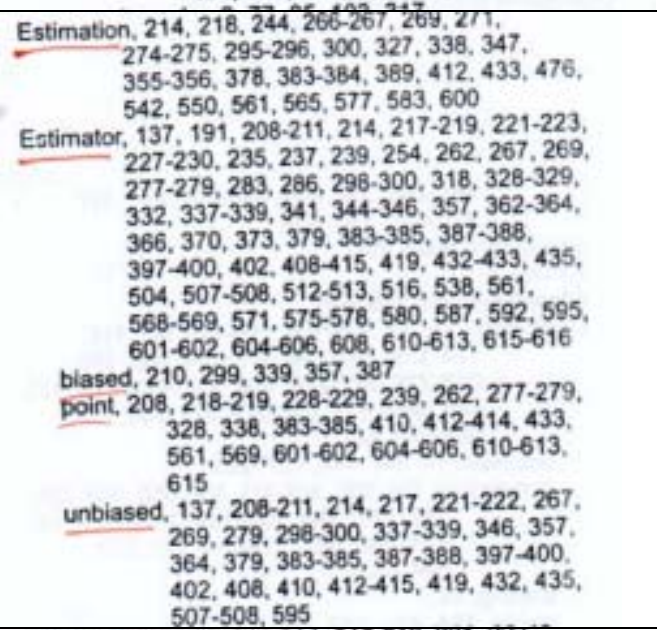 & $\begin{array}{l}\text { Estimasi } \\
\text { Estimator } \\
\text { Bias } \\
\text { Titik } \\
\text { Tak bias }\end{array}$ \\
\hline 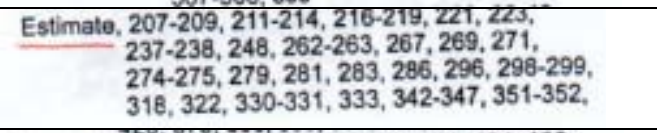 & Taksiran \\
\hline $\begin{array}{l}\text { Expected value, } 53,56-57,81-82,84,101,104,120, \\
124,141,157,224,235,243,259,400,410, \\
412,471,550,610\end{array}$ & Nilai Harapan \\
\hline F-distributions, 191, 195, 496, 631 & Distribusi-F \\
\hline
\end{tabular}




\begin{tabular}{|c|c|}
\hline 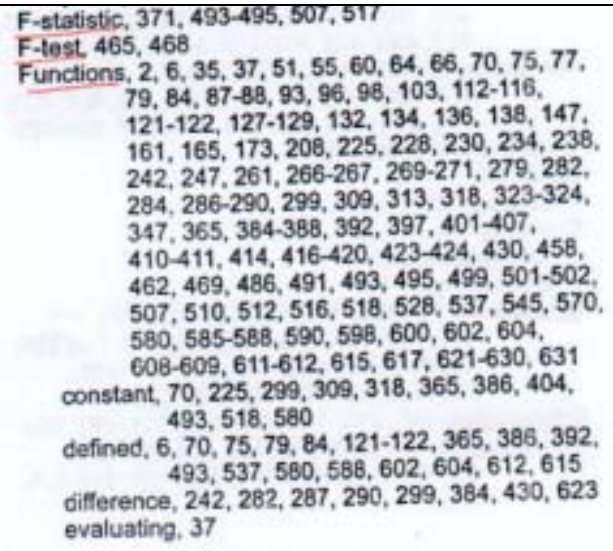 & $\begin{array}{l}\text { Statistik-F } \\
\text { Uji-F } \\
\text { Fungsi }\end{array}$ \\
\hline 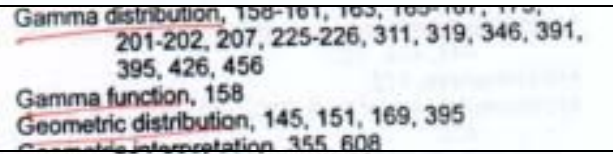 & $\begin{array}{l}\text { Gamma (distribusi) } \\
\text { Fungsi Gamma } \\
\text { Geometrik (distribusi) }\end{array}$ \\
\hline 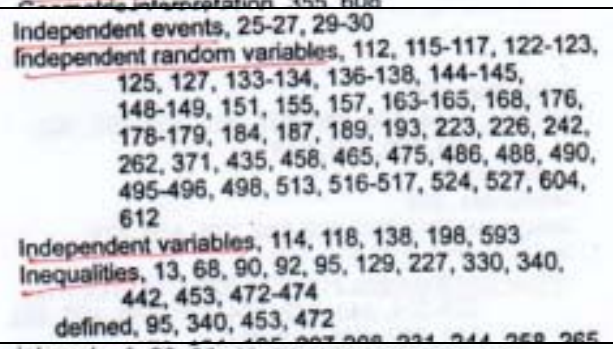 & $\begin{array}{l}\text { Kejadian saling bebas } \\
\text { PEubah acak saling bebas } \\
\text { Peubah Acak } \\
\text { Ketidaksamaan }\end{array}$ \\
\hline $\begin{array}{l}\text { Intervals, } 1,20,33,40,60,153,155,164,207, \\
244-223,227,238,244,248,254,267,259, \\
277,281,283-284,286,291,295,31,342, \\
347,383,410,499,501-502,513,515-516, \\
537,542,561,565 \\
\text { of convergence, } 295\end{array}$ & $\begin{array}{l}\text { Selang } \\
\text { Konvergensi (Selang) }\end{array}$ \\
\hline Joint probability density function, 77,95 & $\begin{array}{l}\text { Fungsi kepekatan peluang } \\
\text { gabungan }\end{array}$ \\
\hline $\begin{array}{l}\text { aw of Large Numbers, 144, 296, 298-299, 322, } 328 . \\
340-341\end{array}$ & Hukum Bilangan Besar \\
\hline 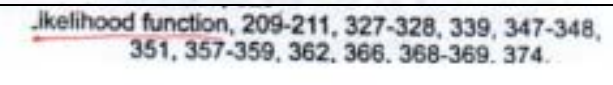 & Fungsi Likelihood \\
\hline 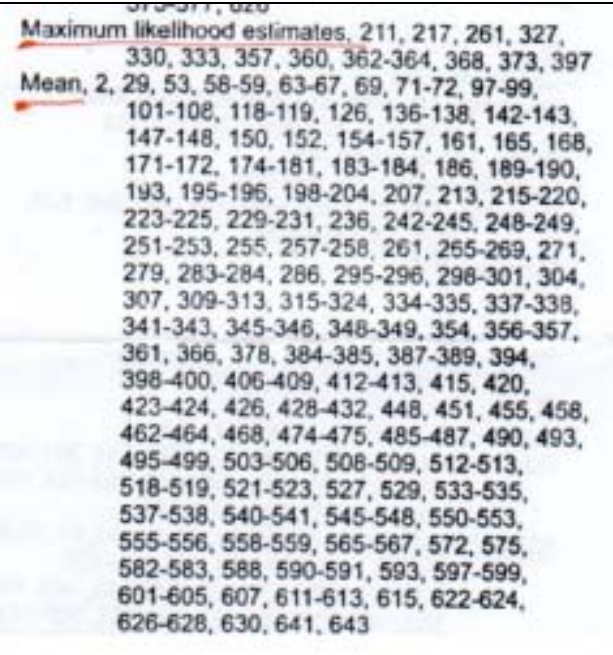 & $\begin{array}{l}\text { Taksiran likelihood Maximum } \\
\text { Rataan }\end{array}$ \\
\hline $\begin{array}{l}\text { Marginal probability density functions, } 84,96,98, \\
112-113,121-122,127 \\
\ldots \ldots \ldots \ldots\end{array}$ & $\begin{array}{l}\text { Fungsi kepekatan peluang } \\
\text { marjinal }\end{array}$ \\
\hline
\end{tabular}


INDEX

\begin{tabular}{|c|c|}
\hline $\begin{array}{l}\text { Median, } 50-51,65,167,216,223,232,234-236, \\
239-240,243,285-286,329,332-333,342, \\
345-346,352,358,409,425-426,429, \\
537-540,542-543,546,548,550-553, \\
561-562,575,582,584,588,590,601-607 . \\
611-613\end{array}$ & $\begin{array}{l}\text { Median } \\
\text { Metode kuadrat terkecil }\end{array}$ \\
\hline $\begin{array}{l}\text { Multivariate distributions, } 75-140,320 \\
\text { conditional expectations, } 98,122 \\
\text { conditional probabilities, } 98 \\
\text { joint probability density function, } 77,95 \\
\text { marginal probability density functions, } 84,96,98 \text {, } \\
\qquad 112-113,121-122,127\end{array}$ & Multivariat (Distribusi) \\
\hline 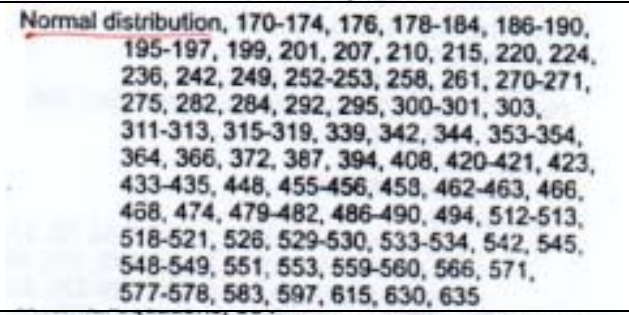 & Normal (Distribusi) \\
\hline $\begin{array}{c}\text { Normal random variables, } 173,187,195,270,512 \text {, } \\
518,523\end{array}$ & Normal (peubah acak) \\
\hline $\begin{array}{l}\text { Null hypothesis, } 244,247,251,284-285,348-350, \\
353,355,368,371,373,439,452-453,457, \\
476,490,496,541,544-545,553-554,563 \\
570,572,586,589,594-595,597,599-600 \\
\text { composite, } 247,251,371,452,457,490,544 \\
\text { simple, } 247,251,453,457,476,544,553,595 \\
599-600\end{array}$ & $\begin{array}{l}\text { Hipotesis Null } \\
\text { Hipotesis komposit } \\
\text { Hipotesis sederhana }\end{array}$ \\
\hline $\begin{array}{r}\text { Order statistics, 231-243, 251, 278, 269, 291-292, } \\
313,332,356,365,371,388,392,396,400,\end{array}$ & Statistik terurut \\
\hline $\begin{array}{l}\text { Sample mean, } 137-138,176,219,230,248-249,252, \\
271,279,284,286,295,298,315,318,322, \\
342,345,389,423,464,474,508,523,545 \\
547-548,550,552,559,601-602,604-605, \\
607,611-612,622\end{array}$ & Rataan Sampel \\
\hline $\begin{array}{r}\text { Sample variance, } 137,139,219,223,298-299,322, \\
347,360,364,389,426,429,465,523,526\end{array}$ & Varians Sampel \\
\hline $\begin{array}{l}\text { Statistics, } 1-2,42,75,137,141,161,187,191, \\
207-208,211,218-220,231-243,247,251, \\
254,265,278,282,289,291-292,295-296, \\
298,313,318,327,332,350-351,356,365, \\
371,383,388-389,392,396-397,400,405, \\
416-436,439,455,458,461-463,465,467, \\
481,485-487,489,493,508,537-616,617, \\
620,621-623,631,641 \\
\text { population, } 220,232,238,298,596,598\end{array}$ & Statistik \\
\hline $\begin{array}{r}\text { Significance level of the lest, } 251,255,259,271,354, \\
441,444,449,461,465,478-479,493,584\end{array}$ & Uji ... \\
\hline 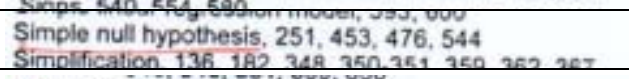 & Hipotesis Null sederhana \\
\hline Standard deviations, $180,186,223$ & Simpangan Baku \\
\hline 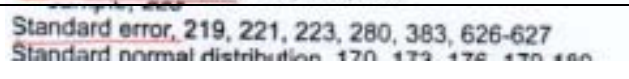 & Galat baku \\
\hline Tests of hypotheses, 207, 244, 295, 439-483, 501 & Uji Hipotesis \\
\hline $\begin{array}{c}\text { Unbiased estimator, } 137,208-210,214,217,221-222, \\
267,269,279,298-300,337-339,346, \\
383-385,387-388,397-400,402,408,410, \\
412,414-415,419,595 \\
\text { Uniform distribution, } 45,52,141,168,211,241-242, \\
268,270,274,289,298,304,319,356,365 . \\
388,395,400,403,422-424,428\end{array}$ & Estimator tak bias \\
\hline
\end{tabular}


INDEX

\begin{tabular}{|c|c|}
\hline $\begin{array}{l}\text { Variables, } 32-35,40,42,44,58,60,62,70,75-79,81, \\
83-89,93,95-98,101-105,107-123,125, \\
127-134,136-139,141,144-149,151,155, \\
157,161,163-166,168,170,173,176, \\
178-181,184,187,189-190,193-199,203, \\
208,219,221,223,226-227,235,242,244, \\
258,262,266,268,270,272,276,289-290, \\
295-296,299-301,305-309,320,327,331, \\
364,370-371,373,377,383,389,391-392, \\
396,398,400,409,411,417,420,426-427, \\
434-435,442-443,446,458,465-466,472, \\
474-478,485-486,488,490,493,495-498, \\
502-503,505,509,512-513,516-519 \\
522-528,530-533,537,539-541,547 \\
550-551,554,569,573,575-576,580,589 \\
593-594,600,604,607,610-612\end{array}$ & Peubah \\
\hline $\begin{array}{r}\text { Variance, } 58-59,64-67,69-70,97-100,102,107-108, \\
111,118-119,125-126,136-139,141,143, \\
148,150,152,154,161,165,168,171-172, \\
176-179,181,184,186,188,190-191,193, \\
195,198-201,203,207,216-220,222-226, \\
236,248-249,252,254,256,258,261,280, \\
296,298-299,310,312-313,315-324,333,\end{array}$ & Varians \\
\hline
\end{tabular}




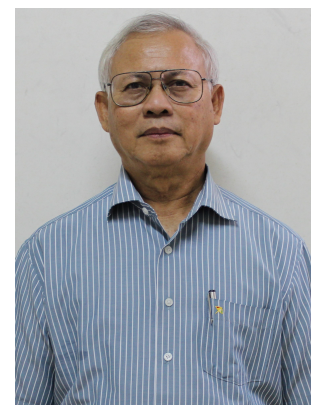

Figure 6.1: Siswadi lulus Sarjana dari IPB. Kemudian, ia melanjutkan pendidikan S2 Statistika di The University of Minnesota. Pendidikan S3 ditempuh di Universitas North Carolina, Raleigh. Terhitung mulai tahun 2013 diangkat sebagai Guru Besar di Institut Pertanian Bogor. SINTA ID : 6029265

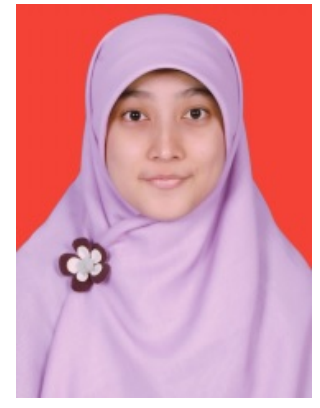

Figure 6.2: Windiani Erliyana lulus program sarjana di Departemen Matematika FMIPA IPB. Kemudian, ia melanjutkan pendidikan S2 Matematika Terapan di IPB melalui Program Sinergi S1-S2. 